Érica Fernanda Aiko Kimura

\title{
COMPORTAMENTO ESTRUTURAL DE PERFIS FORMADOS A FRIO COM SEÇÃO TRANSVERSAL COMPOSTA DE U ENRIJECIDO EM TEMPERATURAS ELEVADAS
}

Tese apresentada à Escola de Engenharia de São Carlos da Universidade de São Paulo, como parte dos requisitos para obtenção do Título de Doutor em Engenharia de Estruturas.

Orientador: Prof. Jorge Munaiar Neto

Versão corrigida

A versão original encontra-se na Escola de Engenharia de São Carlos

São Carlos

Agosto de 2014 
AUTORIZO A REPRODUÇÃO TOTAL OU PARCIAL DESTE TRABALHO, POR QUALQUER MEIO CONVENCIONAL OU ELETRÔNICO, PARA FINS DE ESTUDO E PESQUISA, DESDE QUE CITADA A FONTE.

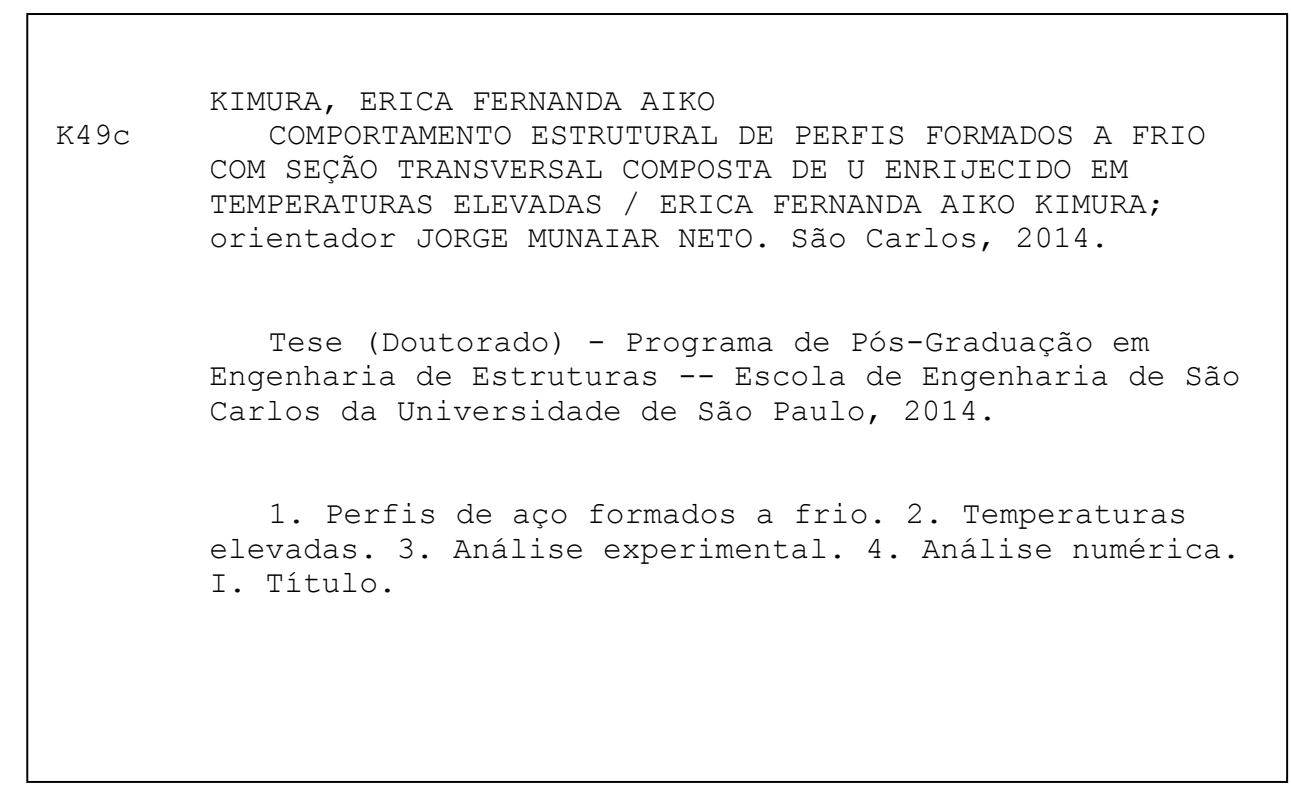




\section{FOLHA DE JULGAMENTO}

Candidata: Engenheira ERICA FERNANDA AIKO KIMURA.

Título da tese: "Comportamento estrutural de perfis formados a frio com seção transversal composta de U enrijecido em temperaturas elevadas".

Data da defesa: 05/06/2014

\section{Comissão Julgadora:}

Prof. Associado Jorge Munaiar Neto (Orientador) (Escola de Engenharia de São Carlos/EESC)

Prof. Associado Maximiliano Malite (Escola de Engenharia de São Carlos/EESC)

Prof. Dr. Armando Lopes Moreno Junior

(Universidade Estadual de Campinas/UNICAMP)

Prof. Dr. Valdir Pignatta e Silva (Escola Politécnica/USP)

Profa. Dra. Silvana De Nardin

(Universidade Federal de São Carlos/UFSCar)
Resultado:
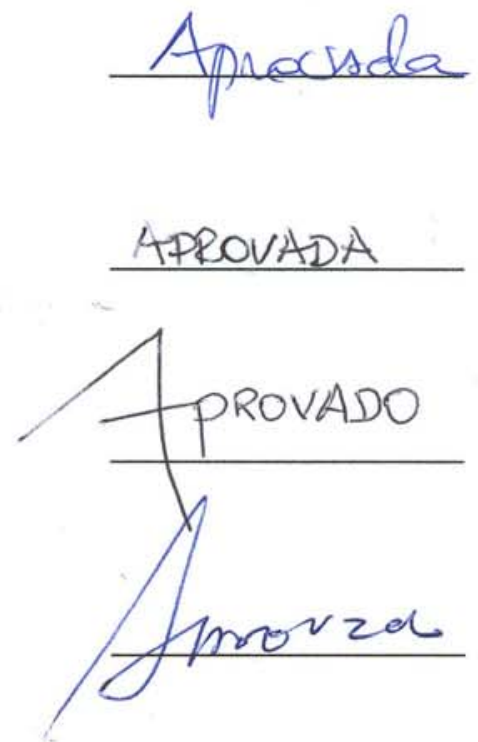

APROVADO

Coordenadora do Programa de Pós-Graduação em Engenharia Civil (Engenharia de Estruturas):

Profa. Associada Ana Lucia Homce de Cresce El Debs

Presidente da Comissão de Pós-Graduação:

Prof. Titular Denis Vinicius Coury 
À Minha Família 


\section{Agradecimentos}

Primeiramente, agradeço a Deus.

A minha família pela educação a princípios que me foram passados.

Ao Departamento de Engenharia de Estruturas da Escola de Engenharia de São Carlos, e que tenho a honra de fazer parte desde a graduação e devo toda minha formação acadêmica e profissional.

Ao Professor Jorge Munaiar Neto pela orientação e por toda atenção dispensada.

Ao Professor Maximiliano Malite pelo auxílio e orientação no programa experimental.

Ao Professor Armando Lopes Moreno Junior, pela orientação nos ensaios no Laboratorio de Estruturas da Unicamp.

Aos Professores Valdir Pignatta e Silva, Silvana De Nardin, Maximiliano Malite, Armando Lopes Moreno Junior e Jorge Munaiar Neto pela atenção como membros da banca.

À equipe técnica do Laboratório de Estruturas do Departamento de Engenharia de Estruturas, por todo auxilio no trabalho experimental.

Ao Departamento de Estruturas da Faculdade de Engenharia Civil, Arquitetura e Urbanismo da Universidade Estadual de Campinas que possibilitou a realização do programa experimental.

À coordenação e corpo técnico do Laboratório de Estruturas da Unicamp, em especial Luciano Passos e Marcelo Francisco Ramos pelo trabalho e atenção dispensada durante a realização do programa experimental.

À equipe técnica da oficina mecânica do Departamento de Engenharia Mecânica, pela fabricação das barras compostas e auxílio nos ensaios térmicos.

Ao Serviço de transportes da Escola de Engenharia de São Carlos.

À equipe técnica da Maitec, pelo auxílio na manutenção do forno de ensaios. 
A toda equipe do Laboratório de Informática e Mecânica Computacional, pelo auxilio na preparação dos computadores e à pessoa do especialista e amigo Dorival Piedade Neto, pelo auxilio na elaboração do código para compilação de dados.

À equipe profissional da secretaria do Departamento de Engenharia de Estruturas, em especial Antonio Valdair Carneiro, Daniane Prataviera, Maria Nadir Minatel e Rosi Aparecida Jordão Rodrigues, por todo auxílio e atenção dispensada.

À Coordenação de Aperfeiçoamento de Pessoal de Nível Superior - CAPES, ao Conselho Nacional de Desenvolvimento Cientifico e Tecnológico - CNPq e à Fundação de Amparo à Pesquisa do Estado de São Paulo - FAPESP pelo fomento a este projeto de pesquisa e financiamento dos materiais a ela destinados.

Ao Grupo de Pesquisadores de Estruturas em Situação de Incêndio, que muito contribui com os avanços nos trabalhos relacionados à área. A esse grupo agradeço pelas riquíssimas contribuições e pelo exemplo diário de dedicação, união amizade e companheirismo.

Por fim, à parte mais importante, que nos constitui e nos fortalece a cada dia, minha gratidão imensurável aos meus amigos, cujos nomes não serão citados para que não haja possibilidade de cometer injustiças (mesmo porque não cabem todos os nomes nesta página), e a quem desejo o merecido sucesso. Agradeço por todos os momentos de descontração que, de certa forma foram vitais durante a realização deste trabalho. Agradeço por todas as reuniões formais e informais e por todo precioso aprendizado compartilhado, pois a nossa convivência será sempre lembrada e revivida. Agradeço a todos que fizeram parte desse período de tal forma que é impossível imaginar como seria um único dia na ausência destes amigos. 
"Jamais considere seus estudos como uma obrigação, mas como uma oportunidade invejável para aprender a conhecer a influência libertadora da beleza do reino do espírito, para seu próprio prazer pessoal e para proveito da comunidade à qual seu futuro trabalho pertencer." 


\section{Resumo}

Kimura, E. F. A. Comportamento estrutural de perfis formados a frio com seção transversal composta de $\mathbf{U}$ enrijecido em temperaturas elevadas. Tese (Doutorado) Escola de Engenharia de São Carlos, Universidade de São Paulo, São Carlos, 2014.

No contexto da construção civil brasileira, é reconhecido o fato de que os perfis de aço formados a frio têm grande demanda em diversos tipos de sistemas estruturais. Uma das aplicações refere-se às barras com seções transversais compostas em duplo U enrijecido, comumente presente no sistema de vigas e pilares de edificações. Quando submetido à ação térmica decorrente de um incêndio, o comportamento dos perfis formados a frio se torna de avaliação relativamente complexa, pois há ocorrência de dois fenômenos que levam à perda da sua capacidade portante: a ocorrência dos modos de instabilidade e a redução da resistência do material. Dessa forma, neste trabalho foi desenvolvido um estudo sobre perfis de aço formados a frio submetidos a temperaturas elevadas. As seções transversais adotadas foram do tipo I enrijecido e tubular retangular do tipo caixão, compostas por dois perfis U enrijecido unidos por solda intermitente. A ação mecânica aplicada consistiu em uma compressão centrada, bem como uma ação térmica, cuja taxa de aquecimento segue a curva de incêndio padrão definida pela International Organization for Standardization. A investigação aqui apresentada foi desenvolvida em campo experimental e numérico. Foram realizados ao todo 17 ensaios de compressão, cinco à temperatura ambiente e 12 com aplicação da ação térmica. A ação mecânica dos ensaios termoestruturais, ao ser aplicada, foi mantida constante em patamares de 40\% e 70\% da capacidade resistente à temperatura ambiente. Em seguida foram desenvolvidos modelos numéricos calibrados com parâmetros obtidos experimentalmente, com vistas a futuras análises paramétricas a partir desta pesquisa. Por fim, tais resultados foram comparados com valores obtidos por procedimentos de cálculo das principais normas em vigor. Com base nesta investigação e no conjunto de resultados apresentados, é possível avaliar a viabilidade da aplicação de tais procedimentos normativos diretamente aos perfis de aço formados a frio, bem como propor adequações onde houver necessidade. Deve-se ressaltar que o trabalho aqui apresentado é o primeiro a realizar ensaios termoestruturais em perfis formados a frio com abordagem na realidade brasileira da construção civil e reconhece a necessidade de abranger novos estudos.

Palavras chave: Perfis de aço formados a frio, temperaturas elevadas, análise experimental, análise numérica, incêndio. 


\section{Abstract}

Kimura, E. F. A. Structural behavior of lipped I and box built-up cold formed steel columns under high temperature. Thesis - São Carlos School of Engineering, University of São Paulo, São Carlos, 2014.

Due to its known versatility, cold formed steel has been widely used in civil construction as load bearing members in several types of structural systems. Built-up lipped I and box cross section are often used as beams and columns of commercial and even industrial buildings. When such structural cold formed steel members are submitted to a thermal load arising from a fire condition, their structural behavior becomes complex, inasmuch as two phenomena that lead to loss of strength is likely to occur: the reduction of material's properties of the cold formed steel and the buckling modes thin walled steel are susceptible. Hence, in this doctoral thesis, a study on the behaviour of built-up cold formed steel subjected to compression load and submitted to high temperature is presented. In the first stage of this research, 21 specimens were subjected to axial compression load; in which 11 specimens were lipped I and 10 were box built-up cross section. Five tests of the total amount were carried out at ambient temperature and 16 in hugh temperature. Such tests in high temperature were carried out in thermal transient condition whose magnitude of the applied compression load was equivalent to $40 \%$ and $70 \%$ of the one obtained at ambient temperature. Thus, the ultimate time and temperature of the specimens were determined. In the second phase of this research, numerical analysis was developed and the numerical models were validated by the comparison with experimental results. Since this numerical strategy has considered geometric and material non linearity varying according to increasing thermal load, it has shown to be suitable for future parametric analysis. Regarding to standard codes, based on this reseach, the suitability of design method for fire condition recommended by Brazilian, European and North American standards applied to cold formed steel were evaluated. The ultimate load capacity obtained from Brazilian and European fire design codes resulted conservative in comparison with experimental results. The Direct Strength Method available in North American, Brazilian and Australian standards, considering appropriated reduction of material's properties according to its temperature conducted to satisfatory results for built-up lipped I and box cold formed steel columns. In addition, this thesis emphasizes the need for an extensive research on cold formed steel structures under fire condition in accordance with Brazilian civil construction.

Keywords: Cold formed steel, High temperature experimental analysis, Numerical analysis, Fire. 


\section{Lista de símbolos}

A Área bruta da seção transversal; área sob a curva de incêndio obtida do ensaio;

$\mathrm{A}_{\mathrm{ef}} \quad$ Área efetiva;

$\mathrm{A}_{\mathrm{s}} \quad$ Área sob a curva de incêndio de incêndio padrão;

b largura do elemento;

$\mathrm{b}_{\mathrm{f}} \quad$ largura nominal da mesa;

h altura da alma

C Contração inicial medido a partir do inicio do ensaio;

$\mathrm{c}_{\mathrm{a}} \quad$ Calor específico;

$\frac{d C}{d t} \quad$ Taxa de contração axial;

$\mathrm{d}_{\mathrm{e}} \quad$ Desvio percentual;

d Largura do enrijecedor de borda;

e Excentricidade

E Módulo de elasticidade do aço;

$\mathrm{r}_{\mathrm{i}} \quad$ Raio interno de dobramento;

$\mathrm{E}_{\theta} \quad$ Módulo de elasticidade do aço em temperatura elevada;

$\sigma_{\mathrm{cr}, \theta} \quad$ Tensão de compressão resistente nominal devido à instabilidade por flexão em temperaturas elevadas;

$\sigma_{\mathrm{e}, \theta} \quad$ Tensão crítica de flambagem elástica, calculada em temperaturas elevadas;

$\mathrm{f}_{\mathrm{p}} \quad$ Tensão de proporcionalidade;

$\mathrm{f}_{\mathrm{u}} \quad$ Resistência à ruptura; 


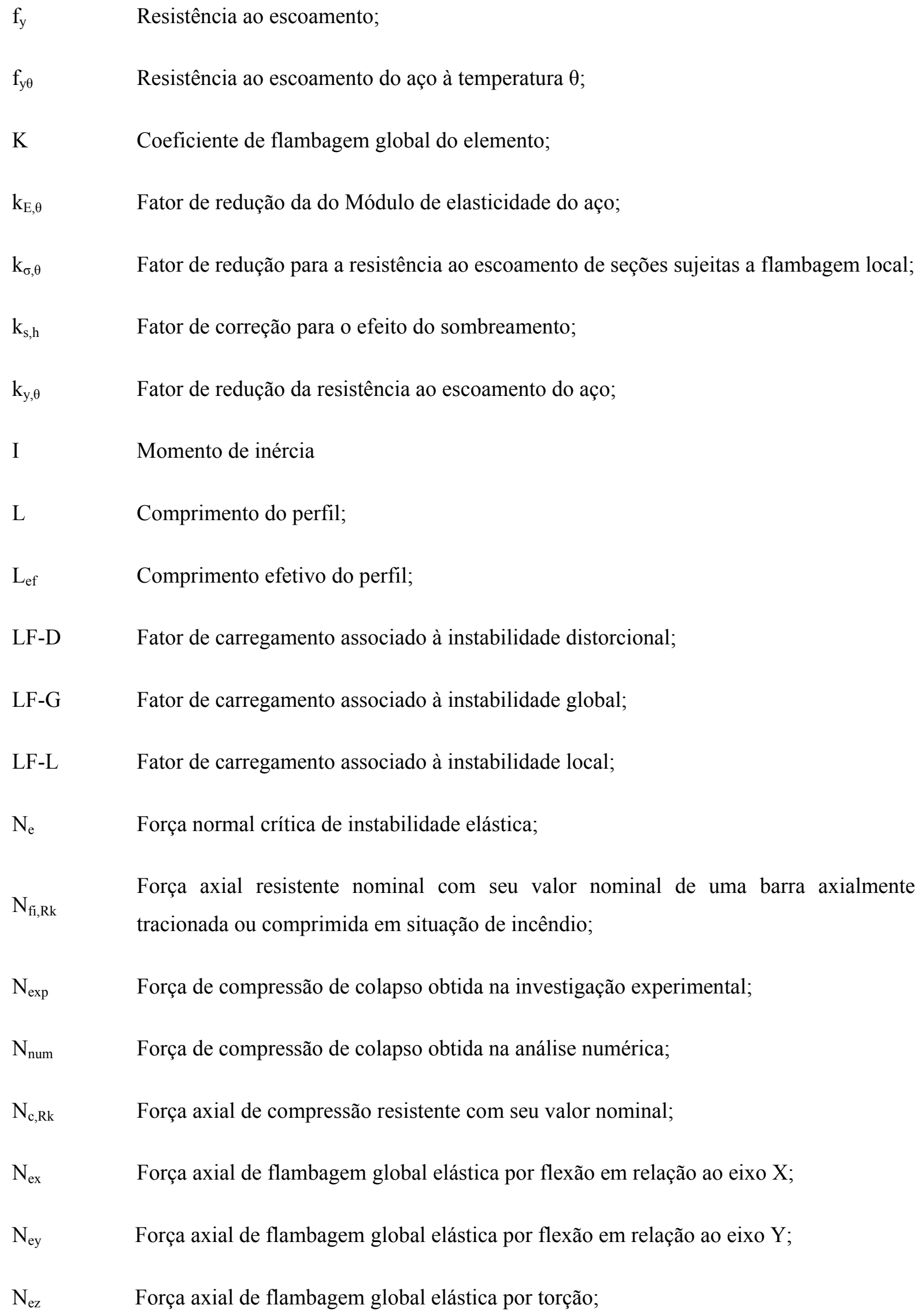




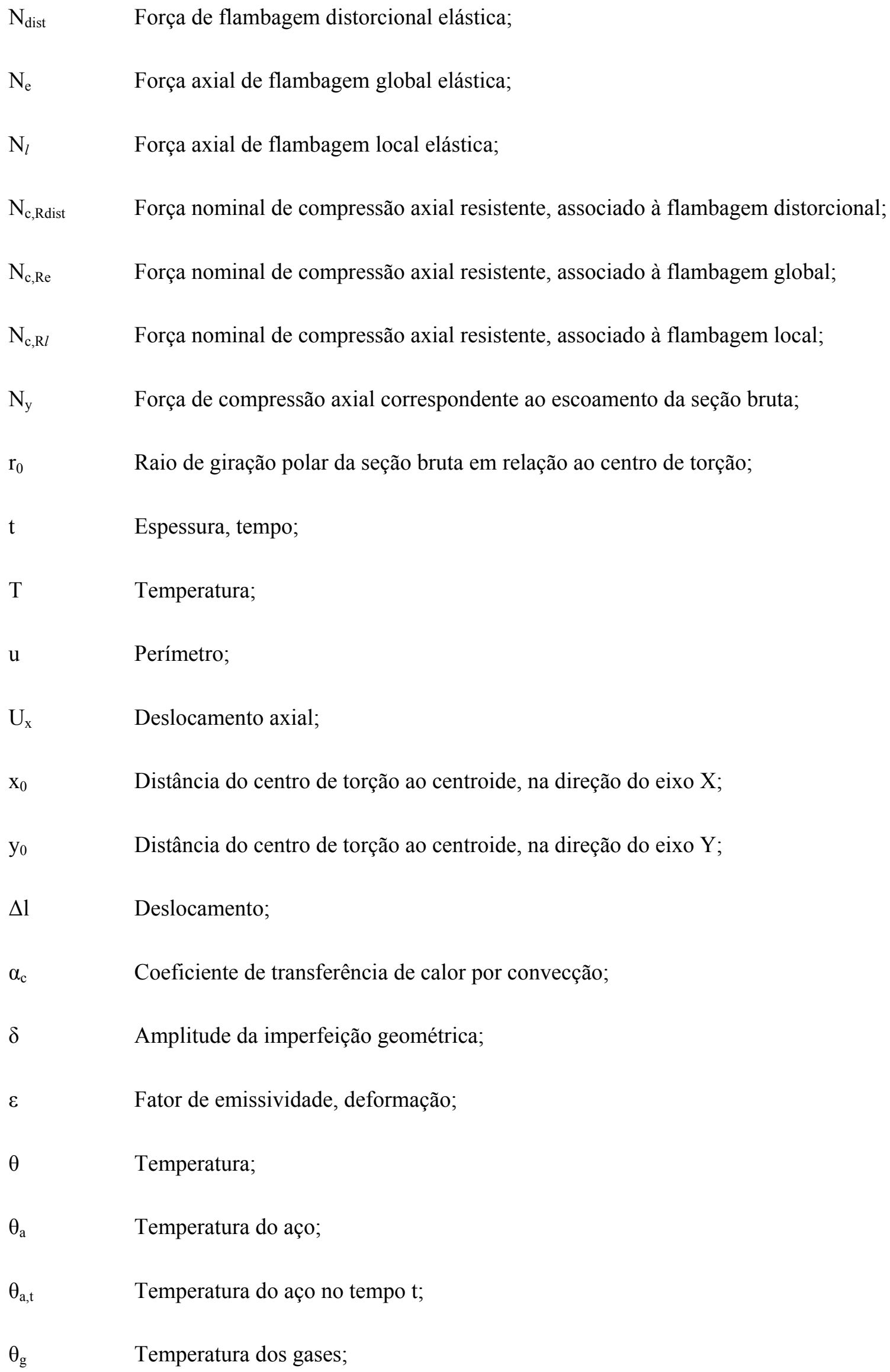


$\lambda$

$\lambda_{0}$

$\lambda_{0, \mathrm{fi}}$

$\lambda_{\mathrm{a}}$

$\lambda_{\text {dist }}$

$\lambda_{1}$

$v$

$\rho_{\mathrm{a}}$

$\sigma_{\text {cr }}$

$\sigma_{\mathrm{e}}$

$\varphi$

$\varphi_{\mathrm{c}}$

$\varphi_{\mathrm{r}}$

$\chi$

$\chi_{\mathrm{fi}}$

$\chi_{\text {dist }}$

Índice de esbeltez

Índice de esbeltez reduzido associado à flambagem global à temperatura ambiente;

Índice de esbeltez reduzido em situação de incêndio;

Condutividade térmica do aço

Índice de esbeltez reduzido associado flambagem distorcional à temperatura ambiente;

Índice de esbeltez reduzido associado flambagem local à temperatura ambiente;

Coeficiente de Poison;

Massa específica do aço;

Tensão convencional de flambagem elástica de chapa;

Tensão crítica de flambagem elástica

Fluxo de calor por unidade de área;

Componente de fluxo de calor devido à convecção;

Componente de fluxo de calor devido à radiação;

Fator de redução associado à resistência a compressão;

Fator de redução associado à resistência a compressão em situação de incêndio;

Fator de redução do esforço resistente associado à flambagem distorcional; 


\section{Lista de siglas}

ABCEM Associação Brasileira da Construção Metálica

ABNT Associação brasileira de Normas Técnicas

AISC American Institute of Steel Construction

AISI American Iron and Steel Institute

ANSI American National Standards Institute

AS/NZS Australian/New Zealand Standard

ASTM American Standards for Testing and Materials

BSI British Standard Institution

CBCA Centro Brasileira da Construção em Aço

CSA Canadian Standards Association

EESC/USP Escola de Engenharia de São Carlos / Universidade de São Paulo

FEC/UNICAMP Faculdade de Engenharia Civil e Arquitetura e Urbanismo / Universidade Estadual de Campinas

IPT Instituto de Pesquisas Tecnológicas

ISO International Organization for Standardization

LVDT Linear Variable Displacement Transducer

MRD Método da Resistência Direta

TRF Tempo de Resistência ao Fogo 


\section{Sumário}

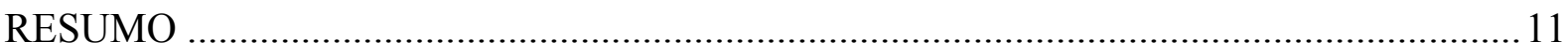

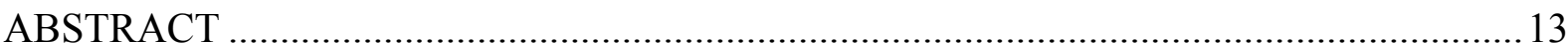

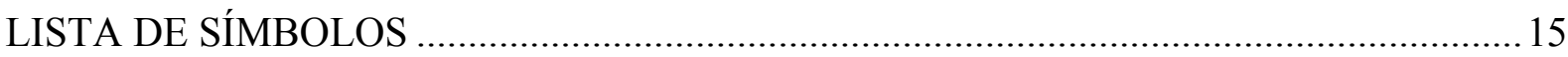

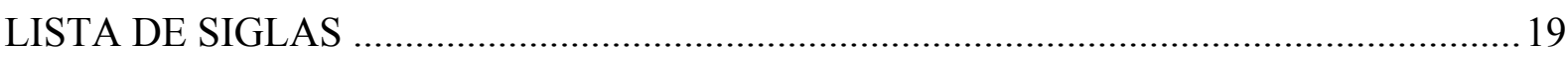

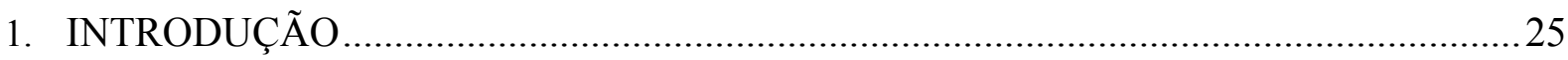

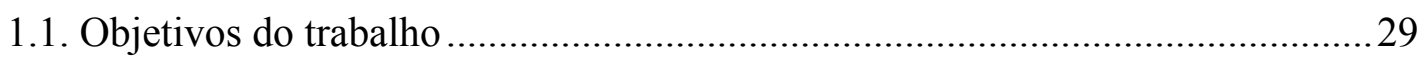

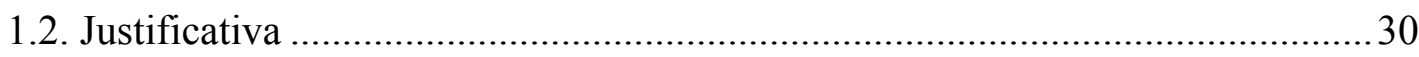

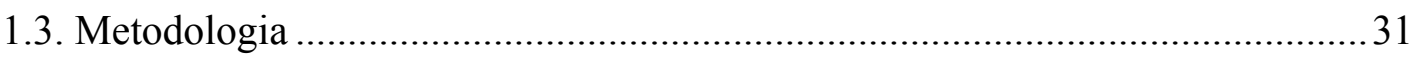

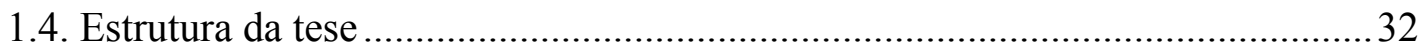

2. SOBRE OS PERFIS DE AÇO FORMADOS A FRIO EM SITUAÇÃO DE INCÊNDIO35

2.1. Efeito do trabalho a frio sobre as propriedades mecânicas do aço .....................36

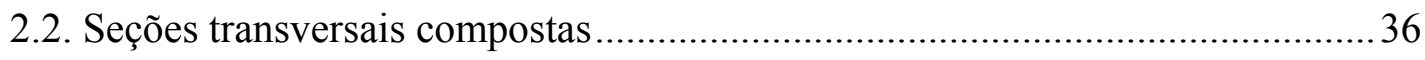

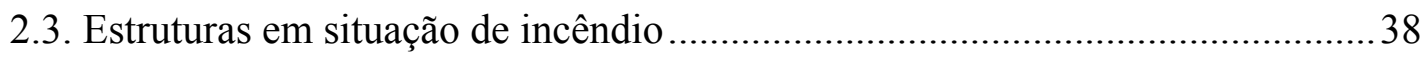

2.4. Consideração da ação térmica em perfis aço formados a frio............................ 42

3. PROCEDIMENTOS DE VERIFICAÇÃO PARA PERFIS SUJEITOS À COMPRESSÃO

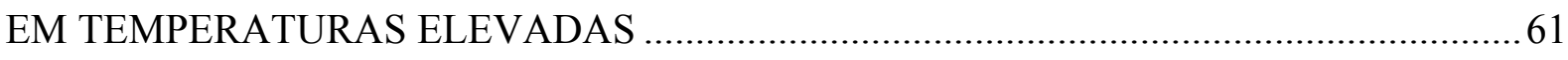

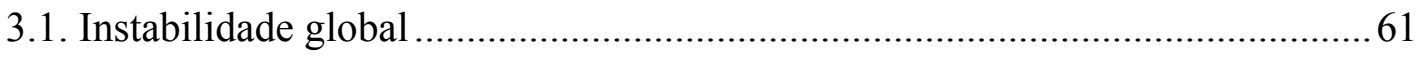

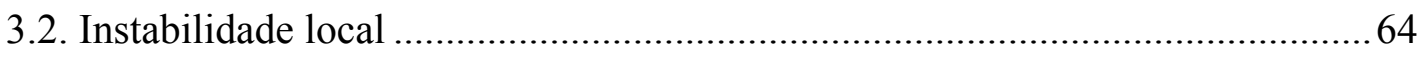

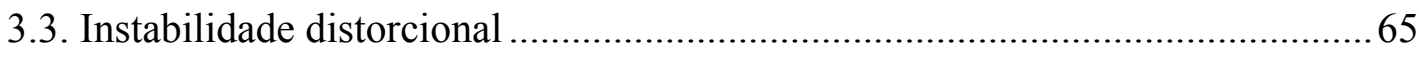

3.4. Dimensionamento em situação de incêndio.......................................................66 
3.4.1. Procedimento de cálculo recomendado pela norma ABNT NBR $14323: 2013$

3.4.2. Procedimento de cálculo recomendado pela norma Eurocode 3 Part 1.2 .... 68

3.4.3. Procedimento de cálculo recomendado pela norma ANSI/AISC 360-10 ... 69

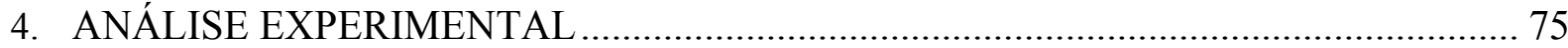

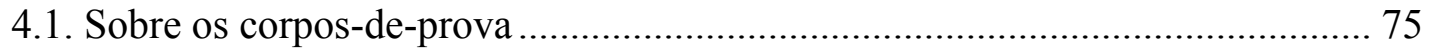

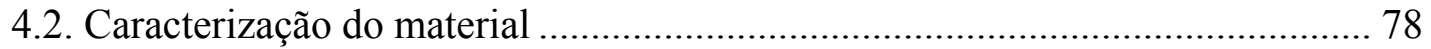

4.3. Ensaios de compressão centrada: comentários gerais ................................... 81

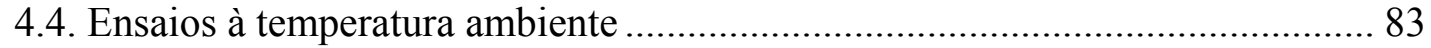

4.4.1. Resultados dos ensaios à temperatura ambiente ...................................... 85

4.5. Ensaios em temperaturas elevadas - situação de incêndio ............................... 91

4.5.1. Vistoria do equipamento de ensaio para temperaturas elevadas................ 91

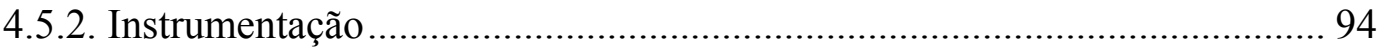

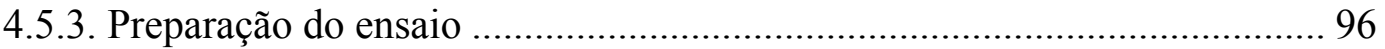

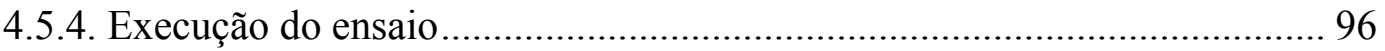

4.5.5. Resultados dos ensaios realizados em temperaturas elevadas................... 98

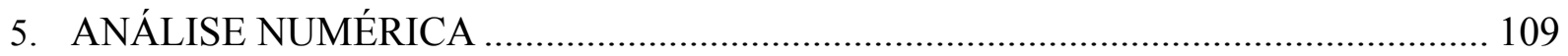

5.1. Considerações referentes à Análise térmica ................................................... 110

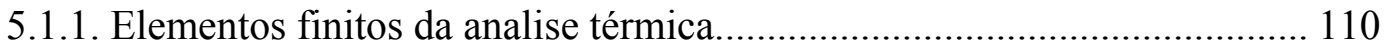

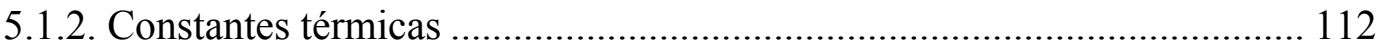

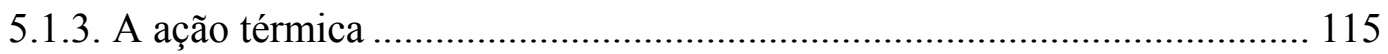

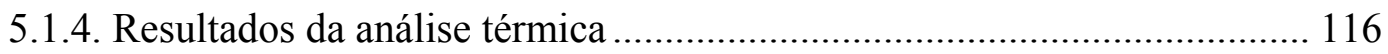


5.2. Considerações referentes ao modelo estrutural

5.2.1. Construção do modelo de elementos finitos

5.2.2. Propriedades do material

5.2.3. Não linearidade geométrica

5.3. Análise acoplada térmica e estrutural

5.3.1. Resultados da análise numérica termoestrutural 123

6. ANÁLISE E DISCUSSÃO DOS RESULTADOS 133

6.1. Sobre a análise térmica 133

6.1.1. Ação térmica do forno 133

6.1.2. Campo térmico resultante no modelo 136

6.2. Sobre a análise termoestrutural 140

6.3. Procedimentos normativos aplicados aos perfis formados a frio de seção transversal composta

6.3.1. Investigação à temperatura ambiente 145

6.3.2. Investigação em temperaturas elevadas 150

7. CONCLUSÕES 163

8. REFERÊNCIAS BIBLIOGRÁFICAS 169 


\section{INTRODUÇÃO}

A utilização dos perfis de aço formados a frio teve início nos Estados Unidos e na GrãBretanha por volta de 1850 , porém, as primeiras pesquisas foram iniciadas pelo professor George Winter, da Universidade de Cornell, com apoio da AISI Committee on Building Research and Technology, em 1939. Naquela época, o objetivo era estudar o desempenho de elementos estruturais de perfis formados a frio e obter informações consistentes para a formulação de um projeto específico de normas técnicas.

Segundo Chodraui (2006) a aplicação dos perfis de aço formados a frio (antigamente chamados de perfis de chapa dobrada) na construção civil brasileira foi impulsionada inicialmente por empresas de pequeno e médio portes do Estado de São Paulo. A migração para esse tipo de perfil foi motivada pela escassez à época dos laminados no mercado, além das evidentes vantagens, citadas com mais detalhes em Yu (2010), apresentadas pelos perfis de aço formados a frio, tais como:

- elevada relação inércia/peso;

- grande variabilidade na composição de seções transversais;

- menor custo energético na produção em relação aos perfis soldados e laminados.

No entanto, no início dessa expansão, era perceptível a necessidade de formular documentos técnicos mais consistentes voltados para o setor de projeto e construção. As normas brasileiras existentes à época em vigência, ou seja, a ABNT NB 143:1967 - Cáculo de estruturas de aço, constituídas por perfis leves e a ABNT NBR 6355:1980 - Perfis estruturais de aço formados a frio se encontravam em total obsolescência obrigando projetistas a adotarem o uso normas estrangeiras como a AISI (American Iron and Steel Institute), a CSA (Canadian Standards Institute), entre outras.

Nesse cenário, as pesquisas sobre normas estrangeiras e trabalhos que deram origem aos seus procedimentos, aliados às particularidades da construção metálica brasileira, permitiram colaborar na elaboração da ABNT NBR 14762:2001 - Dimensionamento de 
estruturas de aço constituídas por perfis formados a frio - Procedimento, a qual foi revista e substituída pela atual ABNT NBR 14762:2010 - Dimensionamento de estruturas de aço constituídas por perfis formados a frio, cujos procedimentos são compatíveis com as principais normas estrangeiras atualmente em vigor. Assim como a referida norma técnica, a ABNT NBR 6355:1980, que padroniza os requisitos exigíveis dos perfis de aço formados a frio, passou por revisões em 2003 e, mais recentemente, foi substituída pela $\boldsymbol{A B N T} \boldsymbol{N B R}$ 6355:2012 - Perfis estruturais de aço formados a frio - Padronização.

A demanda crescente pelos perfis de aço formados a frio tornou importante também o desenvolvimento de pesquisas sobre seu comportamento estrutural em temperaturas elevadas. Klipstein (1978) é considerado como primeiro trabalho sobre estruturas em perfil formado a frio submetidos a temperaturas elevadas. Além de recentes, a maioria das pesquisas realizadas nessa área envolve análise de compressão em peças curtas de seção transversal do tipo $U$ e U enrijecido $\left(\right.$ ou $U_{e}$ ). Tal fato se justifica pela sua utilização no sistema estrutural do tipo Steel Framing, muito comum em países europeus e da América do Norte (Canadá e Estados Unidos).

No Brasil, a aplicação do sistema Light Steel Framing ainda é pouco expressiva. O emprego dos perfis de aço formados a frio é voltado principalmente para coberturas e pilares de edificações, além de fazer parte de sistemas secundários em estruturas de grande porte. No caso de pilares, a versatilidade desse tipo de perfil permite seu emprego desde as seções mistas em aço e concreto até o uso de sistemas treliçados. As figuras 1.1 a 1.3 ilustram alguns exemplos da utilização dos perfis formados a frio na construção civil brasileira.

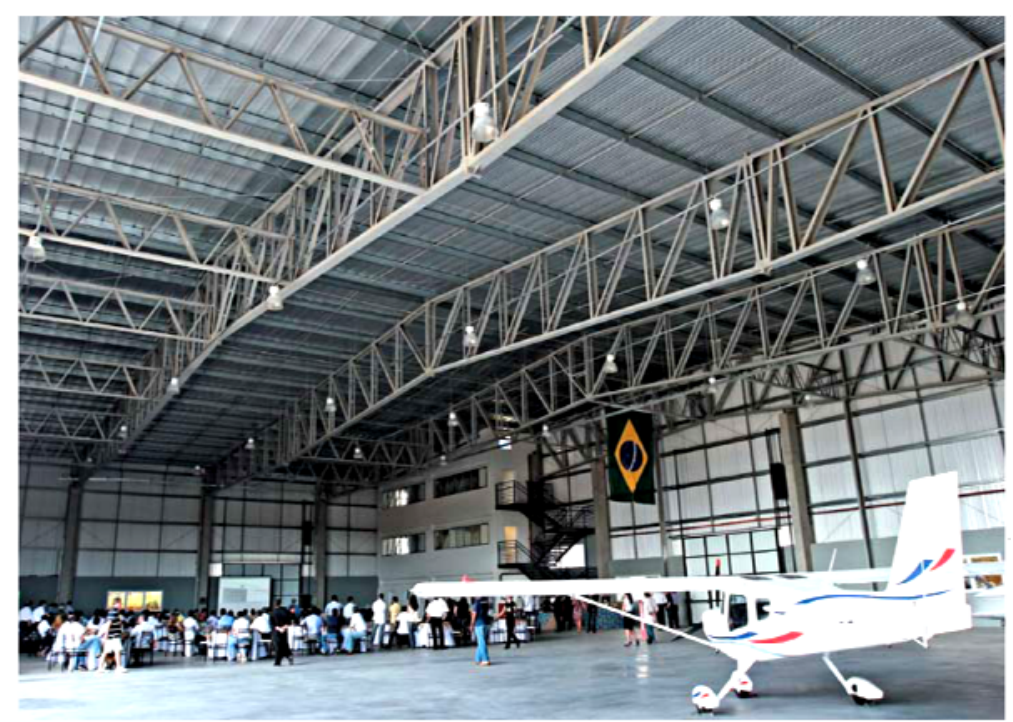

Figura 1.1: Hangar do Aeroporto de Amarais, Campinas - SP. Fonte: Revista Construção Metálica, n. 94, ABCEM 


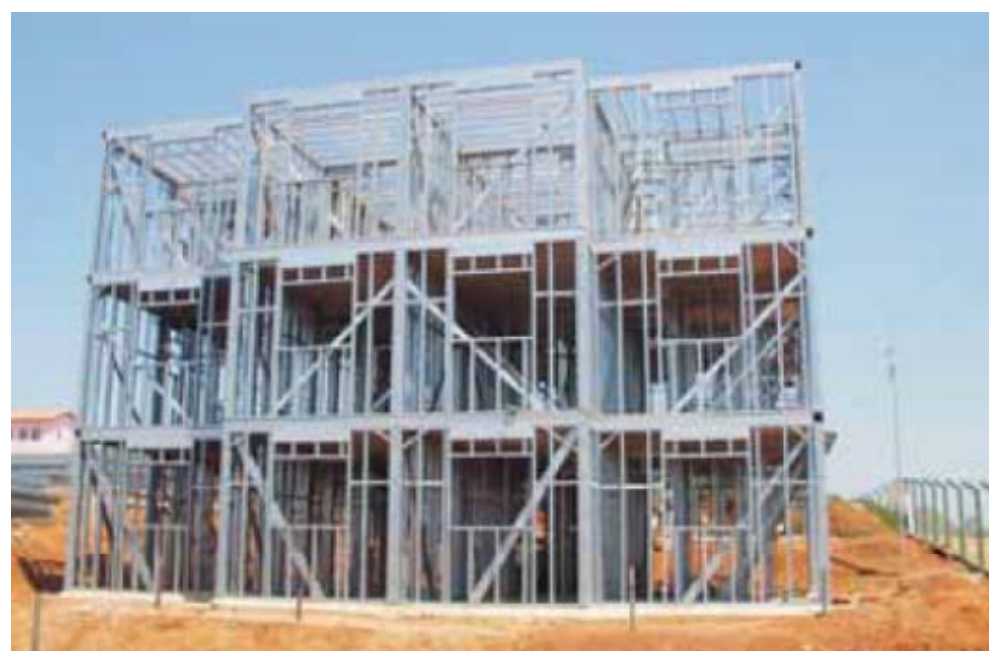

Figura 1.2: Edificação construída no sistema Light Steel Framing. Fonte: Revista Arquitetura \& Aço, CBCA.

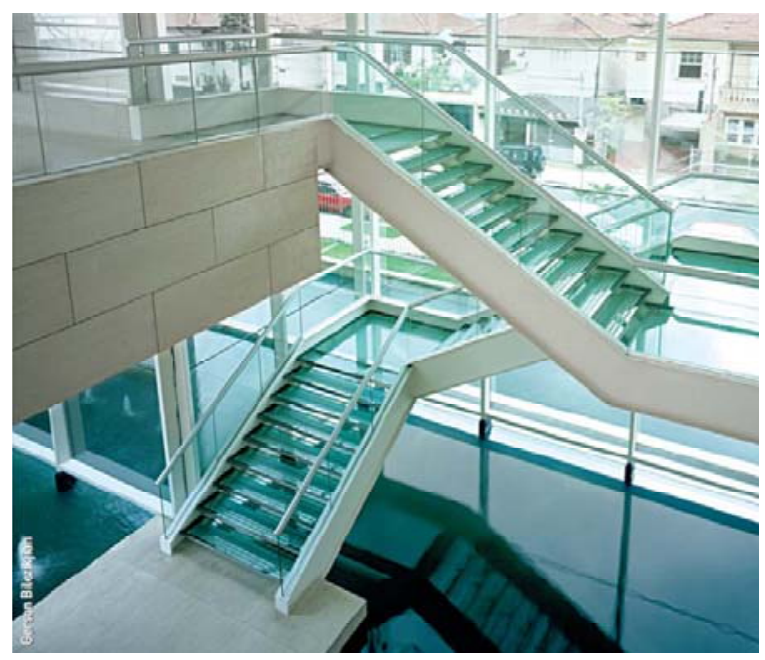

Figura 1.3: Escada do edifício multifuncional do Centro Brasileiro Britânico. Fonte: Revista Arquitetura \& Aço, n.15 - CBCA.

Sob essa mesma ótica, é comum no Brasil o uso de outros tipos de seções transversais além daquelas utilizadas no sistema Light Steel Framing (LSF), ou seja, seções dos tipos $U$ e $U_{e}$. A Figura 1.5 indica algumas seções transversais e suas aplicações mais comuns.

Quando em situação de incêndio, a capacidade resistente desses perfis é afetada tanto pela redução de sua resistência ao escoamento $\left(f_{\mathrm{y}}\right)$ e de seu módulo de elasticidade longitudinal (E) em função da elevação da temperatura, bem como pelo surgimento de esforços adicionais induzidos pela restrição à expansão (extremidades fixas, por exemplo) e tensões secundárias que podem ser desenvolvidas devido às deformações provocadas por um gradiente de temperatura. 
Pórticos

Sistemas de fechamento de telhado
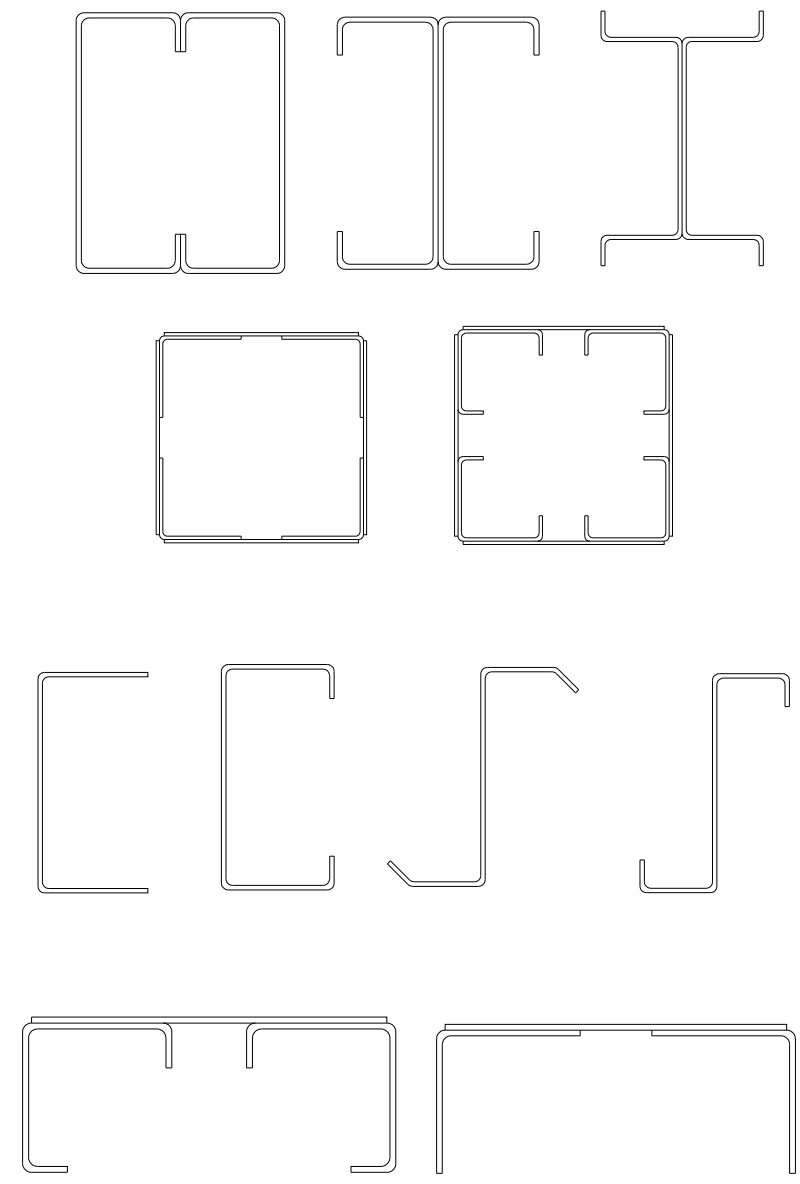

Treliças
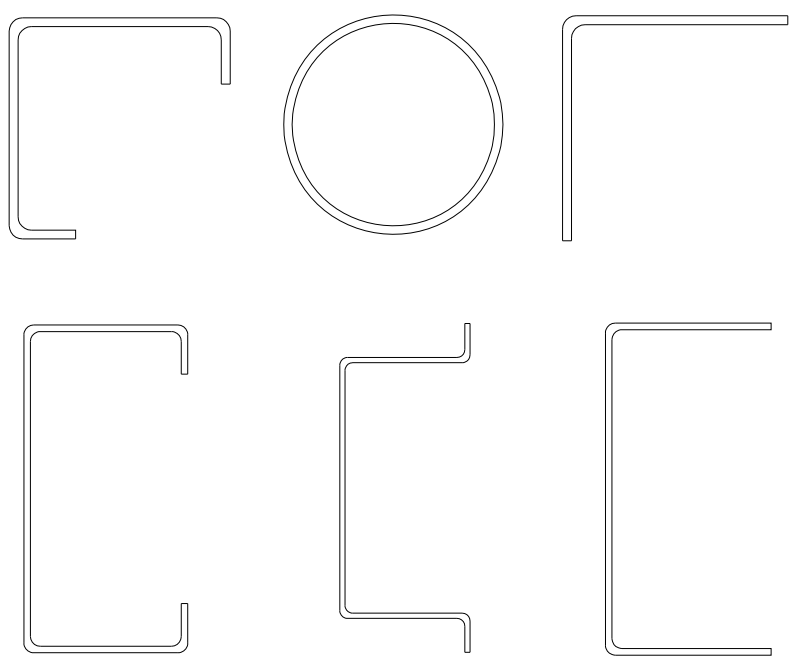

Figura 1.5: Seções transversais usuais na construção civil.

No meio científico é reconhecido o fato de as investigações em perfis formados a frio em situação de incêndio ainda serem consideradas restritas. Há uma dificuldade considerável no levantamento de referências que tratem de problemas típicos dos perfis formados a frio, a citar os fenômenos de instabilidade global, local e distorcional, ou mesmo a combinação dos 
três, relacionados a outras seções geométricas diferentes daquelas utilizadas no sistema Light Steel Framing.

Os procedimentos simplificados de dimensionamento, tanto da norma brasileira como de outras normas estrangeiras são voltados especificamente aos perfis laminados e soldados. Aos perfis formados a frio, de forma aproximada, é adotado o mesmo procedimento, porém com os fatores de redução das propriedades mecânicas que são aplicáveis a todos os perfis sujeitos à instabilidade local. Salvo essa alternativa, é proposto também que o dimensionamento seja realizado mediante os métodos avançados, ou seja, por meio de análises em contexto experimental ou numérico.

Nesse sentido, percebeu-se a importância de novos estudos sobre o comportamento dos perfis de aço formados a frio em situação de incêndio. Neste trabalho, apresentam-se estudos sobre barras com seções transversais compostas por perfis $U$ enrijecido $\left(U_{\mathrm{e}}\right)$ comumente utilizados em pilares de edificações. Com este trabalho, pretende-se contribuir no sentido de ampliar o conhecimento prático e teórico sobre os perfis formados a frio em situação de incêndio.

\subsection{Objetivos do trabalho}

O presente trabalho tem como objetivos:

- Investigar o comportamento estrutural de perfis de aço formados a frio submetidos à compressão axial em situação de incêndio;

- Construir modelos numéricos capazes de fornecer campos de temperatura variáveis ao longo do comprimento, de forma semelhante ao que ocorre numa investigação em laboratório. Além das variáveis térmicas, o modelo deve incluir a não linearidade geométrica na forma de imperfeições geométricas globais e de chapa (locais e distorcionais), bem como a não linearidade física do aço.

- Avaliar os procedimentos simplificados de cálculo atualmente em vigor para verificação, em temperaturas elevadas, da capacidade resistente de perfis formados a frio com a seção transversal abordada nessa pesquisa. 
Foram contemplados estudos em caráter numérico e experimental de perfis compostos por dois perfis do tipo $U$ enrijecido, com seções transversais aberta (tipo I enrijecido) e fechada (tipo caixão). Este trabalho foi desenvolvido de forma complementar àquele apresentado em Almeida (2012), em que foram realizadas investigações numérica e experimental de diversos tipos de seção transversal compostas, cujos perfis possuem restrição rotacional.

\subsection{Justificativa}

A verificação estrutural em situação de incêndio deve-se ao fato de as propriedades mecânicas dos materiais (aço, madeira e concreto, por exemplo) resultarem reduzidas quando expostas a elevada temperatura, provocando o colapso estrutural em intervalo de tempo que pode não ser suficiente para garantir a desocupação da edificação.

Além dos fatores relativos à natureza do material, os perfis de aço formados a frio, principalmente aqueles com seções transversais abertas, por apresentar elevada relação b/t, estão sujeitos ao fenômeno de instabilidade. Em Feng et al. (2003 - a e b) se observou experimentalmente que, em alguns casos o modo de colapso por instabilidade de perfis de seção transversal $U$ e $U_{e}$ se altera durante o aumento da temperatura. A forma com que os modos de instabilidade ocorrem durante a exposição de perfis formados a frio aos gases aquecidos ainda não é totalmente esclarecida. A influência da temperatura na resistência ao escoamento e módulo de elasticidade do aço pode ser observada na figura 1.13, com base na norma europeia Eurocode 3 - Design of steel structures - Part 1.2: General rules - Structural fire design.

Aliado aos fatores mencionados anteriormente, razões de natureza econômica como a expansão no uso dos perfis formados a frio na construção civil, em edificações residenciais, industriais e comerciais, principalmente de pequeno e médio porte, expõe a importância em considerar a ação do incêndio sobre essas estruturas. Nesse contexto, é evidente a necessidade de estudos com a finalidade de esclarecer dúvidas quanto ao seu comportamento estrutural. 


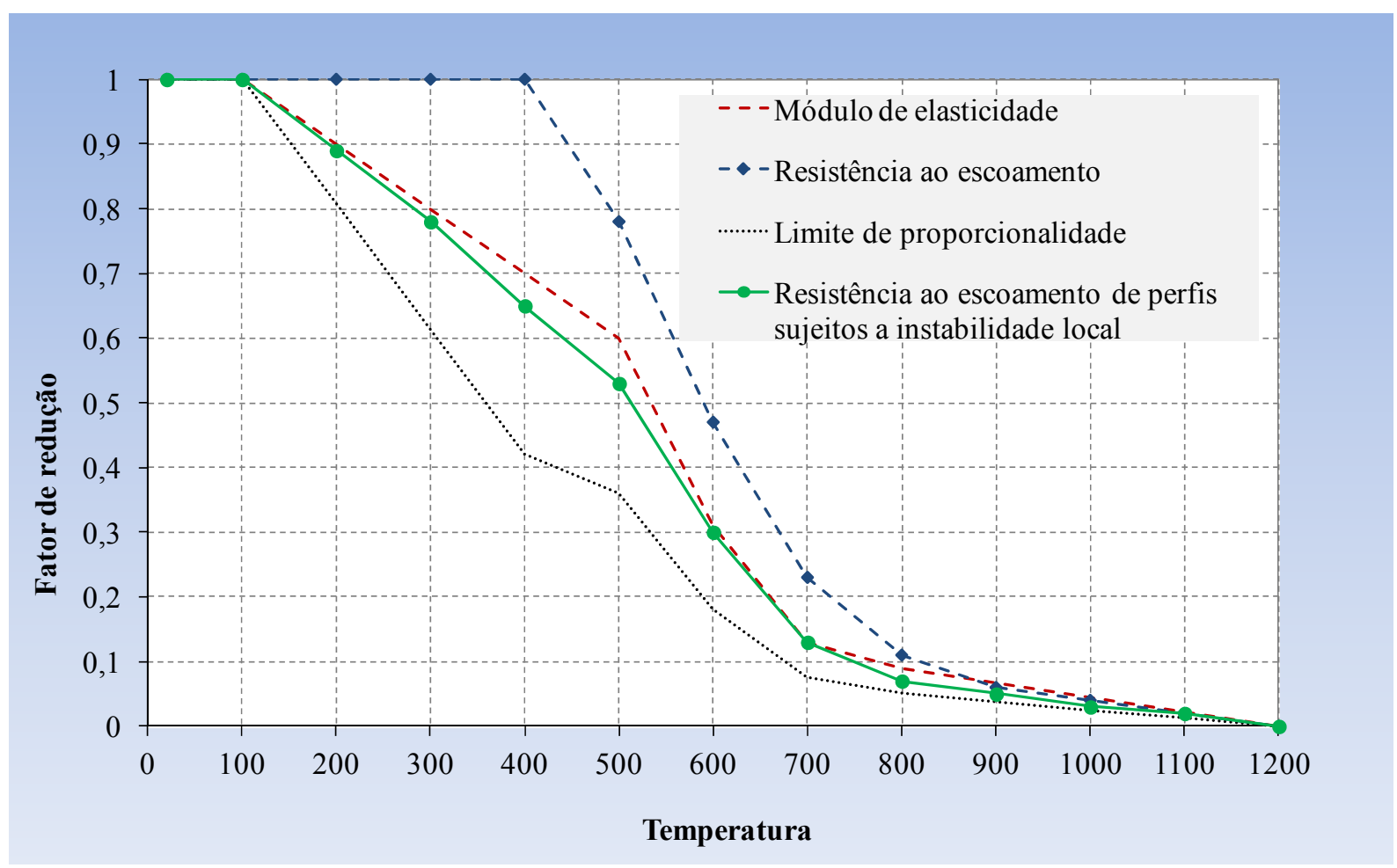

Figura 1.13: Reduções da resistência ao escoamento e do módulo de elasticidade, respectivamente, do aço e do concreto, em função da temperatura. Fonte: ABNT NBR 14323:2013.

\subsection{Metodologia}

De um modo geral, o presente trabalho dividiu as investigações numéricas e experimentais em três fases:

Investigação numérica preliminar: Foram desenvolvidas estratégias numéricas de forma a contemplar as verificações das barras submetidas à compressão axial à temperatura ambiente e em situação de incêndio. As análises termoestruturais consideraram as propriedades térmicas e a curva tensão x deformação definidas pela norma europeia Eurocode 3 , part 1.2. O objetivo dessa etapa foi estabelecer um planejamento adequado para o programa experimental.

Investigação experimental: Nesta etapa foi realizada inicialmente a caracterização dos corpos de prova à temperatura ambiente. Também foi verificado o desempenho dos perfis sob compressão axial à temperatura ambiente. A obtenção da força de colapso nessa etapa é importante para definir o valor da força axial aplicada e mantida constante na análise em situação de incêndio em regime térmico transiente. 
Uma vez conhecido o valor da força de colapso à temperatura ambiente, foram realizados ensaios de compressão axial sob ação da elevação da temperatura controlada artificialmente com auxílio do forno de ensaios. Por se tratar de elementos de pequena espessura, a maioria dos trabalhos experimentais encontrados na literatura aborda a ação térmica em regime estacionário. No presente trabalho, a temperatura consiste em uma ação que foi considerada em regime transiente.

O programa experimental foi desenvolvido no Laboratório de Estruturas da Faculdade de Engenharia Civil da Universidade Estadual de Campinas - Unicamp e contou com a colaboração do Professor Armando Lopes Moreno Junior. A execução dos ensaios exigiu inicialmente que fossem feitos testes de calibração do forno, para que a elevação da temperatura seguisse a curva de incêndio padrão estabelecida pela norma ISO 834-1:1999 Fire resistance tests - Elements of building construction - Part 1: General requirements. Uma vez programada a curva de incêndio, as seguintes respostas foram extraídas dos ensaios:

- elevação da temperatura ao longo do comprimento da barra;

- tempo e temperatura de colapso da barra (no caso de análise térmico-transiente);

- variação do deslocamento axial;

- modos de falha no instante do colapso estrutural.

Calibração dos modelos numéricos: A terceira etapa retoma a análise numérica com a finalidade de melhorar os resultados obtidos na primeira etapa, nesse momento, de posse dos parâmetros e respostas da análise experimental. A incorporação das informações dos ensaios torna a análise numérica mais representativa com o que venha a acontecer na realidade. $\mathrm{O}$ aprimoramento do modelo numérico permite inserir os gradientes não uniformes de temperatura (devido aos limites da dimensão do forno), bem como a realização da análise de outros parâmetros de interesse, ou seja, geometria do perfil, esbeltez (local e global) e dos modos de instabilidade.

\subsection{Estrutura da tese}

Esta monografia foi organizada em sete capítulos. O primeiro capítulo faz as considerações gerais sobre o assunto e enfatiza a importância do estudo da ação de incêndio 
em estruturas. São apresentados objetivos, justificativas e a metodologia que se pretende aplicar no desenvolvimento deste trabalho.

O capítulo 2 faz referência a importantes publicações relacionadas ao tema em questão. O primeiro item trata do comportamento mecânico dos perfis formados a frio. $\mathrm{O}$ segundo trata especificamente dos perfis abordados neste projeto. Os tópicos seguintes estão relacionados às estruturas em incêndio. São apresentados alguns trabalhos já desenvolvidos na EESC - USP, bem como algumas publicações relacionadas aos perfis formados a frio que serviram de base para este projeto.

O capítulo 3 apresenta breves comentários sobre o fenômeno de instabilidade em perfis de paredes esbeltas com seções transversais abertas. É apresentada uma definição analítica do fenômeno e dos modos possíveis de ocorrência, também são apresentadas as recomendações das principais normas em vigor atualmente para o dimensionamento em situação de incêndio.

O capítulo 4 descreve a elaboração do programa experimental realizado durante o presente trabalho. Primeiro, é comentado sobre a caracterização do material, em seguida a investigação em temperatura ambiente e, por fim, a série de ensaios em temperaturas elevadas. Também são apresentados os resultados obtidos na investigação experimental.

O capítulo 5 descreve a análise numérica. É apresentada a metodologia de construção do modelo, a definição das características do material, os elementos finitos utilizados, bem como a estratégia de resolução do modelo. Por fim, são apresentados resultados parciais referentes à análise numérica.

O capítulo 6 apresenta uma discussão dos resultados experimentais e numéricos obtidos juntos aos valores resultantes de procedimentos de cálculo recomendados pelas normas brasileira e europeia. Também faz uma comparação com o Método da resistência direta aplicada à temperaturas elevadas.

No capítulo 7 são apresentadas as principais conclusões deste trabalho de doutorado e as propostas futuras para continuidade deste estudo. 
Por fim, são apresentadas as referencias bibliográficas e as demais bibliografias consultadas durante o período do trabalho presente. 


\section{SOBRE OS PERFIS DE AÇO FORMADOS A FRIO EM SITUAÇÃO DE INCÊNDIO}

É de conhecimento que os perfis de aço formados a frio oferecem pouca (ou quase nenhuma) capacidade resistente quando em situação de incêndio. Relatos em Dubina, Ungureanu e Landolfo (2012) afirmam que, devido ao alto fator de massividade, até mesmo a cobertura intumescente não é adequada para oferecer proteção suficiente para garantir o tempo requerido de resistência ao fogo. Alguns tipos de proteção ainda não são recomendáveis para superfícies galvanizadas, típico nestes tipos de perfis, a exemplo das argamassas cimentícias e as coberturas a base de gesso. Dessa forma, a resistência ao incêndio é oferecida por outros materiais que compõem um sistema de revestimento, à base de materiais isolantes como lã de rocha, fibra cerâmica, entre outros. A interação dos perfis formados a frio com o revestimento é amplamente estudada em paredes do tipo light steel framing.

Porém, a exemplo de Silva et. al. (2007), os perfis de aço formados a frio podem compor sistemas de vigas e pilares usuais em edificações correntes, como ilustrado na figura 2.1 extraída da mesma referência. $\mathrm{Na}$ ocorrência do incêndio, essa estrutura metálica diretamente exposta ao fogo apresenta um tempo de resistência relacionado com o nível de carregamento aplicado, além dos gradientes de temperatura e isolamento a depender da configuração das paredes. Os itens a seguir descrevem características gerais dos perfis formados a frio e os estudos de interesse sobre o seu comportamento em incêndio.
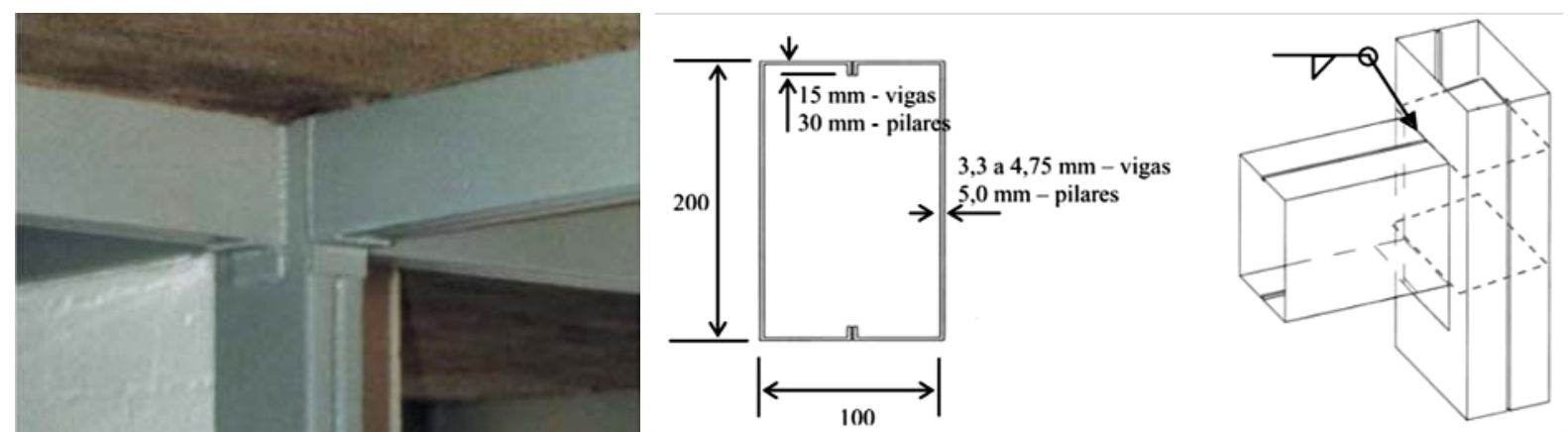

Figura 2.1: Ligação viga-pilar da edificação, (a) foto e (b) detalhamento. Fonte: Silva et. al. (2007). 


\subsection{Efeito do trabalho a frio sobre as propriedades mecânicas do}

aço

Como observado em Yu (2010), a conformação a frio para a obtenção dos perfis formados a frio altera as propriedades dos materiais, pois provoca o encruamento, ou seja, aumenta a resistência ao escoamento e à ruptura, ao passo que reduz a ductilidade. Resultados de vários estudos ainda mostram que a porcentagem no acréscimo da resistência à ruptura é muito menor em relação à da resistência ao escoamento e, dessa forma, a razão $f_{u} / f_{y}$ é reduzida.

Os efeitos do trabalho a frio nas propriedades mecânicas do material, principalmente na região das dobras, em geral, dependem do tipo de aço, do tipo de tensões solicitantes (tração ou compressão), da direção da tensão em relação à direção do trabalho a frio (longitudinal ou transversal), da quantidade de trabalho a frio que a chapa de aço apresenta, da relação entre a resistência ao escoamento e a resistência à ruptura $-\boldsymbol{f}_{\boldsymbol{u}} / \boldsymbol{f}_{\boldsymbol{y}}$ e da relação entre o raio interno de dobramento e a espessura do perfil $-\boldsymbol{r}_{\boldsymbol{i}} / \boldsymbol{t}_{\boldsymbol{n}}$.

\subsection{Seções transversais compostas}

Os perfis de seções transversais compostas são utilizados em situações em que é desejável obter um sistema estrutural mais leve, o que proporciona, além de estética, economia de material. Ao fazer uso de tais seções compostas, deve-se atentar às questões não consideradas em seções singulares. Uma delas é a deformação por cisalhamento que surge na região das chapas de ligação, o que contribui para a redução da capacidade estável da barra. A segunda questão é o modo de instabilidade global no segmento do perfil entre dois pontos conectado.

Em Stone e LaBoube (2005) é apresentado um estudo experimental sobre o comportamento de barras curtas com seção transversal composta por perfis de aço formados a frio, cujos resultados são confrontados com os procedimentos da norma americana North American Specification for the Design of Cold Formed Steel Structural Members (2001).

Tais perfis possuem seção transversal do tipo I enrijecido composta por dois perfis do tipo $U$ enrijecido perfurados na alma. As extremidades consistiram de perfis $U$ formados a 
frio, conectadas à barra por meio de parafusos. Esses compunham as bases e tinham a função de manter as extremidades de cada componente unidas. As figuras 2.2 (a) e (b) ilustram o esquema de ensaio e os parâmetros geométricos, respectivamente. A espessura variou entre $0,8 \mathrm{~mm}$ e $1,4 \mathrm{~mm}$.

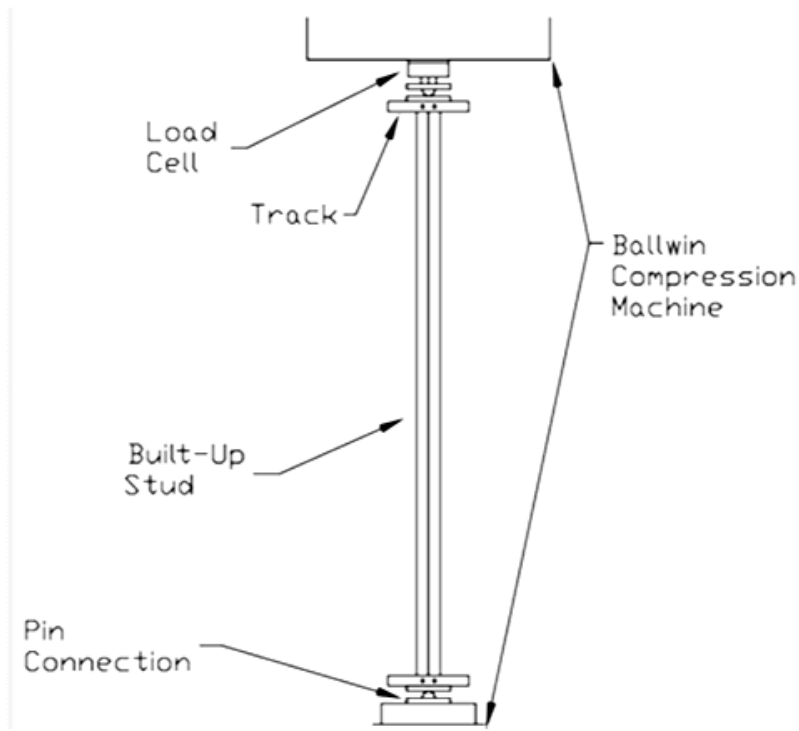

(a)

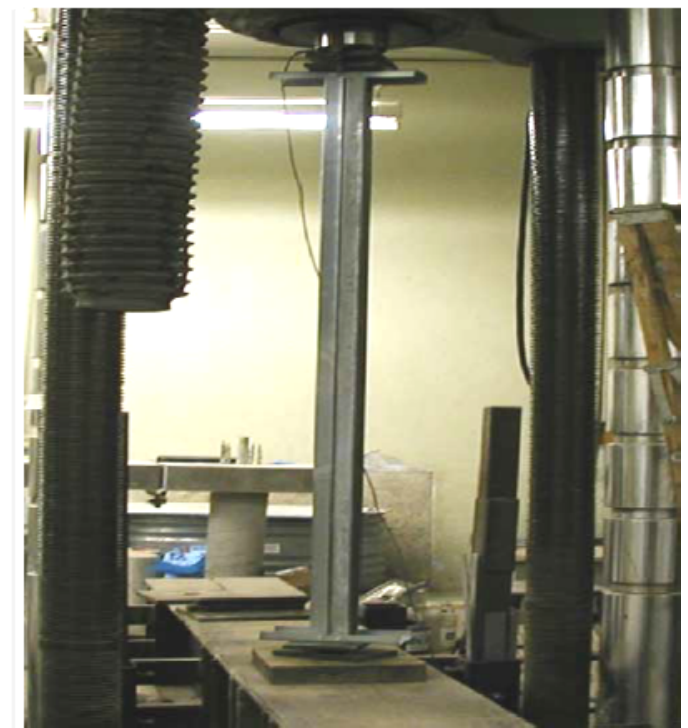

(b)

Figura 2.2: (a) Esquema geral de ensaio e (b) Procedimentos do ensaio de compressão centrada. Fonte: Stone e LaBoube (2005).

O programa experimental consistiu em avaliar o comportamento das seções I compostas por duplo perfil U formado a frio sob compressão centrada e determinar o quão válido é o método de dimensionamento proposto pelo AISI. A união das barras foi garantida por meio de conexão por parafusos.

Antes de atingir a força última de colapso, as barras apresentaram instabilidade local entre os conectores e em cada extremidade. Porém, a configuração no colapso apresentou também uma curvatura suave no eixo axial. Os resultados obtidos na análise experimental citada foram comparados aos procedimentos do AISI.

Para perfis constituídos por elementos de aço com maior espessura, a equação de dimensionamento do AISI, considerando as extremidades apoiadas, conduziu a valores conservadores em até $43 \%$. Mesmo para os perfis mais esbeltos localmente, o valor calculado por meio do AISI foi subestimado se comparado ao valor obtido experimentalmente. O estudo mostra que as recomendações do AISI para o dimensionamento são consideradas conservadoras e, portanto, a favor da segurança no cálculo da força última. 


\subsection{Estruturas em situação de incêndio}

As primeiras exigências de proteção contra incêndio surgiram por volta de 1666, porém, este tema só começou a ser realmente estudado em meados do século XIX e início do século XX. Conforme mencionado em Claret (2000) e Kirchhof (2004), a ASTM - American Society for Testing and Materials lançou em 1911 a primeira norma para testes de resistência ao fogo, intitulada "Standard tests for fireproof constructions". Em 1932, a British Standard Institution (BSI) publicou a norma BS 476, intitulada "Fire tests on buildings materials and structures", a qual, com as devidas revisões e ampliações, ainda hoje é bastante utilizada e tem por base ensaios de elementos isolados em fornos.

$\mathrm{Na}$ década de 90, foram realizados ensaios, em escala real, em edifícios construídos de madeira, de concreto e misto de aço e concreto, todos submetidos à elevadas temperaturas, realizados entre os anos de 1995 e 1997, no "Cardington Laboratory of the Building Research Establishment", no Reino Unido.

Em 1995 representantes do corpo universitário e técnico do Brasil, juntamente com o Corpo de Bombeiros/SP, fabricantes de estruturas metálicas e de materiais de revestimento contra fogo, siderúrgicas, o Instituto de Pesquisas Tecnológicas - IPT, entre outras instituições deram inicio ao trabalho de normatização de estruturas em situação de incêndio. Assim, foi lançada a norma brasileira ABNT NBR 14323:1999 intitulada "Dimensionamento de estruturas de aço de edifícios em situação de incêndio”, em que são apresentados critérios para dimensionamento de perfis de aço laminados ou soldados.

Em seguida, foi lançada a ABNT NBR 14432:2000 - "Exigências de resistência ao fogo de elementos construtivos das edificações”, que trata da determinação do tempo de referência que as estruturas devem resistir antes do colapso (tempo requerido de resistência ao fogo - TRRF).

A publicação da primeira edição da ABNT NBR 15200 "Projeto de estruturas de concreto em situação de incêndio" no ano de 2004 foi o primeiro passo para a regulamentação dos projetos em estruturas de concreto em situação de incêndio. 
Também há um grande esforço por parte da ABNT em considerar a ação térmica, para fins de dimensionamento na revisão da ABNT NBR 7190:1997, intitulada "Projeto de estruturas de madeira”.

Atualmente, a norma de estrutura de aço e mistas de aço e concreto, bem como a norma de estruturas de concreto em situação de incêndio tiveram suas versões atualizadas para a ABNT NBR 14323:2013 e a ABNT NBR 15200:2012, respectivamente.

Atualmente, no Departamento de Engenharia de Estruturas da EESC/USP, se encontram inseridos trabalhos já concluídos e em andamento, em níveis de mestrado e doutorado, como consequência da participação de docentes da EESC/USP, bem como a colaboração de pesquisadores de outras instituições. No contexto das estruturas de aço em situação de incêndio, foram abordados temas referentes aos perfis formados a frio, às vigas mistas de aço e concreto e análise de seções transversais e de elementos estruturais, dentro do campo da modelagem numérica.

Em Mendes (2004) foram catalogados os principais trabalhos relacionados à ação do incêndio em estruturas metálicas constituídas por perfis formados a frio. Por meio da coletânea de informações reunidas, foi proposto um método simplificado de dimensionamento de perfis formados a frio em situação de incêndio. De acordo com a referência citada, a verificação das barras pode ser realizada seguindo a formulação da ABNT NBR 14672:2001, porém devem ser considerados os fatores de redução recomendados pelo Eurocode 3 part 1.2 e utilizar o valor da resistência ao escoamento correspondente a $0,2 \%$ da deformação total da barra.

Em Regobello (2007), foram realizados modelos numéricos em que se estudou variação da temperatura ao longo do tempo em seções transversais de elementos de aço e mistas de aço e concreto, com vistas a avaliar as equações de fator de massividade (u/A) da ABNT NBR 14323:1999. Os modelos foram elaborados por meio do programa ANSYS v9.0, para avaliar a evolução dos níveis de temperatura ao longo do tempo e também, com vistas à análise do efeito da elevação de temperatura no comportamento mecânico (análise acoplada) em vigas de aço. As figuras 2.3 e 2.4 apresentam resultados obtidos no referido trabalho com o ANSYS v9.0 e comparados com resultados do código computacional SUPERTEMPCALC. 
Ponto 1

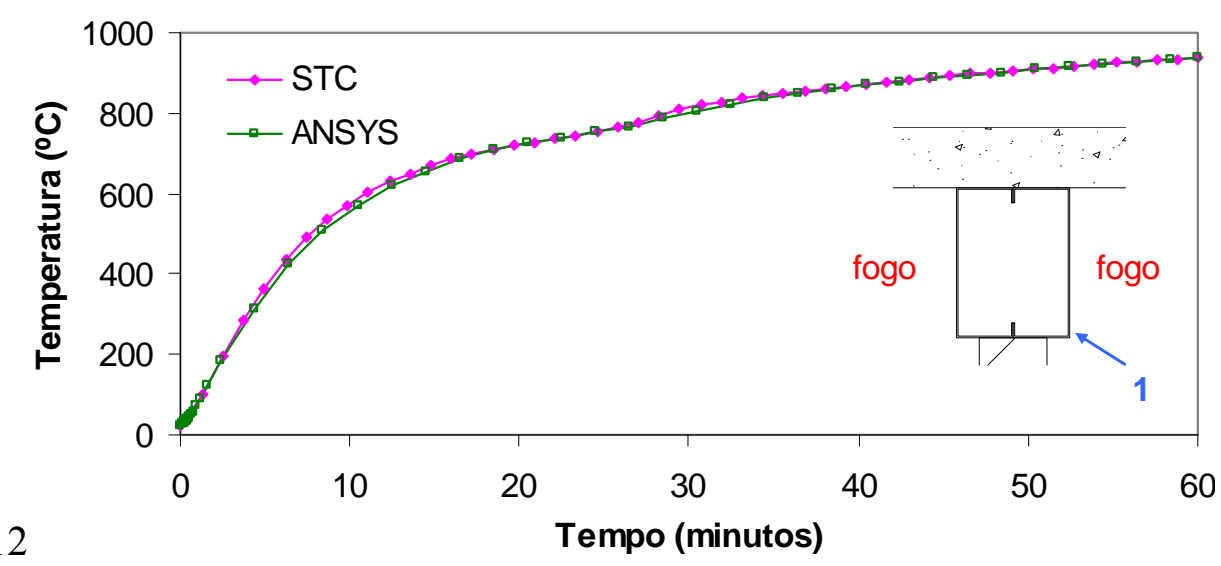

Figura 2.3: Caso U5-VLA9-EIT: Variação da temperatura no ponto 1 ao longo do tempo.

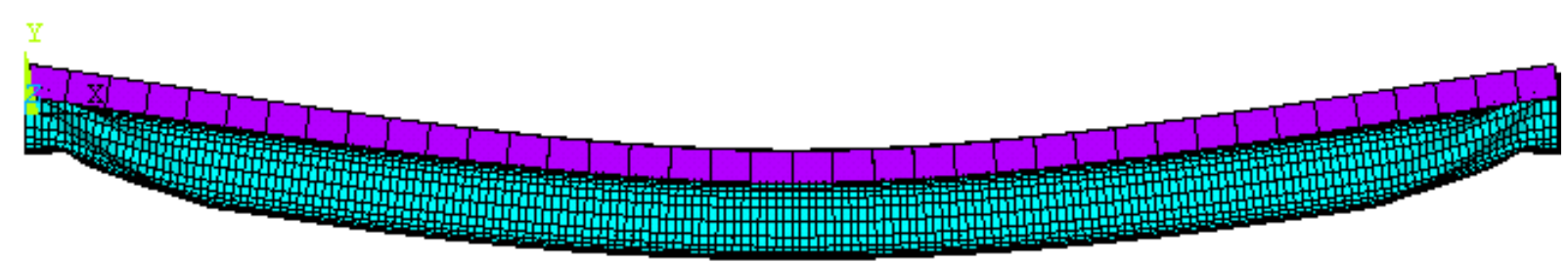

Figura 2.4: Configuração deformada da viga, em correspondência ao caso de carregamento de 25 $\mathrm{kN} / \mathrm{m}$ e tempo de 21 minutos de exposição ao incêndio.

A importância desse estudo buscou abordar casos em que a ação térmica nos elementos não ocorre de maneira simétrica nos pontos que constituem a seção transversal. Como consequência, passa a ser considerada a possibilidade de obtenção de valores de temperatura máxima na seção que resultem mais próximos daqueles que de fato venha a ocorrer na prática. Esse, juntamente com Kotinda (2006), Kirchhof (2004) foram importantes estudos para estabelecer as primeiras estratégias numéricas na análise das estruturas em situação de incêndio na EESC/USP.

Em Kimura (2009) se avaliou o efeito das imperfeições geométricas, porém em perfis de aço laminados, em que foram abordadas condições de não-simetria do campo de temperatura na determinação do tempo de resistência ao fogo do perfil. A figura 2.5 e 2.6 ilustram um dos resultados obtidos no trabalho citado, para o perfil metálico em contato com paredes de alvenaria em ambas as mesas. 
(a)
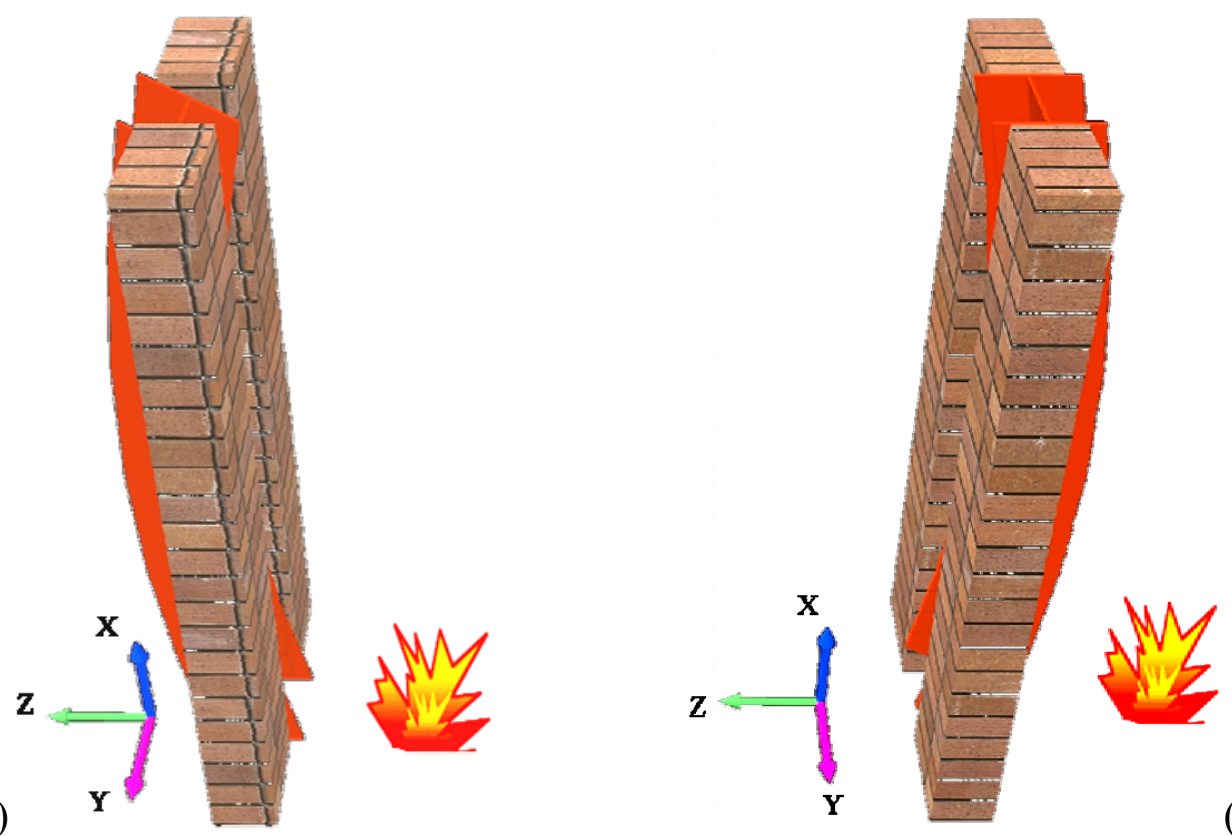

(b)

Figura 2.5: Imperfeição geométrica inicial e localização do campo térmico: (a) em sentidos opostos e (b) no mesmo sentido.

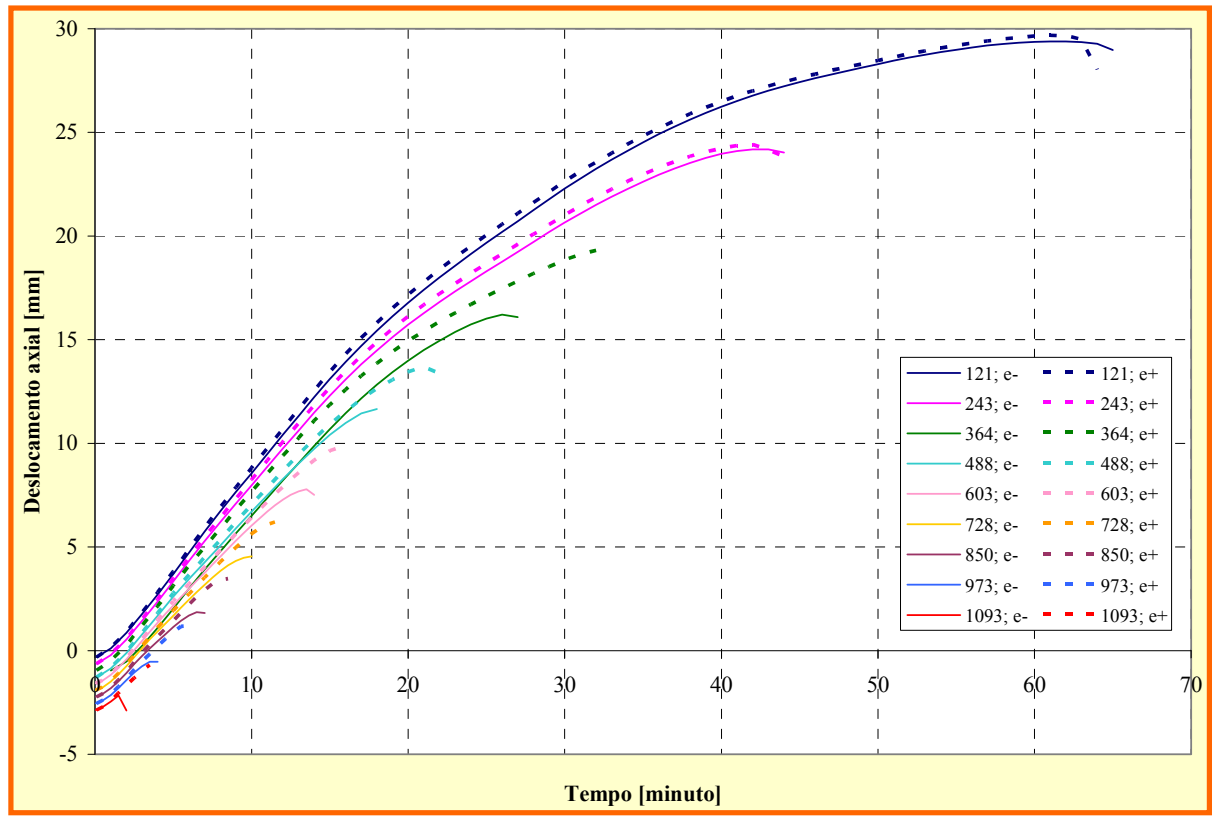

Figura 2.6: Comparativo entre o deslocamento axial considerando deslocamentos iniciais de sentidos opostos

As simulações numéricas apresentadas em Kimura (2009) foram aprimoradas em Dorr (2010), em que foram obtidos resultados eficientes com menor custo computacional. Adicionalmente, foi realizada uma análise paramétrica das restrições axiais do perfil sob compressão. Em Rigobello (2011) foram desenvolvidos códigos computacionais, com base no Método dos Elementos Finitos Posicionais para análise térmica e estrutural de pórticos tridimensionais expostas às ações térmicas típicas de situações de incêndio. Em Almeida 
(2012) foram apresentas investigações experimental e numérica do comportamento de perfis de aço formados a frio em temperaturas elevadas. Neste estudo foram analisadas as condições de restrição axial de perfis cujas características geométricas são usuais na construção civil europeia.

Atualmente, encontram-se em desenvolvimento pesquisas na área das estruturas mistas de aço e concreto, madeira e concreto e de madeira, em caráter experimental e numérico. Tais estudos serão de grande importância para o desenvolvimento de documentos técnicos e científicos na área das estruturas em situação de incêndio.

\subsection{Consideração da ação térmica em perfis aço formados a frio}

Embora uma quantidade considerável de trabalhos tenha sido publicada na área, algumas questões sobre o comportamento de perfis formados a frio em incêndio ainda são cabíveis de discussão. Grande parte dos trabalhos investiga o comportamento estrutural de perfis do tipo U, muito utilizado no sistema Steel Framing. Portanto, percebeu-se que ainda existem questões a ser exploradas em relação a outros sistemas estruturais, mais comuns na construção civil brasileira.

Em Klippstein (1978) foram apresentados os primeiros estudos em que foi abordado o sistema estrutural em Steel Framing em situação de incêndio com apoio do American Iron and Steel Institute, AISI. Naquela época, já existia interesse em desenvolver um método analítico para prever o comportamento estrutural dos elementos de aço, além de contribuir com possíveis reformulações da ASTM E119 - 11a Standard Test Methods for Fire Tests of Building Construction and Materials, que trata da padronização dos ensaios de incêndio. Para tanto, foram desenvolvidas análises experimentais, conforme figuras 2.7(a) a 2.7(c). 

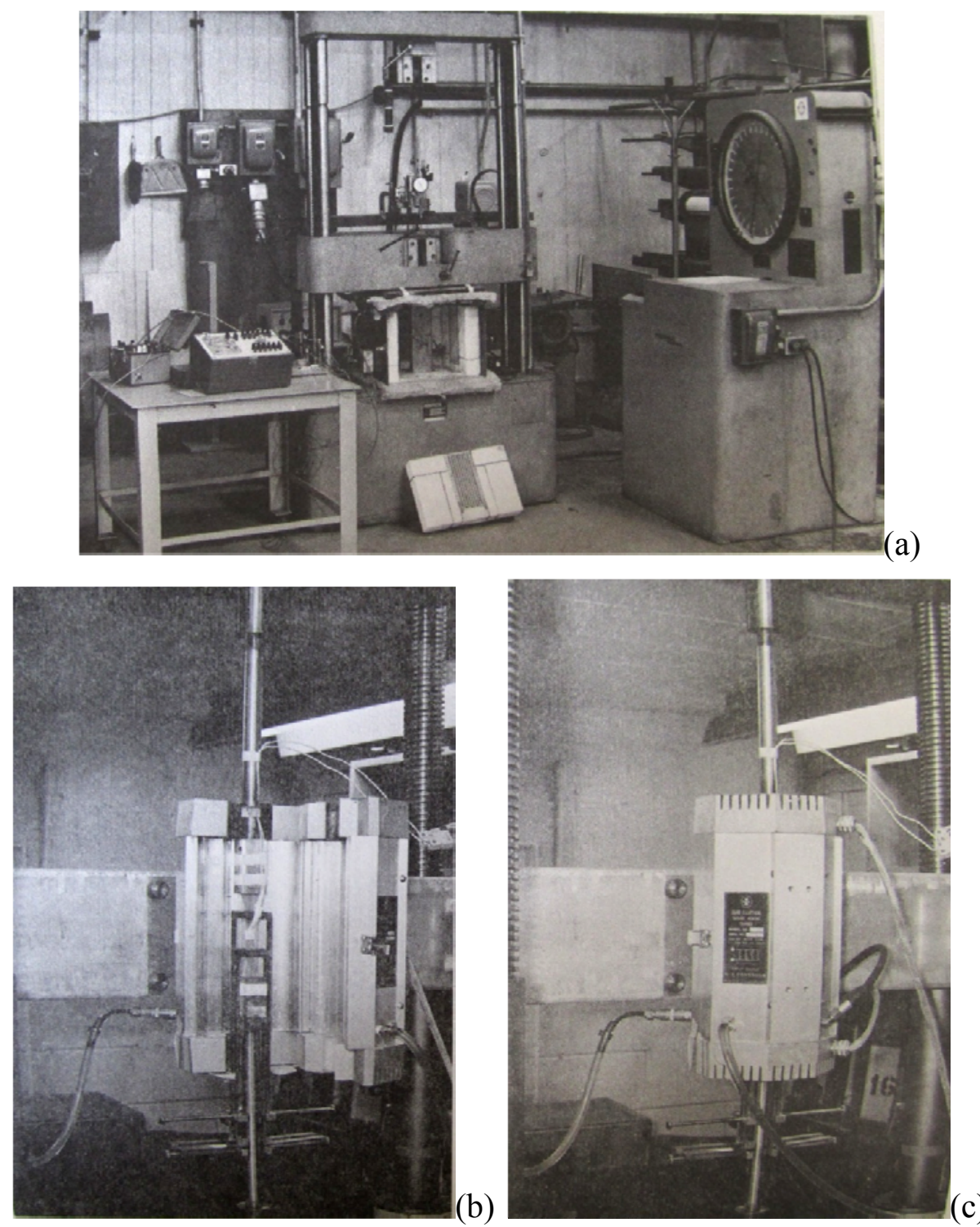

Figura 2.7: Ensaio realizado em Klippstein (1978): (a) Esquema geral, (b) forno de ensaios aberto e (c) forno de ensaios fechado.

Os testes foram realizados sobre uma parede quadrada de $3,05 \mathrm{~m}$ de lado submetida a carregamentos verticais. A evolução da temperatura em função do tempo seguiu a curva da ASTM E119. O trabalho aqui comentado ressaltou a dificuldade na época em se determinar a complexa relação temperatura $x$ tempo e deslocamento $x$ tempo nos modelos de paredes do tipo steel framing. Durante a fase inicial do ensaio, foi observado um constante aumento no gradiente de temperatura pela seção transversal dos perfis. Neste caso, a aba próxima a face em contato com o incêndio encontrou-se mais aquecida que a aba oposta, em contato com a temperatura ambiente. Este gradiente resultou em um deslocamento horizontal na direção da câmara de incêndio. 
A fase final do ensaio ocorreu com a ruptura da placa de gesso, expondo partes do interior da parede às temperaturas de incêndio e, consequentemente, o gradiente de temperatura nas barras adjacentes reduziu rapidamente. Foi observado também que a temperatura média das barras individuais aumenta em taxas diferentes. Logo, nos instantes finais do ensaio, os parâmetros mencionados, a citar o gradiente de temperatura, o deslocamento lateral e a temperatura média, apresentaram grandes diferenças entre as barras que compõem a parede.

Tais inconsistências na investigação experimental obrigou o desenvolvimento do respectivo método analítico a assumir algumas simplificações. Uma delas era admitir que o material aço se comportasse de acordo com a curva tensão $\mathrm{x}$ deformação bilinear, as solicitações aplicadas fossem uniformemente distribuídas e que todos os perfis estivessem submetidos ao mesmo gradiente de temperatura, deslocamentos horizontais e temperaturas médias durante o ensaio, em que se observou os painéis apresentando deslocamento lateral devido ao gradiente térmico decorrente do aquecimento em uma das faces, mantendo a outra em contato com a temperatura ambiente. Devido à dificuldade em avaliar o campo de deslocamento em função do tempo, principalmente nos instantes próximos ao colapso, o método analítico foi simplificado de modo a representar uma relação linear do deslocamento.

O método analítico proposto em Klippstein (1978) forneceu respostas conservadoras para os painéis estudados, em comparação aos resultados experimentais obtidos, além de mostrar limitações por ser fortemente dependente da determinação empírica da variação da temperatura e deslocamento lateral. Além disso, para uma força aplicada em incêndio com valores acima de $50 \%$ da força de colapso à temperatura ambiente, não se sabia na época se a relação linear assumida do deslocamento lateral em função do tempo poderia ser aplicada. Esse método era aplicável apenas aos perfis $U_{\mathrm{e}}$ para paredes do tipo steel framing submetidos à curva de incêndio da $\mathrm{ASTM}$ até $649^{\circ} \mathrm{C}$. Logo, essa era a temperatura limite à que os modelos poderiam ser submetidos durante os ensaios.

Como já comentado, os perfis de aço formados a frio tendem a rapidamente ter suas propriedades mecânicas reduzidas, quando não revestidos por material de proteção. Nesse contexto, em Kaitila (2002) foi avaliada a possibilidade de se aplicar a mesma formulação de dimensionamento referente aos perfis de aço formados a frio à temperatura ambiente ao dimensionamento em temperaturas elevadas. Para tanto, foi tomado como base seção 
transversal do tipo U $100 \times 40 \times 15 \times 1,0$ e comprimento de $2500 \mathrm{~mm}$, com resistência ao escoamento de $350 \mathrm{MPa}$ e com restrição a torção. Dessa forma, apenas o modo de flexão em torno do eixo de maior inércia, juntamente com o modo local, foi considerado na referência citada. As condições de contorno foram consideradas validas até a temperatura de $600{ }^{\circ} \mathrm{C}$.

A análise por elementos finitos forneceu valores de força de colapso maiores que aquelas calculadas pelo Eurocode 3 Part 1.2. Quando comparado ao valor calculado usando a curva $\mathrm{C}$ de resistência à compressão do Eurocode 3 Part 1.1 (que é a recomendação no caso de temperaturas elevadas), a maior diferença ocorreu nas análises à temperatura ambiente, resultando em torno de $16 \%$ a $27 \%$ a depender da amplitude da imperfeição inicial. Para temperatura em torno de $300{ }^{\circ} \mathrm{C}$ a força última varia de $5 \%$ a $16 \%$, e para $600{ }^{\circ} \mathrm{C}$ resulta entre $1 \%$ e $23 \%$. Houve uma correspondência entre a amplitude da imperfeição inicial adotada no modelo numérico com a força de colapso, observando-se que quanto maior a amplitude menor a força de colapso.

Ao utilizar a curva $\mathrm{B}$ de resistência à compressão, a referência citada observou que os valores obtidos resultaram mais próximos da resposta numérica. Para temperaturas de $300^{\circ} \mathrm{C}$ e $600{ }^{\circ} \mathrm{C}$, essa diferença fica abaixo de $10 \%$. Em geral, mesmo utilizando a curva $\mathrm{B}$, os valores obtidos pelo Eurocode 3 Part 1.2 resultaram conservadores em relação ao resultado da análise numérica. Embora os resultados apontem um maior ajuste para a curva $\mathrm{B}$ de resistência, não é possível fazer nenhuma recomendação quanto ao método de dimensionamento, pois tal investigação se manteve restrita a apenas um tipo de seção transversal.

Estudos no campo experimental que abordam perfis de aço formados a frio submetidos a um carregamento qualquer dentro do limite $F_{\theta} / F<1$, em situação de incêndio, geralmente são realizados sob a ótica da metodologia de temperatura estacionária. Nesse caso, a temperatura é mantida fixa em um determinado valor e a ação (força ou deslocamento) é aplicada gradualmente. Essa estratégia foi utilizada na investigação experimental apresentada em Feng et. al. (2002) em que se investigou o comportamento de barras curtas de perfis de aço formados a frio galvanizados de seção $U$ e $U_{e}$ sujeitos à instabilidade local. Para tanto, os perfis foram posicionados sobre apoios fixos em suas extremidades, de forma a permitir rotação fora do plano e restringir as rotações de torção no plano da base. 
Foram tomadas as medidas de deslocamento longitudinal no topo e na base, além do deslocamento lateral tomado na altura média, tanto na alma como em ambas as mesas. Também foram posicionados extensômetros para medida da deformação na altura média da barra. Para os ensaios sob temperatura elevada, os pilares curtos e os suportes de base e de topo foram posicionados dentro do forno, conforme ilustrado na figura 2.8. As temperaturas foram tomadas por meio de cinco termopares igualmente posicionados na alma dos perfis. Além disso, ressalta-se que, como as placas de base são muito mais rígidas que o perfil, foi assumido que o deslocamento relativo entre essas placas era o deslocamento axial do pilar.
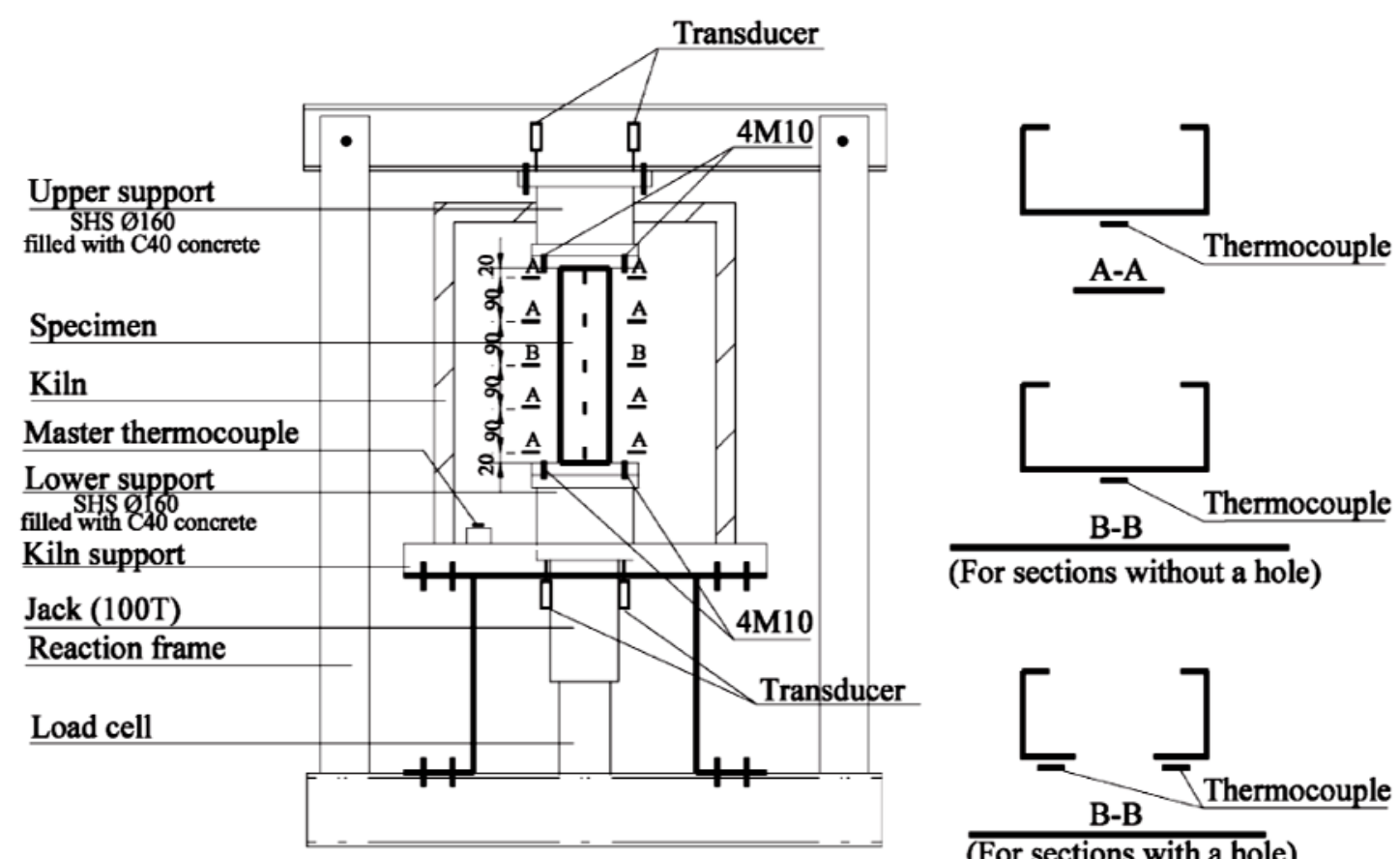

(For sections without a hole)

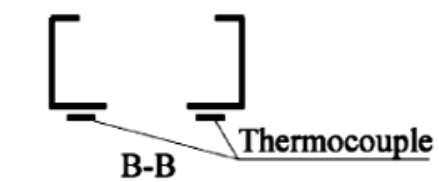

(For sections with a hole)

Figura 2.8: Esquema do ensaio de barras curtas em perfis formados a frio realizado em Feng et. Al. (2002). Fonte: Feng et. Al. (2002).

A análise estrutural foi realizada em cinco níveis de temperatura pré-estabelecidos, em regime estacionário, as quais foram $20^{\circ} \mathrm{C}, 250{ }^{\circ} \mathrm{C}, 400{ }^{\circ} \mathrm{C}, 550{ }^{\circ} \mathrm{C}$ e $700{ }^{\circ} \mathrm{C}$. O forno foi controlado até atingir a temperatura desejada e o modelo foi então mantido por 20 minutos, de modo a assegurar que o campo térmico estivesse uniforme no material. Durante o processo de aquecimento, o modelo apresentou expansão térmica sem qualquer restrição no sentido axial. Após atingir a temperatura esperada, a força de compressão foi aplicada com incremento igual a $1,0 \mathrm{kN}$ para as temperaturas de $20^{\circ} \mathrm{C}, 250{ }^{\circ} \mathrm{C}$ e $550{ }^{\circ} \mathrm{C}$, e $0,5 \mathrm{kN}$ para temperaturas de 700 ${ }^{\circ} \mathrm{C}$ até o colapso, caracterizada pelo instante em que a força aplicada não pôde mais ser mantida, o que caracteriza esse como ensaio com controle do incremento de força. 
Nos ensaios em temperatura elevada, apenas deformações finais no perfil puderam ser observadas. A configuração deformada da barra ao final do ensaio à temperatura elevada se mostrou semelhante àquela mesma obtida à temperatura ambiente. Na configuração deformada, perfis de aço com seção transversal sem enrijecedores de borda apresentaram esmagamento local no topo, provocado por uma longa deformação pós-crítica no interior do forno. Em situação de incêndio, esse grau de esmagamento se mostrou mais severo que à temperatura ambiente.

Perfis do tipo $\mathrm{U}_{\mathrm{e}}$ com espessura igual a $1,2 \mathrm{~mm}$, quando à temperatura ambiente, apresentaram modos de falha local e distorcional, além do modo global de flexão, e nenhuma diferença nas características das falhas foram detectadas à temperaturas elevadas. Contudo, observou-se que, para temperaturas inferiores a $400{ }^{\circ} \mathrm{C}$ houve predominância do modo de falha local, e acima de $550{ }^{\circ} \mathrm{C}$ o modo que dominou foi do tipo distorcional. Para seções $U_{e}$ mais espessas $(2,0 \mathrm{mms})$, o modo de falha foi predominantemente distorcional e, em alguns casos, acompanhado de instabilidade local e flexão em torno do menor eixo de inércia devido às imperfeições iniciais. A figura 2.9 ilustra as configurações pós-críticas observadas em algumas barras no programa de ensaio.
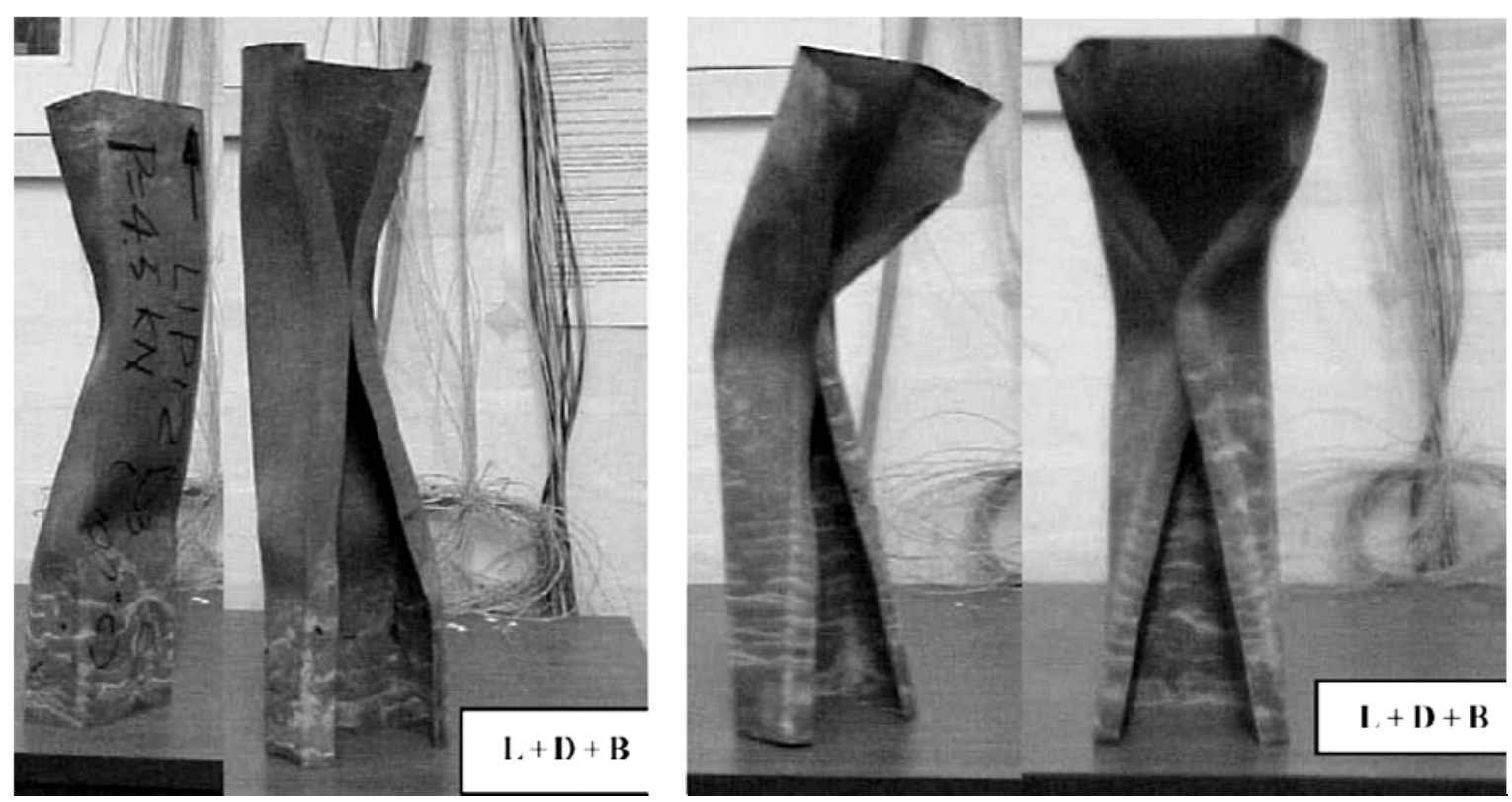

Figura 2.9: Modos de instabilidade obtidos em dois dos modelos submetidos à análise experimental, a $700^{\circ} \mathrm{C}$, apresentada em Feng et. al. (2002). Fonte: Feng et. al. (2002)

Os ensaios descritos apontaram uma grande variação na deformação longitudinal medida nos diferentes extensômetros. Tal distribuição de caráter fortemente não linear se dá 
em decorrência da flexibilidade desses perfis de chapas finas afetados pela imperfeição geométrica inicial. Porém, a quantificação precisa dessas deformações é de difícil determinação devido à impossibilidade de se medir as deformações iniciais no início do ensaio.

Nos ensaios apresentados, observou-se que o efeito da temperatura consiste basicamente em reduzir a força resistente de colapso do pilar. Porém, nos instantes iniciais do aquecimento, barras $U_{e}$ com espessura de chapa de 2,0 $\mathrm{mm}$ apresentaram força de colapso maior se comparada àquela identificada à temperatura ambiente. Embora as razões para esse fato não tenham sido foi totalmente esclarecidas, a justificativa sustentada é a de que essa temperatura, correspondente ao estágio inicial do aquecimento, alivia as tensões residuais na seção transversal devido o trabalho a frio, mas não reduz de forma significativa a resistência do aço. O programa experimental apresentado na última referência observou que o modo de falha de dois pilares idênticos pode ser diferente, pois depende das imperfeições iniciais apresentadas pelo perfil. Essa regra foi observada tanto para temperatura ambiente como em situação de incêndio. Contudo, os diferentes modos de instabilidade para barras idênticas não resultaram em diferença na força de colapso.

Em Feng, Wang e Davies (2002) foi apresentada uma análise numérica realizada por meio do código computacional ABAQUS referente ao estudo experimental publicado na referência supracitada. Nesta investigação, foram considerados apenas os modos instabilidade local e distorcional tratados isoladamente com o perfil à temperatura uniforme. A relação tensão $x$ deformação em temperatura elevada usada na análise numérica seguiu o modelo do Eurocode 3 Part 1.2. Foram realizados testes de malha de elementos finitos e de parâmetros relativos a não linearidade geométrica. A análise numérica apresentada obteve respostas, em termos de trajetória de deslocamento $x$ tempo, ilustradas nas figuras 2.10 a 2.12, respectivamente, para diferentes densidades de malha de elementos finitos, amplitudes de imperfeição geométrica inicial e limites de proporcionalidade $f_{p}$. Por meio destes resultados numéricos e experimentais, foram propostos ajustes nos métodos de dimensionamento das normas britânica e europeia vigentes. 


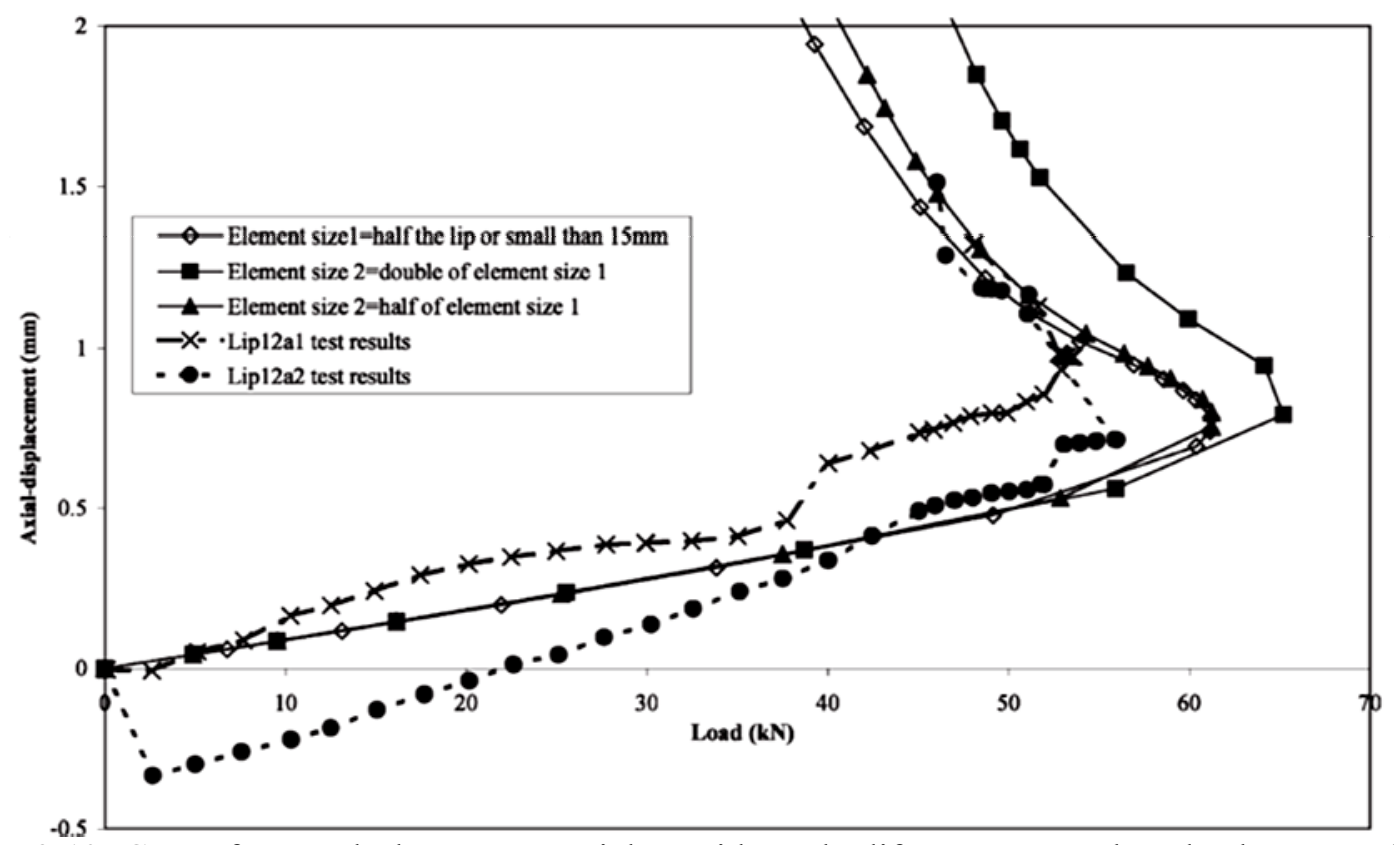

Figura 2.10: Curva força $\mathrm{x}$ deslocamento axial considerando diferentes tamanhos de elementos finitos para o perfil $\mathrm{U}_{\mathrm{e}} 100 \times 54 \times 15 \times 1,2$.

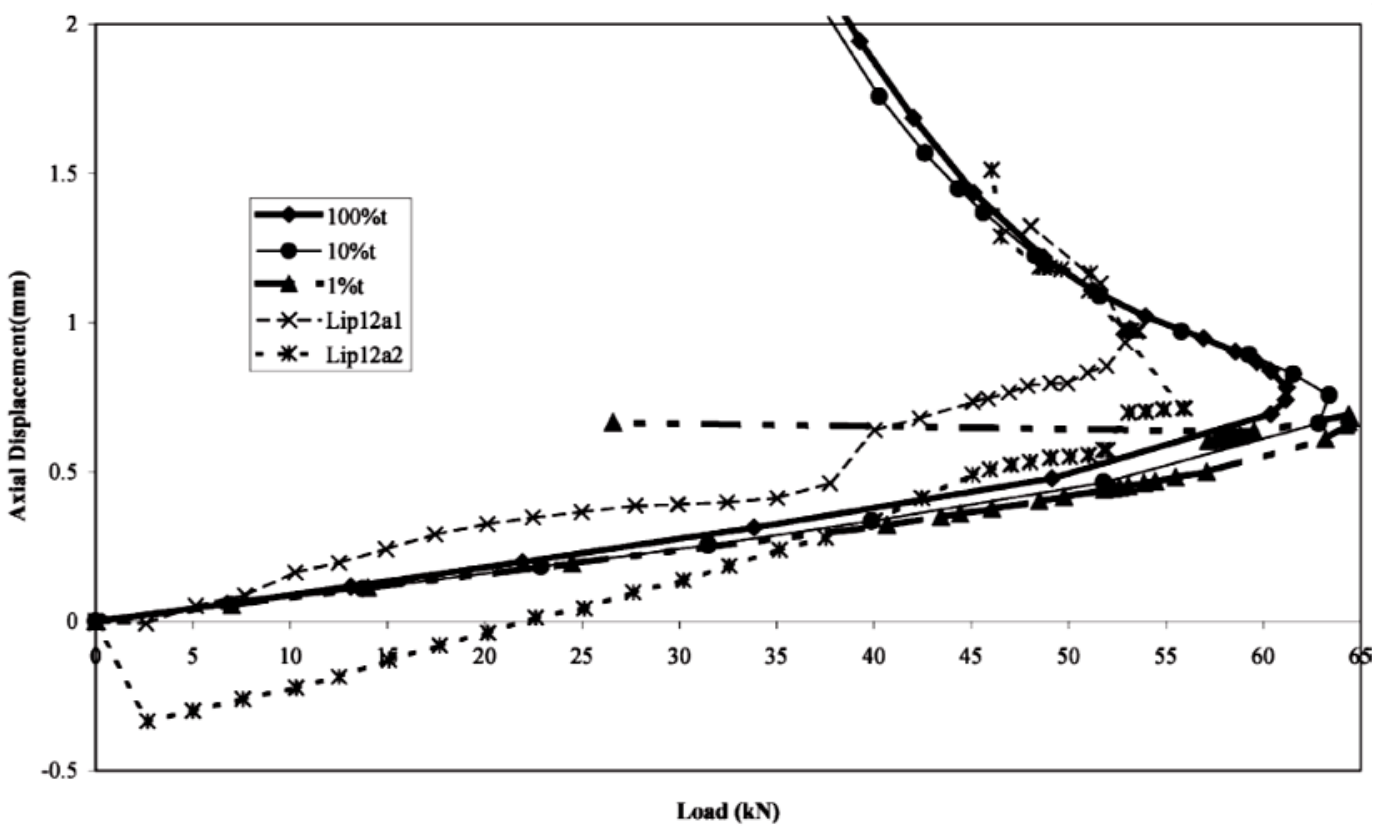

Figura 2.11: Curva força $x$ deslocamento axial considerando diferentes amplitudes de imperfeição geométrica inicial para o perfil $\mathrm{U}_{\mathrm{e}} 100$ × 54 × 15 × 1,2. 


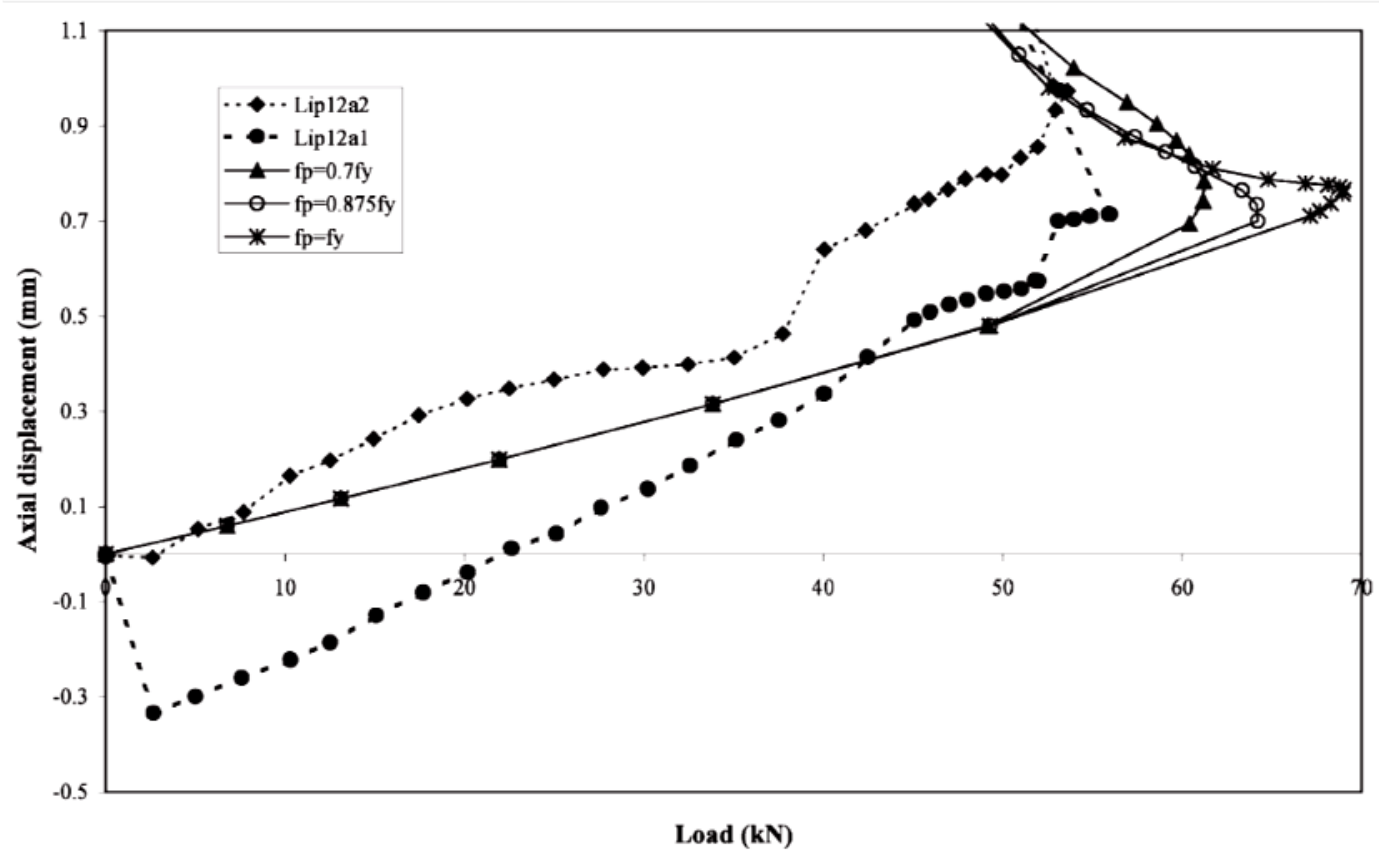

Figura 2.12: Curva força $x$ deslocamento axial considerando diferentes valores de tensão de proporcionalidade adotados na análise numérica do perfil $U_{\mathrm{e}} 100$ × 54 × 15 × 1,2.

Um fato também interessante sobre o uso dos perfis de aço formados a frio em paredes do tipo steel framing é a formação do gradiente de temperatura em caso de incêndio. Uma vez que tais perfis são protegidos pelo revestimento das paredes, a exposição ao incêndio ocorre geralmente em uma das faces, o que resulta em um campo térmico não uniforme na seção transversal da barra. Em Feng, Wang e Davies (2003) são apresentados resultados numéricos de resistência de perfis de aço pertencentes a paredes do tipo ligth steel framing, com seção transversal do tipo $\mathrm{U}$, submetidos ao aquecimento em um lado, referente ao eixo de simetria do perfil. Esta condição acarreta gradiente de temperatura na alma e nas mesas, devido à rápida dissipação do calor para os materiais circundantes, o que contribui para a distribuição não uniforme de temperatura também nesse elemento.

Uma das consequências do gradiente de temperatura é que o comportamento estrutural decorrente da ação térmica se torna complexo e de difícil avaliação. A primeira razão é a de que o gradiente de deformação térmica na barra sob compressão axial favorece o surgimento de momento fletor. A segunda razão é que este gradiente térmico resulta com distribuição não uniforme de resistência e rigidez que, por sua vez provoca um deslocamento na posição da linha neutra na seção transversal, o que não é considerado na análise estrutural. 
O aquecimento não uniforme resultou num comportamento variável em relação aos modos de instabilidade. Os perfis que, à temperatura ambiente apresentaram modo de falha local, quando em situação de incêndio, além desse mesmo modo local, apresentaram também os modos de flexão oblíqua e flexo torção. A mudança dos modos de falha foi resultado, principalmente, do momento fletor induzido pela deformação térmica.

Em barras curtas submetidas por um curto período de exposição ao incêndio, o gradiente de temperatura é relativamente pequeno, logo, o momento fletor induzido pela deformação térmica axial era relativamente pequeno, e a falha tende a ocorrer por instabilidade local. Conforme essa exposição se prolonga, o momento fletor em torno do eixo de simetria torna-se significante devido ao gradiente acentuado na seção transversal do pilar, de forma que o colapso é comandado pela flexão. Em longos períodos de exposição ao fogo, o gradiente de temperatura mostrou tendência a se tornar constante, com grande redução na resistência do pilar em relação à instabilidade por flexotorção, de forma que essa se tornasse o modo de falha dominante.

Ainda de acordo com a última referência, ao tomar a temperatura variável linearmente na alma e constante na mesa, é possível adequar o procedimento de cálculo Eurocode 3 Part 1.3 para estimar a força de colapso de pilares de forma a considerar a plasticidade parcial, redução na resistência e rigidez, momento fletor adicional resultante da deformação térmica axial e mudança na posição do eixo neutro. Perfis de aço formados a frio são suscetíveis a vários modos de instabilidade e suas interações, dentre os quais, os modos local e distorcional são os mais comuns de ocorrer em peças curtas sob compressão.

Nesse contexto, em Ranawaka e Mahendran (2009-a) foram apresentados estudos sobre o modo distorcional de instabilidade de perfis formados a frio que compõem lajes com forma incorporada ou paredes do tipo dry wall, contemplando uma série de ensaios de compressão axial, conforme esquematiza a figura 2.21, avaliando aços de baixa resistência (G250) e elevada resistência (G550), em que se utilizaram perfis $\mathrm{U}_{\mathrm{e}}$ com e sem enrijecedores adicionais, com espessuras nominais iguais a $0,6 \mathrm{~mm}, 0,8 \mathrm{~mm}$ e $0,95 \mathrm{~mm}$, com seis diferentes estágios de temperatura entre $20^{\circ} \mathrm{C}$ e $800{ }^{\circ} \mathrm{C}$. Como características dos perfis de aço utilizados, perfis de geometria semelhantes, cujos materiais possuem diferentes propriedades físicas apresentaram, naturalmente, diferentes resistências à compressão à temperatura ambiente. Porém, quando expostos a temperaturas acima de $400^{\circ} \mathrm{C}$, essa diferença tende a 
reduzir. A resistência ao escoamento do aço de alta resistência decaiu rapidamente em temperaturas superiores a $400^{\circ} \mathrm{C}$, quando comparado ao aço de baixa resistência.

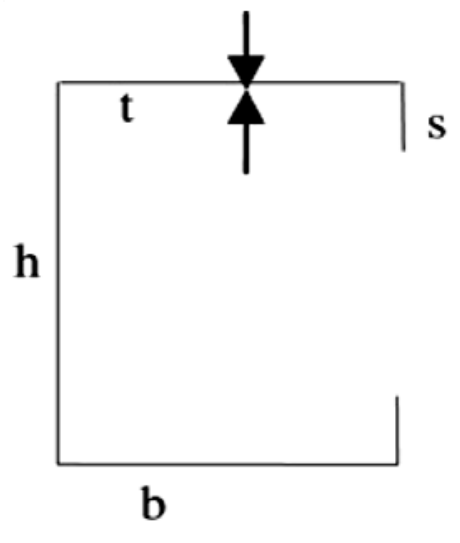

Type A

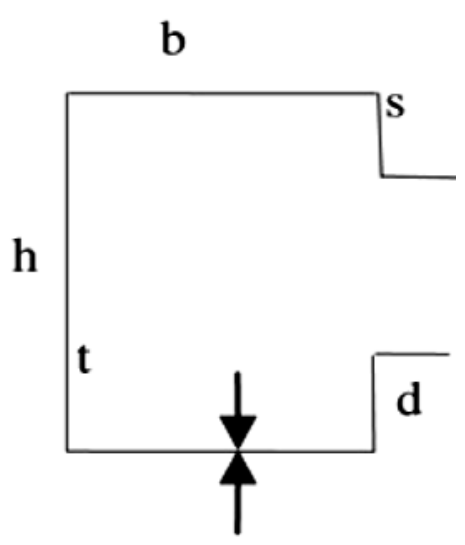

Type B

Figura 2.13: Seção transversal considerada em Ranawaka e Mahendran (2008) para a análise do modo distorcional.

A uma temperatura de $400^{\circ} \mathrm{C}$, o aço virgem ainda responderia integralmente com o valor da sua resistência. Porém, quando se trata de perfis de aço formados a frio, as propriedades físicas começam a ser penalizadas logo nos instantes iniciais do aquecimento. Dessa forma, as previsões encontradas diferem, em parte, das curvas de redução propostas por normas técnicas. Essa conclusão pode conduzir algumas das previsões de força de colapso em incêndio a valores ou conservadores ou contra a segurança. Na comparação dos resultados experimentais com o Método da Resistência Direta - MRD ajustado para considerar a situação de incêndio, conclui-se que as equações deste método analítico fornecem resultados de grande variabilidade de modo a ser considerado menos confiável em comparação à norma australiana AS/NZS 4600.

Em decorrência dos aços de diferentes valores de resistências apresentarem diferentes coeficientes de redução destas resistências, em Ranawaka e Mahendran (2009-b) é enfatizada a importância de se conhecer a redução das propriedades mecânicas dos perfís de aço formados a frio sob elevação de temperatura para o dimensionamento de estruturas. Como já comentado anteriormente, a importância desta investigação justifica pois, em temperaturas elevadas, tais perfis estão sujeitos a perder a resistência que obtiveram devido ao trabalho a frio à temperatura ambiente. O estudo experimental para a determinação de tais propriedades englobou perfis de aço formados a frio de baixa $(250 \mathrm{MPa})$ e alta $(550 \mathrm{MPa})$ resistência 
estrutural. Foram realizados ensaios de tração em regime térmico estacionário com controle de velocidade de deformação de acordo com os códigos normativos australianos.

Por meio destes ensaios, foram obtidas equações para os fatores de redução da resistência ao escoamento, módulo de elasticidade, resistência à ruptura, bem como a variação da ductilidade do aço. A resistência ao escoamento foi tomada como a relação $f_{y} / f_{y}$, que apresentam funções distintas para os dois tipos de aço estudados, conforme as equações $2.1 \mathrm{e}$ 2.2, em que $f_{y \theta}$ é a resistência ao escoamento em temperatura elevada e $f_{y}$ é a resistência ao escoamento à temperatura ambiente.

Para o aço de alta resistência:

$$
\begin{array}{ll}
\frac{f_{y \theta}}{f_{y}}=-0,00016 \cdot \theta+1,0003 & 20{ }^{\circ} \mathrm{C}<\theta \leq 200^{\circ} \mathrm{C} \\
\frac{f_{y \theta}}{f_{y}}=0,97-\frac{(\theta-200)^{1,81}}{58500} & 200{ }^{\circ} \mathrm{C}<\theta<600^{\circ} \mathrm{C} \\
\frac{f_{y \theta}}{f_{y}}=-0,00037 \cdot \theta+0,3363 & 600^{\circ} \mathrm{C} \leq \theta \leq 600^{\circ} \mathrm{C}
\end{array}
$$

Para o aço de baixa resistência:

$$
\begin{array}{ll}
\frac{f_{y \theta}}{f_{y}}=-0,0007 \cdot \theta+1,014 & 20^{\circ} \mathrm{C}<\theta \leq 200^{\circ} \mathrm{C} \\
\frac{f_{y \theta}}{f_{y}}=3,7-\frac{(\theta-74)^{0,15}}{0,736} & 200{ }^{\circ} \mathrm{C}<\theta<800^{\circ} \mathrm{C}
\end{array}
$$

Em relação às características dos materiais, foi observado que os perfis de aço de baixa resistência têm a resistência ao escoamento reduzida mais rapidamente no início do aquecimento, ou seja, até $400{ }^{\circ} \mathrm{C}$ em comparação aos perfis de aço de alta resistência. A partir dessa temperatura observou-se uma inversão no comportamento, e os perfis de aço de alta resistência apresentaram maior velocidade de degradação física. Uma das razões citadas para esse comportamento é que, conforme ocorre o aumento da temperatura, a resistência adquirida no processo de conformação a frio se reduz mais rapidamente nos perfis de alta 
resistência em comparação aos perfis de aço de baixa resistência. Dessa forma, observou-se que a redução da resistência ao escoamento entre perfis de aço de diferentes propriedades mecânicas ocorre com variações distintas.

Em contrapartida, o módulo de elasticidade em ambos os tipos de perfis de aço formados a frio resultou com reduções semelhantes, expressa pela função de redução da equação 2.3. No tocante à resistência à ruptura, foi observado um comportamento atípico do perfil de aço de baixa resistência. Quando a temperatura aumenta da ambiente a até $200{ }^{\circ} \mathrm{C}, \mathrm{o}$ aço tem um acréscimo na resistência última devido às reações químicas na sua composição. As mesmas reações também ocorrem em aços de alta resistência, porém, a resistência adquirida no trabalho a frio deste material decai (e este decaimento é mais significativo em aços de alta resistência) devido ao aumento de temperatura.

$$
\begin{array}{ll}
\frac{E_{\theta}}{E}=1,0 & 20{ }^{\circ} \mathrm{C}<\theta \leq 200^{\circ} \mathrm{C} \\
\frac{E_{\theta}}{E}=-0,0013 \cdot T+1,1297 & 200{ }^{\circ} \mathrm{C}<\theta<800^{\circ} \mathrm{C}
\end{array}
$$

O trabalho a frio adicionado às reações químicas decorrentes da exposição a altas temperaturas também contribuem para que o aço tenha a capacidade dúctil alterada conforme ocorre o aumento da temperatura. Tanto perfis de alta como os de baixa resistência apresentaram perda de ductilidade para temperaturas até $200^{\circ} \mathrm{C}$. Porém, para temperaturas acima de $300{ }^{\circ} \mathrm{C}$, os perfis de aço de baixa resistência resultaram num comportamento mais dúctil em relação aos de alta resistência e, acima de $600{ }^{\circ} \mathrm{C}$, a diferença no comportamento dúctil de ambos os tipos de aço é insignificante. Por meio desta investigação, foi observado que grande parte dos fatores de redução propostos pelas normas europeias Eurocode 3, part 1.2 e BS 5930, tanto para a resistência ao escoamento como para o módulo de elasticidade estão contra a segurança, principalmente para o intervalo de temperatura entre $300{ }^{\circ} \mathrm{C}$ e 600 ${ }^{\circ} \mathrm{C}$ (a investigação cobriu até a temperatura de $800^{\circ} \mathrm{C}$ ).

Uma vez que os perfis de aço formados a frio estão sujeitos a apresentar estado-limite último por instabilidade em regime elástico, em Pierin (2006) foi realizado uma análise numérica sobre a estabilidade dos perfis de aço formados a frio em situação de incêndio. Tal estudo tomou como ferramenta o código computacional INSTABFAIXA com base no 
Método das Faixas Finitas (MFF) e teve como objetivo avaliar a influência da temperatura na força crítica de bifurcação e no respectivo modo de instabilidade.

Para essa análise linear de estabilidade, tomaram-se como base dois perfis, $\mathrm{U}_{\mathrm{e}} 100 \mathrm{x}$ $50 \times 7 \times 2$ e U $100 \times 75 \times 3$, cujo comprimento efetivo de ambos foi adotado como iguais a $800 \mathrm{~mm}$. Por meio do Método das Faixas Finitas, foram obtidas as curvas força correspondente ao ponto de bifurcação do equilíbrio em função da relação comprimento/altura da alma para temperaturas variando entre $100^{\circ} \mathrm{C}$ e $700^{\circ} \mathrm{C}$. As curvas do perfil $\mathrm{U}_{\mathrm{e}}$, ilustradas na figura 2.14 apresentaram o primeiro ponto de mínimo associado ao modo local de chapa, e o segundo ponto associado ao modo distorcional. A força crítica de bifurcação do equilíbrio teve redução de $87 \%$ dentro do intervalo de temperatura avaliado.

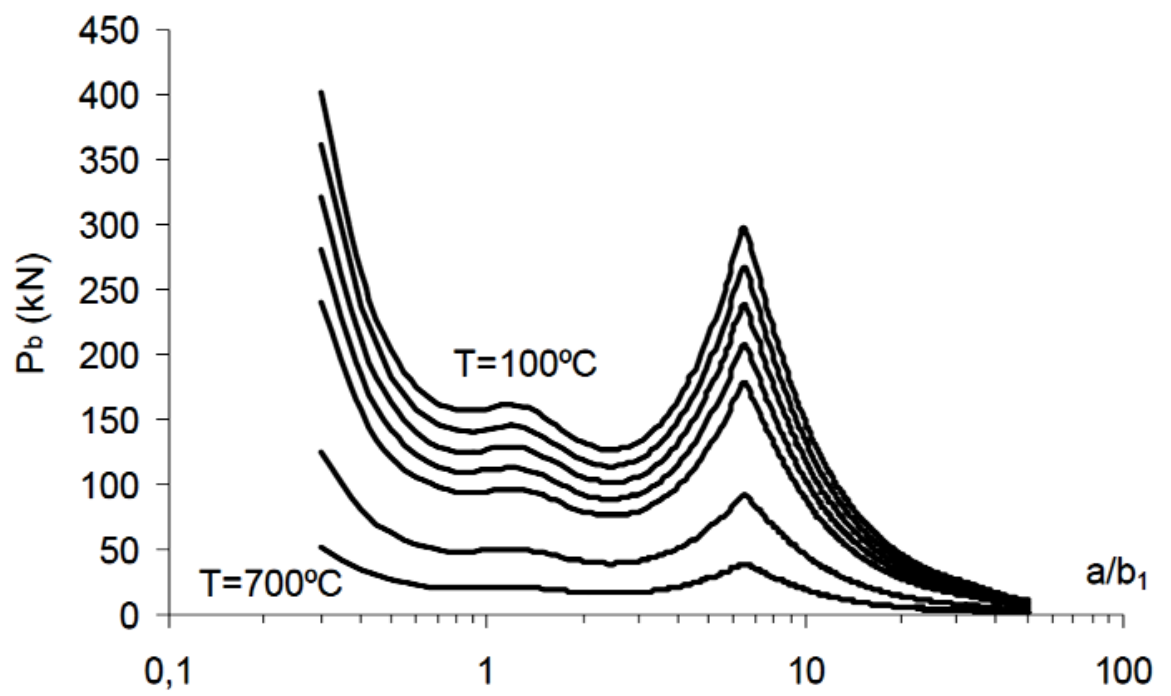

Figura 2.14: Força de bifurcação do equilíbrio do perfil Ue em função da relação comprimento/altura da alma para temperaturas uniformes entre $100^{\circ} \mathrm{C}$ e $700^{\circ} \mathrm{C}$. Fonte: Pierin (2006)

O perfil U exibiu um primeiro ponto de mínimo associado ao modo local e um ramo descendente associado ao modo global de flexão. Para a seção transversal estudada, a redução da força crítica de bifurcação foi de $94 \%$ para o intervalo de temperatura avaliado. As curvas obtidas para o perfil U estão ilustradas na figura 2.15 .

Para estimar a força resistente de tais perfis sob compressão axial, as respostas encontradas na análise de estabilidade elástica foram aplicadas às curvas de resistência fornecidas pelo Método da Resistência Direta considerando a degradação das propriedades do aço devido ao incêndio. Pela figura 2.16 foi concluído que a ação térmica é mais severa em 
perfis com menos enrijecedores. Nesse caso, a redução da carga última em função do incêndio para o perfil $U$ é mais acentuada que para o $U_{\mathrm{e}}$.

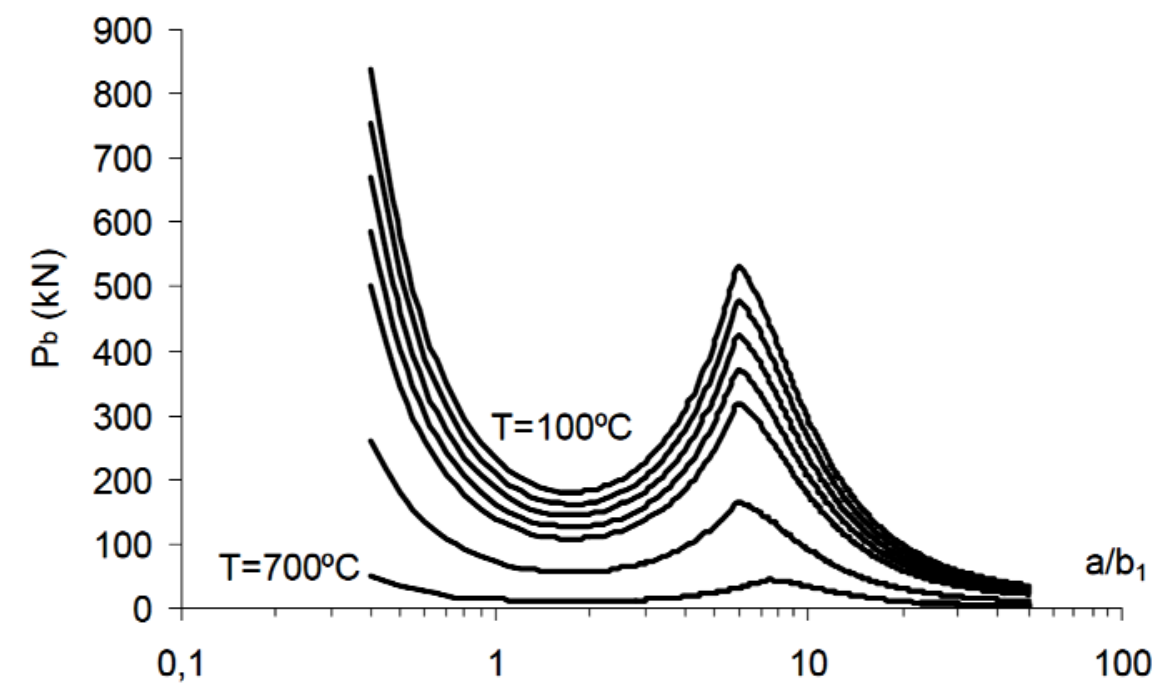

Figura 2.15: Força de bifurcação do equilíbrio do perfil $U$ em função da relação comprimento/altura da alma para temperaturas uniformes entre $100^{\circ} \mathrm{C}$ e $700^{\circ} \mathrm{C}$. Fonte: Pierin (2006)

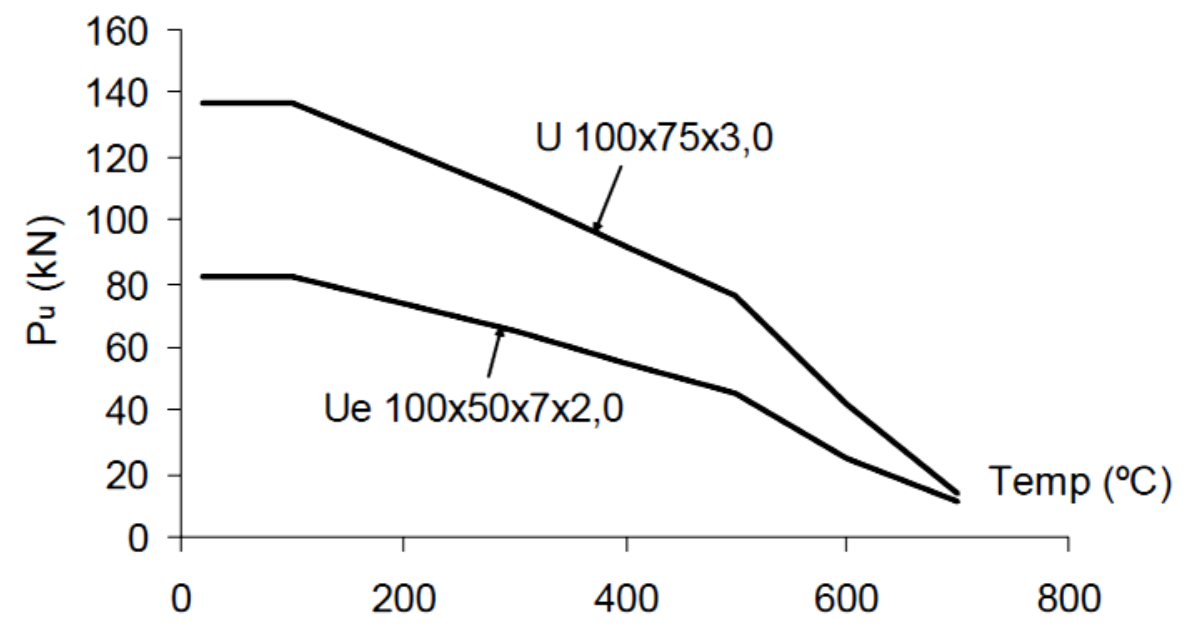

Figura 2.16: Esforços de compressão de colapso obtidos sob temperatura uniforme.

Fonte: Pierin (2006)

Considerando-se que o Método da Resistencia Direta se torna referência no cálculo de perfis formados a frio, outras causas físicas devem ser consideradas na sua aplicação. Em Shahbazian e Wang (2011-a), em Shahbazian e Wang (2012) e em Shahbazian e Wang (2011b) foram apresentados estudos sobre a aplicação do Método da Resistência Direta no cálculo da força de instabilidade elástica global, local e distorcional respectivamente. Esse conjunto de análises engloba perfis formados a frio do tipo U enrijecido, sujeitos a uma elevação de 
temperatura não uniforme ao longo da seção transversal. Tal gradiente de temperatura é típico em paredes do tipo steel framing em situação de incêndio.

Para os casos de temperatura uniformemente distribuída, mesmo com a curva tensão $x$ deformação a se tornar mais abatida, a força de flambagem elástica é calculada tomando o módulo de elasticidade inicial em elevadas temperaturas. Para esta situação, o MRD fornece resultados satisfatórios. Quando sujeito a um aquecimento não uniforme, conforme ilustrado na figura 2.17, o eixo neutro da seção transversal muda de posição de forma a se localizar na região menos aquecida e o perfil passa a apresentar curvatura em torno da região aquecida. Logo, o campo térmico não uniforme causa um momento fletor adicional, o que configura uma flexocompressão.

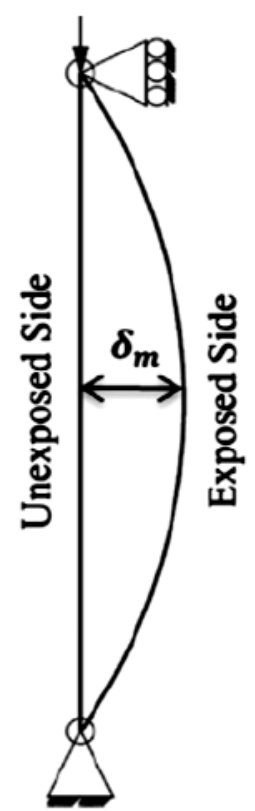

(a)

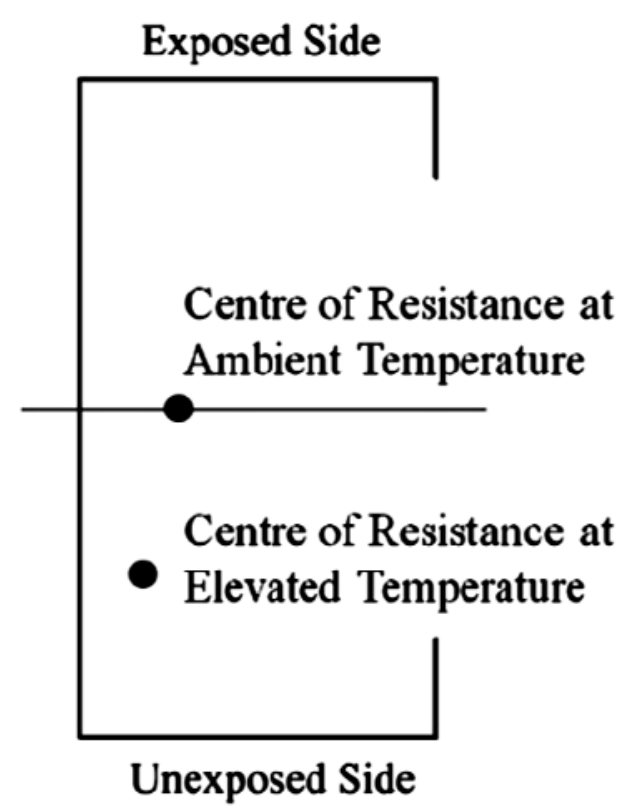

(b)

Figura 2.17: Efeitos do gradiente de temperatura no perfil; (a) curvatura lateral e (b) mudança de posição do eixo neutro. Fonte: Shahbazian e Wang (2011-a)

Dessa forma, o MRD deve ser ajustado para considerar ambos os efeitos simultaneamente. Para tanto, foram propostas novas equações analíticas, equações $2.4,2.5$ e 2.6, de forma a considerar o efeito composto. Com tais modificações, a curva de instabilidade elástica obtida se aproxima dos resultados das análises numéricas apresentadas nas referências citadas. 
Instabilidade Global:

$$
\begin{array}{ll}
\text { Se } \lambda_{0} \leq 1,5 & N_{c, R e}=\left(0,495^{\lambda_{0}^{2}}\right) \cdot A \cdot f_{y} \\
\text { Se } \lambda_{0}>1,5 & N_{c, R e}=\left(\frac{0,462}{\lambda_{0}^{2}}\right) \cdot A \cdot f_{y}
\end{array}
$$

Instabilidade Distorcional:

Se $\lambda_{\text {dist }} \leq 0,561 \quad N_{c, \text { Rdist }}=A \cdot f_{y}$

Se $\lambda_{\text {dist }}>0,561 \quad N_{c, \text { Rdist }}=0,65 \cdot\left(1-0,14 \cdot\left(\frac{N_{\text {dist }}}{A \cdot f_{y}}\right)^{0,7}\right) \cdot\left(\frac{N_{\text {dist }}}{A \cdot f_{y}}\right)^{0,7} \cdot A \cdot f_{y}$

Instabilidade Local:

Se $\lambda_{l} \leq 0,776 \quad N_{c, R l}=N_{c, R e}$

Se $\lambda_{l}>0,776 \quad N_{c, R l}=\left(1-0,22 \cdot\left(\frac{N_{l}}{N_{c, R e}}\right)^{0,75}\right) \cdot\left(\frac{N_{l}}{N_{c, R e}}\right)^{0,75} \cdot N_{c, R e}$

Como observações finais relacionadas à bibliografia sobre o tema proposto, conclui-se que o estudo dos perfis formados a frio em situação de incêndio sempre se apresentou predominantemente voltado ao sistema construtivo do tipo light steel framing, o que não é o mais comum na realidade da construção civil brasileira. Ressalvas devem ser feitas a Almeida (2013) e Laim (2013) em que foram apresentados, respectivamente, estudos em pilares e vigas de perfis de aço formados a frio em situação de incêndio. Tais investigações foram realizadas em caráter experimental e numérico, considerando a rigidez axial decorrente da interação com outros componentes da edificação que não estão submetidos a temperaturas elevadas.

Nas investigações apresentadas em Almeida (2013), conforme ilustrado na figura 2.18 e 2.19, foi estudada a influência da restrição à deformação axial no esforço normal resistente de perfis de aço formados a frio submetido à compressão centrada, em temperaturas elevadas. O estudo experimental foi realizado sobre perfis de seções transversais abertas e fechadas de 
diferentes índices de esbeltez e condições de vínculo nas extremidades. Foi observado que perfis mais esbeltos com extremidades engastadas apresentaram colapso instantâneo em comparação aos perfis curtos. Já na condição de extremidades rotuladas, o comportamento pós-crítico das barras menos esbeltas resultaram num colapso mais brusco em comparação às barras de maior esbeltez.

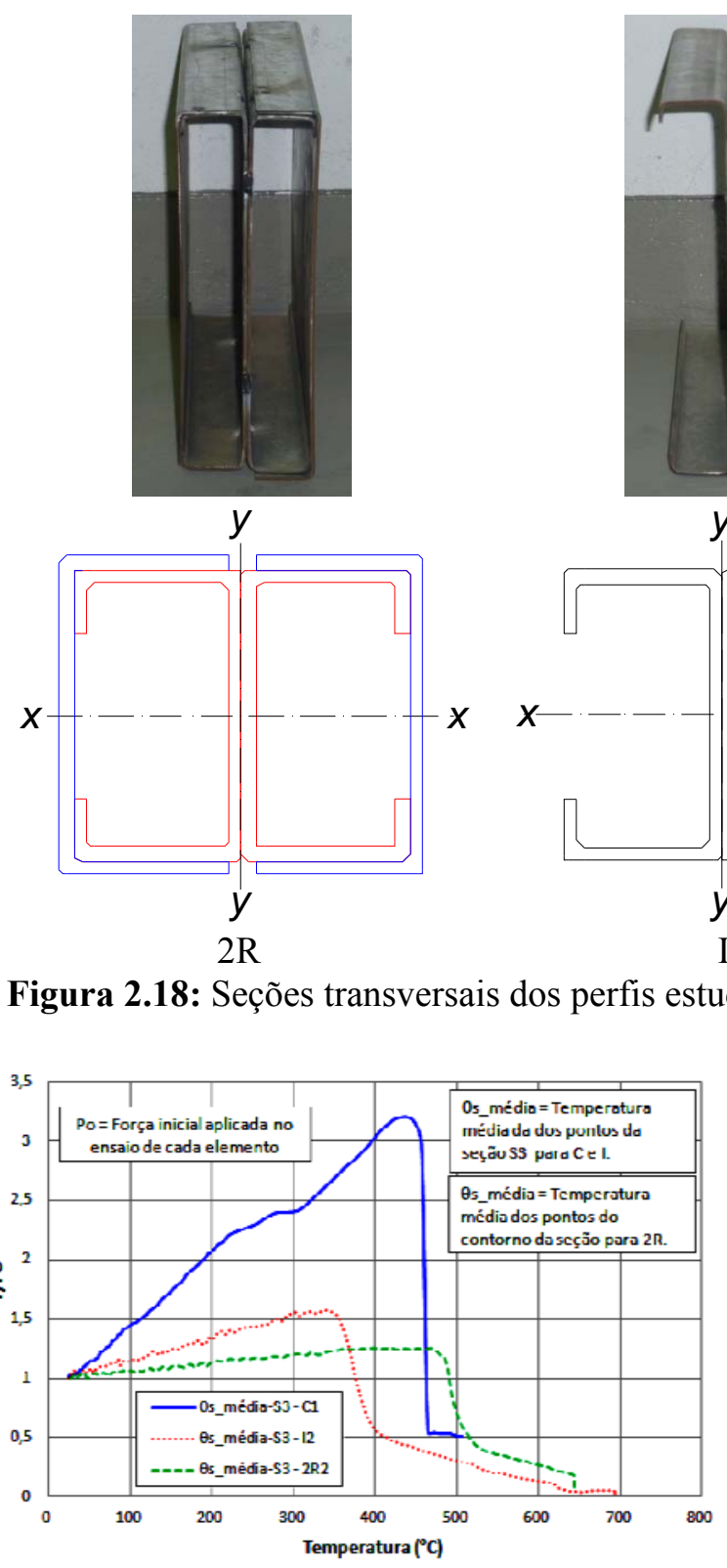

(a)

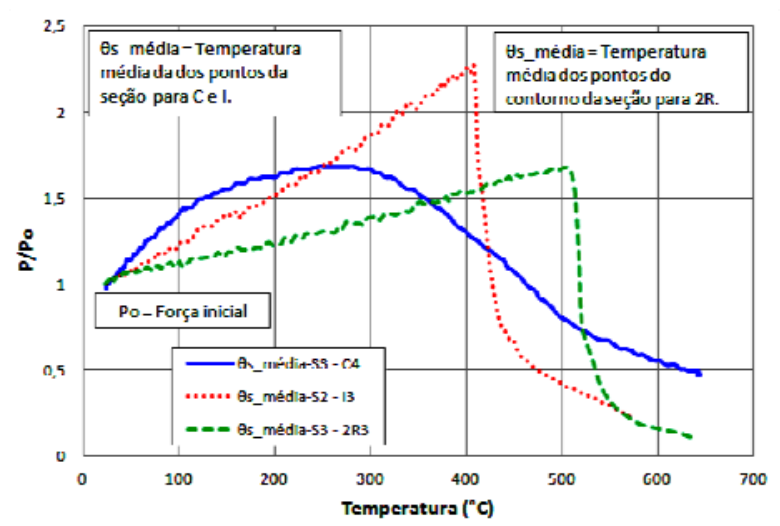

(b)

Figura 2.19: Resultados obtidos para os perfis com extremidades (a) engastadas e (b) rotuladas. Fonte: Almeida (2013) 
No capítulo seguinte é apresentado um breve comentário sobre o fenômeno de instabilidade em perfis de paredes esbeltas com seções transversais abertas, bem como os métodos de dimensionamento em situação de incêndio das principais normas em vigor. 


\section{PROCEDIMENTOS DE VERIFICAÇÃO PARA PERFIS SUJEITOS À COMPRESSÃO EM TEMPERATURAS ELEVADAS}

Perfis de aço de paredes esbeltas podem apresentar, em geral três modos simples de instabilidade, tais como global (por flexão - F, torção - T ou flexotorção - FT), local — L e distorcional - D, além dos modos acoplados. A título de exemplificação, figura 3.1 ilustra os modos de instabilidade possíveis de ocorrer em perfis de aço do tipo $\mathrm{U}_{\mathrm{e}}$. Nos itens a seguir, são descritas as equações referentes às forças axiais de instabilidade para cada modo.

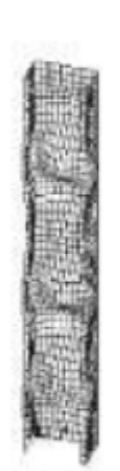

(a)

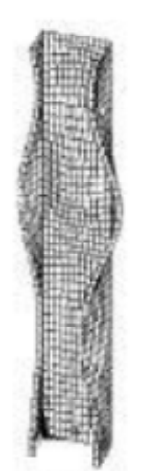

(b)

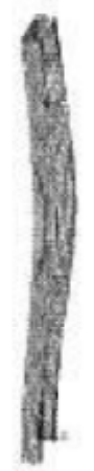

(c)

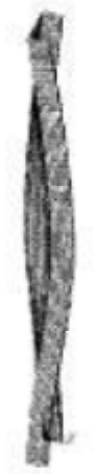

(d)

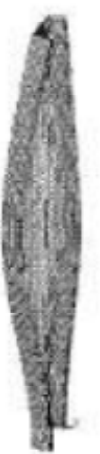

(e)

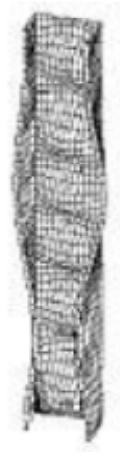

(f)

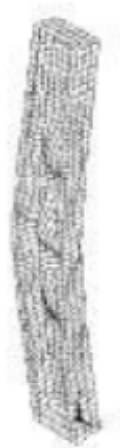

(g)

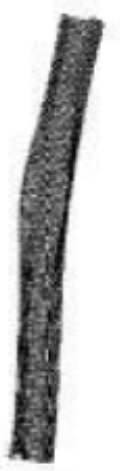

(h)

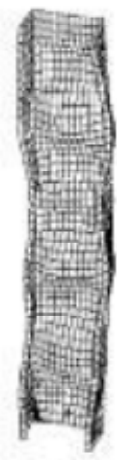

(i)

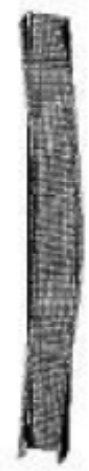

(i)

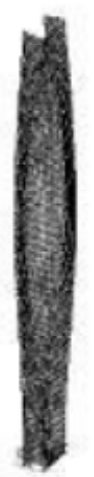

(k)

Figura 3.1: Modos de instabilidade apresentados pelo perfil $U_{\mathrm{e}}$ : (a) local, (b) distorcional, (c) global por flexão, (d) global por torção, (e) global por flexotorção, (f) L e D, (g) F e L, (h) F e D, (i) FT e L, (j) FT e D e (k) F e FT. Adaptado de: Chodraui (2006).

\subsection{Instabilidade global}

Como observado em Hancock (2001), grande parte dos perfis formados a frio utilizados na construção civil possui seção transversal monossimétrica, cujo centro de torção e o centroide são não coincidentes. Quando o perfil é solicitado a esforços de flexão (no caso das vigas) ou compressão excêntrica em relação ao centro de torção, tais situações resultam na possibilidade desses perfis apresentarem instabilidade por flexão, torção ou flexotorção.

No caso de perfis submetidos à compressão centrada (em relação ao centroide), como ilustrado na figura 3.2 (a), a excentricidade da força axial em relação ao centro de torção pode 
resultar em instabilidade por flexotorção (figura 3.2 (c)) a um patamar de força inferior a aquele que causaria o modo de instabilidade por flexão (figura 3.2 (b)). A instabilidade por flexotorção é caracterizada pela mudança da posição do centro de torção com ocorrência simultânea de uma translação e rotação no plano da seção transversal.

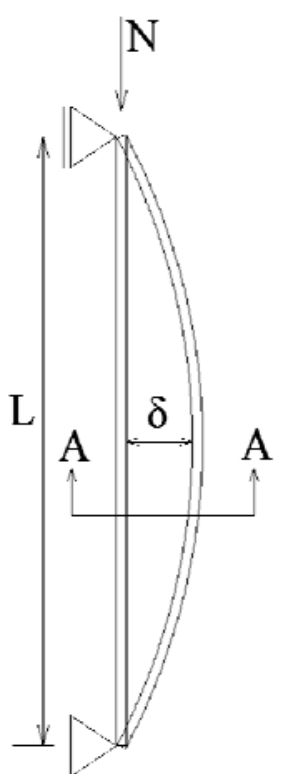

(a)

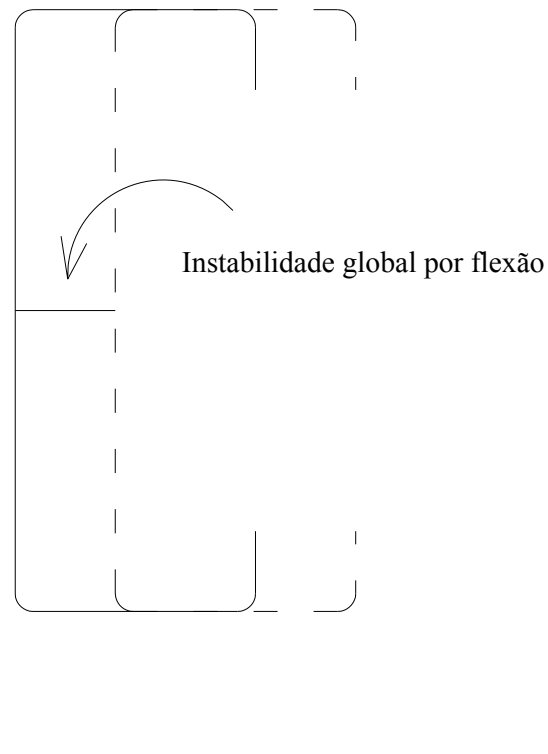

(b)

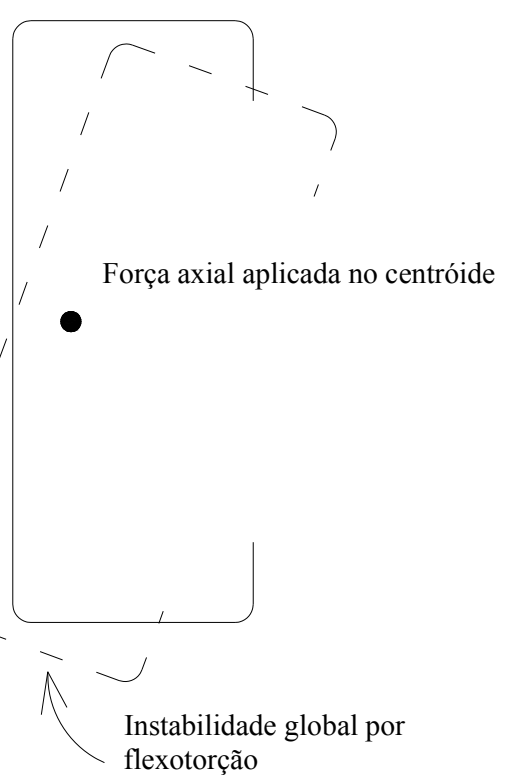

(c)

Figura 3.2: (a) Modos de instabilidade de um perfil monossimétrico sob compressão axial: (b) flexão e (c) flexotorção. Adaptado de Hancock (2001)

A força normal crítica de instabilidade em regime elástico, no caso de compressão centrada, considerando perfis de seção transversal qualquer é obtida na posição deslocada, a partir da equação 3.1. No caso dos perfis monossimétricos, caso de interesse no presente trabalho, a equação 3.1 é simplificada para a equação 3.2 .

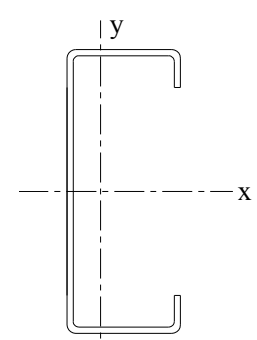

$$
\begin{gathered}
r_{0}^{2}\left(N_{c r}-N_{x}\right)\left(N_{c r}-N_{y}\right)\left(N_{c r}-N_{z}\right)-\left(N_{c r}\right)^{2}\left(y_{0}\right)^{2}\left(N_{c r}-N_{x}\right) \\
-\left(N_{c r}\right)^{2}\left(x_{0}\right)^{2}\left(N_{c r}-N_{y}\right)=0 \\
\left(N_{c r}-N_{y}\right)\left(r_{0}^{2}\left(N_{c r}-N_{x}\right)\left(N_{c r}-N_{z}\right)-\left(N_{c r} x_{0}\right)^{2}\right)=0
\end{gathered}
$$


Da equação 3.2, obtém-se a força crítica de flambagem elástica por flexão em torno do eixo y, expressa pela equação 3.3 desacoplada das demais em torno de x e z, podendo ser tratada de forma independente. A equação quadrática 3.4, em contrapartida, resulta acoplada, em função de $\mathrm{N}_{\mathrm{x}}$ e $\mathrm{N}_{z}$, cuja resolução nos fornece a força de flambagem por flexotorção, expressa pela equação 3.5 .

$$
\begin{aligned}
& \left(N_{c r}\right)_{1}=N_{y}=\frac{\pi^{2} \cdot E \cdot I_{y}}{(K \cdot L)_{y}^{2}} \\
& \left(r_{0}^{2}\left(N_{c r}-N_{x}\right)\left(N_{c r}-N_{z}\right)-\left(N_{c r} x_{0}\right)^{2}\right)=0 \\
& \left(N_{c r}\right)_{3}=\frac{1}{2 \beta}\left[\left(N_{x}+N_{z}\right)-\sqrt{\left(N_{x}+N_{z}\right)^{2}-4 \beta N_{x} N_{z}}\right] \\
& \beta=1-\left(\frac{y_{0}}{r_{0}}\right)^{2}
\end{aligned}
$$

Ao representar em termos de tensão de flambagem elástica, a equação 3.3 resulta na equação 3.7 .

$$
\sigma_{e}=\frac{\pi^{2} \cdot E}{\lambda^{2}}
$$

Casos em que a tensão crítica de flambagem elástica seja maior que a tensão de proporcionalidade, o comportamento elastoplástico do material deve ser considerado. $\mathrm{O}$ regime elastoplástico pode ser adequadamente abordado por meio da Teoria do Módulo Reduzido ou Módulo Duplo. Essa teoria afirma que, no regime elastoplástico, o trecho de carregamento é governado pelo módulo de elasticidade tangente $E_{t}$ e o trecho de descarregamento, pelo módulo de elasticidade E. A força normal e a tensão crítica de flambagem no regime elastoplástico são dadas pelas equações 3.8 e 3.9, respectivamente.

$$
N_{r}=\frac{\pi^{2} \cdot E_{r} \cdot I}{K \cdot L^{2}}=\frac{E_{r}}{E} N_{e}
$$


$\sigma_{c r, r}=\frac{\pi^{2} \cdot E_{r}}{\lambda^{2}}$

\subsection{Instabilidade local}

A formulação do problema de instabilidade depende da forma com a qual a seção é solicitada e das vinculações dos elementos. A equação diferencial para a determinação da tensão crítica de flambagem de chapas é representada pela equação 3.10, a qual foi proposta por Bryan em 1891, na condição de pequenos deslocamentos.

$\frac{\partial^{4} \omega}{\partial x^{4}}+2 \frac{\partial^{4} \omega}{\partial x^{2} \partial y^{2}}+\frac{\partial^{4} \omega}{\partial y^{4}}+\frac{f_{x} \cdot t}{D} \cdot \frac{\partial^{2} \omega}{\partial x^{2}}=0$

A amplitude $\omega$ da semionda é expressa por uma função senoidal em série dupla como mostra a equação 3.11 para a chapa apoiada em todas as bordas. Essa função depende dos parâmetros $m$, que representa o número de semiondas na direção longitudinal do comprimento $a$, ilustrado na figura 3.3, e $n$, na direção da largura $b$.

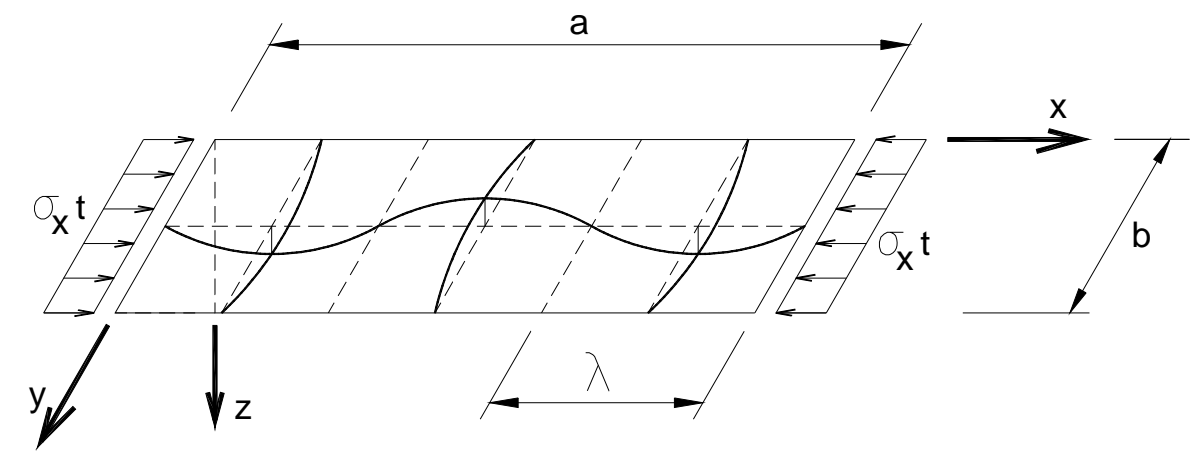

Figura 3.3: Deformada de uma chapa apoiada em todas as bordas sob compressão uniforme.

$\omega=\sum_{m=1}^{\infty} \sum_{n=1}^{\infty} a_{m n} \operatorname{sen} \frac{m \pi x}{a} \operatorname{sen} \frac{n \pi x}{b}$

Das equações 3.10 e 3.11, é possível obter a equação 3.12 para a determinação da tensão crítica de instabilidade local elástica. 
$\sigma_{c r}=\frac{\pi^{2} \cdot E}{12\left(1-v^{2}\right)\left(\frac{b}{t}\right)^{2}} \cdot k$

O valor do coeficiente de instabilidade local $k$ depende da relação $a / b$, do número de meia onda $m$, das condições de contorno e da distribuição das tensões na chapa. Em caso de regime elasto-plástico, ou seja, a tensão de compressão maior que a tensão de proporcionalidade, a equação diferencial de chapa segue a forma da equação 3.13, em que R é a relação entre o módulo de elasticidade tangente e o módulo de elasticidade $-\mathrm{E}_{\mathrm{t}} / \mathrm{E}$.

$R \frac{\partial^{4} \omega}{\partial x^{4}}+2 \sqrt{R} \frac{\partial^{4} \omega}{\partial x^{2} \partial y^{2}}+\frac{\partial^{4} \omega}{\partial y^{4}}+\frac{f_{x} \cdot t}{D} \cdot \frac{\partial^{2} \omega}{\partial x^{2}}=0$

A solução da equação 3.13 fornece a equação 3.14 para a determinação da tensão crítica de instabilidade no regime elasto-plástico.

$\sigma_{c r}=\frac{\pi^{2} \cdot E \sqrt{R}}{12\left(1-v^{2}\right)\left(\frac{b}{t}\right)^{2}} \cdot k$

\subsection{Instabilidade distorcional}

Este modo está associado à distorção ou mudança de forma da seção transversal, e ocorre em seções transversais com bordos enrijecidos, a exemplo dos perfis $\mathrm{U}$ e $\mathrm{Z}$ enrijecidos. O comprimento de meia onda da flambagem distorcional é maior que o da flambagem local e menor que da flambagem global. A tensão de flambagem elástica por distorção também é determinada com base na teoria de estabilidade elástica, por meio das equações 3.10 e 3.11. Portanto, a equação da tensão crítica de flambagem distorcional resulta na mesma forma da equação 3.14, porém, com o coeficiente $k$ associado a esse modo de flambagem. O modo simplificado de cálculo do AISI limita o valor desse coeficiente, denominado $k_{d}$, de acordo com a equação 3.15 .

$0,05 \leq k_{d}=0,1 \cdot\left(\frac{b_{o} \cdot D \cdot \sin \theta}{h_{o} \cdot t}\right)^{1,4} \leq 8,0$ 


\subsection{Dimensionamento em situação de incêndio}

Nos subitens a seguir, são comentados os procedimentos de cálculo das principais normas em vigor. É importante observar que tais códigos normativos não fornecem procedimentos de cálculo para perfis formados a frio especificamente, mas sim para aqueles sujeitos a apresentar flambagem local. Os métodos de cálculo apresentados referem-se à verificação da força normal de compressão resistente em perfis formados a frio apenas, por se tratar do enfoque deste trabalho.

\subsubsection{Procedimento de cálculo recomendado pela norma ABNT NBR}

\section{3:2013}

A verificação da resistência a temperaturas elevadas recomendada pela ABNT NBR 14323:2013 é aplicável a todos os perfis abordados tanto pela norma técnica ABNT NBR 8800:2008 como a ABNT NBR 14762:2010. Inicialmente, é apresentada a equação para se determinar a força de compressão resistente em situação de incêndio aos perfis não sujeitos a instabilidade local, equação 3.16. Nesse caso, o índice de esbeltez reduzido de todos os elementos da seção transversal, $\lambda_{\mathrm{p}}$, não deve ser superior a $0,85 \cdot \lambda_{\mathrm{p}, \mathrm{lim}}$, em que $\lambda_{\mathrm{p}, \mathrm{lim}}$ é o máximo valor de $\lambda_{\mathrm{p}}$ à temperatura ambiente que não implica em redução decorrente da instabilidade local;

$N_{f i, R d}=\chi_{f i} \cdot k_{y, \theta} \cdot A_{g} \cdot f_{y}$

Em que:

$\chi_{f i}=\frac{1}{\varphi_{0, f i}+\sqrt{\varphi_{0, f i}^{2}-\lambda_{0, f i}^{2}}}$

$\varphi_{0, f i}=0,5 \cdot\left(1+\alpha \cdot \lambda_{0, f i}+\lambda_{0, f i}^{2}\right)$

$\alpha=0,022 \sqrt{\frac{E}{f_{y}}}$ 


$$
\lambda_{0, f i}=\frac{\lambda_{0}}{0,85}
$$

Das equações 3.16 a 3.20, os parâmetros são descritos da seguinte forma:

$\chi_{f i}$ é o fator de redução global associado à força normal de compressão resistente em situação de incêndio;

$\lambda_{0, f i}$ é o índice de esbeltez reduzido em situação de incêndio;

$\lambda_{0}$ é o índice de esbeltez reduzido à temperatura ambiente.

Perfis sujeitos à instabilidade local têm a força de compressão resistente de cálculo determinada pela equação 3.21. Essa verificação deve considerar a área efetiva calculada à temperatura ambiente. $\mathrm{O}$ fator de redução associado à instabilidade global $\chi_{f i}$ é calculado conforme 3.17 .

$N_{f i, R d}=\chi_{f i} \cdot k_{\sigma, \theta} \cdot A_{e f} \cdot f_{y}$

Em que:

$\mathrm{k}_{\sigma, \theta}$ é o fator de redução da resistência ao escoamento do aço das seções sujeitas a instabilidade local à temperatura elevada,tomada como a que corresponde a $0,2 \%$ da deformação plástica residual;

$\mathrm{A}_{\mathrm{ef}}$ é a área efetiva da seção transversal, para os perfis formados a frio, obtida com base no método das larguras efetivas ou das seções efetivas, conforme a ABNT NBR 14762:2010;

Perfis de seção transversal aberta e paredes esbeltas também estão sujeitas a apresentar instabilidade distorcional e devem, portanto ter esse estado limite verificado. Para tais perfis, a força axial de compressão resistente de cálculo é a menor entre a equação 3.21 e 3.22.

$N_{f i, R d}=\chi_{d i s t} \cdot k_{\sigma, \theta} \cdot A_{g} \cdot f_{y}$ 
O fator de redução associado à instabilidade distorcional $\chi_{\text {dist }}$ é calculado conforme $\mathrm{o}$ procedimento da ABNT NBR 14762:2010, indicada nas equações 3.23 e 3.24. Na equação $3.25, \lambda_{\text {dist }}$ é o índice de esbeltez reduzido associado à instabilidade distorcional.

$\chi_{\text {dist }}=1$

se $\lambda_{\text {dist }} \leq 0,561$

$\chi_{\text {dist }}=\left(1-\frac{0,25}{\lambda_{\text {dist }}^{1,2}}\right) \cdot \frac{1}{\lambda_{\text {dist }}^{1,2}}$

se $\lambda_{\text {dist }}>0,561$

$\lambda_{\text {dist }}=\left(\frac{A \cdot f_{y}}{N_{\text {dist }}}\right)^{0,5}$

A força de flambagem distorcional elástica $N_{\text {dist }}$ é calculada com base na análise de estabilidade elástica.

\subsubsection{Procedimento de cálculo recomendado pela norma Eurocode 3 Part 1.2}

A determinação da força normal resistente de compressão axial de perfis sujeitos à variação uniforme de temperatura quando em situação de incêndio é semelhante ao proposto pela norma brasileira e expressa pela equação 3.26. Esta norma aplica as classificações de perfis fornecidas pelo Eurocode 3, part 1.1. Quando se trata de perfis formados a frio, cujo procedimento de cálculo à temperatura ambiente segue o Eurocode 3, part 1.3, o Eurocode 3, part 1.2 aplica o coeficiente de redução da resistência ao escoamento recomendado para as seções de classe 4, ou seja, aquelas sujeitas a instabilidade local.

$N_{f i, R d}=\frac{\chi_{f i} \cdot k_{\sigma, \theta} \cdot A_{e f} \cdot f_{y}}{\gamma_{M, f i}}$

Em que:

$\chi_{f i}=\frac{1}{\varphi_{0, \mathrm{fi}}+\sqrt{\varphi_{0, \mathrm{fi}}^{2}-\lambda_{0, \mathrm{fi}}^{2}}}$ 
$\varphi_{0, \mathrm{fi}}=\frac{1}{2} \cdot\left[1+\alpha \cdot \lambda_{0, \mathrm{fi}}+\lambda_{0, \mathrm{fi}}^{2}\right]$

$\alpha=0,65 \sqrt{\frac{235}{f_{y}}}$

$\lambda_{0, \mathrm{fi}}=\lambda \cdot\left\lceil k_{y, \theta} / k_{E, \theta}\right]^{0,5}$

As variáveis das equações 3.26 a 3.31 são definidas da seguinte forma:

$\chi_{f i}$ é o fator de redução resistência à compressão em situação de incêndio, associado à instabilidade global;

$\lambda_{0, \mathrm{fi}}$ é o índice de esbeltez reduzido em situação de incêndio;

$\lambda_{0}$ é o índice de esbeltez reduzido à temperatura ambiente;

$A_{e f}$ é a área efetiva da seção transversal, calculada com base no método das larguras efetivas ou no método das seções efetivas, conforme os procedimentos do Eurocode 3, part 1.3 ou Eurocode 3, part 1.5;

$k_{\sigma, \theta}$ é o fator de redução para a resistência ao escoamento das seções de classe 4. Para os perfis formados a frio, este parâmetro é definido pela equação 3.32.

$k_{\sigma, \theta}=f_{y, \theta} / f_{y}$

Em que $f_{y}$ é a resistência ao escoamento dos perfis formados a frio.

\subsubsection{Procedimento de cálculo recomendado pela norma ANSI/AISC 360-10}

O método de verificação em situação de incêndio por essa norma, assim com os demais procedimentos, é voltado para os perfis laminados e soldados. A determinação da resistência à compressão de um elemento isolado é realizada por meio do mesmo procedimento utilizado para as verificações à temperatura ambiente, com as propriedades mecânicas reduzidas. Uma ressalva é feita apenas para a instabilidade global por flexão. Neste 
caso, é recomendado que a resistência à compressão, com seu valor nominal, $\sigma_{c, \theta}$ seja determinada conforme a equação 3.33 .

$\sigma_{c, \theta}=\left[0,42 \sqrt{f_{y, \theta} / \sigma_{e, \theta}}\right] f_{y, \theta}$

Os parâmetros da equação 3.33 são definidos da seguinte forma:

$f_{y, \theta}$ é a resistência ao escoamento em temperatura elevada;

$\sigma_{e, \theta}$ é a tensão crítica de instabilidade elástica, calculada com o módulo de elasticidade $E_{\theta}$ do material em temperatura elevada.

A equação 3.33 é válida somente para a variação de temperatura conforme a norma americana ASTM E119-12a. Ressalta-se também que as propriedades físicas variam de acordo com a tabela A-4.2.1 da norma ANSI/AISC 360-10.

\subsubsection{Aplicação do Método da Resistência Direta para verificação em}

\section{temperaturas elevadas}

O Método da Resistência Direta - MRD - é definido como um procedimento para determinação da força normal de compressão resistente e flexão simples de perfis com seções transversais abertas de paredes finas. Esse método é parte integrante das especificações norte americanas para o dimensionamento de perfis de aço formados a frio desde 2004. Conforme apresentado em Li (2011), o método da resistência direta tem o mesmo embasamento empírico do método das larguras efetivas, em que a resistência nominal é definida em função da força crítica de instabilidade elástica e da máxima força de compressão aplicada no perfil. A força de instabilidade elástica é obtida com base na área total da seção transversal e o cálculo é realizado por meio da teoria da estabilidade elástica, ou por métodos numéricos como faixas finitas ou elementos finitos.

Esse método é aplicável a seções transversais pré-qualificadas, ou seja, aquelas que se enquadram dentro de limites geométricos e de características de materiais, conforme informa a tabela 1.1.1.1 da especificação americana AISI S100-07. A figura 3.5 ilustra os limites para os perfis pré-qualificados da seção transversal $U_{e}$, extraídos da mesma norma. 


$$
\begin{array}{ll}
h_{0} / t<472 \\
b_{0} / t<159 \\
4<D / t<33 \\
0,7<h_{0} / b_{0}<5 \\
& 0,05<D / b_{0}<0,41 \\
& \theta=90^{\circ} \\
& E / f_{y}>340\left[f_{y}<86 \mathrm{ksi}\left(593 \mathrm{MPa} \text { ou } 6050 \mathrm{~kg} / \mathrm{cm}^{2}\right)\right]
\end{array}
$$

Figura 3.5: Perfil U enrijecido pré qualificado de acordo com a norma AISI S100-07

A aplicação do método da resistência direta para perfis submetidos a temperaturas elevadas tem sido estudada por diversos pesquisadores. Em Landesmann e Camotim (2010), por exemplo, é sugerida uma modificação na formulação do MRD para o modo distorcional, de forma que o módulo de elasticidade e resistência ao escoamento assumam os valores reduzidos conforme a temperatura do material.

Devido à possibilidade de se ajustar o Método da resistência direta para a verificação de perfis submetidos a temperaturas elevadas, optou-se por descrevê-lo neste subitem. De acordo com o procedimento proposto no Anexo 1 da norma americana, a força de compressão axial com seu valor nominal $\mathrm{N}_{\mathrm{c}, \mathrm{Rk}}$ é definida pela equação 3.34 .

$$
N_{c, R k}=\min \left[N_{c, R e}, N_{c, R l}, N_{c, R d i s t}\right]
$$

\section{Em que:}

$N_{c, R e}$ é a força de compressão nominal resistente por instabilidade por flexão, torção ou flexo-torção;

$N_{c, R l}$ é a força de compressão nominal resistente por instabilidade local;

$N_{c, \text { Rdist }}$ é a força de compressão nominal resistente por instabilidade distorcional.

A determinação de $N_{c, R e}, N_{c, R l}$ e $N_{c, \text { Rdist }}$ segue conforme o equacionamento apresentado a seguir.

\section{a) Instabilidade global por flexão, torção ou flexotorção}




$$
\begin{array}{ll}
\text { Se } \lambda_{0} \leq 1,5 & N_{c, R e}=\left(0,658^{\lambda_{c}^{2}}\right) \cdot A \cdot f_{y} \\
\text { Se } \lambda_{0}>1,5 & N_{c, R e}=\left(\frac{0,877}{\lambda_{c}^{2}}\right) \cdot A \cdot f_{y}
\end{array}
$$

Em que $\lambda_{0}=\sqrt{A \cdot f_{y} / N_{e}}$

$N_{c, R e}$ é valor nominal da força de compressão resistente associado à instabilidade global;

$N_{e}$ é a força axial de flambagem global elástica.

\section{b) Instabilidade local}

Se $\lambda_{l} \leq 0,776 \quad N_{c, R l}=N_{c, R e}$

Se $\lambda_{l}>0,776 \quad N_{c, R l}=\left(1-0,15 \cdot\left(\frac{N_{l}}{N_{c, R e}}\right)^{0,4}\right) \cdot\left(\frac{N_{l}}{N_{c, R e}}\right)^{0,4} \cdot N_{c, R e}$

Em que $\lambda_{l}=\sqrt{N_{c, R e} / N_{l}}$

$N_{c, R l}$ é valor nominal da força de compressão resistente associado à instabilidade local;

$N_{l}$ é a força axial de flambagem local elástica;

\section{c) Instabilidade distorcional}

Se $\lambda_{\text {dist }} \leq 0,561 \quad N_{c, \text { Rdist }}=A \cdot f_{y}$

Se $\lambda_{\text {dist }}>0,561 \quad N_{c, \text { Rdist }}=\left(1-0,25 \cdot\left(\frac{N_{\text {dist }}}{A \cdot f_{y}}\right)^{0,7}\right) \cdot\left(\frac{N_{\text {dist }}}{A \cdot f_{y}}\right)^{0,7} \cdot A \cdot f_{y}$

Em que $\lambda_{d}=\sqrt{A \cdot f_{y} / N_{\text {dist }}}$

$N_{c, \text { Rdist }}$ valor nominal da força de compressão resistente associado à instabilidade distorcional; 
$N_{\text {dist }}$ é a força axial de flambagem distorcional elástica;

Como é possível observar no item 3.4, os procedimentos normativos vigentes para o dimensionamento em situação de incêndio não são formulados especificamente para os perfis formados a frio. A determinação dos parâmetros como a área efetiva e índice de esbeltez reduzido da ABNT NBR 14323:2013 remete à ABNT NBR 8800:2008 ou ABNT NBR 14762:2010, enquanto que a EN 1993-1-2:2005 remete à EN1993-1-1:2005 ou EN 1993-1-3: 2006. O fator de redução da resistência ao escoamento é válido tanto para os perfis formados a frio como para os laminados ou soldados sujeitos à instabilidade local.

Dessa forma, é reconhecido pelo meio acadêmico que, para que maiores contribuições com os métodos de cálculo das normas atuais sejam possíveis, é necessário o desenvolvimento de mais trabalhos experimentais voltados para a realidade da construção civil brasileira. O capítulo seguinte descreve as etapas do programa experimental desenvolvido neste projeto de doutorado. 
Neste capítulo é descrita a metodologia e os resultados da análise experimental desenvolvida no presente projeto. Os perfis abordados neste projeto tem ampla aplicação na construção de edifícios de pequeno porte de ocupação comercial e habitacional. Os ensaios de compressão, à temperatura ambiente e em situação de incêndio, foram realizados no Laboratório de Estruturas da Faculdade de Engenharia Civil, Arquitetura e Urbanismo da Universidade Estadual de Campinas. Esse deslocamento foi necessário pois, à época da realização de tais ensaios, o Laboratório de Estruturas do Departamento de Engenharia de Estruturas da EESC/USP, instituição onde se desenvolveu esse projeto, se encontrava em fase de instalação dos equipamentos necessários para o ensaio de estruturas em situação de incêndio.

\subsection{Sobre os corpos-de-prova}

As barras de aço utilizadas no programa experimental foram adquiridas junto à empresa SOUFER, que forneceu o material comercialmente denominado USI - CIVIL, grau 300 , laminado a quente (de acordo com as especificações do fabricante), produzido pela Usiminas. Foram adquiridos 45 perfis de seção transversal em U enrijecido, nominalmente conhecido como $U_{e} 150 \times 60 \times 20 \times 2,25$, de comprimento comercial de três metros, e cujas dimensões são ilustradas na figura 4.1 .

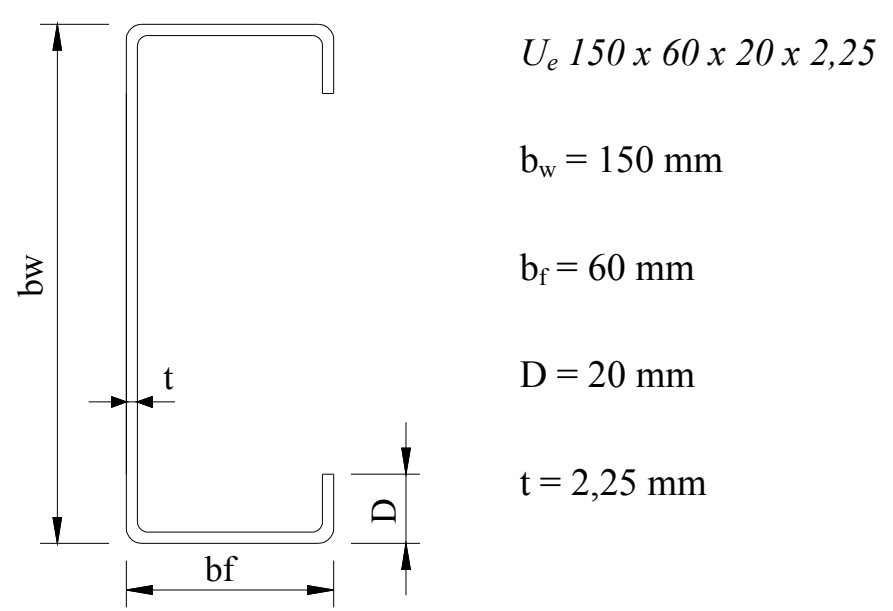

Figura 4.1: Dimensões da seção transversal $U_{e} 150 \times 60 \times 20 \times 2,25$. 
Os modelos consistem de perfis formados a frio com seção transversal composta por dois perfis $U_{e}$, com as extremidades rotuladas segundo o eixo de menor inércia, com comprimento efetivo igual a $2500 \mathrm{~mm}$. Foram estudados dois tipos de seção transversal, no caso, uma fechada do tipo caixão e uma aberta do tipo I enrijecido.

Para garantir a seção composta, os perfis isolados foram unidos por meio de solda, aplicada pelo processo de soldagem TIG - Tungsten Inert Gas, a qual foi aplicada de forma intermitente, cujo comprimento do cordão é igual a $50 \mathrm{~mm}$ e o espaçamento entre eles igual a $400 \mathrm{~mm}$, medido de centro a centro. Em cada extremidade, também foram soldadas chapas de topo, para uniformização da superfície ao aplicar a ação de compressão. Para garantir a condição rotulada proposta no trabalho, foram confeccionados aparelhos de apoio que permitem que o perfil apresente rotação em torno de um eixo. O esquema das barras está ilustrado na figura 4.2 .
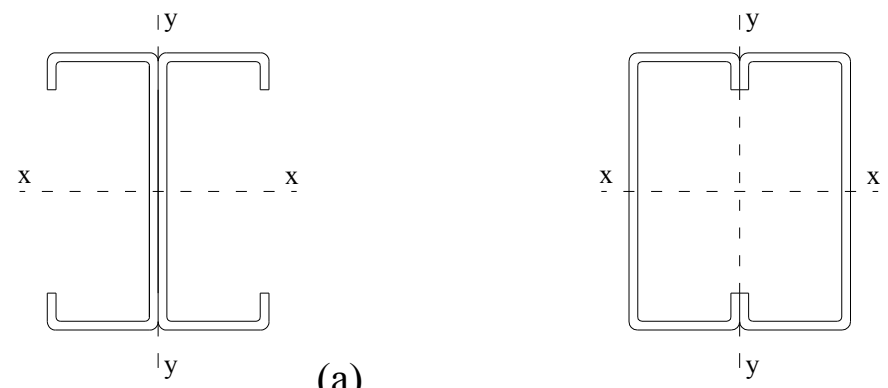

(a)

(b)

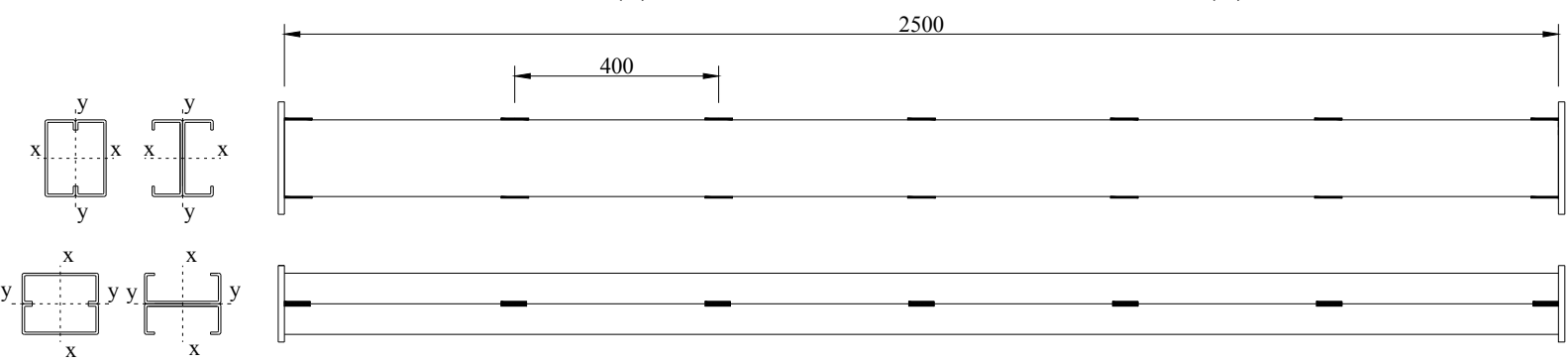

(c)

Figura 4.2: Características das barras: (a) I enrijecido, (b) caixão e (c) posição das soldas.

Foram fabricados 11 perfis de seção I enrijecido e 10 perfis de seção caixão. Inicialmente, foram previstas dois perfis de cada tipo de seção transversal destinadas aos ensaios à temperatura ambiente e quatro ensaios a ser realizados à temperaturas elevadas (situação de incêndio). Porém, em decorrência de imprevistos inerentes à análise experimental, alguns ensaios necessitaram de uma maior quantidade de repetições. A nomenclatura dos modelos seguiu o esquema descrito pela figura 4.3. 


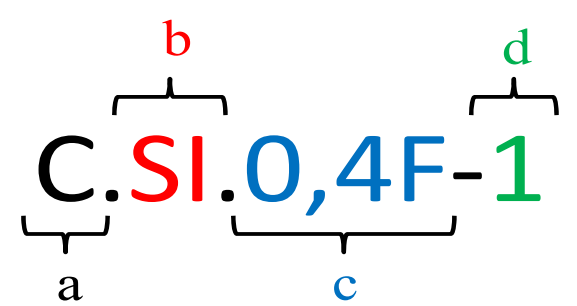

Figura 4.3: Nomenclatura das barras.

Com relação à figura 4.3, valem as seguintes descrições:

$a$ = tipo de seção transversal: C para caixão e I para I enrijecido;

$b$ = campo térmico aplicado: SI para situação de incêndio e $\boldsymbol{T} \boldsymbol{A}$ para temperatura ambiente;

$c=$ nivel de carregamento aplicado em temperatura elevada: 0,4F para $40 \%$ da força de colapso em temperatura ambiente e $\mathbf{0 , 7 F}$ para $70 \%$ da força de colapso em temperatura ambiente;

$d=$ número da barra com as características $a$, $b$ e c. Foram realizadas pelo menos duas repetições para cada modelo.

Dessa forma, o programa experimental do presente trabalho foi composto dos ensaios que estão organizados na tabela 4.1.

Tabela 4.1: Barras ensaiadas

\begin{tabular}{|c|c|c|c|c|c|c|c|}
\hline & & & $\begin{array}{c}\text { Comprimento } \\
\text { efetivo } L_{e f}\end{array}$ & & & & Comprimento \\
\hline & & C.TA-1 & 2500 & & & I.TA-1 & 2500 \\
\hline nู & & C.TA-2 & 2500 & $\dddot{n}$ & & I.TA-2 & 2500 \\
\hline$\underbrace{\star}$ & & C.TA-3 & 2500 & $\stackrel{x}{x}$ & & I.SI04F-1 & 2500 \\
\hline$x$ & =if & C.SI04F-1 & 2500 & $x \sqrt{1}$ & 需 & I.SI04F-2 & 2500 \\
\hline$x$ & & C.SI04F-2 & 2500 & $x$ & & I.SI04F-3 & 2500 \\
\hline$\frac{n}{2}$ & $\mathrm{~m}$ & C.SI04F-3 & 2500 & $n$ & & I.SI04F-4 & 2500 \\
\hline$\vec{v}$ & & C.SI07F-1 & 2500 & $\vec{\lambda}$ & & I.SI04F-5 & 2500 \\
\hline & & C.SI07F-2 & 2500 & & & I.SI07F-1 & 2500 \\
\hline & & & & & & I.SI07F-2 & 2500 \\
\hline
\end{tabular}

Esses perfis apresentaram valores médios de resistência ao escoamento $f_{y}$ igual a $382 \mathrm{MPa}$ e resistência à ruptura $f_{u}$ igual a $505 \mathrm{MPa}$, resultando na relação $f_{u} / f_{y}$ igual a 1,31 , maior que 1,08 recomendado pela ABNT NBR 14762:2010. Tais valores foram obtidos por meio de ensaios de caracterização, descrito no item 4.2. A título de comparação, a resistência nominal ao escoamento 
e a ruptura do aço utilizado, USICIVIL 300, é igual a $300 \mathrm{MPa}$ e entre 400 a $550 \mathrm{MPa}$, respectivamente.

\subsection{Caracterização do material}

O ensaio de caracterização foi realizado de acordo com a metodologia da norma americana ASTM A370 - 12: Standard Test Methods and Definitions for Mechanical Testing of Steel Products. Este ensaio consistiu no seguinte procedimento:

a) Foram retirados três corpos-de-prova da extremidade de três perfis escolhidos aleatoriamente;

b) Dos três perfis, foram extraídos três corpos de prova da parte central dos elementos (alma e mesa) de cada um, ilustrados na figura 4.4 e 4.5.
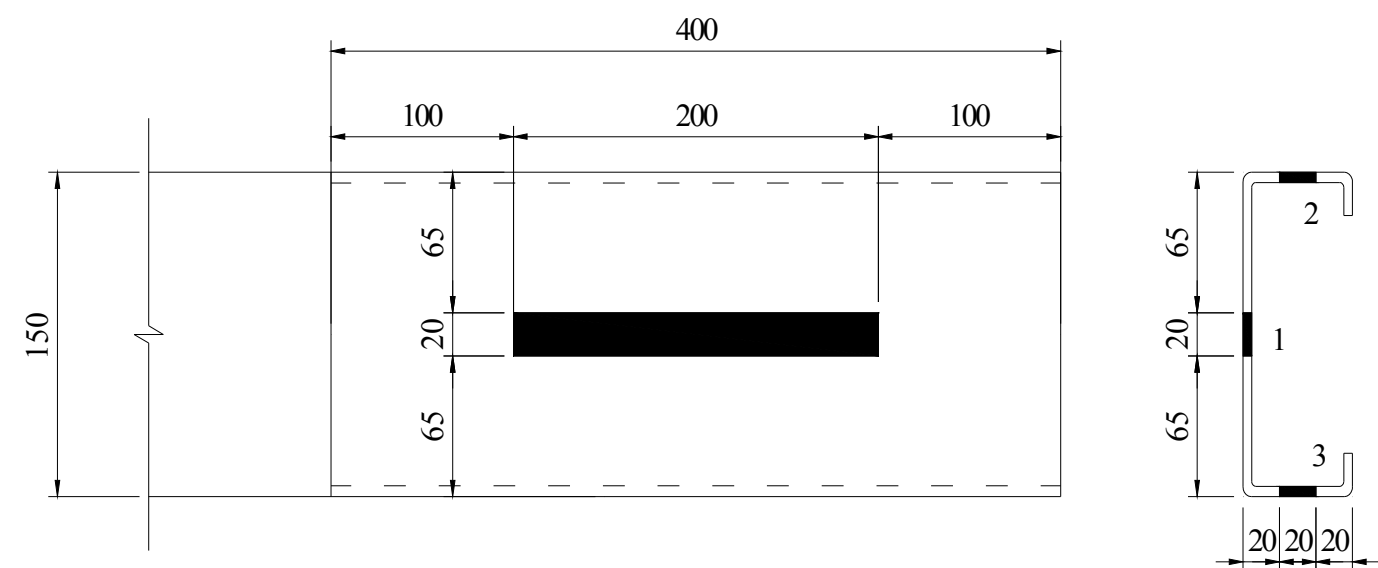

A
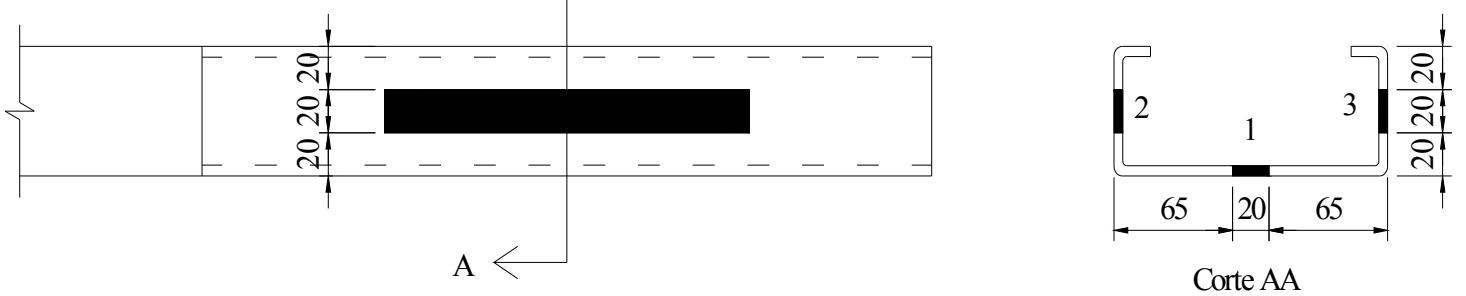

Figura 4.4: Extração dos corpos de prova para a caracterização do material. 


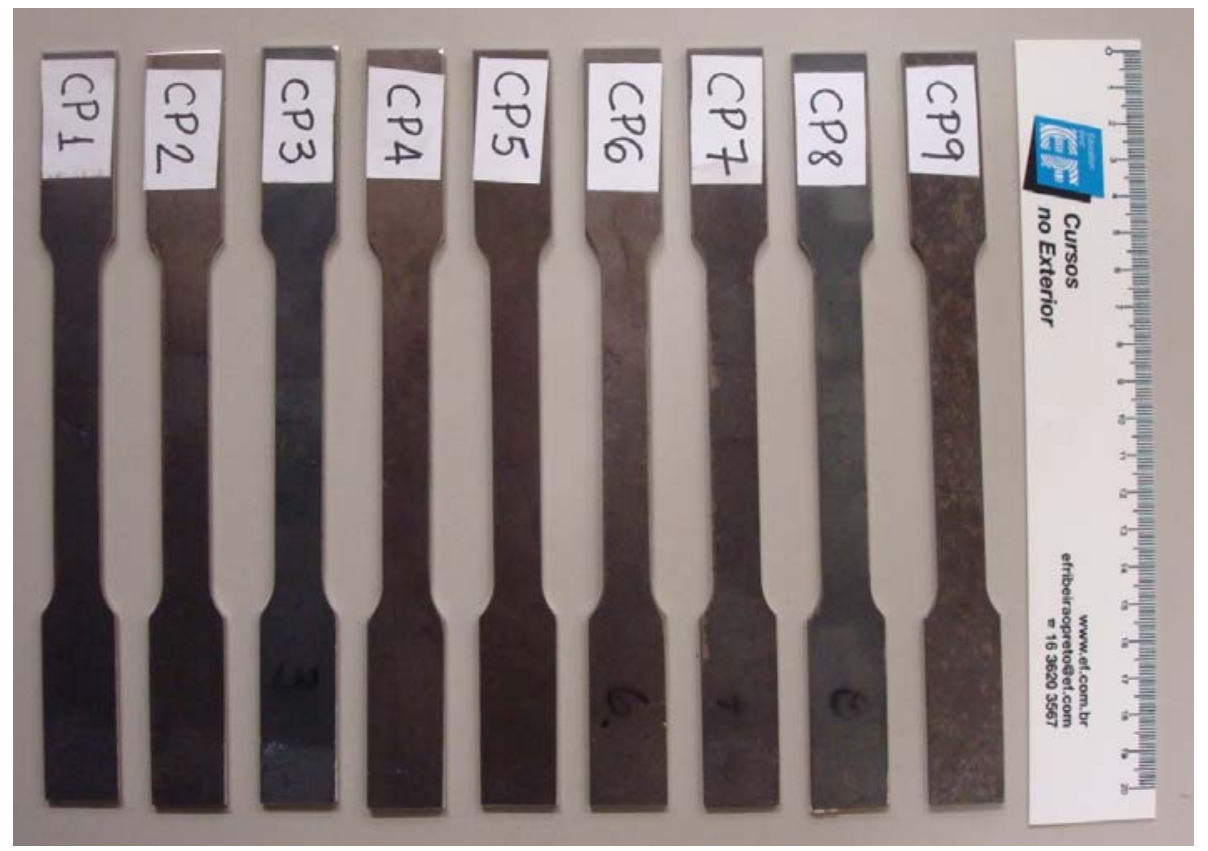

Figura 4.5: Corpos de prova.

O gráfico "tensão $x$ deformação" foi obtido por meio do ensaio de tração direta com controle de deslocamento a uma velocidade igual a 2,0 mm/minuto. Os dois primeiros corpos de prova tiveram seus resultados invalidados devido a defeitos no equipamento de ensaio. Os resultados obtidos nos demais corpos de prova mostram que o material apresentou resistência ao escoamento maior do que o valor nominal. A tabela 4.2 informa os resultados dos ensaios de caracterização. A figura 4.6 ilustra a curva "tensão $x$ deformação" dos corpos de prova 3 a 9 e a figura 4.7 ilustra a curva "tensão $x$ deformação" média obtida para o perfil estudado.

Tabela 4.2: Resultados do ensaio de caracterização do perfil Ue $150 \times 60 \times 20 \times 2,25$.

\begin{tabular}{|c|c|c|c|c|c|c|c|c|}
\hline \multirow[b]{2}{*}{ Perfil } & \multirow[b]{2}{*}{$\begin{array}{c}\text { Corpo } \\
\text { de } \\
\text { prova }\end{array}$} & \multirow[b]{2}{*}{$\begin{array}{c}\text { Área do } \\
\text { corpo de } \\
\text { prova }\left[\mathrm{cm}^{2}\right]\end{array}$} & \multicolumn{3}{|c|}{ Escoamento } & \multicolumn{3}{|c|}{ Ruptura } \\
\hline & & & Força $[\mathbf{k N}]$ & $\begin{array}{l}\text { Tensão } \\
\text { [MPa] }\end{array}$ & $\begin{array}{c}\text { Tensão } \\
\text { média } \\
{[\mathrm{MPa}]} \\
\end{array}$ & Força $[k N]$ & $\begin{array}{l}\text { Tensão } \\
\text { [MPa] }\end{array}$ & $\begin{array}{c}\text { Tensão } \\
\text { média } \\
{[\mathrm{MPa}]}\end{array}$ \\
\hline \multirow{9}{*}{ 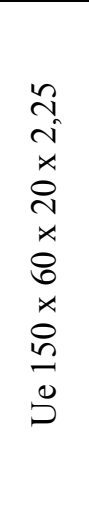 } & 1 & 0,302 & - & - & & - & - & \\
\hline & 2 & 0,301 & - & - & & - & - & \\
\hline & 3 & 0,306 & 11,33 & 369,9 & \multirow{7}{*}{382,2} & 14,17 & 499,5 & \multirow{7}{*}{505,8} \\
\hline & 4 & 0,305 & 11,25 & 369,9 & & 13,92 & 508,0 & \\
\hline & 5 & 0,303 & 11,71 & 387,8 & & 14,16 & 508,9 & \\
\hline & 6 & 0,308 & 11,80 & 385,0 & & 14,31 & 514,8 & \\
\hline & 7 & 0,299 & 11,48 & 385,0 & & 14,10 & 503,3 & \\
\hline & 8 & 0,304 & 11,71 & 386,6 & & 14,10 & 496,9 & \\
\hline & 9 & 0,303 & 11,82 & 390,9 & & 14,16 & 509,0 & \\
\hline
\end{tabular}




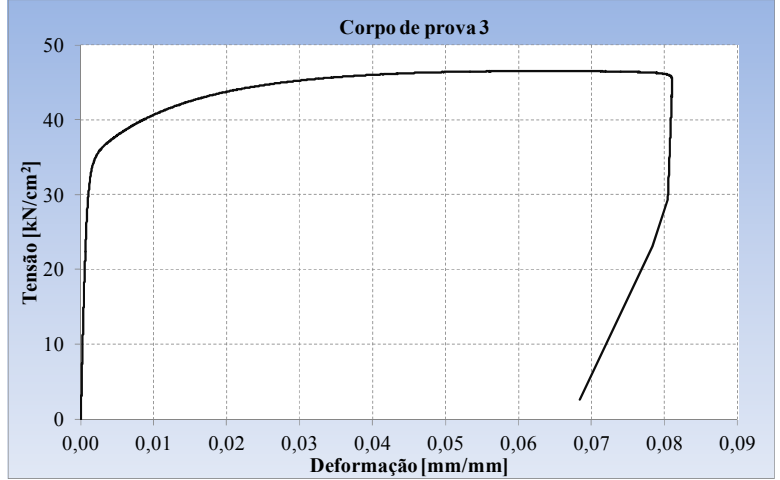

(a)

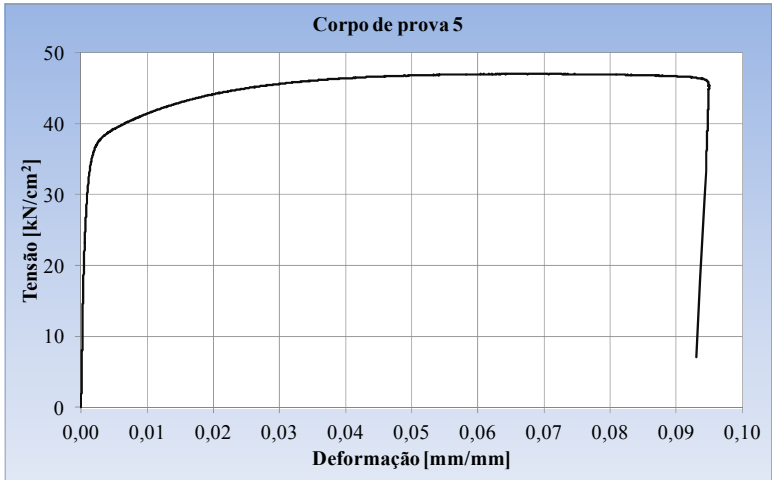

(c)

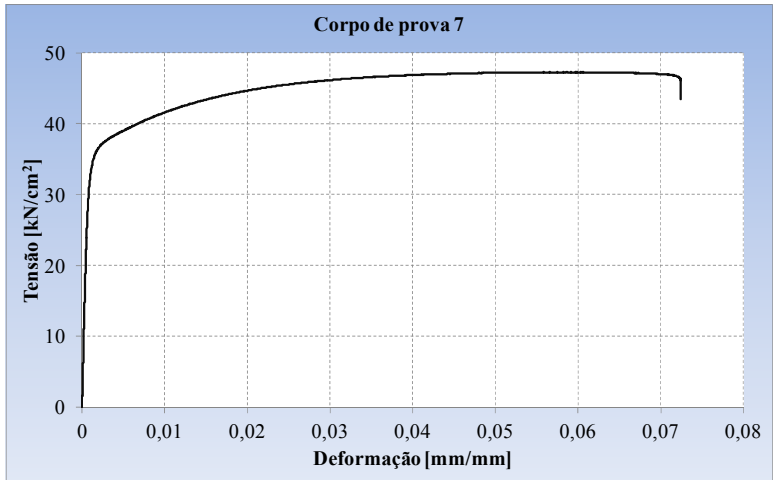

(e)

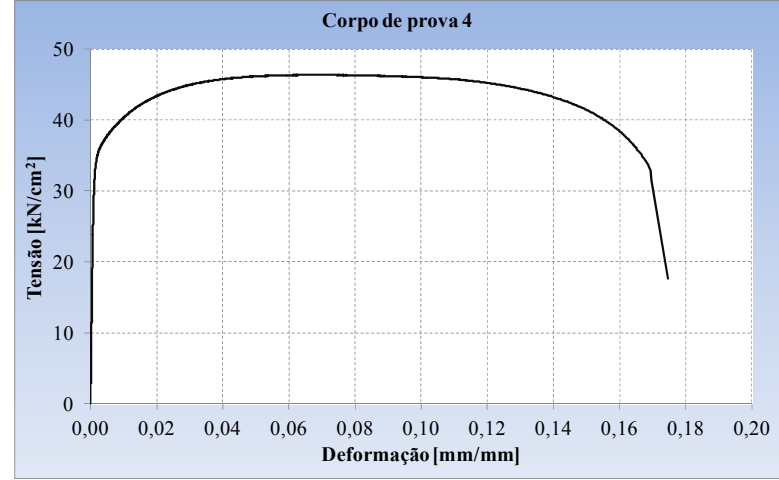

(b)

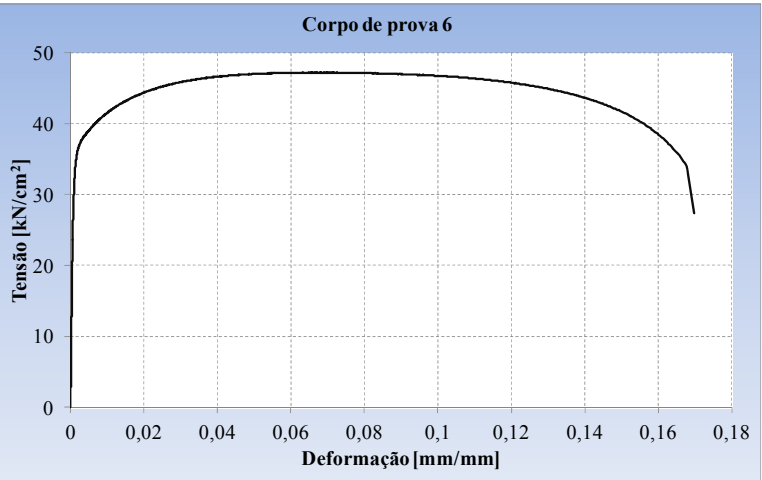

(d)

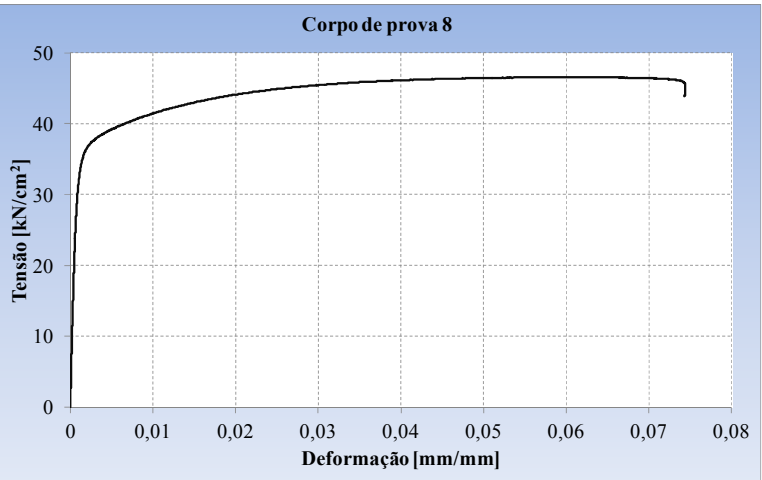

(f)

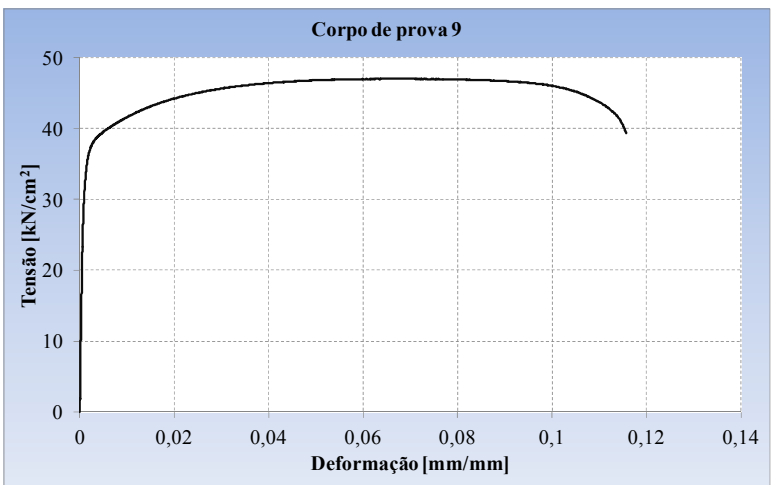

Figura 4.6: Curva "tensão $x$ deformação" obtida para os corpos de prova (a) 3 a (g) 9, referente ao aço dos perfis. 


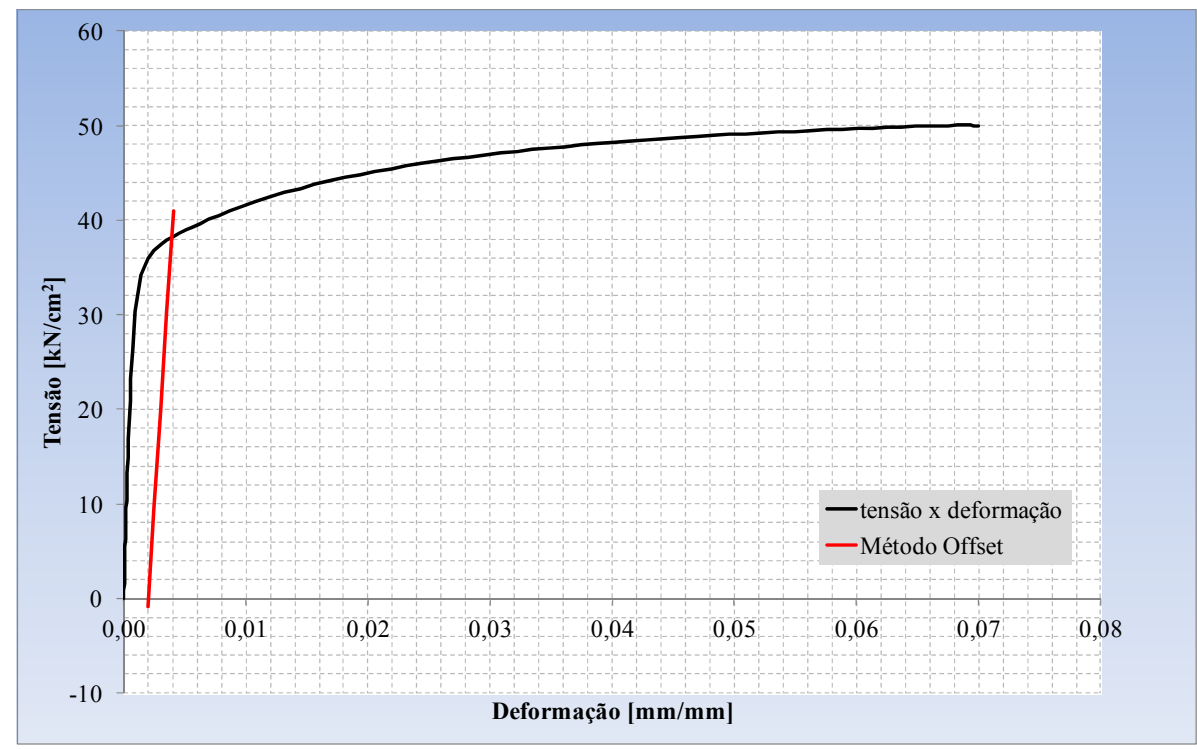

Figura 4.7: Curva média “tensão $x$ deformação" obtida para o aço dos perfis.

\subsection{Ensaios de compressão centrada: comentários gerais}

Todos os ensaios de compressão centrada foram realizados no Laboratório de Estruturas na Faculdade de Engenharia Civil da Universidade Estadual de Campinas. Em todos os ensaios realizados, tanto à temperatura ambiente como em situação de incêndio, foi utilizado um único sistema de aplicação de força - pórtico de reação e cilindro hidráulico, bem como um único sistema de aquisição de dados para ações mecânicas e célula de carga.

O procedimento descrito no parágrafo anterior foi necessário para padronizar e manter a representatividade do ensaio e, consequentemente a fidelidade dos dados. A figura 4.8 ilustra os equipamentos de ensaio. Na figura 4.8, o cilindro hidráulico tem capacidade de 2000 $\mathrm{kN}$ e curso de $150 \mathrm{~mm}$.

No tocante aos instrumentos de medição, para a medida da força aplicada foi utilizada uma célula de carga com capacidade de medida igual a $2000 \mathrm{kN}$. Os deslocamentos lineares foram medidos por meio de dois transdutores de com curso de $100 \mathrm{~mm}$, fabricados pela Kyowa. Também foram utilizados, nos ensaios à temperatura ambiente, dois relógios comparadores com curso de a $10 \mathrm{~mm}$ e $20 \mathrm{~mm}$. Os ensaios à temperatura ambiente também contaram com medidas de deformação. Para tanto, foram utilizados extensômetros com base de medida de cinco milímetros fabricados pela Kyowa. Os dados foram registrados por meio do sistema de aquisição System 5000 fabricado pela Vishay. 


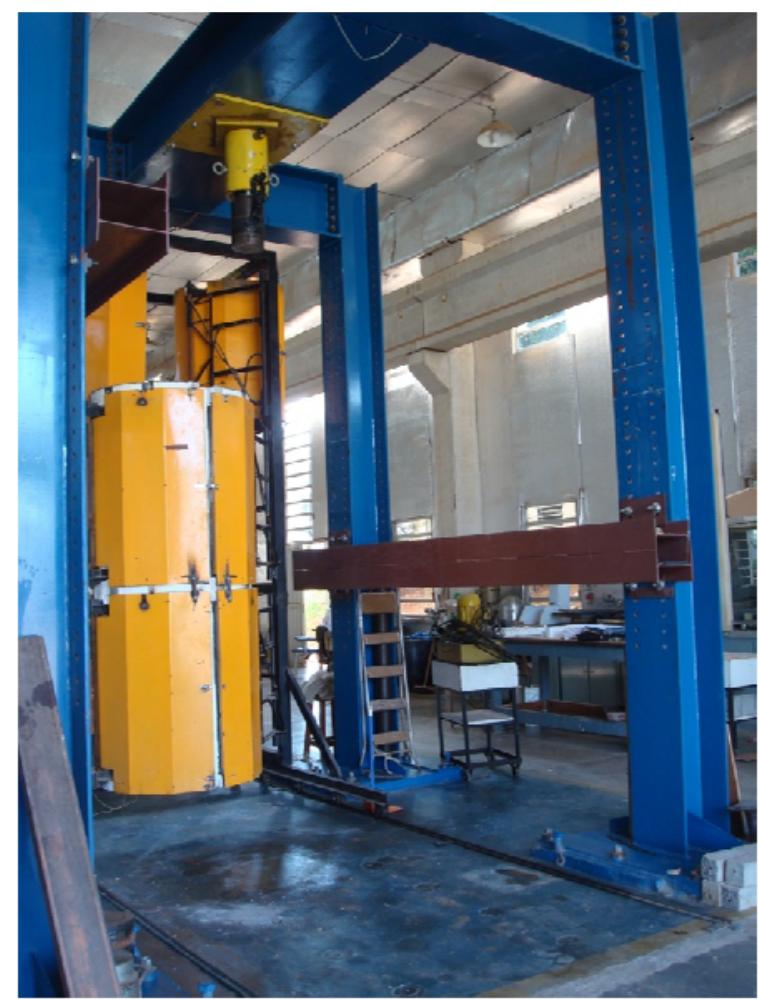

(a)

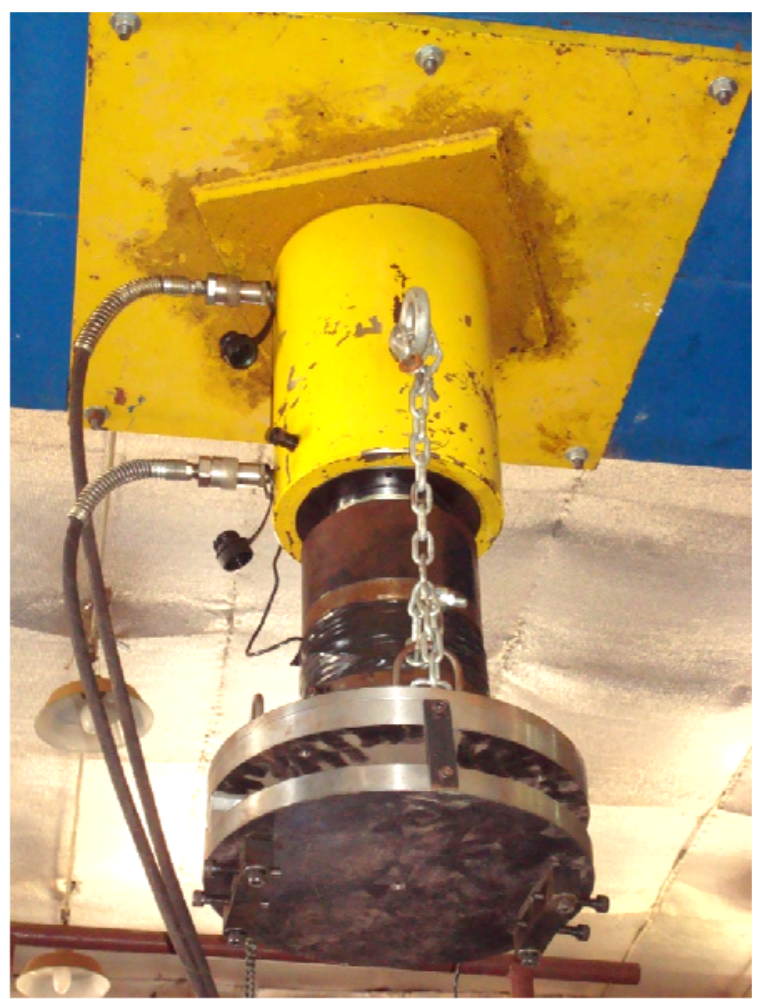

(b)

Figura 4.8: (a) Pórtico de reação e (b) Cilindro hidráulico e célula de carga

Vale ressaltar que os ensaios de compressão consistem em avaliar o comportamento de barras com extremidades rotuladas. Para tanto, foram fabricados aparelhos de apoio, conforme ilustrados na figura 4.9 esquematizados na figura 4.10 , respectivamente.

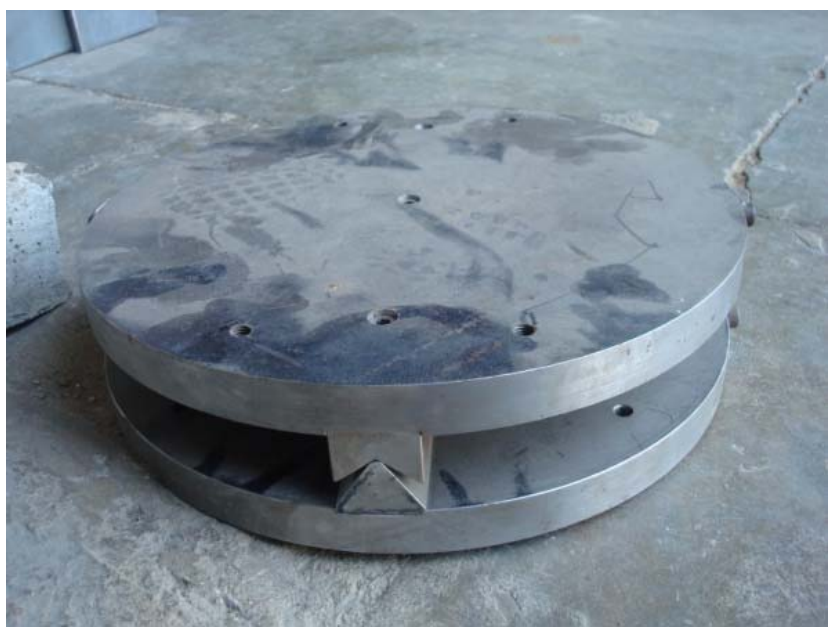

(a)

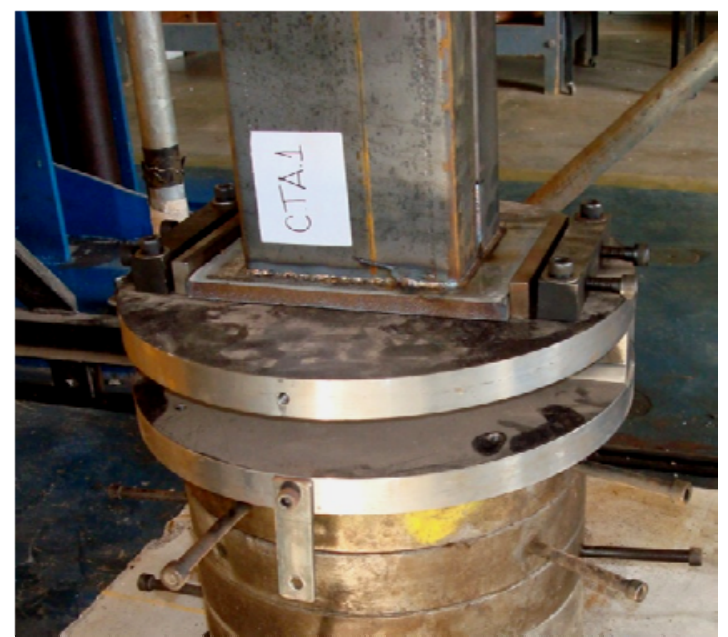

(b)

Figura 4.9: Foto do aparelho de apoio (a) detalhe da rótula cilíndrica e (b) posicionamento do perfil. 


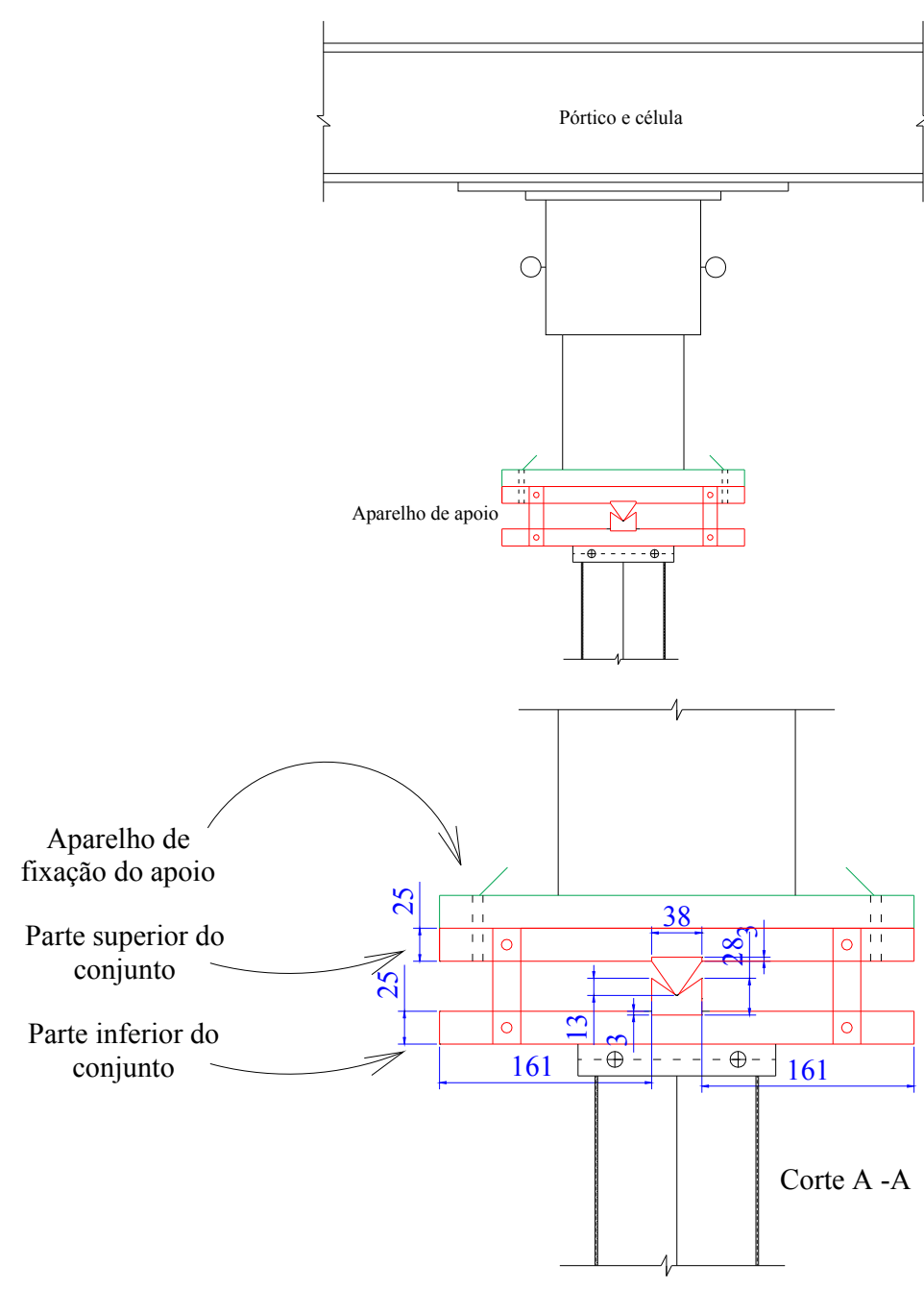

(a)

Figura 4.10: (a) Esquema da fixação da barra e (b) detalhe do aparelho de apoio e do encaixe que garante a rótula cilíndrica

\subsection{Ensaios à temperatura ambiente}

As barras foram instrumentadas com quatro transdutores de deslocamento, dois no apoio do topo, dispostos diametralmente, e dois a meia altura dispostos perpendicularmente, conforme ilustram as figuras 4.11 e 4.12 . Na mesma figura, estão ilustrados os extensômetros colados próximo à região das dobras. $\mathrm{O}$ posicionamento dos extensômetros nessa região, e não na área plana central, busca evitar a interferência das deformações de instabilidade elástica na leitura dos dados. A força foi aplicada na menor velocidade possível do pistão e registrada a cada segundo pelo sistema de aquisição. 
Corte AA

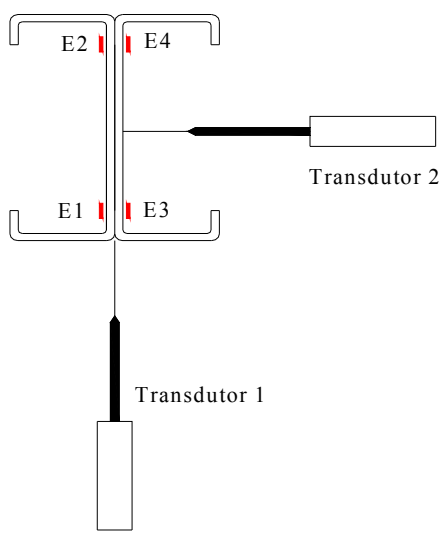

Corte AA

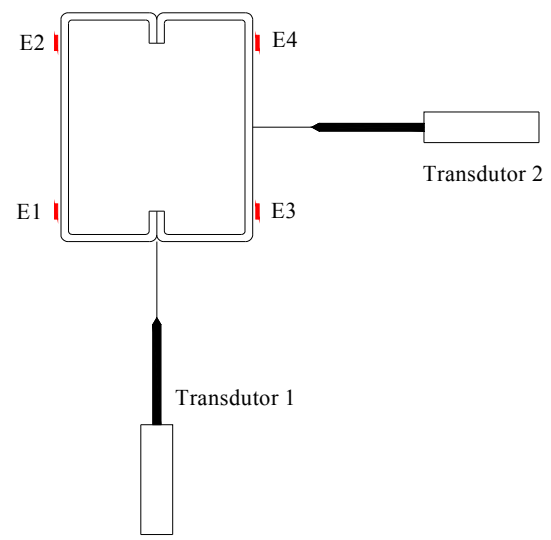

Figura 4.11: Posição dos extensômetros $E_{n}$ e dos transdutores na seção transversal a meia altura.
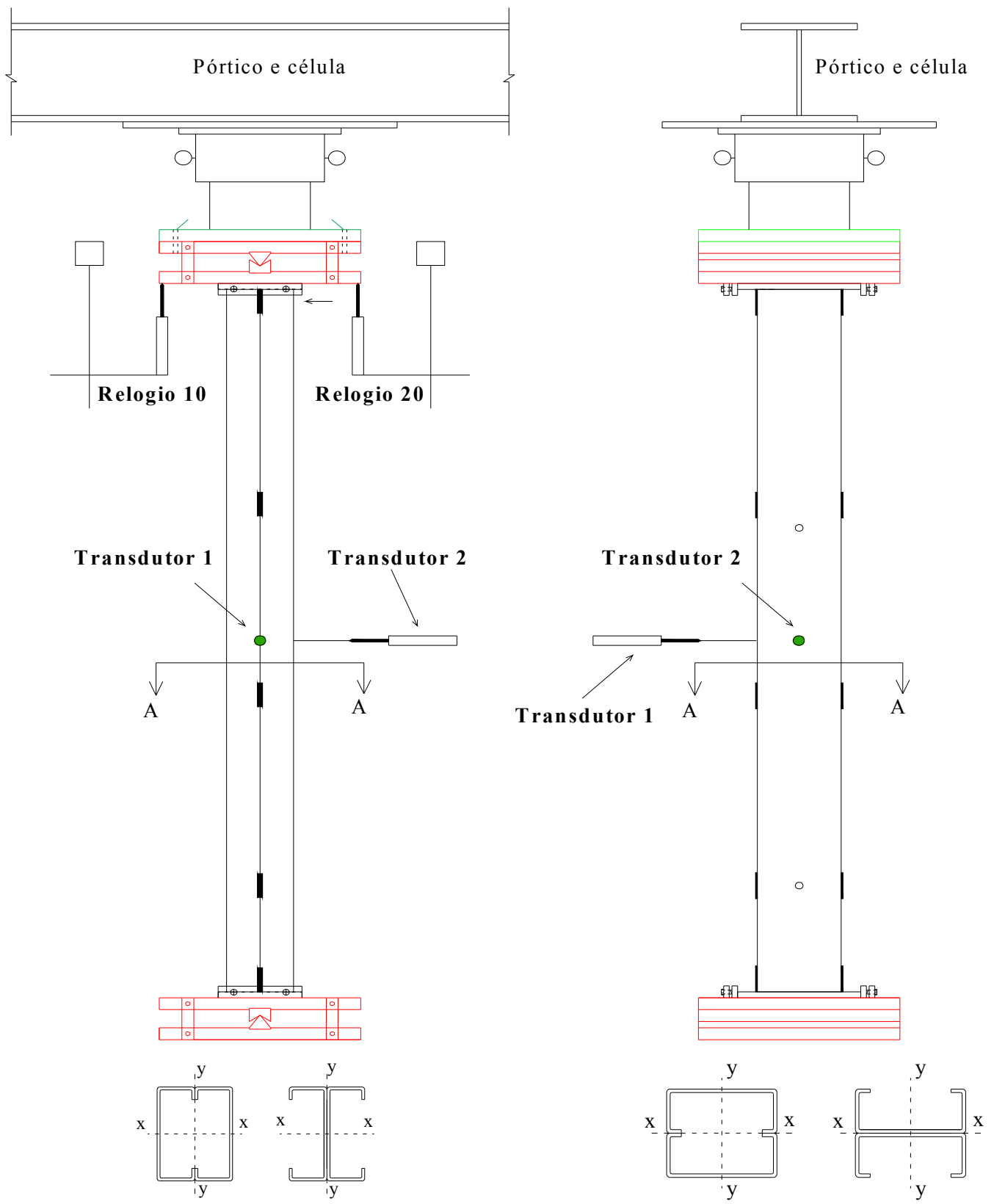

Figura 4.12: Posição dos transdutores na barra. 


\subsubsection{Resultados dos ensaios à temperatura ambiente}

Os resultados dos ensaios à temperatura ambiente mostraram que a força última normal de compressão nos perfis caixão foi maior que nos perfis abertos I enrijecido. Embora ambos os perfis sejam de esbeltez global mediana, no perfil aberto, a instabilidade global por flexão foi visível, ao passo que, no perfil fechado, o deslocamento lateral ocorreu após a alma e (em seguida) a mesa apresentarem instabilidade local.

As figuras 4.13 (a), (b) e (c) são referentes à configuração deformada do perfil I enrijecido, que apresentou instabilidade local na alma entre as soldas, bem como instabilidade distorcional do conjunto mesa - enrijecedor, na mesma altura. O sistema de apoio permitiu que o perfil apresentasse rotação livre nas extremidades à medida que ocorreu a flexão em torno do eixo fraco.
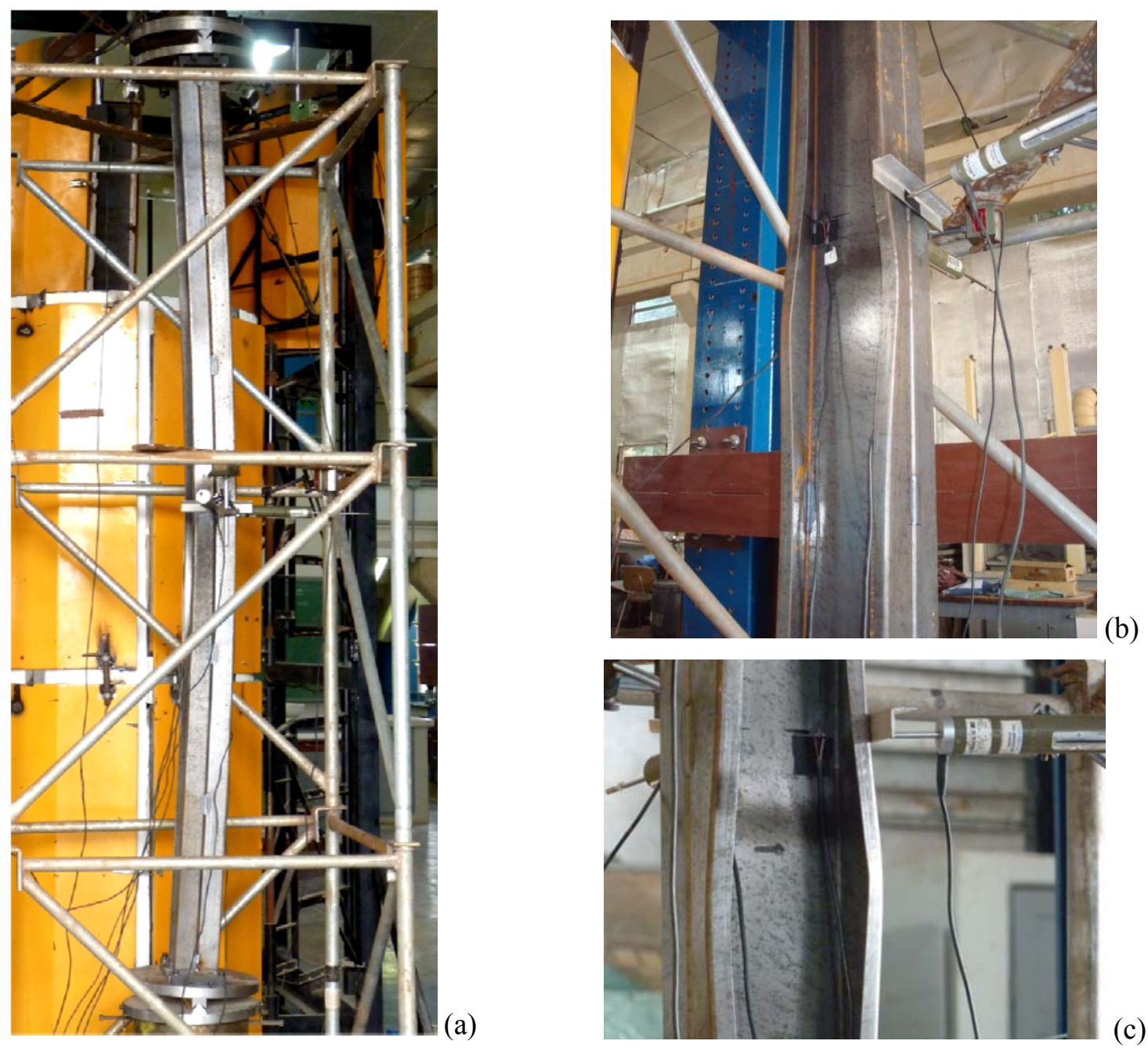

Figura 4.13: Configuração deformada do perfil I enrijecido: (a) modo de falha por flexão, (b) modo de falha local na alma e distorcional e (c) detalhe da perda de estabilidade nos elementos da seção transversal. 
$\mathrm{Na}$ figura 4.14, referente ao perfil caixão, observou-se o modo de falha local na alma, seguido de uma falha local na mesa, localizados entre os dois cordões de solda centrais do perfil.
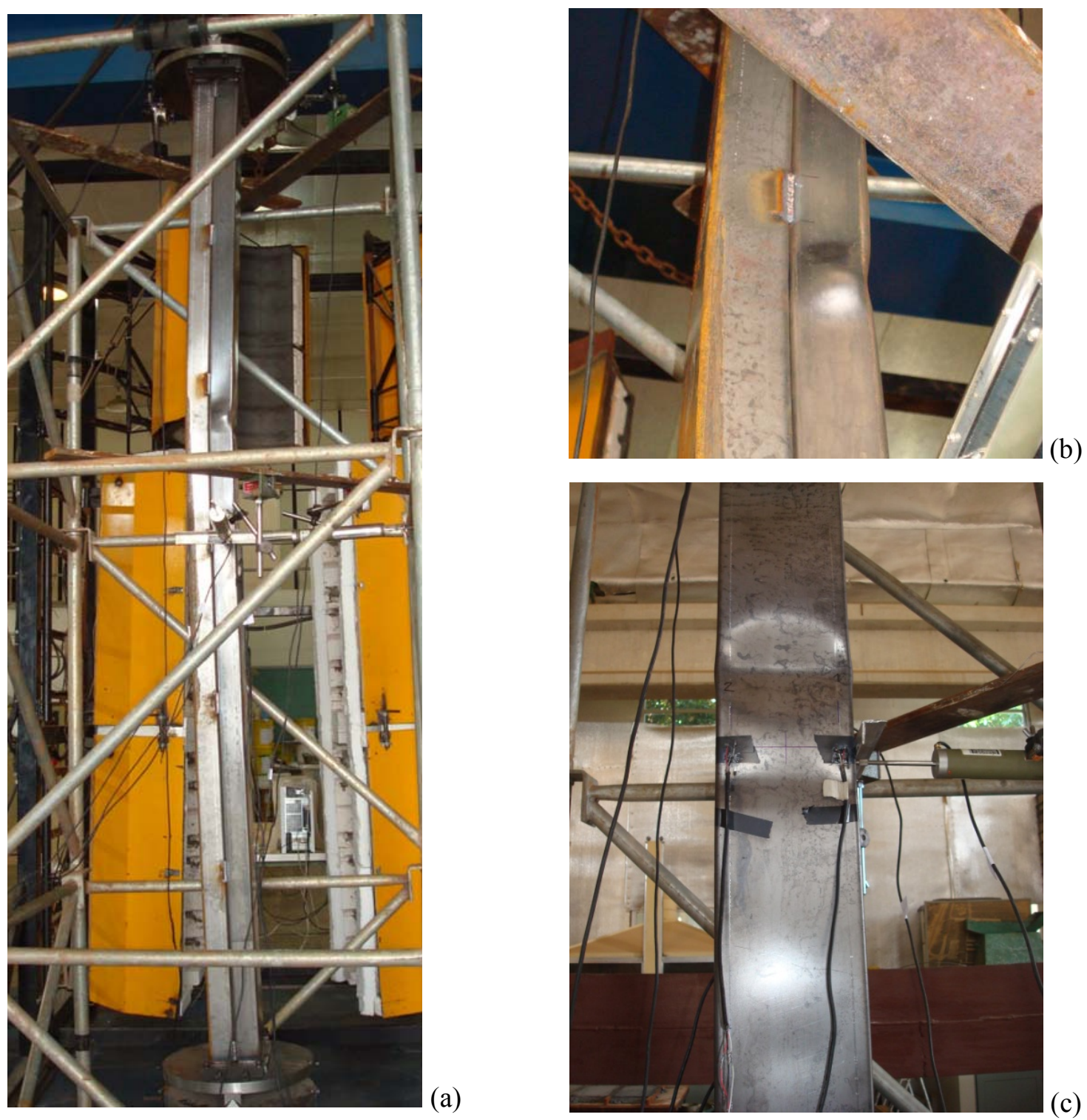

(c)

Figura 4.14: Configuração deformada do perfil caixão (a) deslocamento lateral, (b) modo de falha local na mesa e (c) falha local na alma.

A tabela 4.3 apresenta os resultados da análise experimental à temperatura ambiente. O deslocamento axial último resultante corresponde à diferença entre as leituras do relógio 10 e relógio 20. As figuras 4.15 a 4.22 ilustram as curvas "força $x$ deslocamento" axial e transversal, respectivamente. 
Tabela 4.3: Resultados à temperatura ambiente

\begin{tabular}{|c|c|c|c|c|}
\hline Barra & $\begin{array}{l}\text { Comprimento } \\
\text { efetivo } L_{e f}[\mathrm{~mm}]\end{array}$ & Modo de falha & $\begin{array}{c}\text { Deslocamento } \\
\text { axial [mm] }\end{array}$ & $\begin{array}{c}\text { Compressão } \\
\text { centrada } N_{\exp }[k N]\end{array}$ \\
\hline C.TA-2 & 2500 & $\begin{array}{l}\text { Local na alma e } \\
\text { mesa }\end{array}$ & 6,377 & 192 \\
\hline C.TA-3 & 2500 & $\begin{array}{l}\text { Local na alma e } \\
\text { mesa }\end{array}$ & 5,951 & 191 \\
\hline I.TA-1 & 2500 & $\begin{array}{l}\text { Local na alma/ } \\
\text { distorcional }\end{array}$ & 7,046 & 149 \\
\hline I.TA-2 & 2500 & $\begin{array}{l}\text { Local na alma/ } \\
\text { distorcional }\end{array}$ & 6,683 & 157 \\
\hline$y=38 \mathrm{k}$ & $\mathrm{cm}^{2}$ & $\mathrm{E}=20000 \mathrm{kN} / \mathrm{c}$ & & \\
\hline
\end{tabular}
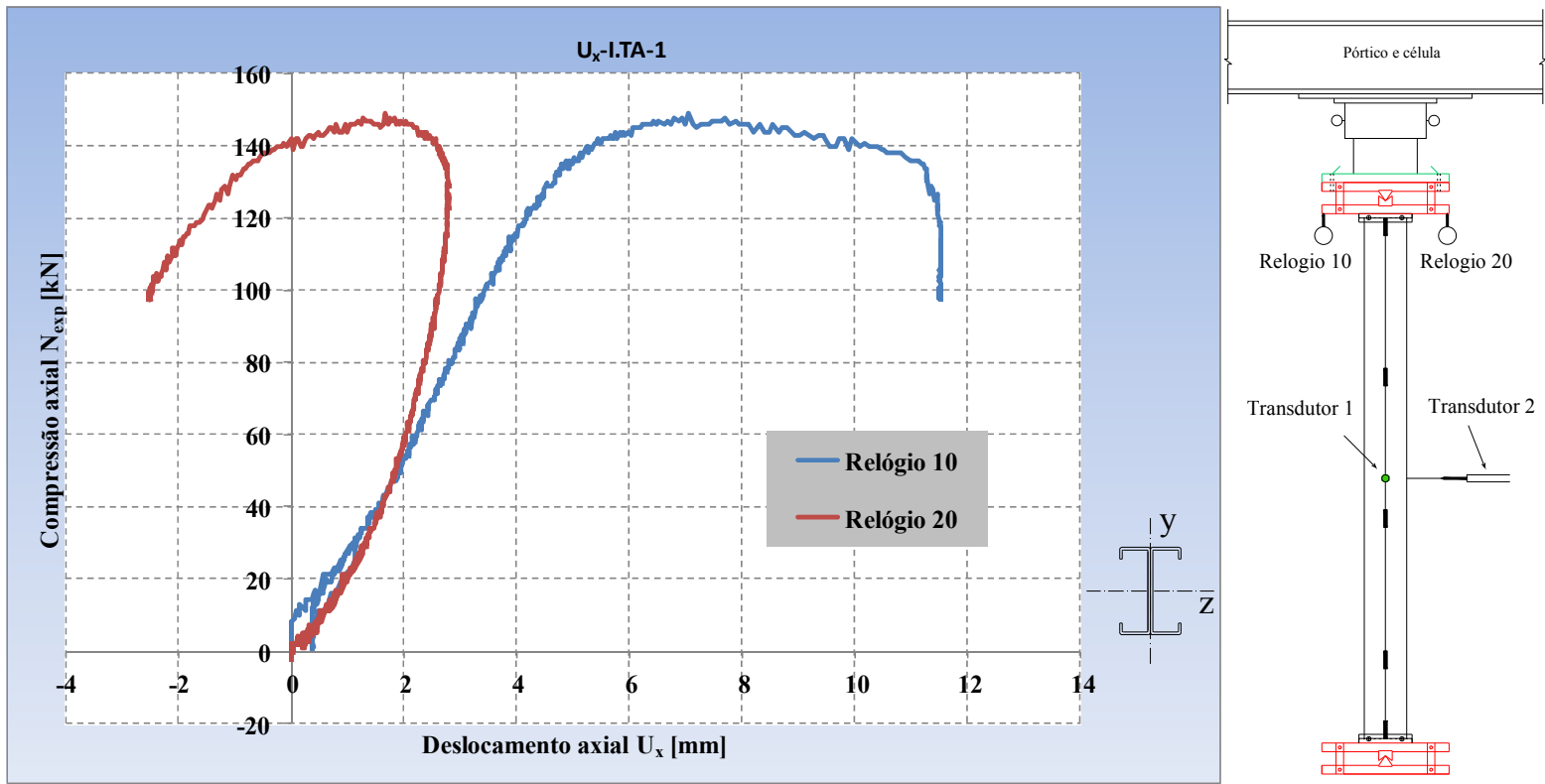

Figura 4.15: Comportamento "compressão aplicada $x$ deslocamento axial” do perfil I enrijecido, barra I.TA-1. 

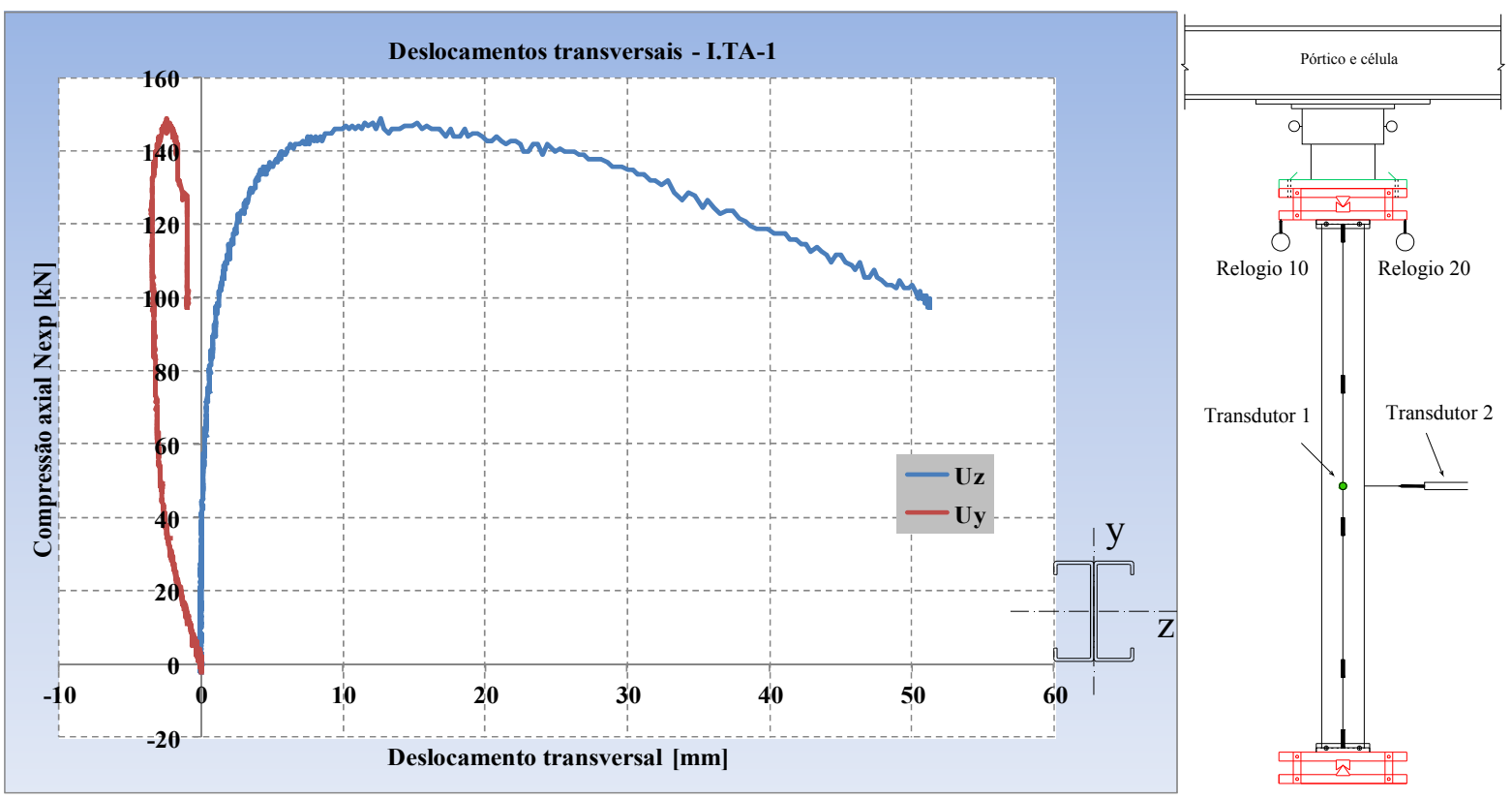

Figura 4.16: Comportamento "compressão aplicada x deslocamento transversal" do perfil I enrijecido, barra I.TA-1.
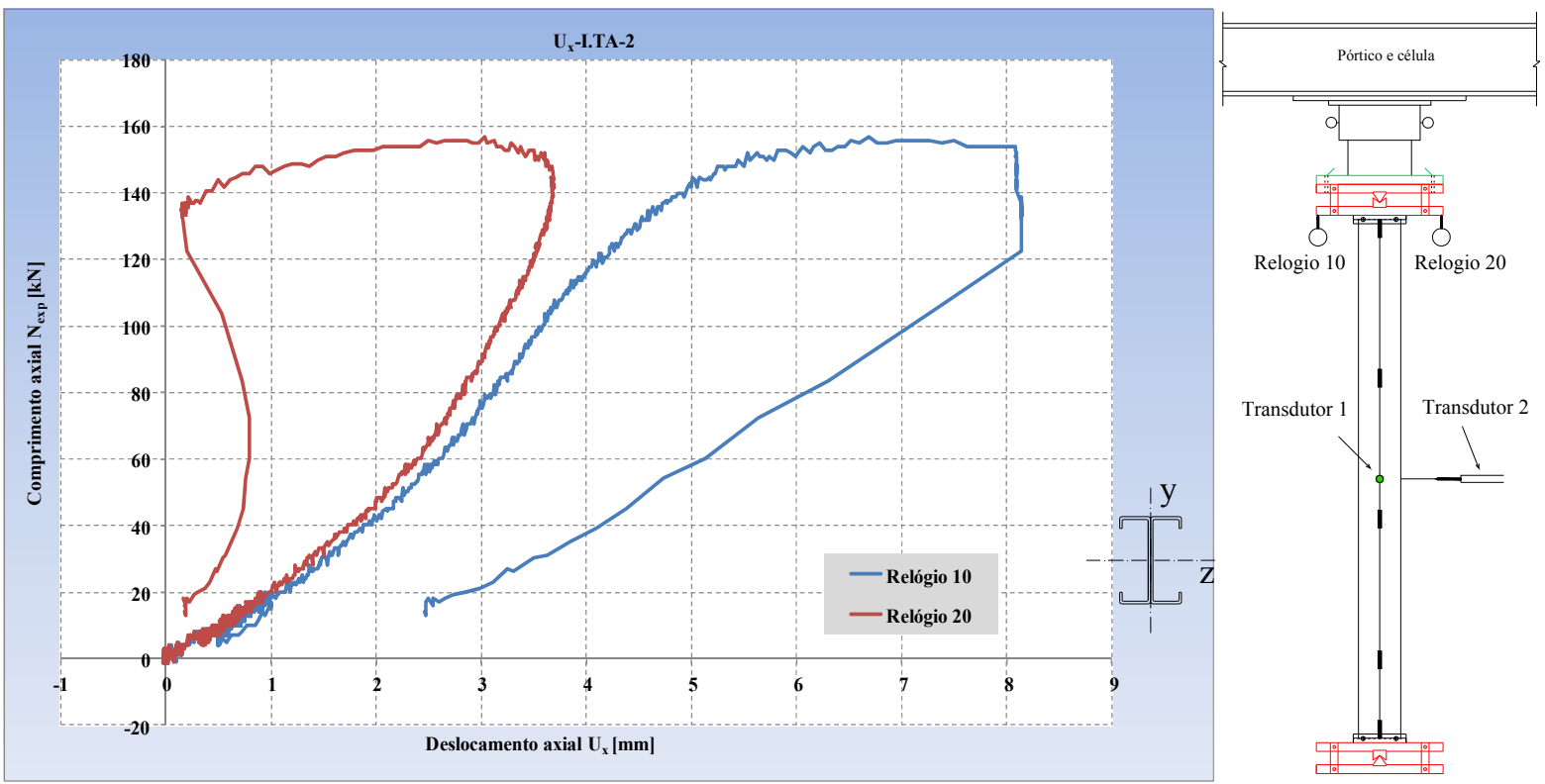

Figura 4.17: Comportamento "compressão aplicada $x$ deslocamento axial" do perfil I enrijecido, barra I.TA-2. 

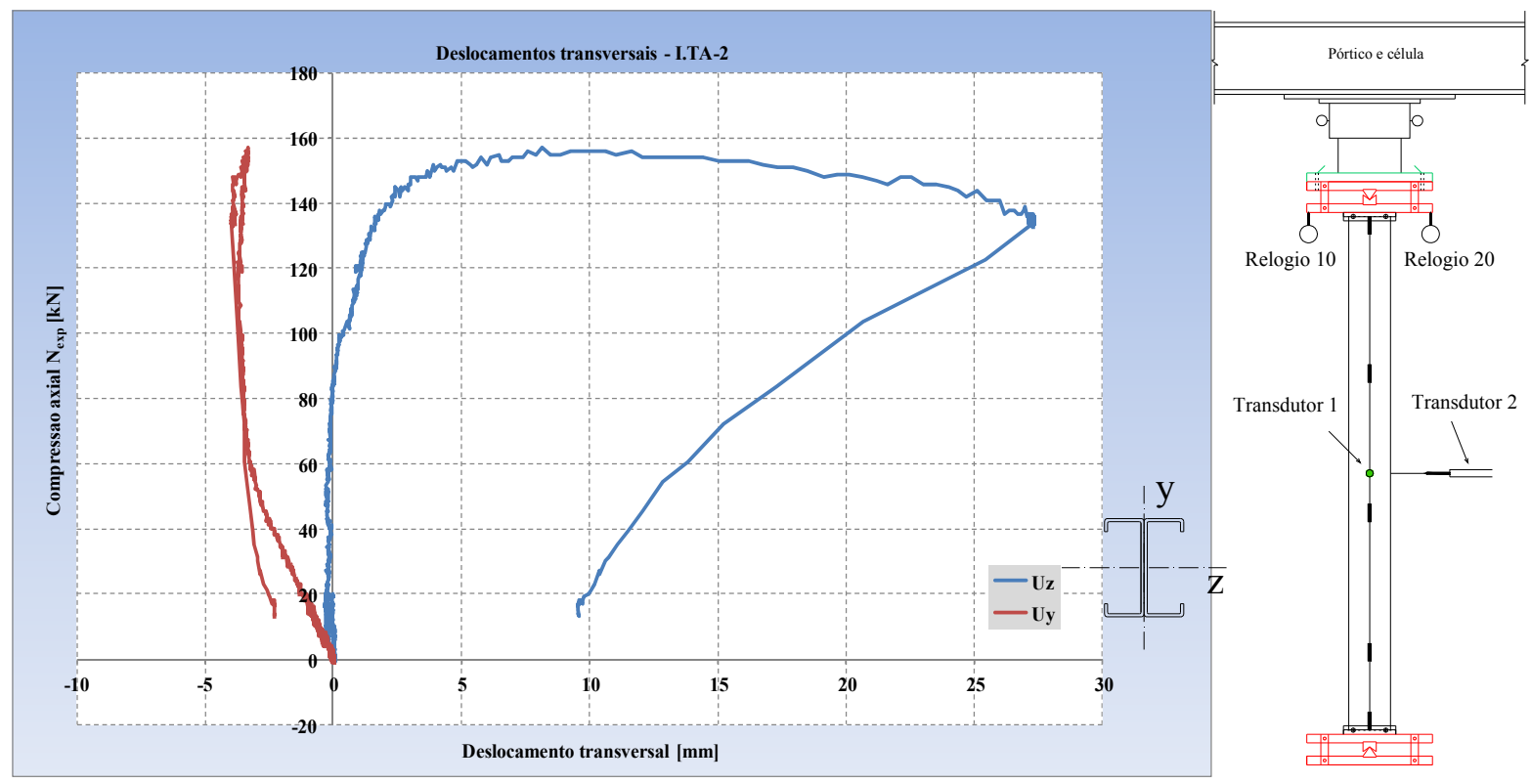

Figura 4.18: Comportamento "compressão aplicada $x$ deslocamento transversal" do perfil I enrijecido, barra I.TA-2.
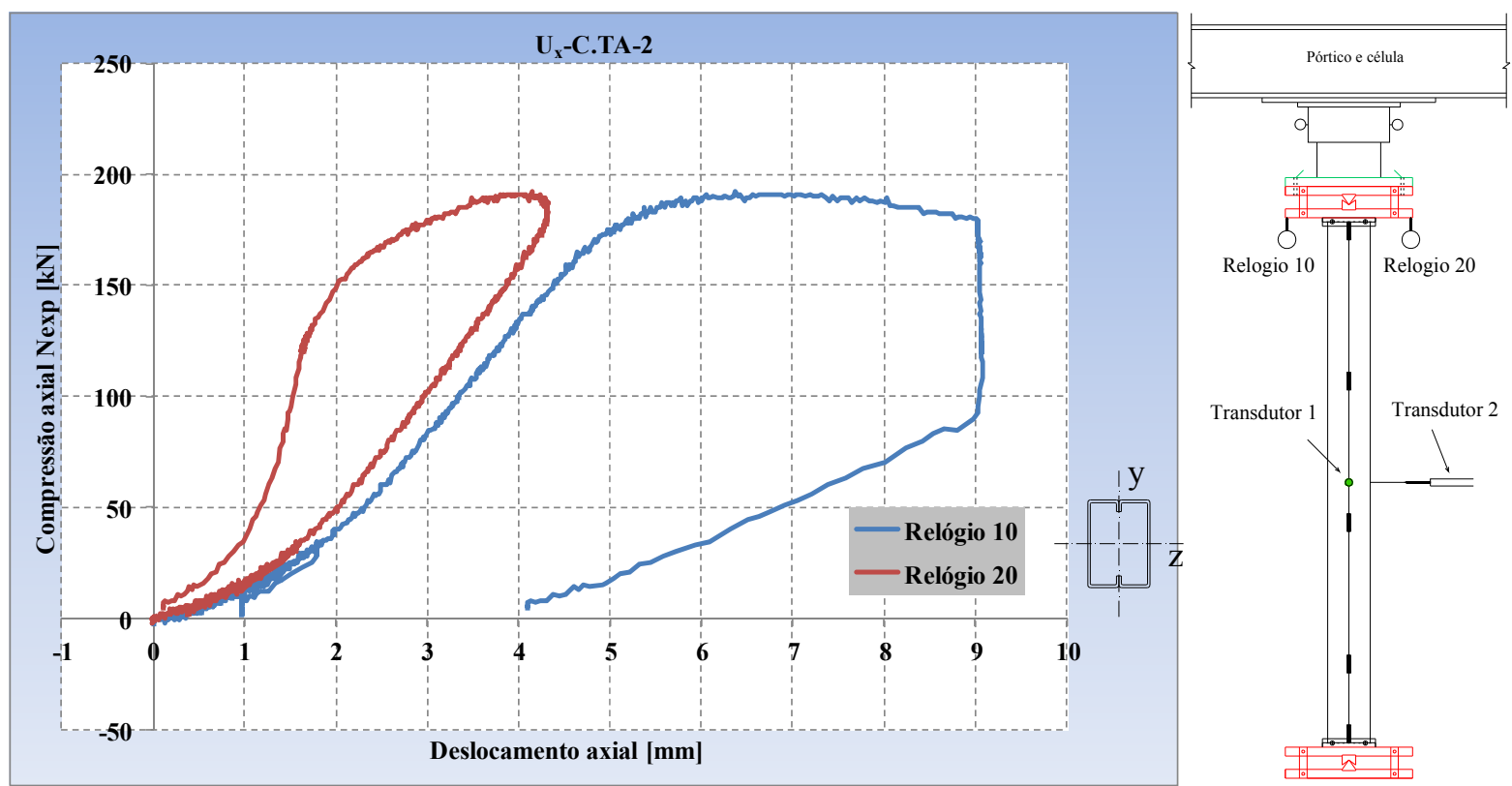

Figura 4.19: Comportamento "compressão aplicada $x$ deslocamento axial" do perfil caixão, barra C.TA-2. 


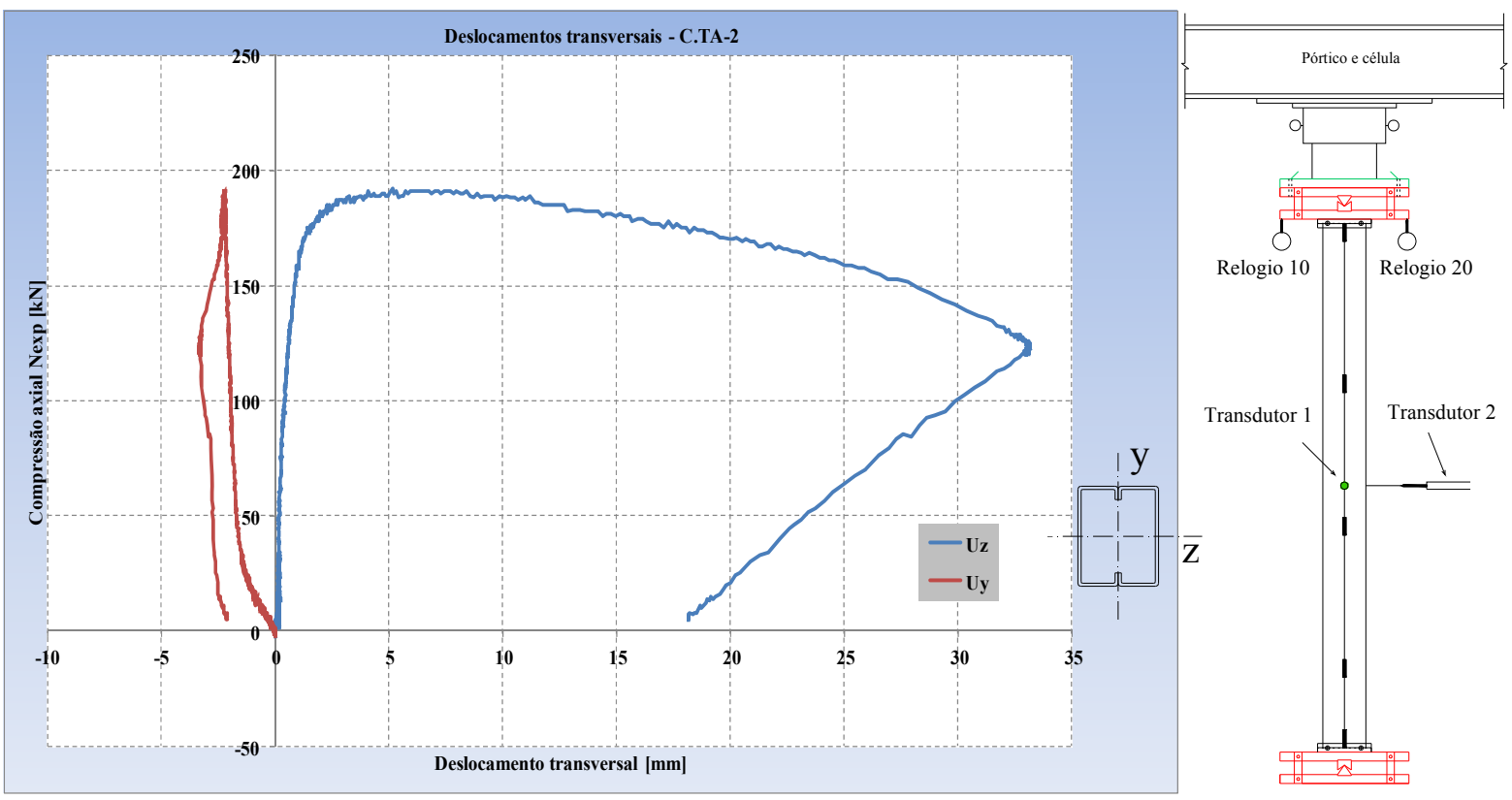

Figura 4.20: Comportamento "compressão aplicada x deslocamento transversal" do perfil caixão, barra C.TA-2.
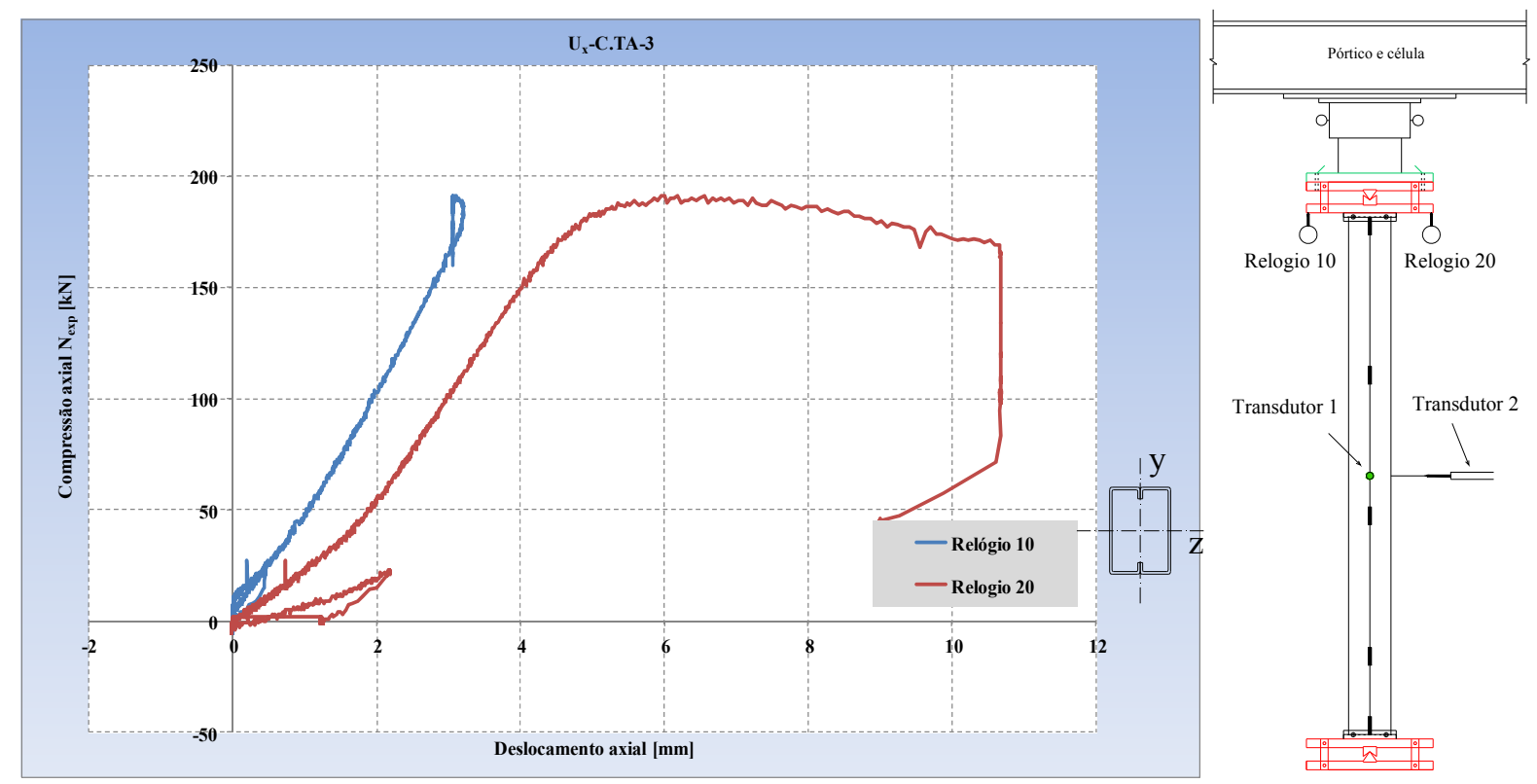

Figura 4.21: Comportamento "compressão aplicada $x$ deslocamento axial" do perfil caixão, barra C.TA-3. 


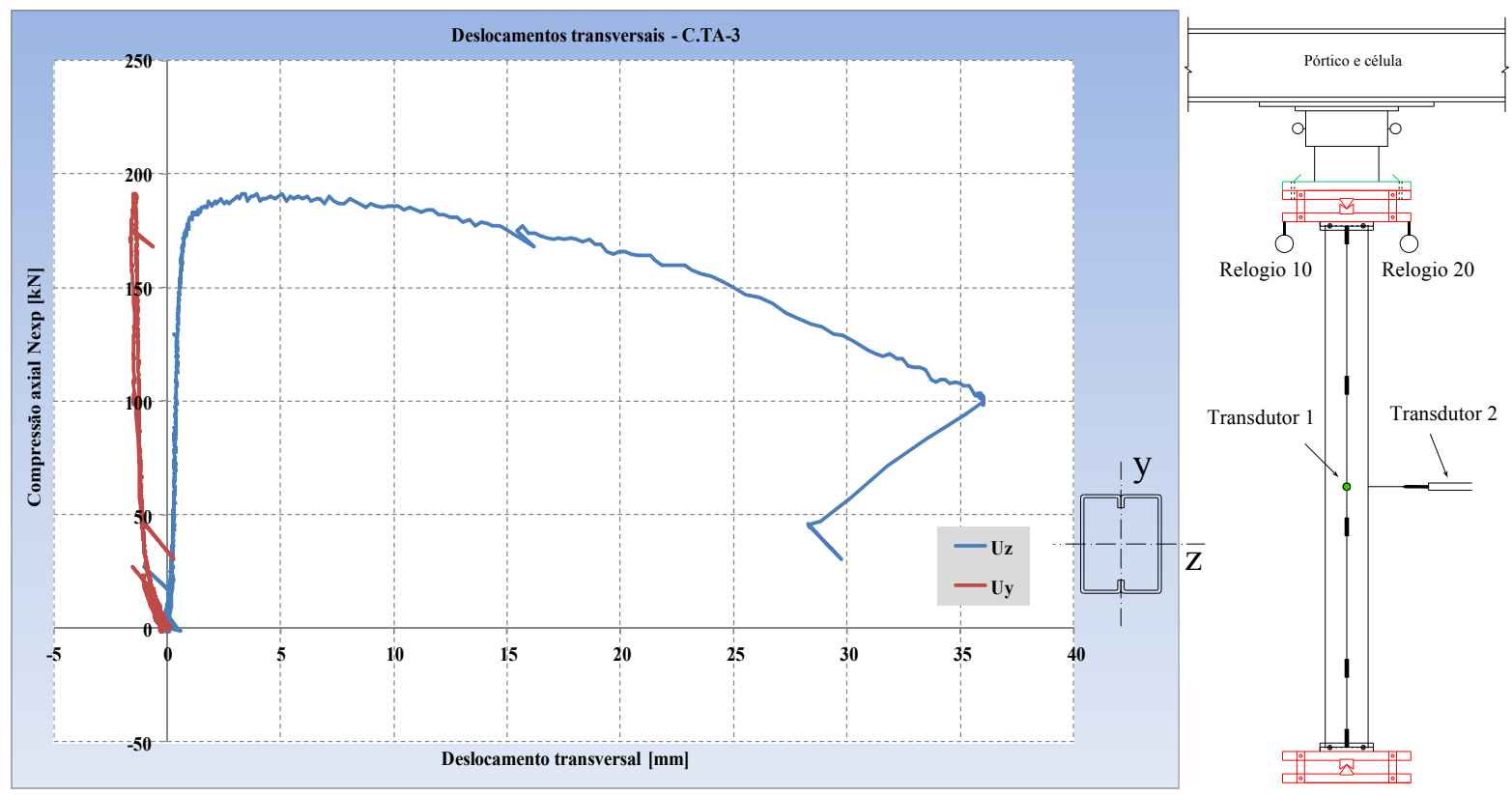

Figura 4.22: Comportamento "compressão aplicada x deslocamento transversal" do perfil caixão, barra C.TA-3.

\subsection{Ensaios em temperaturas elevadas - situação de incêndio}

Antes da realização da análise termoestrutural em caráter experimental, foram necessários trabalhos de vistoria e manutenção do forno elétrico de ensaios. Esses trabalhos foram executados em dois módulos do forno, pela empresa fabricante do equipamento, denominada MAITEC. O objetivo da vistoria era garantir que a ação térmica pudesse ser aplicada de acordo com os procedimentos da norma ISO 834-1:1999, inclusive com distribuição uniforme ao longo do comprimento dos perfis.

\subsubsection{Vistoria do equipamento de ensaio para temperaturas elevadas}

O trabalho de manutenção consistiu em diversas etapas. Inicialmente, foram retirados os restos de materiais de isolamento provenientes de ensaios anteriores, de forma a deixar apenas o revestimento lateral. As resistências elétricas antigas do forno (vale ressaltar que se trata de um forno elétrico de ensaios) foram substituídas por outras novas e reconectadas aos controladores do equipamento. Em seguida, foi realizada a recolocação de novos termopares de controle, em substituição aos antigos.

A caixa metálica externa foi ajustada para o encaixe de novas placas de revestimento cerâmico no topo e na base. Após a vistoria do sistema eletrônico de controle, com as devidas substituições de equipamentos, foram realizados os testes operacionais do forno. 
Esse trabalho de manutenção foi realizado também com o intuito de utilizar dois módulos do forno, de forma que a ação térmica pudesse ocorrer ao longo de todo comprimento das barras. Porém, durante a fase de calibração da curva de incêndio, percebeuse que, mesmo com a troca de resistores, não foi possível obter a velocidade de aquecimento requerida no módulo inferior.

$\mathrm{Na}$ figura 4.23, são ilustradas as velocidades de aquecimento nos módulos inferior e superior obtidas durante a fase de testes do forno de ensaios. Quando ligados simultaneamente, as curvas aquecimento dos gases em ambos os módulos resultaram inferiores à curva de incêndio-padrão da norma ISO 834-1:1999, sendo que a taxa de aquecimento do módulo inferior resultou visivelmente menor que a taxa de aquecimento do módulo central.

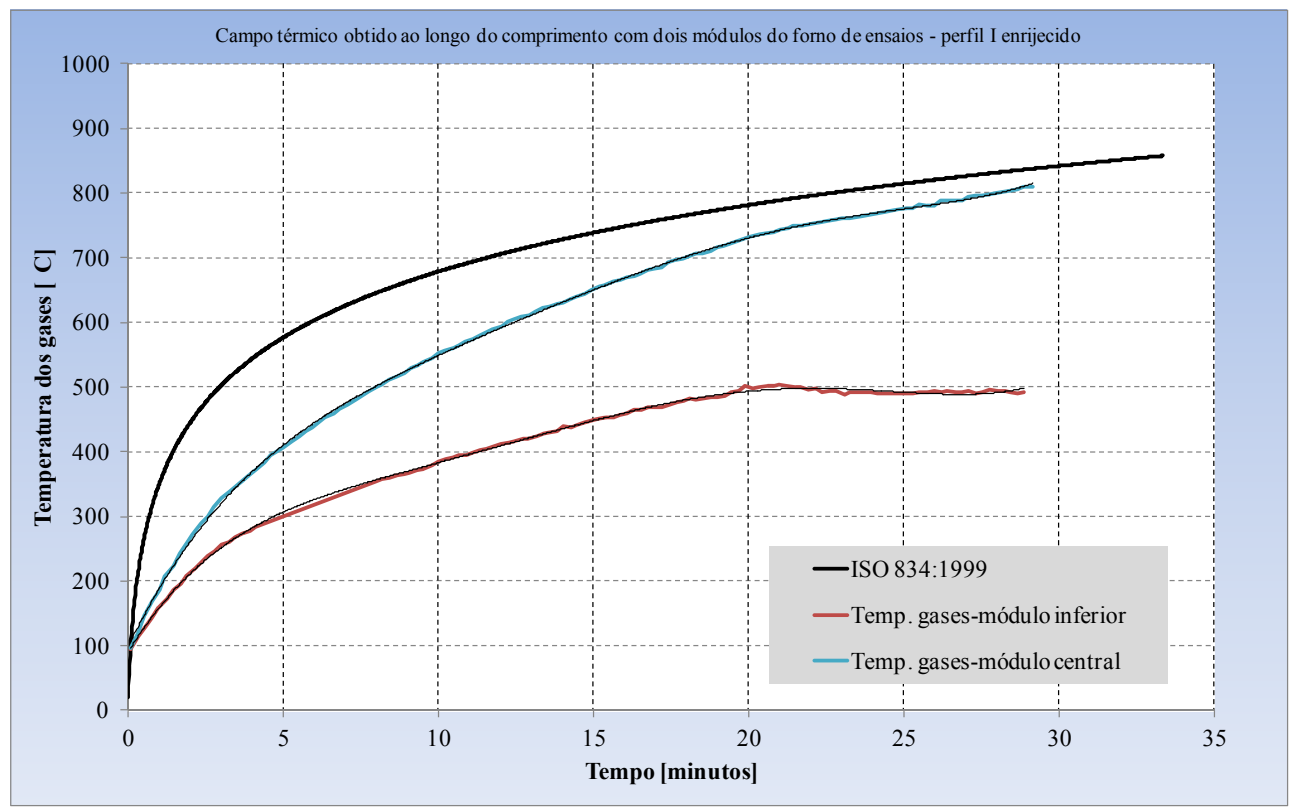

Figura 4.23: Curva de incêndio obtida nos módulos inferior e central em comparação com a curva padrão da norma ISO 834:1999.

Por essa razão, optou-se por seguir o mesmo procedimento utilizado em Gomide (2008), Leite Junior (2009) e Sant'anna (2009), em que a ação térmica foi aplicada apenas pelo aquecimento do módulo central do forno. Na figura 4.24 estão ilustradas a curva da norma ISO 834-1:1999 e a curva obtida pelo forno de ensaios, ao acionar apenas o módulo central. É possível perceber uma diferença entre a curva de aquecimento obtida pelo forno de ensaios e a estabelecida pela norma ISO 834-1:1999. Essa diferença está dentro do critério de tolerância estabelecida pela referida norma, a ser discutida no item 6.1.1. 


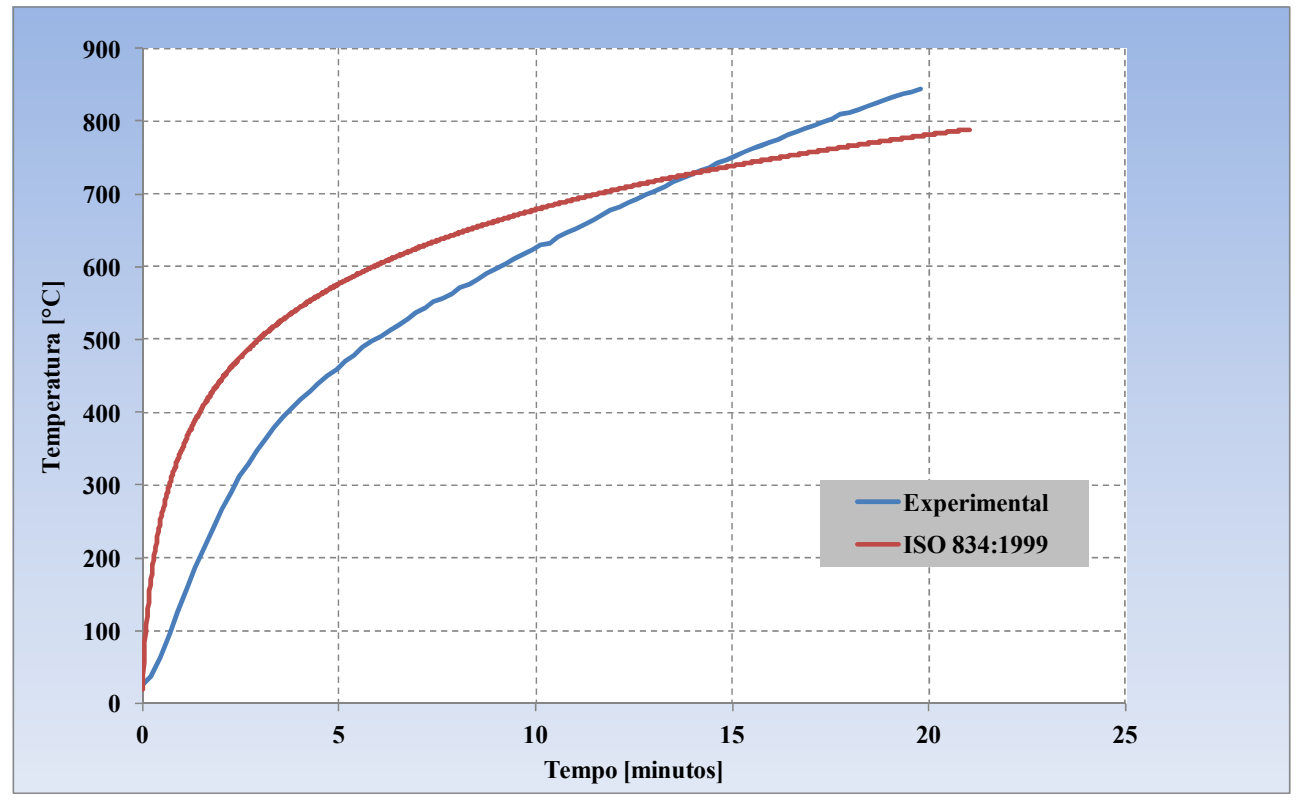

Figura 4.24: Curva de incêndio obtida durante o ensaio em comparação com a curva padrão da norma ISO 834:1999.

As figuras 4.25 (a) e (b) ilustram algumas etapas da reforma do forno. Os novos resistores e material refratário do revestimento permitiram um aquecimento uniforme em cada módulo (porém a taxas diferentes) e um isolamento adequado do ambiente interno aquecido. $\mathrm{Na}$ figura 4.25 (a) é ilustrado o equipamento na forma prevista para ser utilizada e na 4.25 (b) apenas o módulo utilizado, que seguiu a curva de incêndio padrão da ISO 834 -1:1999.

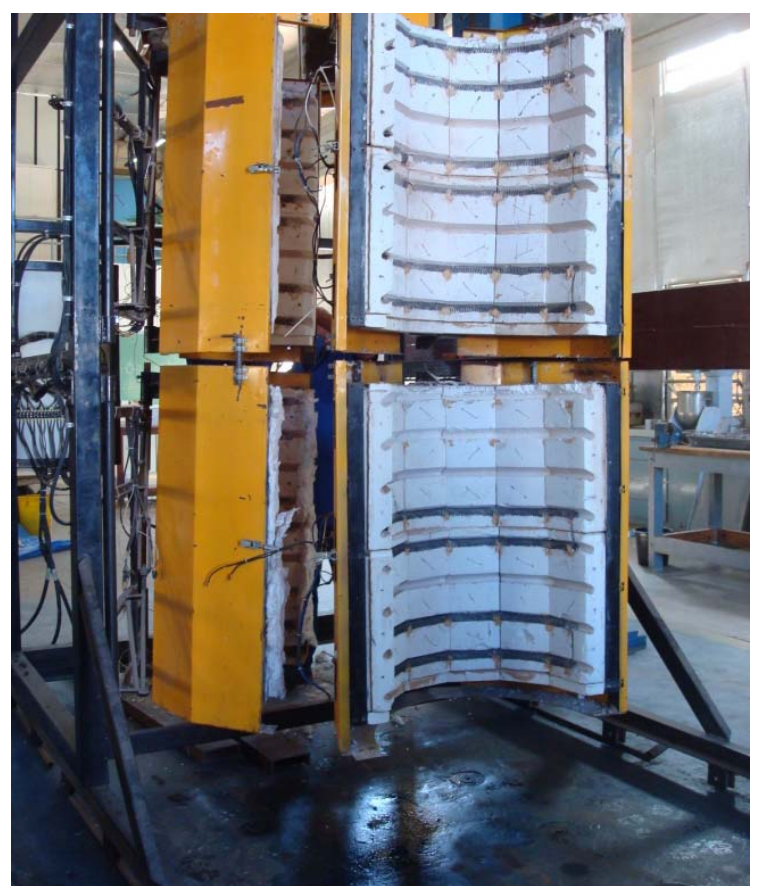

(a)

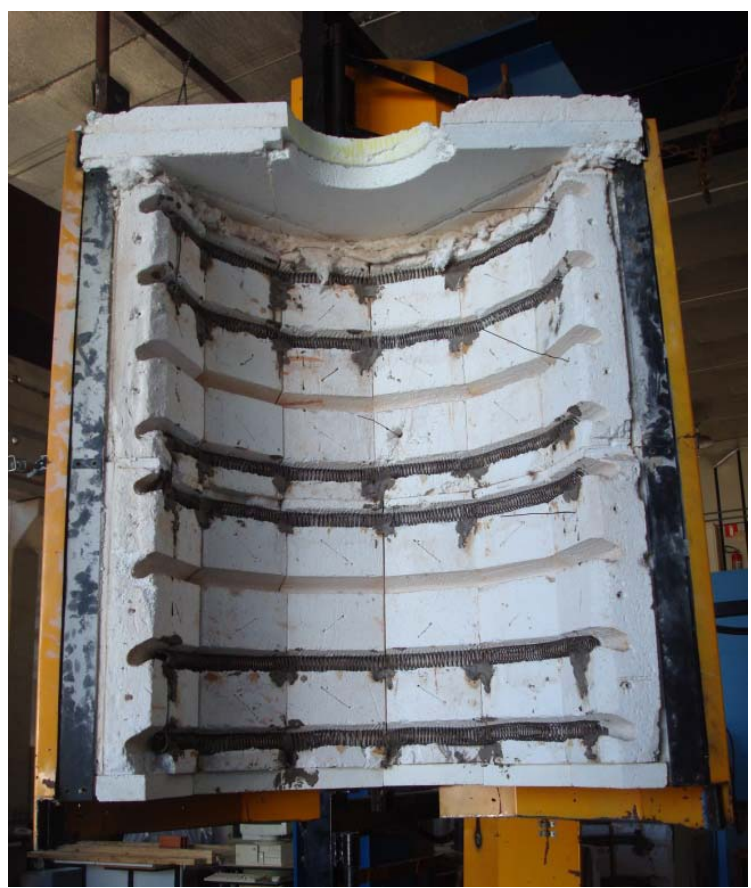

(b)

Figura 4.25: (a) Forno antes da vistoria, apenas com o revestimento lateral e (b) após a reforma, com os resistores e o revestimento cerâmico no topo. 


\subsubsection{Instrumentação}

As respostas de interesse nas análises termoestruturais realizadas são campo térmico e deslocamento em função do tempo de aquecimento. Para a obtenção da temperatura, foram utilizados cabos termopares do tipo K com as seguintes características:

- a composição deste dispositivo de medida consiste de dois fios, ou seja, o Cromel, como termoelemento positivo e Alumel, como termoelemento negativo. Tais termoelementos são formados por duas ligas metálicas, cromo - níquel e alumínio - níquel, respectivamente;

- o diâmetro dos fios é igual a $20 \mathrm{AWG}$, equivalente a 0,81 mm, o que permite uma temperatura máxima de leitura igual a $980{ }^{\circ} \mathrm{C}$. Essa unidade de medida, cuja definição é American Wire Gauge, é usada para a padronização de fios e cabos elétricos;

- revestimento do cabo termopar em fibra cerâmica, que resiste a uma temperatura de até $600{ }^{\circ} \mathrm{C}$ em ensaios dinâmicos. No caso dos ensaios apresentados no presente trabalho, o campo térmico é superior a este limite, mas, devido à condição de ensaio estático, não houve desgaste significativo no revestimento cerâmico.

Os termopares foram posicionados em três seções transversais, com distância igual a $35 \mathrm{~cm}$ entre cada uma. Em cada seção transversal, foram instalados três termopares, conforme ilustra a figura 4.26 para as seções transversais I enrijecido e caixão, respectivamente. Os termopares foram conectados às barras por meio de uma máquina de solda específica para esta finalidade. A unidade de solda para termopares, fabricada pela Stork, está ilustrada na figura 4.27 .

Foram utilizados três sistemas de aquisição de dados para registro da temperatura. $\mathrm{O}$ primeiro é o sistema de aquisição próprio para a leitura dos cabos termopares, desenvolvido pela National Instruments. Este sistema possui sete canais de leitura, com registro de dados a cada dez segundos. O segundo sistema é o que controla o forno, denominado Flycon 2.0 e desenvolvido pelo próprio fabricante do equipamento. Esse aplicativo de controle registra tanto a curva "tempo $x$ temperatura" implementada pelo usuário como a curva "tempo $x$ temperatura" fornecida pelo forno. Essa última leitura é feita por meio de um termopar de controle central, instalado no forno, com frequência de registro de dez segundos. 

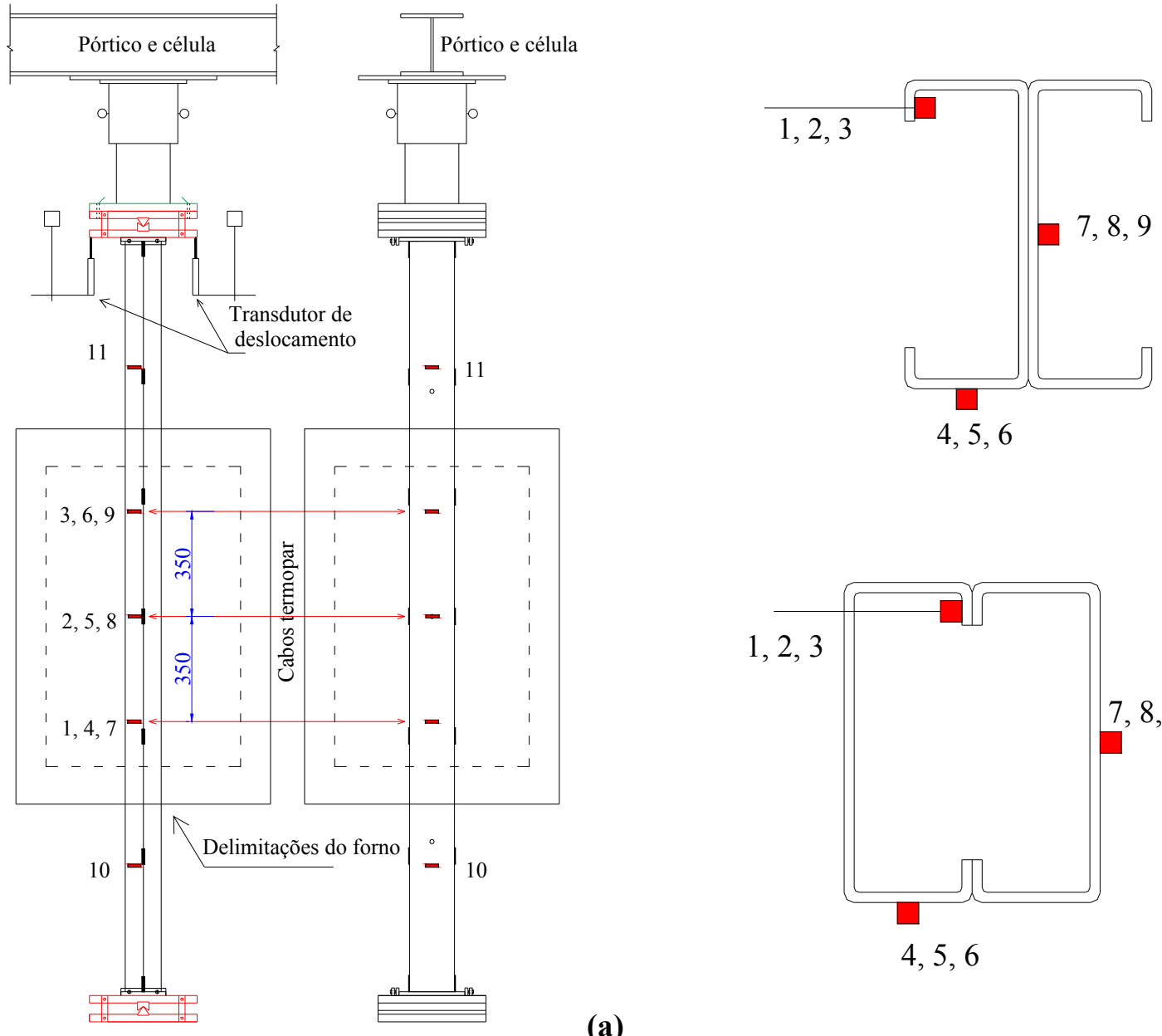

$4,5,6$

(b)

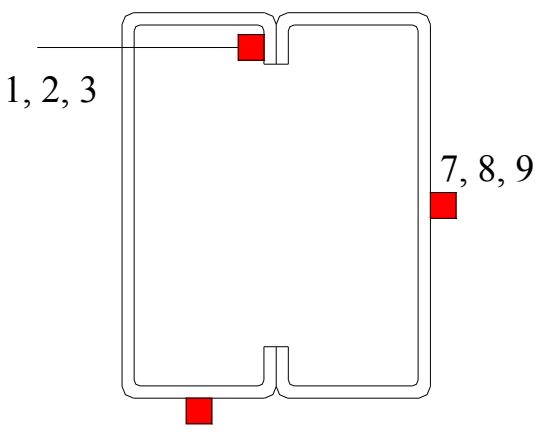

$4,5,6$

(c)

(a)

Figura 4.26: Pontos de medida da temperatura (a) na barra, (b) no perfil I enrijecido e (c) no perfil caixão.

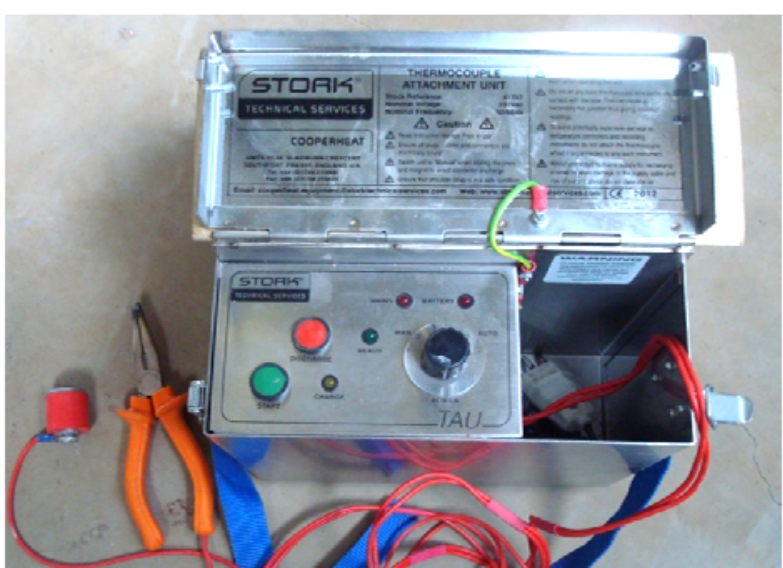

(a)

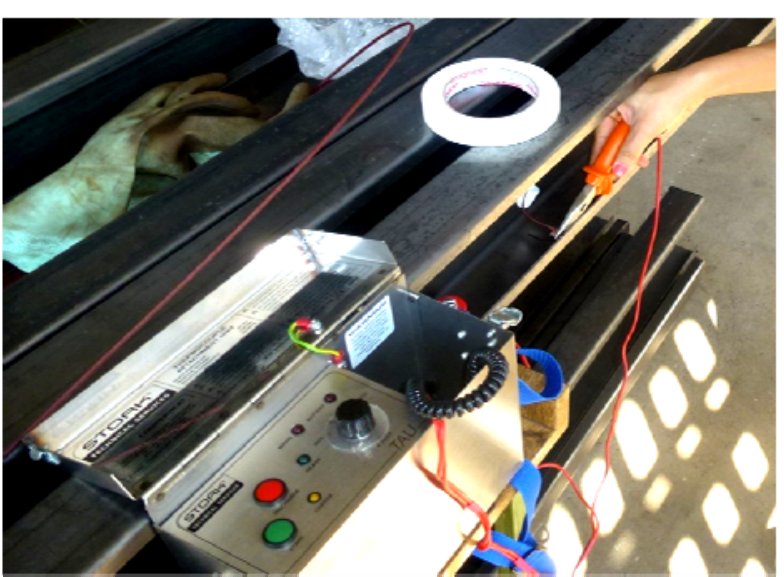

(b)

Figura 4.27: (a) Unidade de solda para cabos; (b) manuseio da máquina.

Observou-se, então que foi necessário trabalhar com quatro sistemas de aquisição de dados independentes, três para registro do campo térmico e um para registro da força e deslocamentos. A complexidade em interpretar cada arquivo de resultados implicou na elaboração de um código por meio da Linguagem de Programação Python capaz de 
sincronizar todos os arquivos de resultados gerados e apresentá-los em um único arquivo, a conter temperatura, deslocamento axial e força aplicada em função do tempo.

\subsubsection{Preparação do ensaio}

$\mathrm{Na}$ preparação da etapa térmica do ensaio, ao fechar o forno, foram aplicadas as mantas de fibra cerâmica em todas as frestas de forma a garantir que não houvesse fuga de calor. Além de garantir o isolamento, tal procedimento é importante também para proteger a estrutura e a instrumentação externa, ou seja, pórtico de reação, cilindro hidráulico, célula de carga e transdutores de deslocamento que se encontram próximos à fonte de calor. As figuras 4.28 (a) e (b) ilustram as etapas de preparação do ensaio.

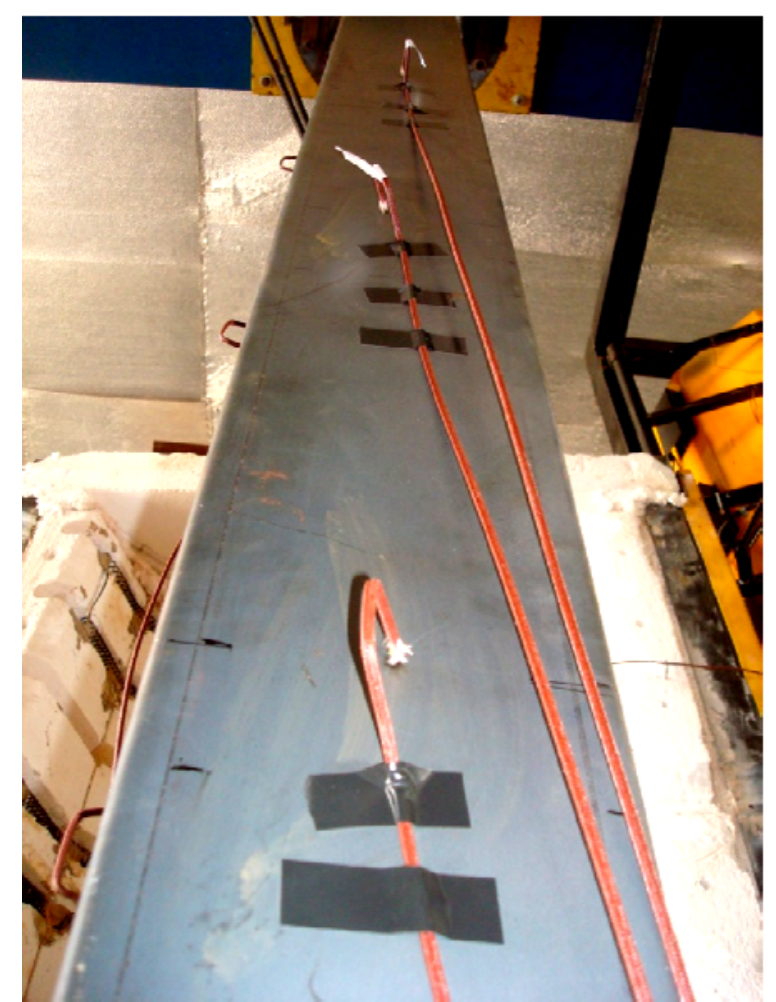

(a)

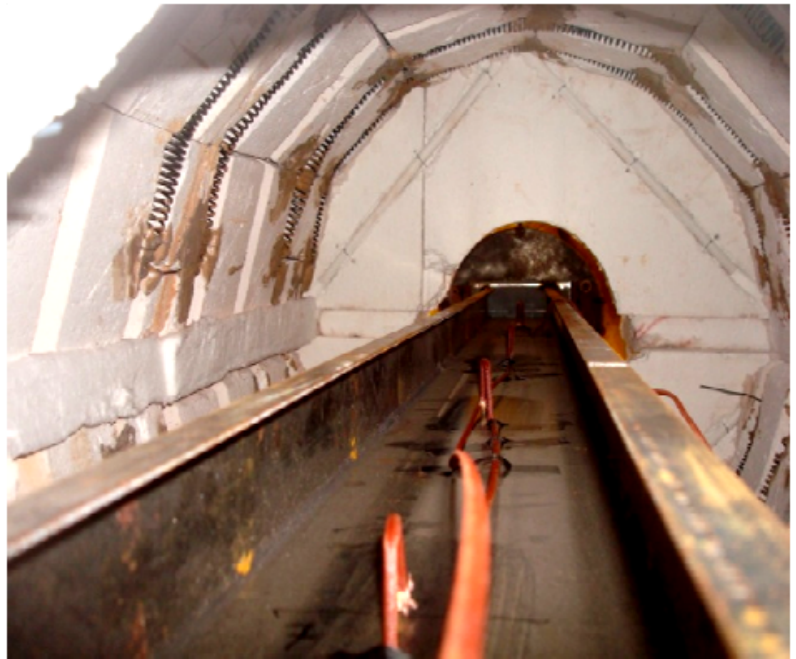

(b)

Figura 4.28: (a) Fixação dos termopares; (b) posição do pilar dentro do forno.

\subsubsection{Execução do ensaio}

O procedimento de ensaio, que segue as prescrições da norma ISO 834-1:1999 - Fire Resistance Tests - Elements of Buildings Construction - Part 1: General Requirements, pode ser descrito das etapas que se seguem: 
- A compressão axial foi aplicada a até um nível de carregamento determinado e mantido constante. No presente trabalho, foram aplicadas ações de compressão cujas magnitudes correspondem a $40 \%$ e a $70 \%$ da força de compressão máxima obtida nos ensaios à temperatura ambiente;

- É aplicada a ação térmica, de acordo com a curva de incêndio-padrão definida pela equação 4.1, da norma ISO 834-1:1999.

$$
\theta=345 \cdot \log _{10}(8 \cdot t+1)+20
$$

Nessa equação, a variável $\theta$ é a temperatura dos gases, em ${ }^{\circ} \mathrm{C}$, após decorrido um tempo $t$, em minutos.

Durante a fase de aplicação da ação térmica, com a compressão mantida constante, o perfil apresenta deformações térmicas de dilatação, portanto um deslocamento ascendente, a até uma determinada temperatura. Após atingir o patamar de deformação, o perfil, cujo material já apresenta redução da sua resistência mecânica devida ao aquecimento, gradualmente perde a capacidade de suportar a compressão aplicada. Ocorre então uma inversão no deslocamento axial, que passa a ser no sentido descendente, seguido de uma queda brusca da força aplicada. Esses dois fatores, que são a inversão do deslocamento axial e a queda da força mantida pelo cilindro hidráulico, caracterizou o colapso da barra.

De um modo geral, esse critério de parada adotado para os ensaios à compressão foi determinado por possíveis riscos à segurança da equipe técnica e à integridade aos equipamentos. A norma ISO 834-1:1999 por exemplo, estabelece, também por razões de segurança, que a barra em um ensaio à compressão atinge a condição de colapso quando ambos os critérios citados a seguir são alcançados, em que $\boldsymbol{h}$ é a altura inicial do perfil em milímetros:

- deformação axial de contração (em milímetros): $C=\frac{h}{100}[\mathrm{~mm}]$

- taxa de deformação axial de contração: $\frac{d C}{d t}=\frac{3 \cdot h}{1000}[\mathrm{~mm} / \mathrm{min}]$

Embora se conheça esses critérios de parada estabelecidos pela ISO 834-1:1999, não foi possível seguir tais recomendações, pois o sistema de aquisição monitora e registra o 
deslocamento axial, mas não a taxa de deslocamento. Dessa forma, foi considerado como término do ensaio a queda brusca da força de compressão aplicada (que deve ser mantida constante durante o ensaio). As figuras 4.29 e 4.30 ilustram o modo de falha do perfil ao fim do ensaio.

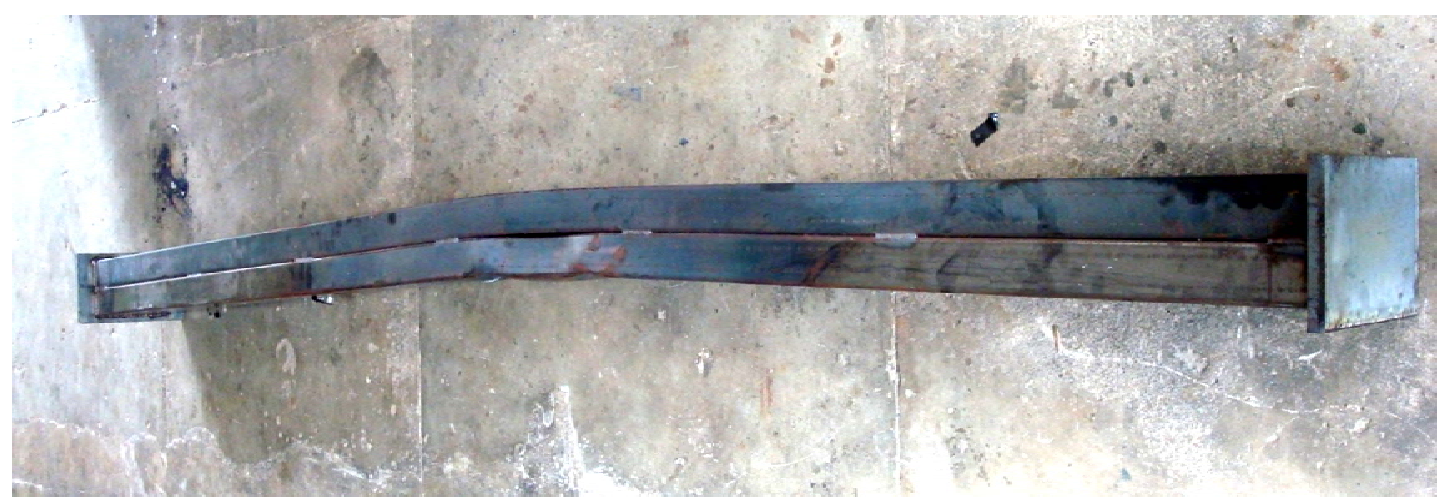

Figura 4.29: Configuração deformada do perfil caixão após o ensaio termoestrutural.

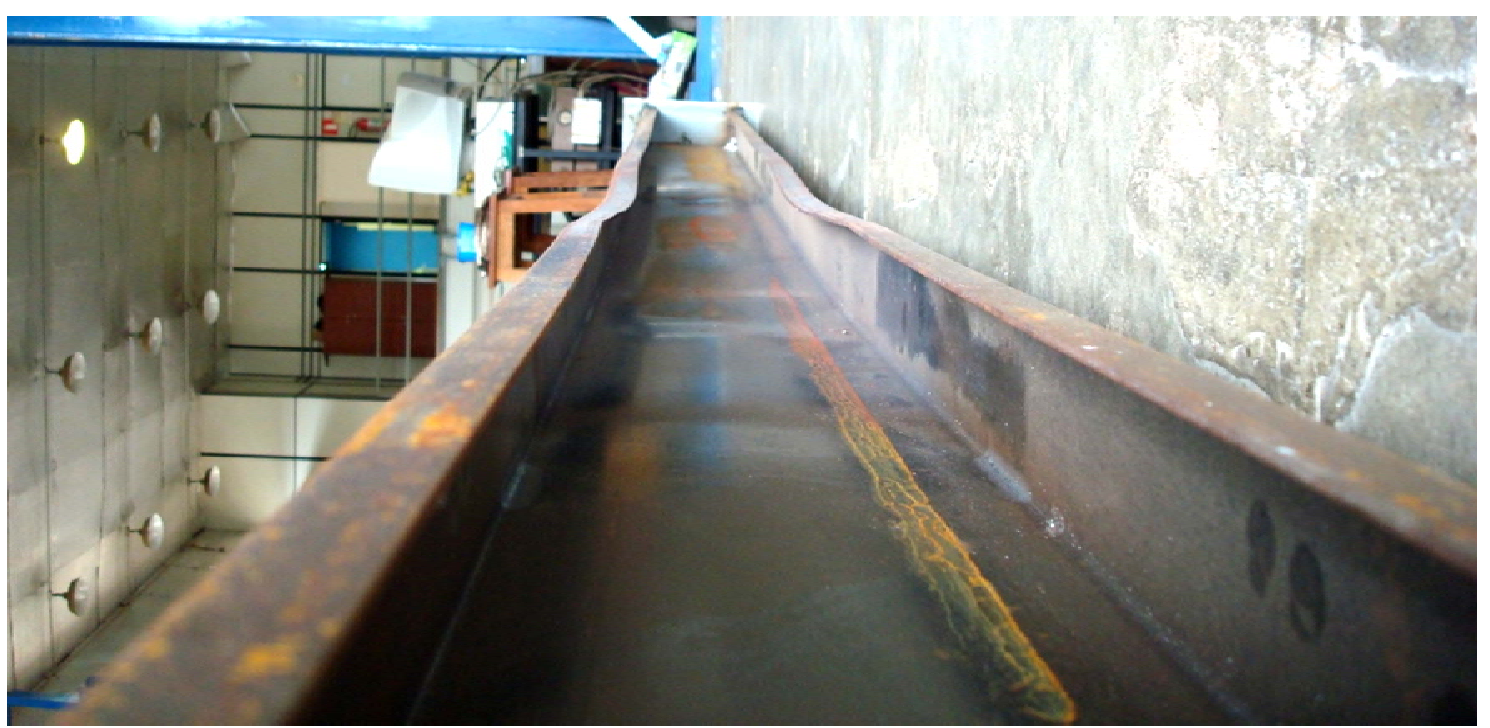

Figura 4.30: Deformações nos elementos do perfil I enrijecido após o ensaio termoestrutural.

\subsubsection{Resultados dos ensaios realizados em temperaturas elevadas.}

Com relação aos ensaios realizados em temperaturas elevadas, a discussão dos resultados foi dividida em duas partes, como seguem.

\subsubsection{Campo térmico}

A figura 4.31 ilustra a variação da temperatura na seção transversal I enrijecido na posição L/2 do comprimento do perfil. As temperaturas obtidas na mesa, alma e enrijecedor apresentaram uma pequena diferença entre si, porém, em termos práticos, essa diferença não 
implica em uma redução de esforços resistentes mais acentuados em um elemento em comparação aos demais na seção transversal.

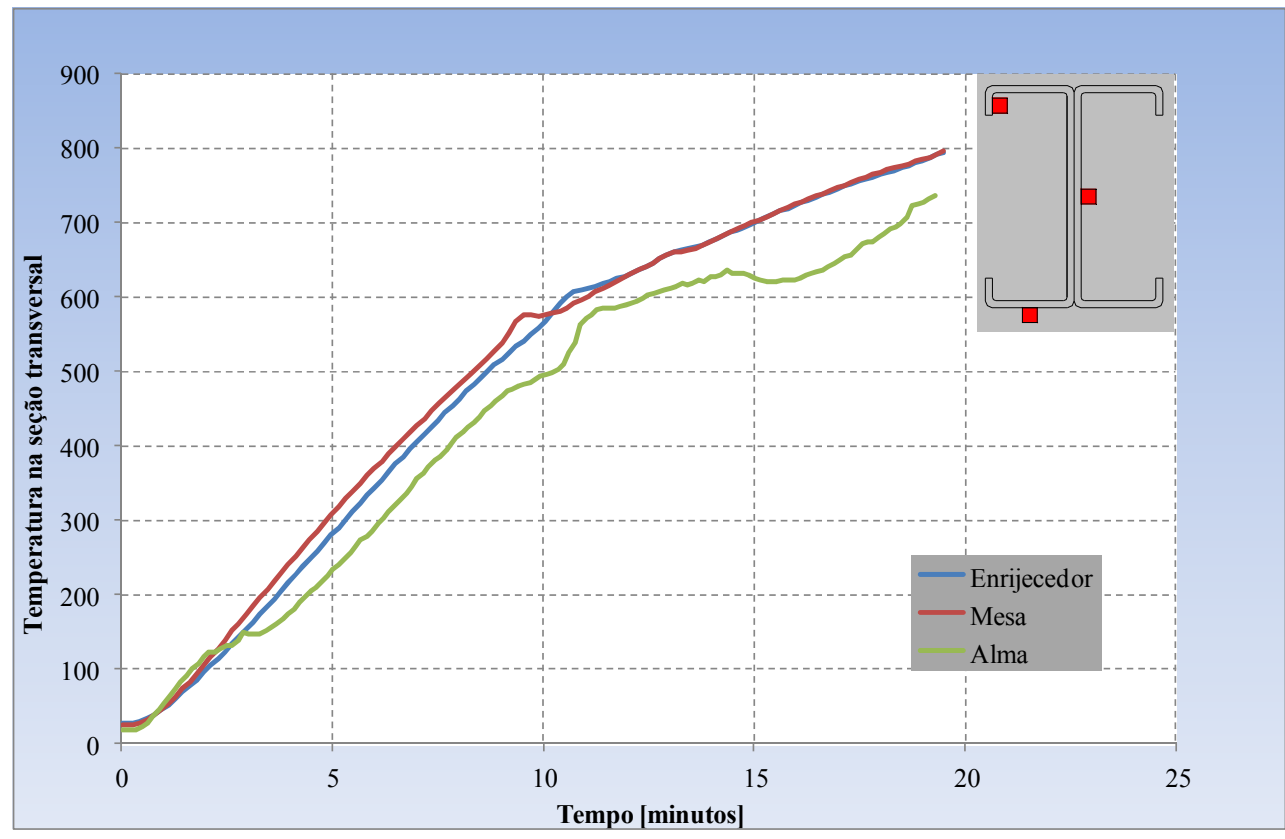

Figura 4.31: Campo térmico no perfil I enrijecido.

$\mathrm{Na}$ seção transversal do tipo caixão, o campo térmico foi tomado na mesa, alma e, internamente, no enrijecedor. As curvas "tempo $x$ temperatura" dos pontos medidos estão ilustrados na figura 4.32, para a seção transversal localizada no comprimento L/2 da barra.

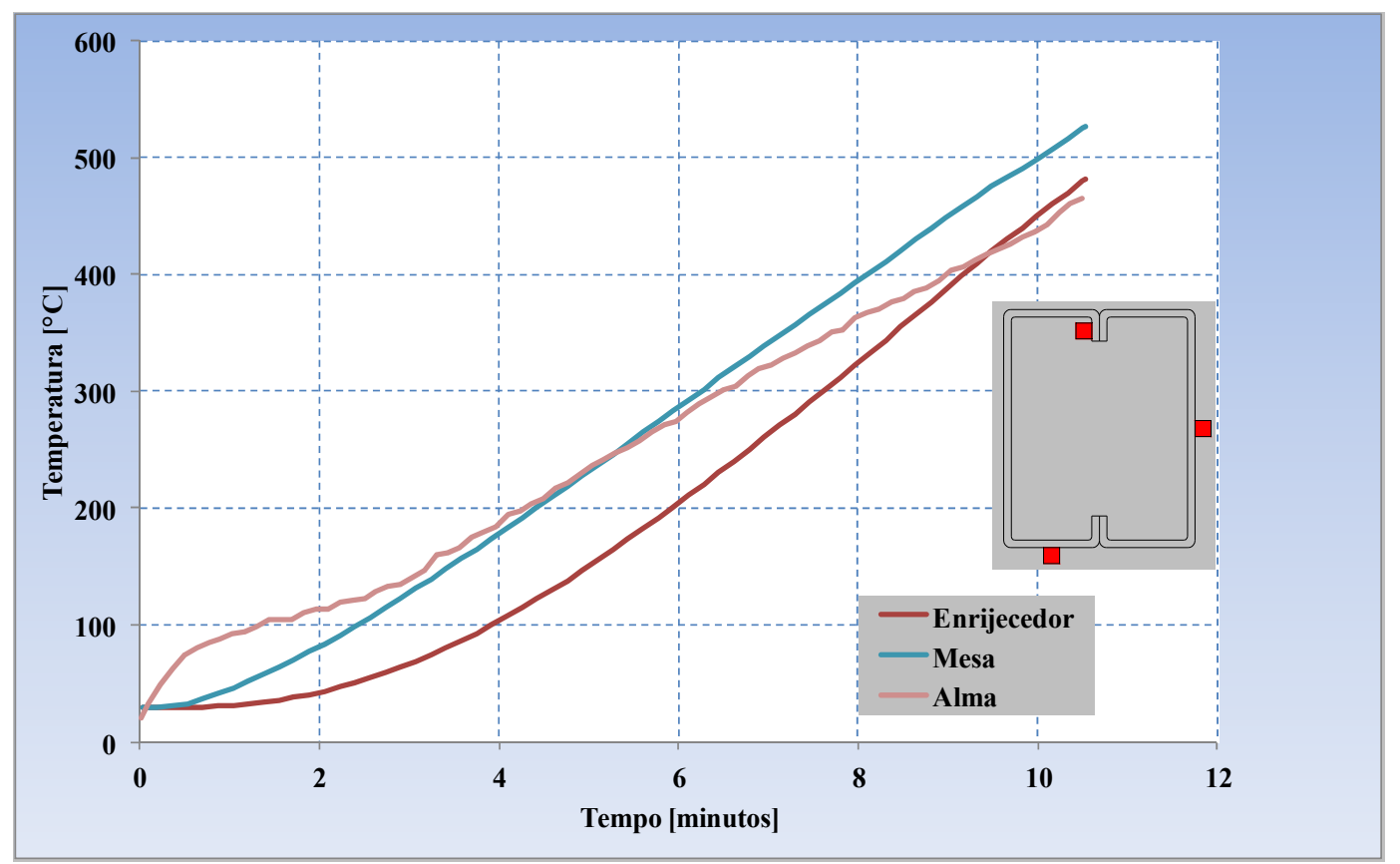

Figura 4.32: Campo térmico no perfil I enrijecido. 
Nos primeiros minutos de aquecimento, o enrijecedor, não exposto diretamente à ação térmica apresenta temperatura inferior aos demais elementos expostos. Ao final do ensaio, o gradiente de temperatura na seção transversal tende a uniformizar. Porém, no decorrer da elevação de temperatura, analogamente ao que aconteceu nos perfis I enrijecido, a diferença entre as temperaturas medidas nos três elementos, para questões práticas, não é representativa, de forma que, aparentemente, não foi considerado fator determinante para o colapso estrutural.

Também foi avaliada a distribuição da temperatura ao longo do perfil. A figura 4.33 ilustra a curvas "tempo $x$ temperatura" obtidas nos perfis I. Este campo térmico no comprimento foi obtido por meio das temperaturas tomadas em três seções transversais distantes $35 \mathrm{~cm}$ entre si e dois pontos externos, um abaixo e um acima do forno. A temperatura nas partes do perfil I enrijecido, externas ao forno, resultou em até $200{ }^{\circ} \mathrm{C}$. Nessa região, em que o ganho de temperatura ocorre apenas por condução, pode se considerar que o material não teve suas propriedades mecânicas penalizadas pela ação térmica.

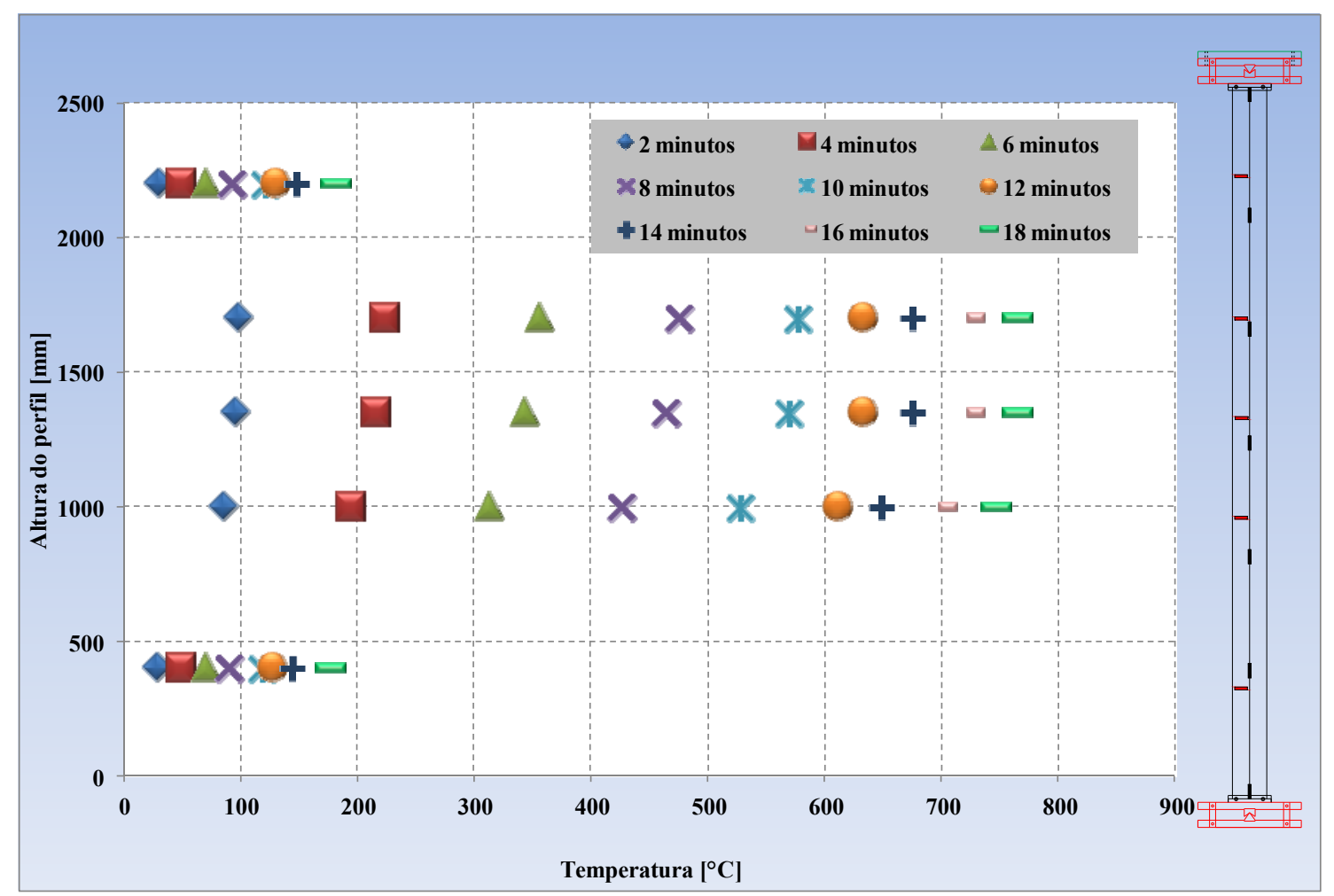

Figura 4.33: Distribuição da temperatura ao longo do perfil I enrijecido.

A figura 4.34 ilustra a mesma curva "tempo $x$ temperatura" ao longo do comprimento do perfil caixão. 


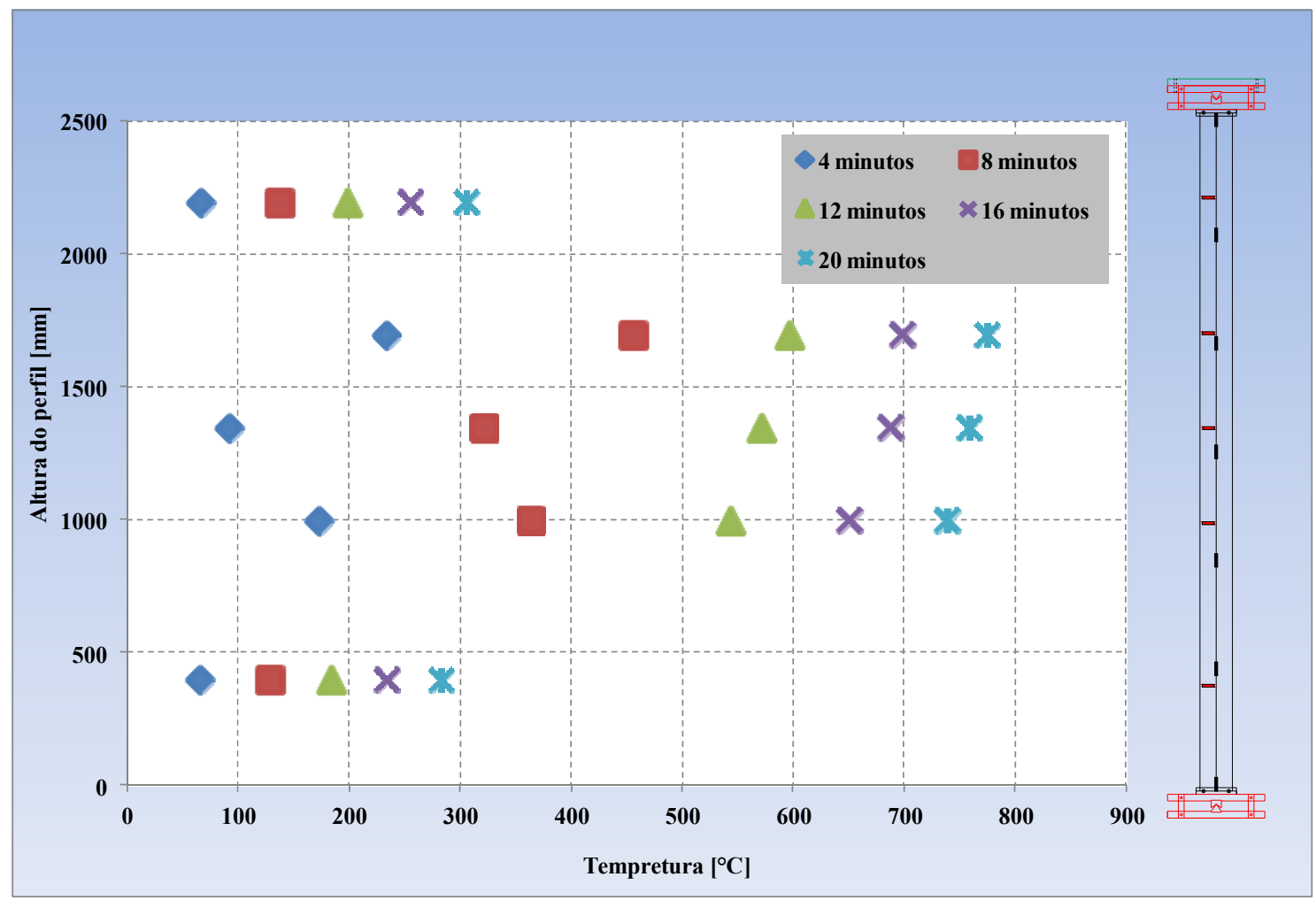

Figura 4.34: Distribuição da temperatura ao longo do perfil caixão.

Ao final do ensaio, a temperatura interna ao perfil caixão tomada fora dos limites do forno, medidos pelos termopares 10 e 11, chegaram a aproximadamente $300{ }^{\circ} \mathrm{C}$. Diferentemente do que foi observado nos perfis abertos, a temperatura externa ao forno medida no perfil caixão ao final do ensaio resultou suficiente para reduzir o módulo de elasticidade e a resistência ao escoamento do aço. Tal aquecimento é justificável pela sua própria geometria, que mantém os gases aquecidos no interior da sua cavidade. As figuras 4.35 e 4.36 comparam a taxa de aquecimento das barras. 


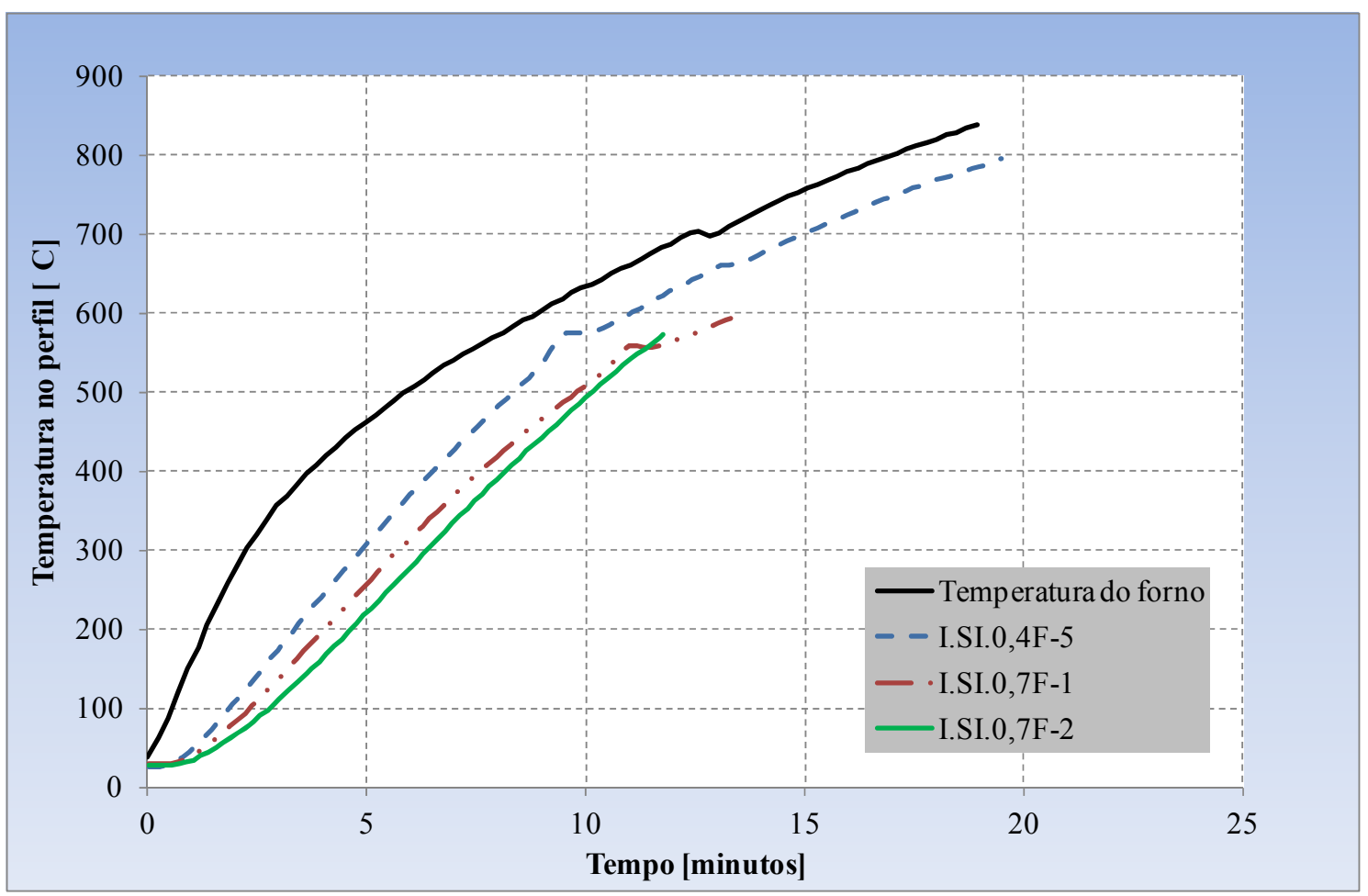

Figura 4.35: Campo térmico das barras de perfil I enrijecido durante a fase de aquecimento.

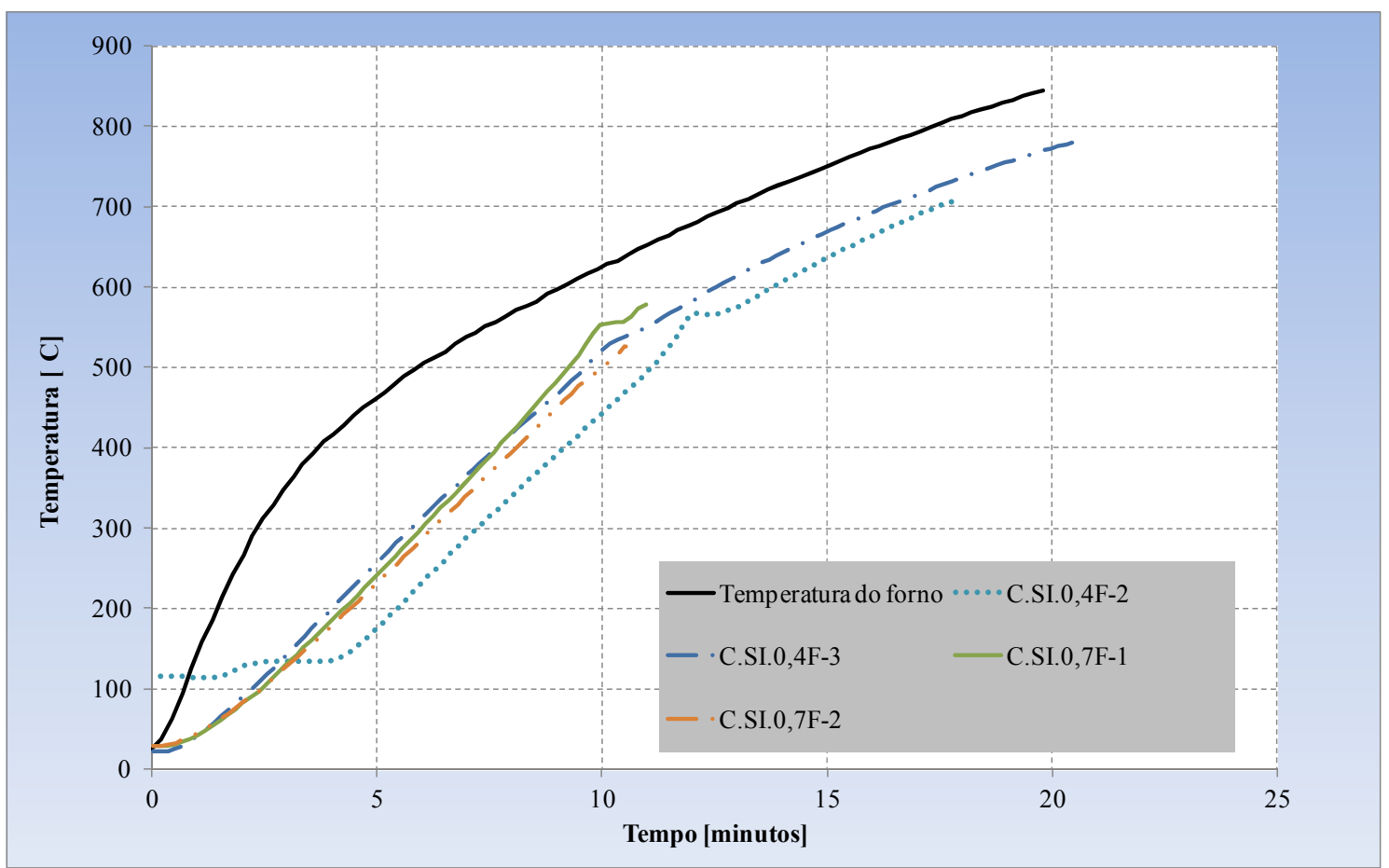

Figura 4.36: Campo térmico das barras de perfil caixão durante a fase de aquecimento

\subsubsection{Resultados referentes às análises termoestruturais}

O forno utilizado nos ensaios realizados em temperaturas elevadas não possui aberturas laterais que possibilitem acompanhar o comportamento estrutural da barra durante a fase de aquecimento. Porém, por ser tratar de perfis de baixa esbeltez global, e lembrando que o forno 
envolve apenas o trecho central, foi esperado que os modos de instabilidade se desenvolvessem de modo semelhante aos testes à temperatura ambiente.

Analogamente ao comportamento à temperatura ambiente, o perfil I enrijecido, ilustrado na figura 4.37, apresentou instabilidade local na alma de um dos perfis $U_{e}$. Na mesma região do perfil, foi observada instabilidade distorcional do conjunto mesa-enrijecerdor. Nos ensaios em situação de incêndio, a configuração deformada do perfil resultou em três comprimentos de meia onda relativos à instabilidade distorcional, figura 4.38, ao passo que à temperatura ambiente, apenas um comprimento de meia onda relativo à instabilidade local e à distorcional foram observados.

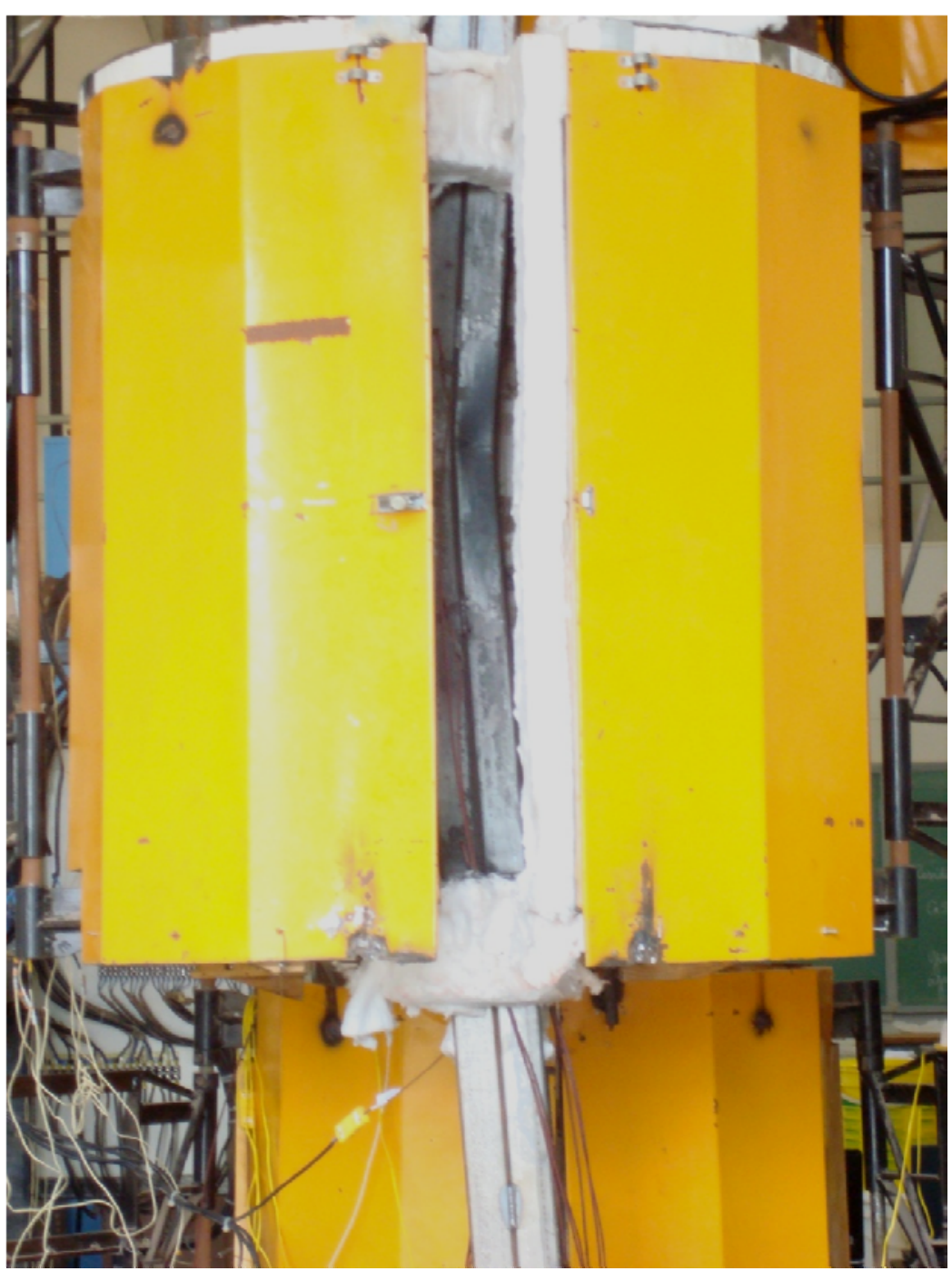

Figura 4.37: Configuração deformada do perfil I enrijecido 


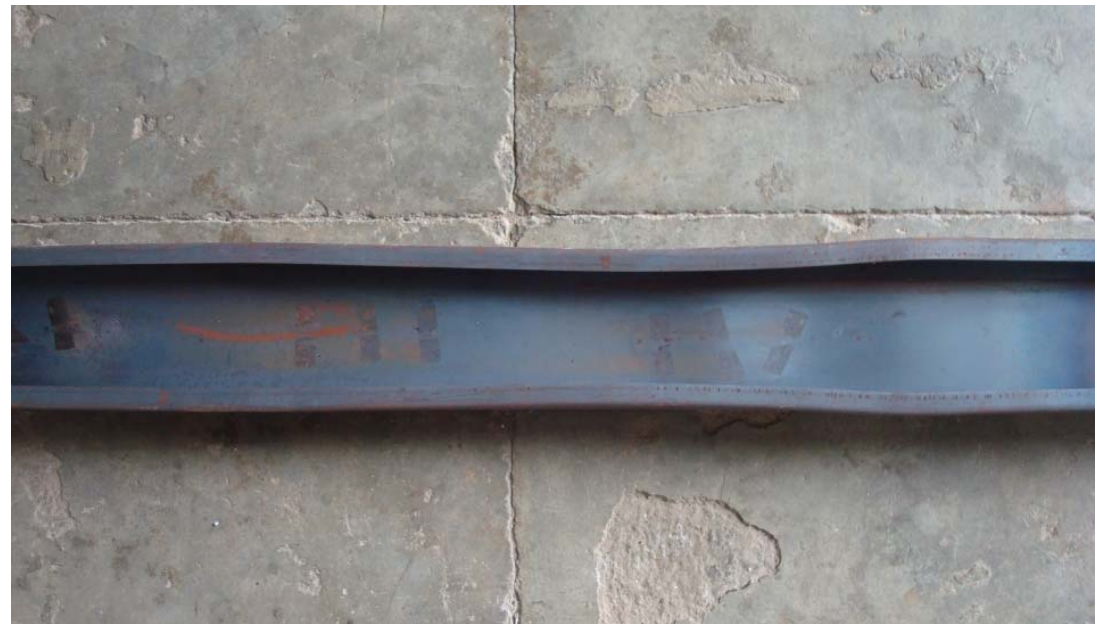

Figura 4.38: Detalhe da falha local na alma e distorcional no conjunto mesa enrijecedor.

O perfil caixão, ilustrado nas figuras 4.39 e 4.40, ao final do ensaio, apresentou um modo de falha distorcional no perfil $U_{e}$ comprimido, além do local já identificado nos ensaios à temperatura ambiente.

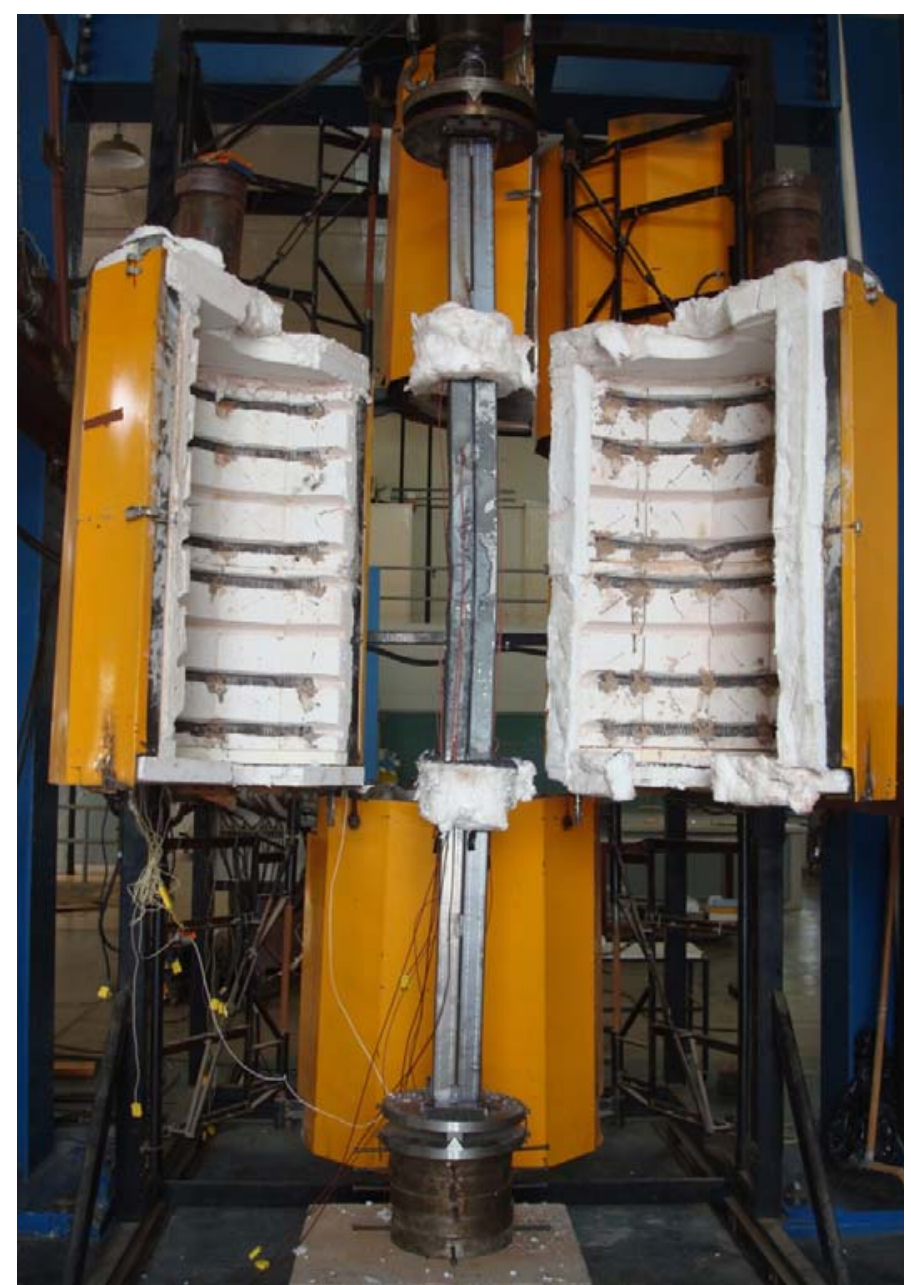

Figura 4.39: Configuração deformada do perfil caixão. 


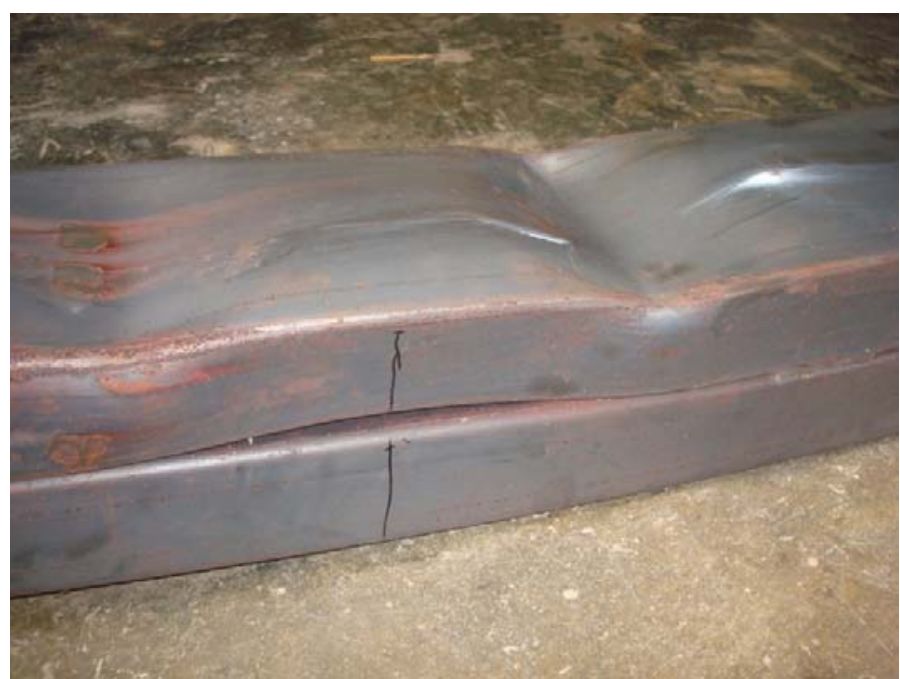

Figura 4.40: Detalhe da falha local na alma e na mesa, bem como o distorcional no conjunto mesa enrijecedor.

As tabelas 4.4 e 4.5 informam, resumidamente, o tempo a que as barras resistiram à ação térmica, a temperatura máxima correspondente ao colapso, a força de compressão aplicada e o modos de falha ao final do ensaio.

Tabela 4.5: Resultados referentes aos ensaios termoestruturais do perfil I enrijecido

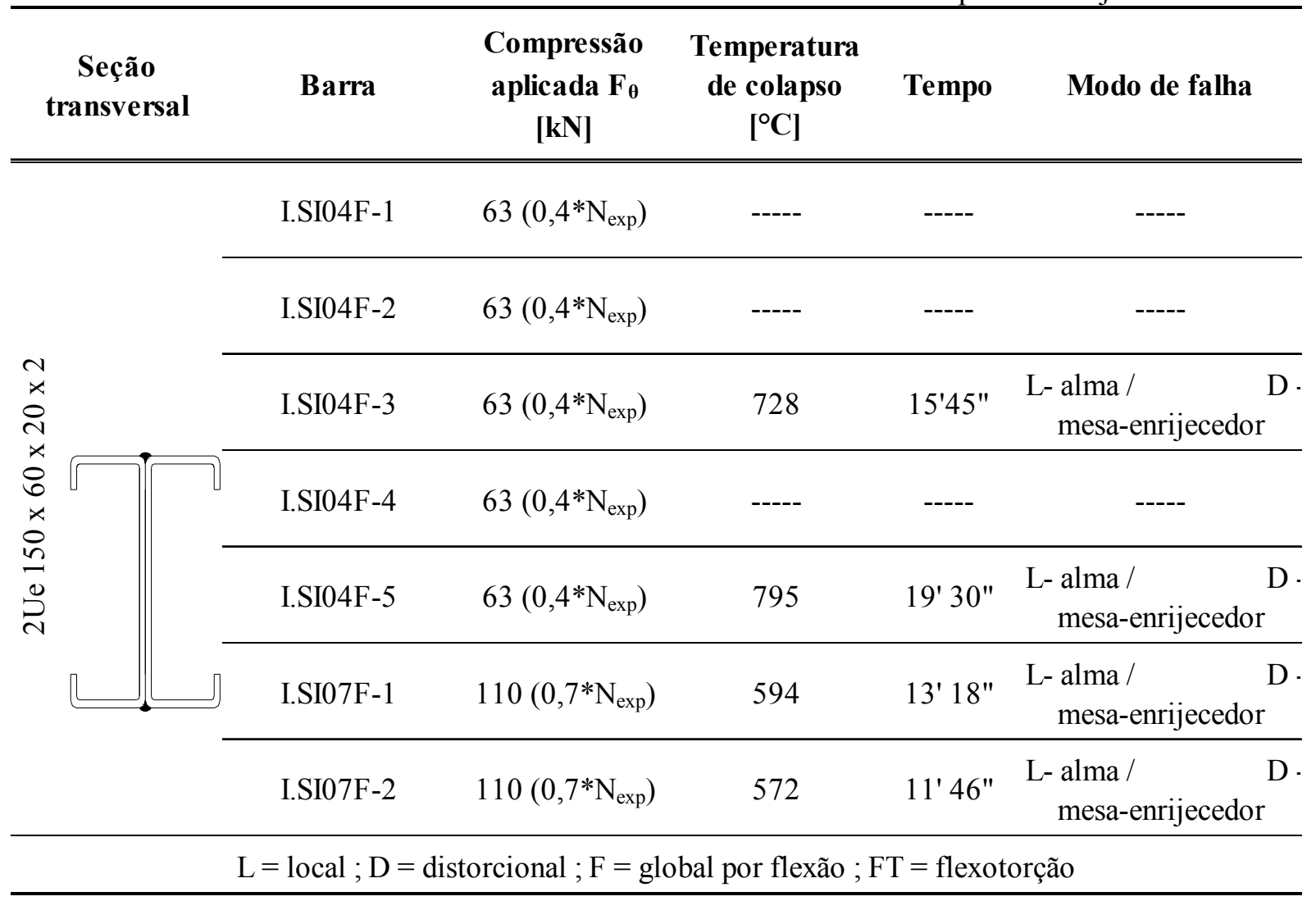


Tabela 4.4: Resultados referentes aos ensaios termoestruturais do perfil caixão

\begin{tabular}{|c|c|c|c|c|c|}
\hline $\begin{array}{c}\text { Seção } \\
\text { transversal }\end{array}$ & Barra & $\begin{array}{c}\text { Compressão } \\
\text { aplicada } F_{\theta} \\
{[k N]}\end{array}$ & $\begin{array}{c}\text { Temperatura } \\
\text { de colapso } \\
{\left[{ }^{\circ} \mathrm{C}\right]}\end{array}$ & Tempo & Modo de falha \\
\hline \multirow{4}{*}{ D. } & C.SI04F-1 & $75\left(0,4 * \mathrm{~N}_{\mathrm{exp}}\right)$ & ----- & ----- & ----- \\
\hline & C.SI04F-2 & $75\left(0,4 * \mathrm{~N}_{\exp }\right)$ & 707 & $18^{\prime} 09^{\prime \prime}$ & $\begin{array}{l}\text { L- alma e mesa / D } \\
\text {-mesa-enrijecedor }\end{array}$ \\
\hline & C.SI04F-3 & $75\left(0,4 * \mathrm{~N}_{\exp }\right)$ & 727 & $20^{\prime} 30^{\prime \prime}$ & $\begin{array}{l}\text { L- alma e mesa / D } \\
\text {-mesa-enrijecedor }\end{array}$ \\
\hline & C.SI07F-1 & $135\left(0,7 * \mathrm{~N}_{\exp }\right)$ & 579 & $11^{\prime}$ & $\begin{array}{l}\text { L- alma e mesa / } D \\
\text {-mesa-enrijecedor }\end{array}$ \\
\hline 的 & C.SI07F-2 & $135\left(0,7 * \mathrm{~N}_{\exp }\right)$ & 526 & $10^{\prime} 30^{\prime \prime}$ & $\begin{array}{l}\text { L- alma e mesa / D } \\
\text {-mesa-enrijecedor }\end{array}$ \\
\hline
\end{tabular}

Do total de ensaios, quatro foram invalidados. Em três deles (barras I.SI.04F-1, I.SI.04F-2, C.SI.04F-1), a velocidade de aquecimento não atendeu à curva de incêndio padrão. O quarto ensaio invalidado (I.SI.04F-4) apresentou problemas em um dos sistemas de aquisição.

No que tange ao caráter estrutural, a ação térmica aplicada no trecho central das barras implica em maior redução da resistência mecânica dessa região em comparação às regiões externas ao forno. Isso implica numa análise à compressão em barras cujas características mecânicas são diferentes ao longo do comprimento. As deformações de dilatação são correspondentes ao trecho central principalmente, por ser gradativamente aquecido.

As figuras 4.41 e 4.42 se referem às curvas "deslocamento axial x temperatura" do perfil I enrijecido e caixão, respectivamente. Em relação às deformações, o colapso por instabilidade das barras ocorreu repentinamente, de forma que seu comportamento estrutural após atingir a compressão máxima é caracterizado por uma inversão brusca do deslocamento axial. 


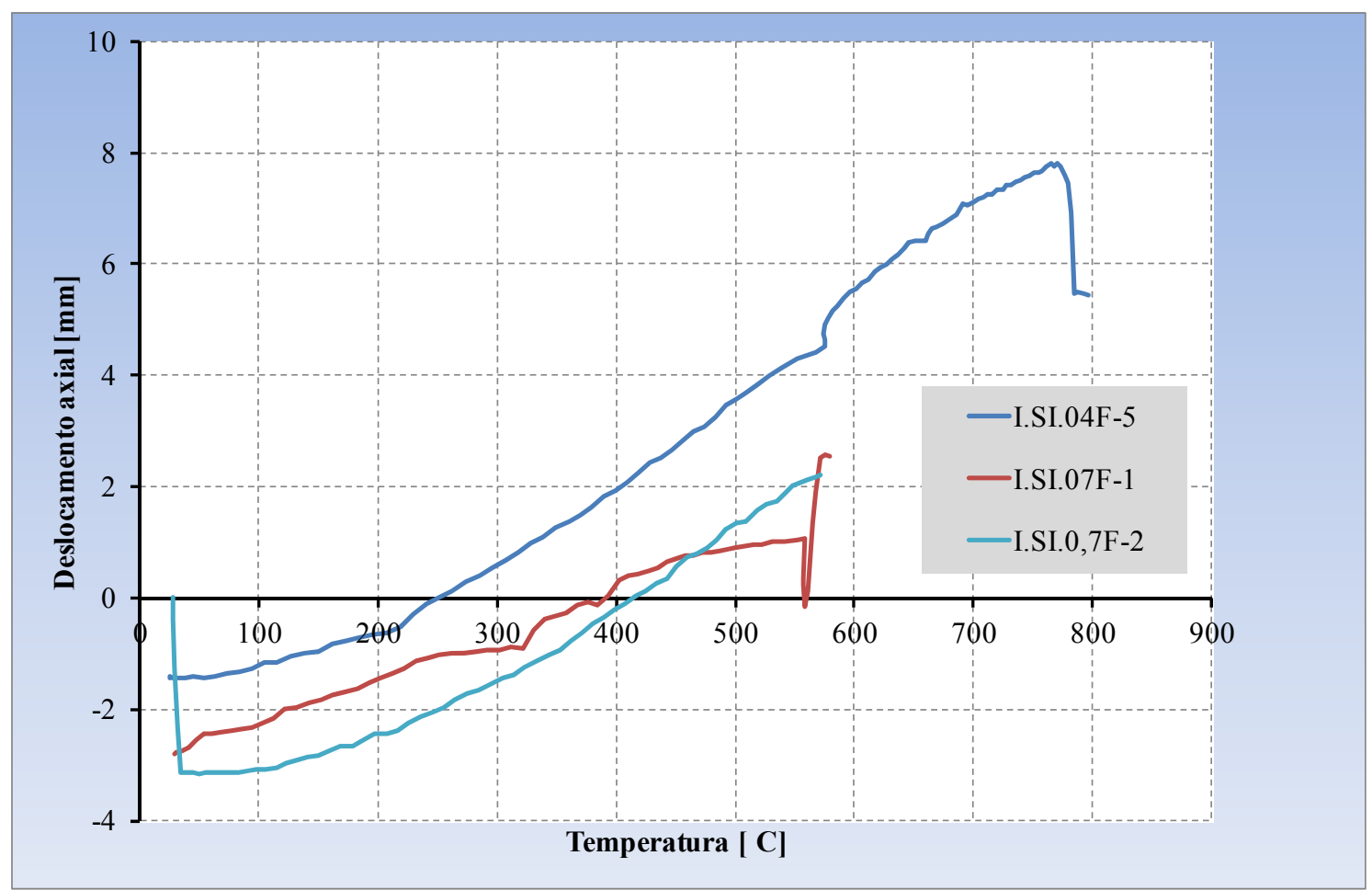

Figura 4.41: Deslocamento axial do perfil I enrijecido em função da temperatura máxima nele registrada, para cada nível de carregamento.

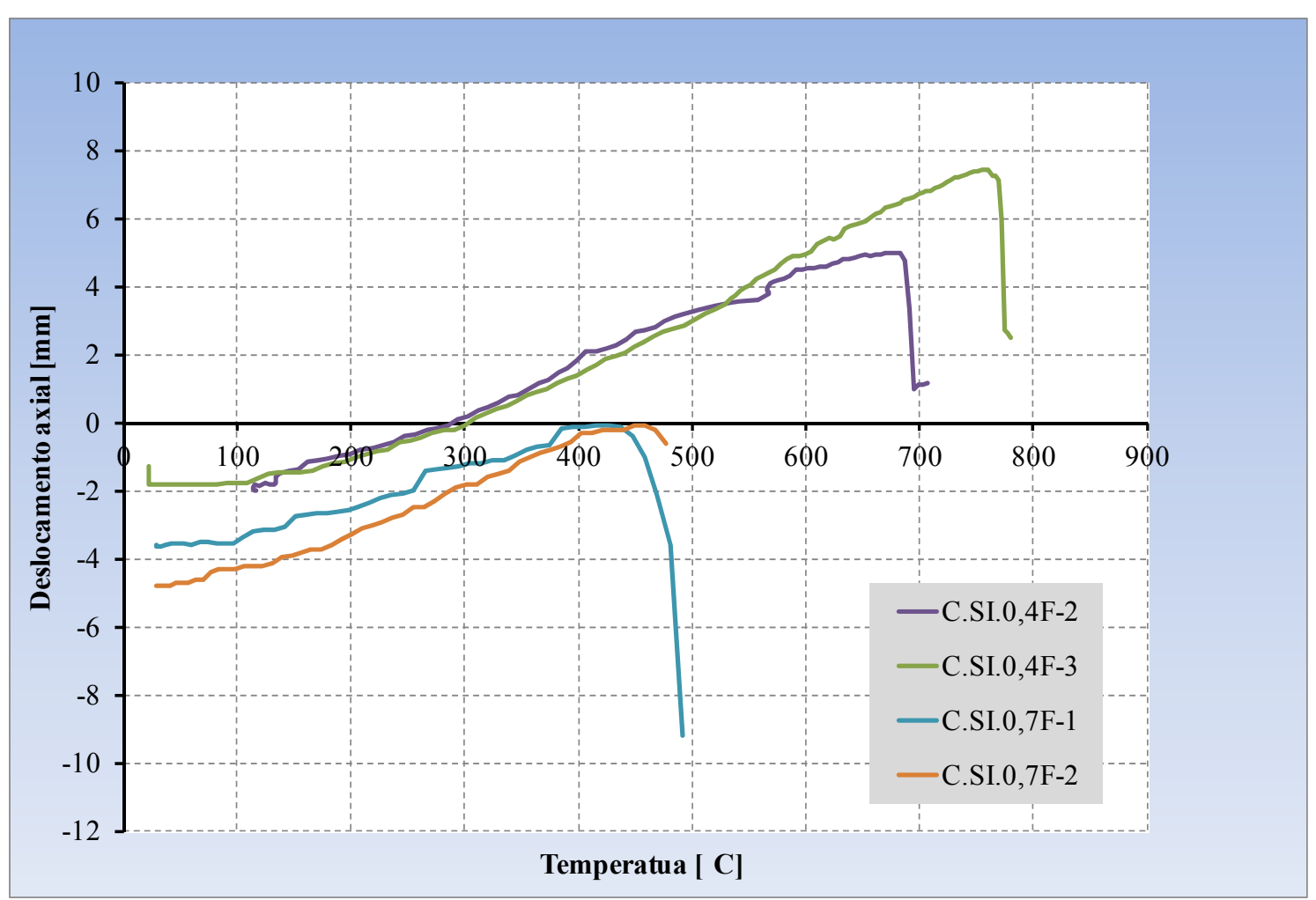

Figura 4.42: Deslocamento axial do perfil caixão em função da temperatura máxima nele registrada, para cada nível de carregamento.

Com base nas análises experimentais, à temperatura ambiente e em temperaturas elevadas, descritas no presente capítulo, ficaram evidente algumas características dos ensaios 
em temperaturas elevadas, a citar a complexidade adicional em sincronizar diferentes arquivos de saída de dados, o alto custo energético para que o forno seja capaz de atender a taxa de aquecimento requerida e o tempo de duração de ensaio que, entre a preparação até o resfriamento do forno, é de 24 horas no mínimo.

Dessa forma, entendeu-se como necessário a elaboração de uma análise numérica, que seja validada por meio do trabalho experimental aqui apresentado. Tal análise numérica, a ser apresentada no capítulo seguinte, será interessante para análises paramétricas, que é sugerida como trabalhos futuros. 


\section{ANÁLISE NUMÉRICA}

O presente capítulo descreve a metodologia para construção dos modelos numéricos para análise termoestrutural de forma a representar o comportamento obtido dos ensaios apresentados no capítulo anterior. A análise numérica foi realizada em campo tridimensional, utilizando o pacote computacional ANSYS v.12.1, o qual é formulado com base no Método dos Elementos Finitos.

A estratégia numérica adotada consiste em um acoplamento entre duas análises independentes, que são a térmica e a estrutural. Esse método já é consolidado em outros trabalhos, a citar Regobello (2007) e Dorr (2010). A simulação numérica desenvolvida por esse método é apresentada em quatro etapas.

A primeira etapa é referente à elaboração da análise térmica, em que, no elemento isolado é aplicada a ação térmica de acordo com aquela obtida no programa experimental. Por meio dessa análise, são obtidas as temperaturas no modelo de interesse, que são importantes para fins de aplicação em análise termoestrutural a ser realizada posteriormente.

A segunda etapa consiste de análise estrutural dos modos de instabilidade, já apresentada em outros trabalhos, como em Almeida (2007), Kimura (2009), Leal (2011) e Maia (2012), feita por meio da análise de autovalor, que permite determinar os modos de instabilidade elástica para uma determinada força crítica elástica.

A terceira etapa é direcionada à análise estrutural estática, à temperatura ambiente, considerando a barra com sua geometria imperfeita, além da não linearidade física do material, a fim de se determinar a força última de colapso por compressão.

A última etapa se trata da análise estrutural, que é realizada considerando a variação da temperatura na barra por meio do acoplamento das respostas obtidas na análise térmica.

Os modelos estruturais propostos para estudo no presente trabalho possuem a nomenclatura, conforme tabela 5.1, cuja geometria já foi apresentada no item 4.1. 
Tabela 5.1: Modelos numéricos elaborados

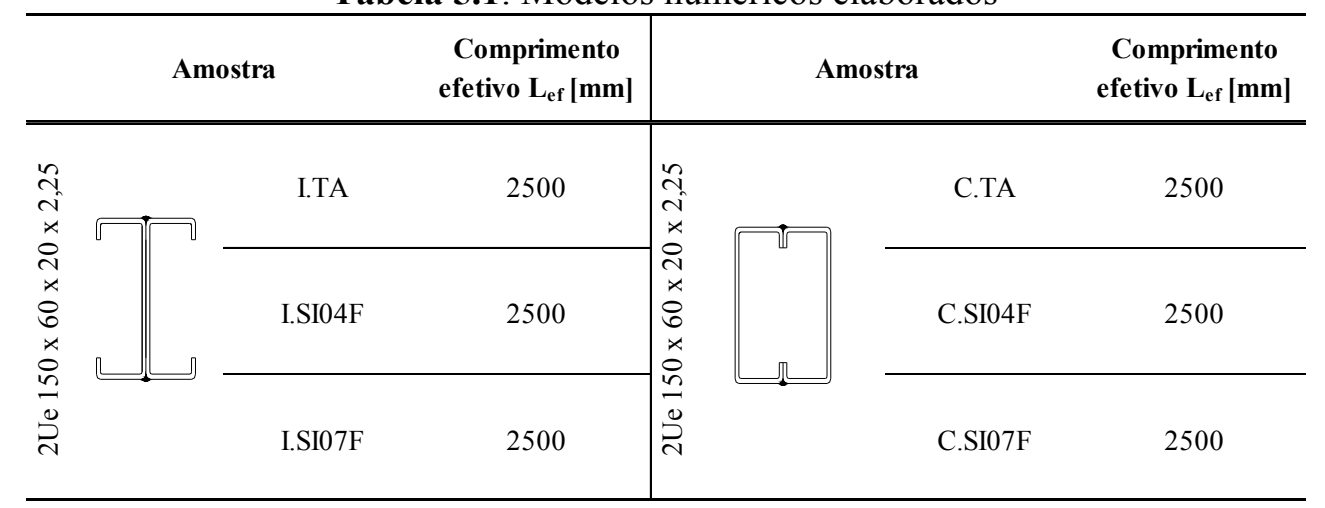

Os itens seguintes descrevem as etapas da análise numérica relacionada ao problema dos perfis formados a frio. A apresentação da análise numérica foi dividida em dois itens, que descrevem separadamente o modelo térmico e o modelo acoplado termoestrutural.

\subsection{Considerações referentes à Análise térmica}

O objetivo da análise térmica é obter a temperatura no material, nesse caso o perfil de aço quando sujeito a um campo térmico. Essa análise é caracterizada como transiente, pois, tanto a ação térmica quanto a resposta obtida, ou seja, a temperatura na superfície do perfil de aço são variáveis em função do tempo.

Para que fosse possível desenvolver essa análise, foi necessário fornecer, como parâmetros do problema, além da temperatura variável no tempo, as propriedades térmicas do material como variáveis em função da temperatura. Os subitens seguintes descrevem os procedimentos para desenvolver a simulação do campo térmico no perfil formado a frio.

\subsubsection{Elementos finitos da analise térmica}

De forma semelhante à estratégia numérica proposta em Dorr (2010), para a construção dos modelos representativos dos pilares de interesse, foi utilizado o elemento finito de casca SHELL 131, constituído de quatro nós, ilustrado na figura 5.1. A quantidade de graus de liberdade depende do número de camadas, também denominadas layers, definido como dado de entrada, podendo variar de um a 32. Para cada camada podem ser definidas a espessura, o ângulo de disposição e as propriedades do material. Na análise numérica 
apresentada neste trabalho, devido à pequena espessura do perfil, foi suficiente adotar duas camadas.

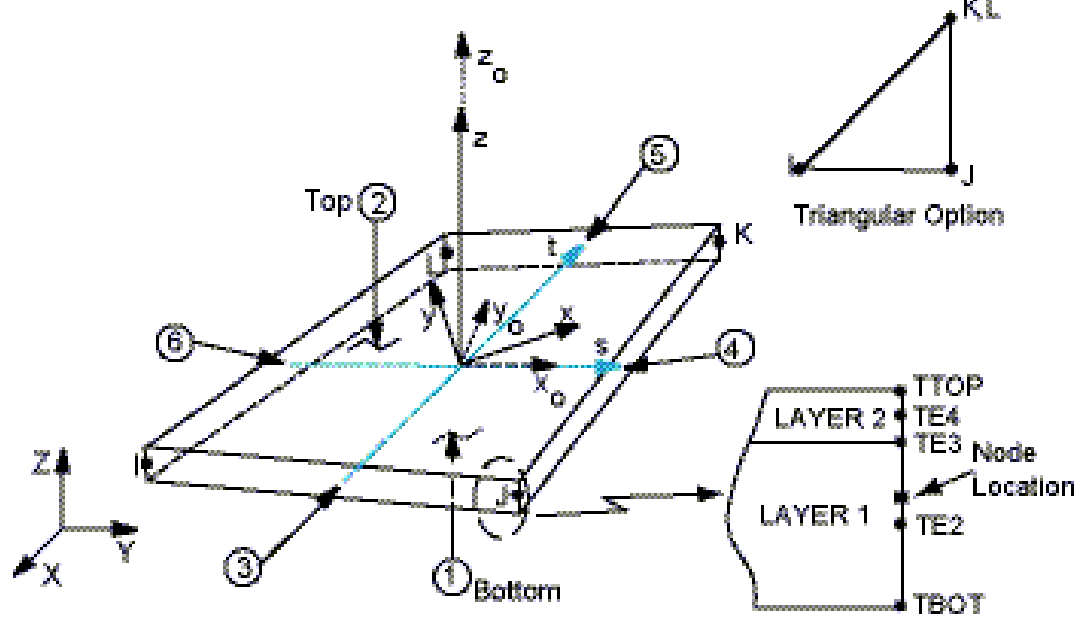

Figura 5.1: Elemento finito SHELL131, utilizado na construção do perfil de aço em análises térmicas.

A troca de calor com o ambiente ocorre com auxílio do elemento finito SURF152, o qual é implementado para consideração dos mecanismos de troca de calor de convecção e de radiação. Nessa análise numérica, esse elemento finito é definido por quatro nós e um nó extra de controle em que se aplica a ação térmica. A figura 5.2 ilustra a geometria e a locação dos nós do SURF152.

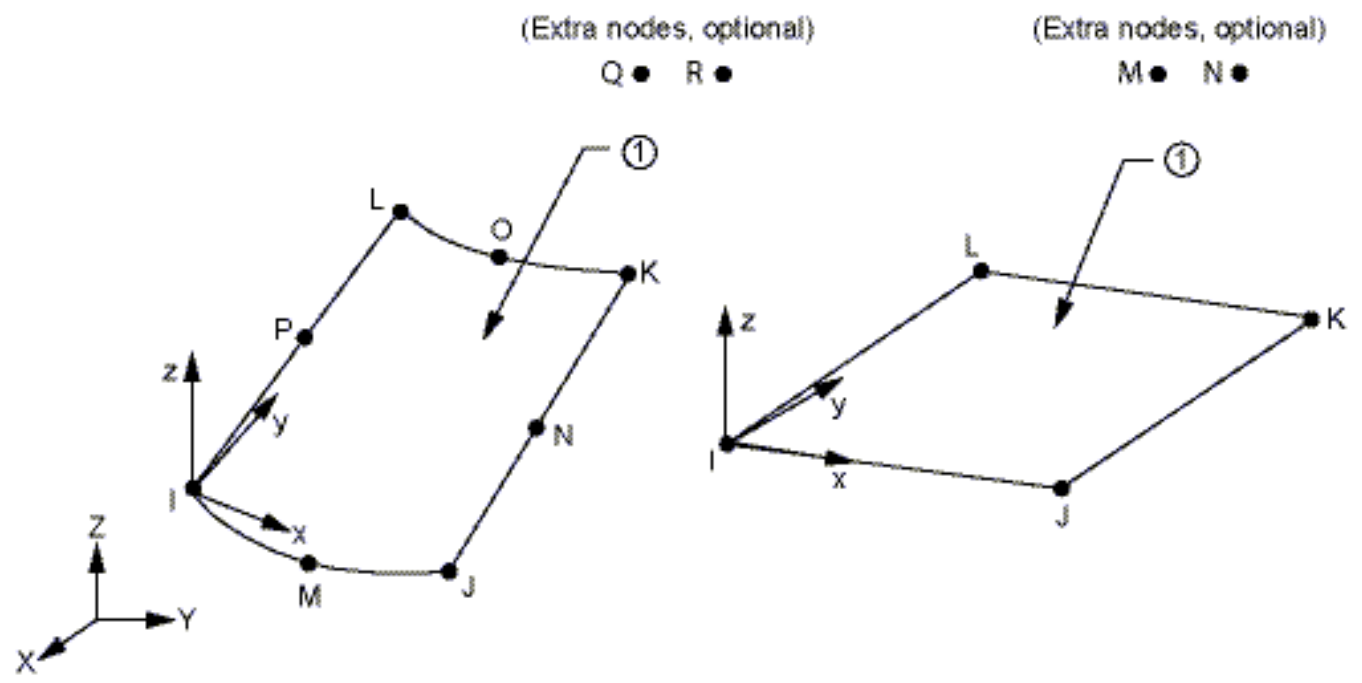

Figura 5.2: Elemento finito SURF152, utilizado na construção da superfície de troca de calor por convecção e radiação.

A forma do modelo numérico referente às análises térmicas de interesse é ilustrada nas figuras 5.3 e 5.4 . 

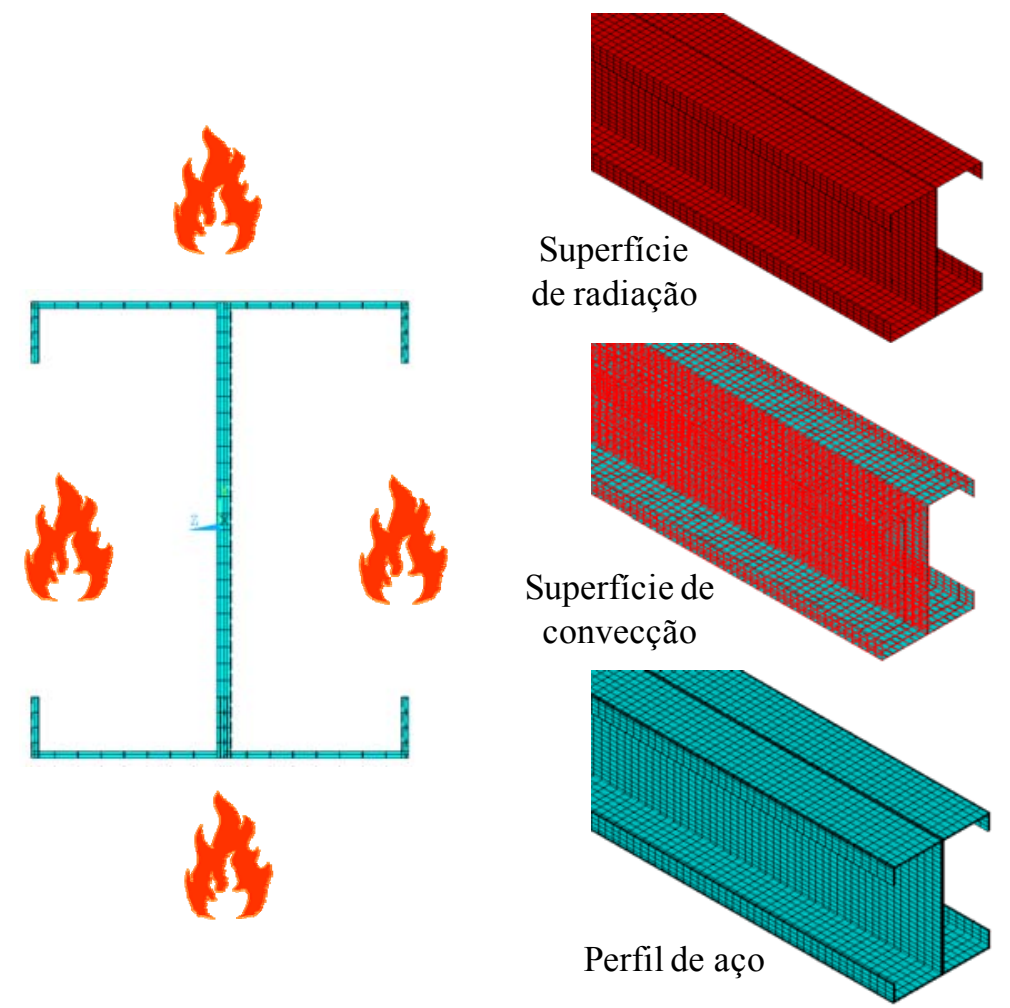

Figura 5.3: Malha de elementos finitos do perfil I enrijecido e das respectivas superfícies de troca de calor.
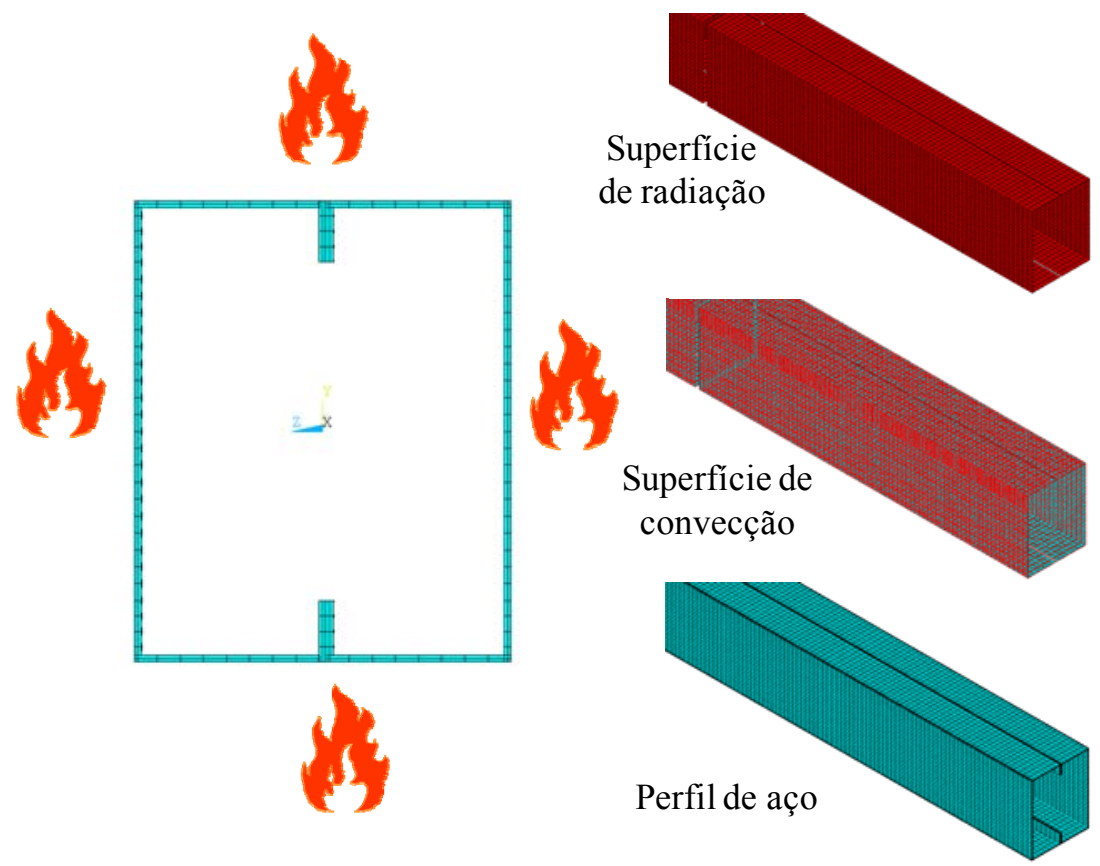

Figura 5.4: Malha de elementos finitos do perfil caixão e das respectivas superfícies de troca de calor.

\subsubsection{Constantes térmicas}

As variáveis inerentes ao modelo térmico foram definidas com base no Eurocode 1 Actions and Structures Part 1.2: General actions - Actions on structures exposed to fire. A constante de troca de calor por convecção da superfície exposta à ação térmica foi tomado 
como $25 \mathrm{~W} / \mathrm{m}^{2} \cdot{ }^{\circ} \mathrm{C}$. Em relação às variáveis que definem a troca de calor por radiação, tem-se a constante de Stefan-Boltzmann igual a $5,67 \times \times 10^{-8} \mathrm{~W} / \mathrm{m}^{2} \cdot \mathrm{K}^{4}$ e a emissividade do perfil com o valor de $\varepsilon=0,7$. O material também é definido por mais três propriedades, as quais são a condutividade térmica, o calor específico e o coeficiente de dilatação térmica, cujos valores são assim definidos:

\section{-Condutividade térmica}

Ainda de acordo com a norma europeia Eurocode 3 part 1.2, a condutividade térmica varia em função da temperatura segundo a equação 5.1 e figura 5.5:

para $20^{\circ} \mathrm{C} \leq \theta_{a}<800{ }^{\circ} \mathrm{C}$

$$
\lambda_{a}=54-3,33 \times 10^{-2} \cdot \theta_{a} \quad[W / m \cdot K]
$$

para $800^{\circ} \mathrm{C} \leq \theta_{a}<1200^{\circ} \mathrm{C}$

$$
\lambda_{a}=27,3 \quad[W / m \cdot K]
$$

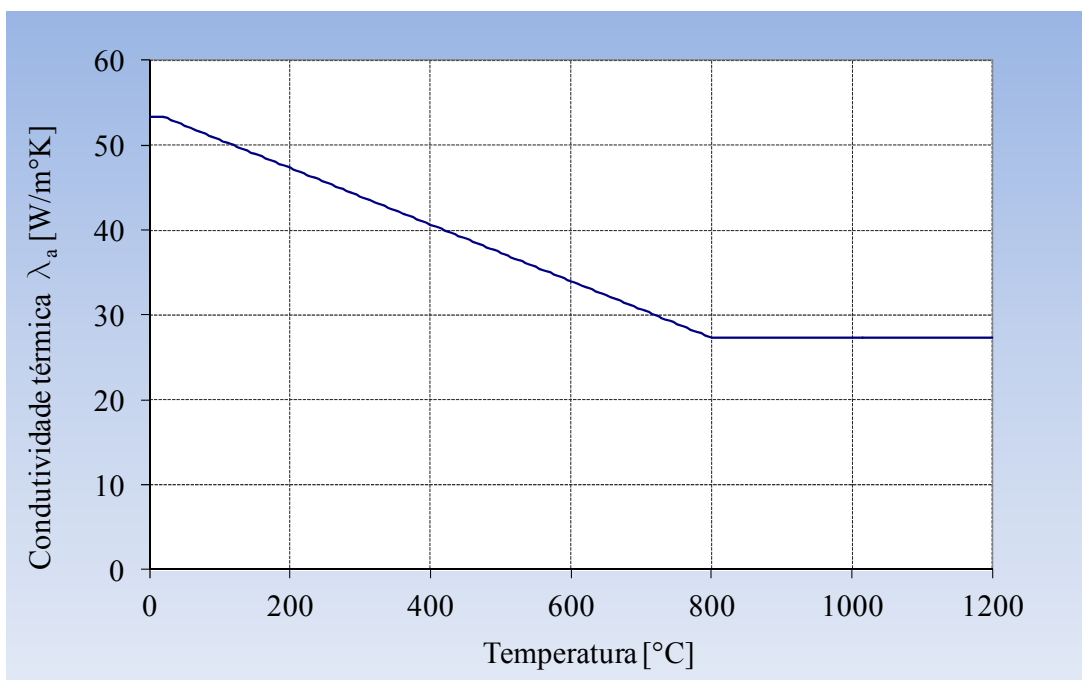

Figura 5.5: Gráfico da condutividade térmica em função da temperatura.

- Calor específico: O calor específico do aço, $\mathrm{c}_{\mathrm{a}}$, cuja unidade é dada em $\mathrm{J} / \mathrm{kg}^{\circ} \mathrm{C}$, pode ser determinado conforme as equações 5.2 (a) a (d). O gráfico da figura 5.6 ilustra a variação dessa propriedade, descrita pelas equações 5.2-a a 5.2-d, de acordo com a temperatura a do aço. 
para $20^{\circ} \mathrm{C} \leq \theta_{a}<600^{\circ} \mathrm{C}$

$$
c_{a}=425+7,73 \times 10^{-1} \cdot \theta_{a}-1,69 \times 10^{-3} \cdot \theta_{a}^{2}+2,22 \times 10^{-6} \cdot \theta_{a}^{3} \quad[\mathrm{~J} / \mathrm{kg} \cdot \mathrm{K}]
$$

para $600{ }^{\circ} \mathrm{C} \leq \theta_{a}<735^{\circ} \mathrm{C}$

$$
c_{a}=666+\frac{13002}{738-\theta_{a}} \quad[\mathrm{~J} / \mathrm{kg} \cdot \mathrm{K}]
$$

para $735^{\circ} \mathrm{C} \leq \theta_{a}<900^{\circ} \mathrm{C}$

$$
c_{a}=545+\frac{17820}{\theta_{a}-731} \quad[\mathrm{~J} / \mathrm{kg} \cdot \mathrm{K}]
$$

para $900{ }^{\circ} \mathrm{C} \leq \theta_{a} \leq 1200{ }^{\circ} \mathrm{C}$

$$
c_{a}=650 \quad[\mathrm{~J} / \mathrm{kg} \cdot \mathrm{K}]
$$

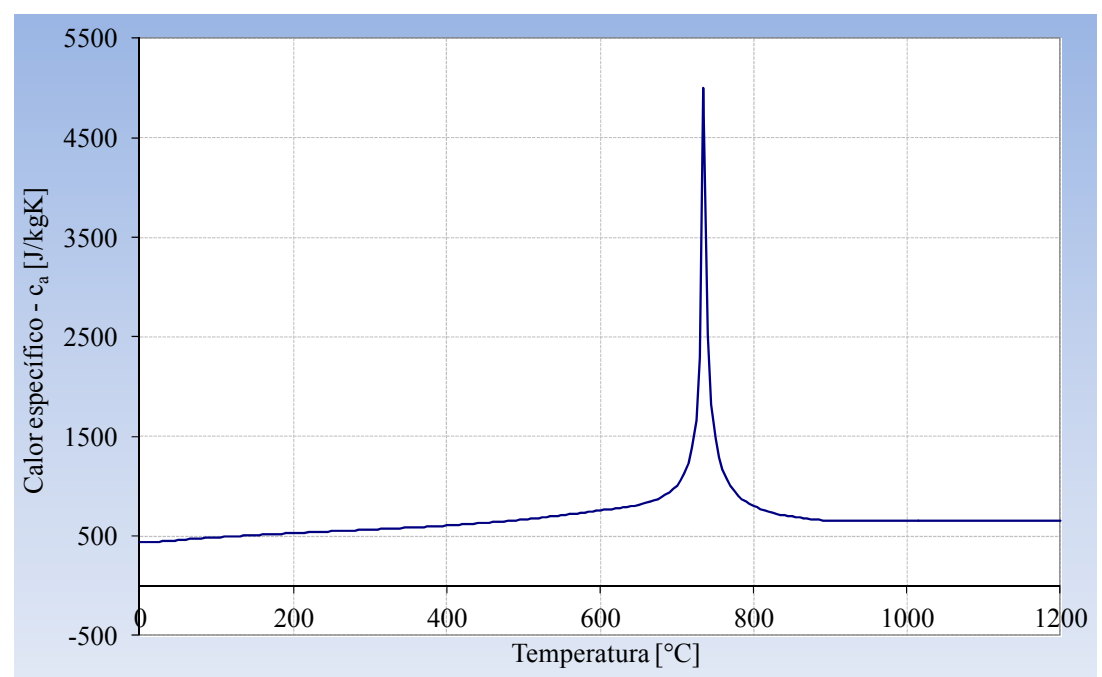

Figura 5.6: Gráfico do calor específico em função da temperatura.

\section{- Alongamento (dilatação térmica)}

$\mathrm{O}$ alongamento do aço é determinado conforme a equação 5.3 , e a variação da dilatação térmica é ilustrada na figura 5.7.

para $20^{\circ} \mathrm{C} \leq \theta_{a}<750^{\circ} \mathrm{C}$

$$
\Delta l / l=1,2 \times 10^{-5} \cdot \theta_{a}+0,4 \times 10^{-8} \cdot \theta_{a}^{2}-2,416 \times 10^{-4}
$$


para $750{ }^{\circ} \mathrm{C} \leq \theta_{a} \leq 860^{\circ} \mathrm{C}$

$\Delta l / l=1,1 \times 10^{-2}$

para $860{ }^{\circ} \mathrm{C}<\theta_{a}<1200{ }^{\circ} \mathrm{C}$

$\Delta l / l=2 \times 10^{-5} \cdot \theta_{a}-6,2 \times 10^{-3}$

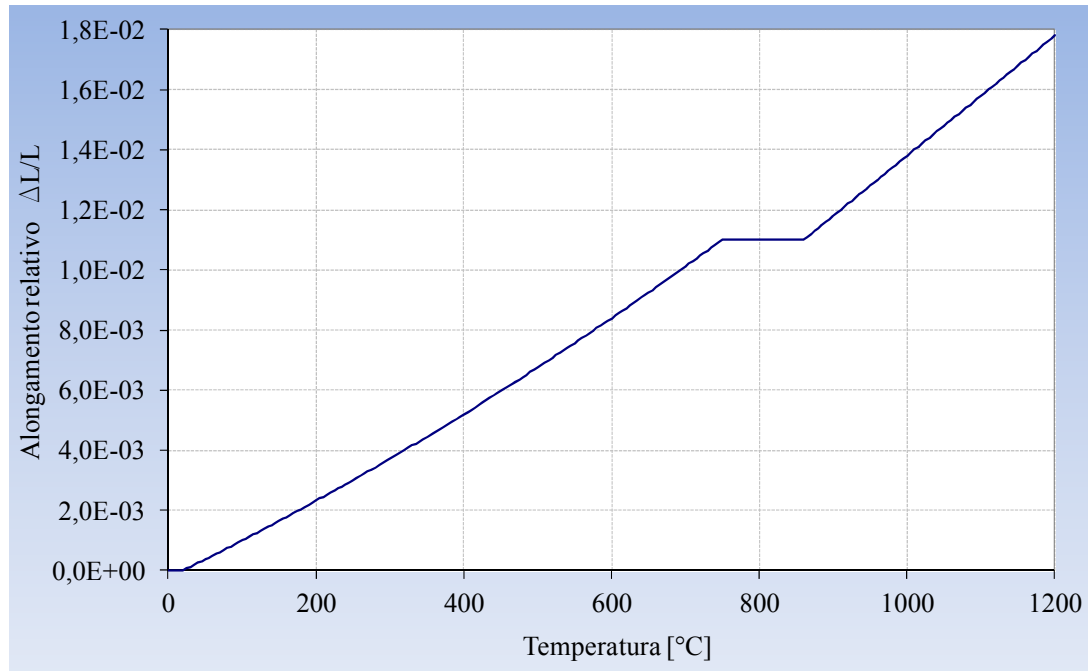

Figura 5.7: Gráfico da dilatação térmica em função da temperatura.

\subsubsection{A ação térmica}

A elevação da temperatura na região aquecida tem como base a curva obtida experimentalmente e comentada no item 4.5.4. Vale ressaltar que, para a obtenção desta curva, o forno foi programado para seguir a curva de incêndio padrão da ISO 834-1:1999. Durante os ensaios, observou-se que os perfis abertos e fechados resultam em campos térmicos distintos. $\mathrm{O}$ fato de os perfis fechados apresentarem temperaturas maiores na região fora do forno está relacionado ao fluxo de ar aquecido no seu interior, o que não ocorre nos perfis abertos. Dessa forma, para a simulação do problema com o perfil caixão, é interessante desenvolver uma terceira análise, o que caracteriza uma análise fluido-termoestrutural. No entanto, esta estratégia extrapola a proposta do presente trabalho.

Para contornar o problema de fluido, a solução dada para representar a variação de temperatura do perfil caixão foi trabalhar com três curvas de ação térmica para três regiões do perfil, a interna ao forno submetida à curva de incêndio experimental e as duas externas, acima e abaixo do forno submetidas à curva de aquecimento dos gases internos. 
De posse, então, dos dados experimentais, a ação térmica implementada no modelo numérico seguiu as curvas dos gráficos "temperatura $x$ tempo" ilustrados nas figuras $5.8 \mathrm{e}$ 5.9 para os perfis I enrijecido e caixão, respectivamente.

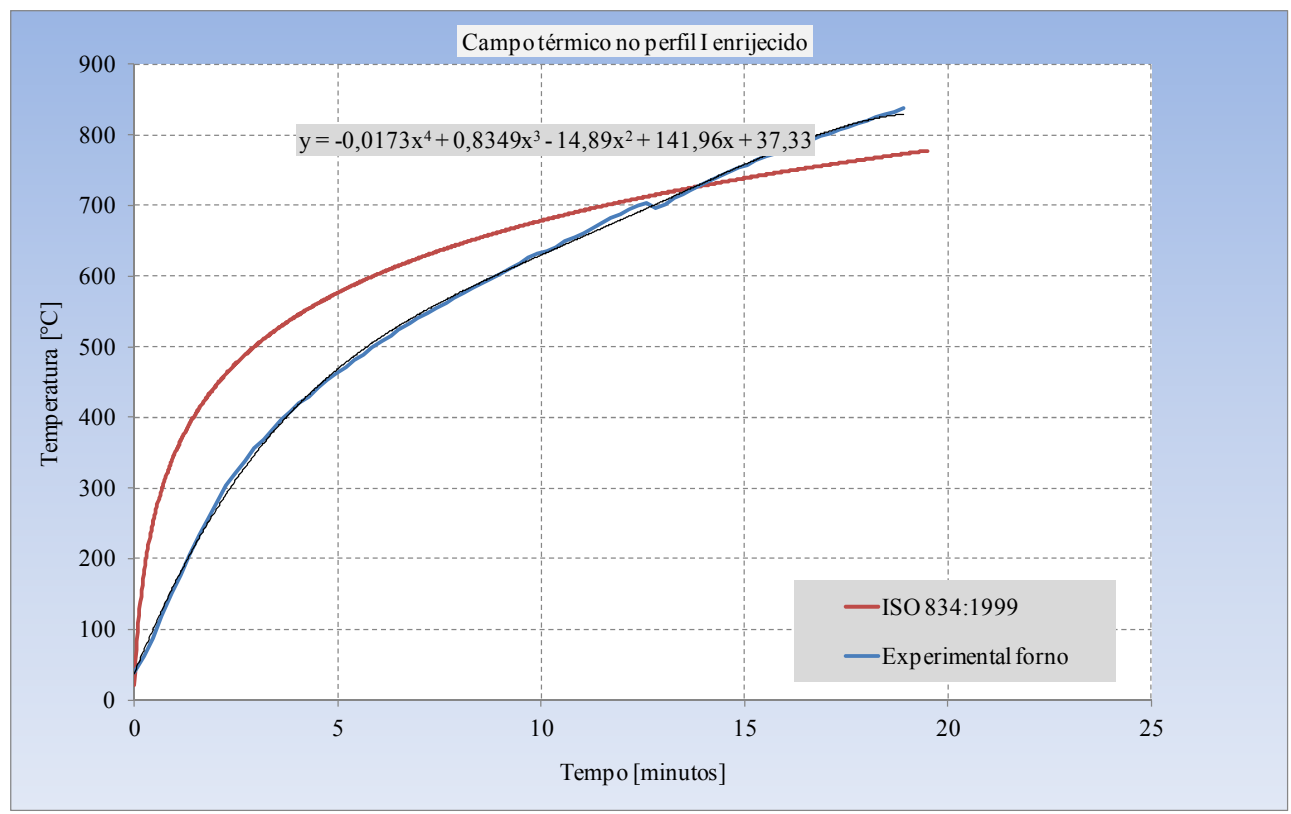

Figura 5.8: Ação térmica inserida numericamente no perfil I enrijecido.

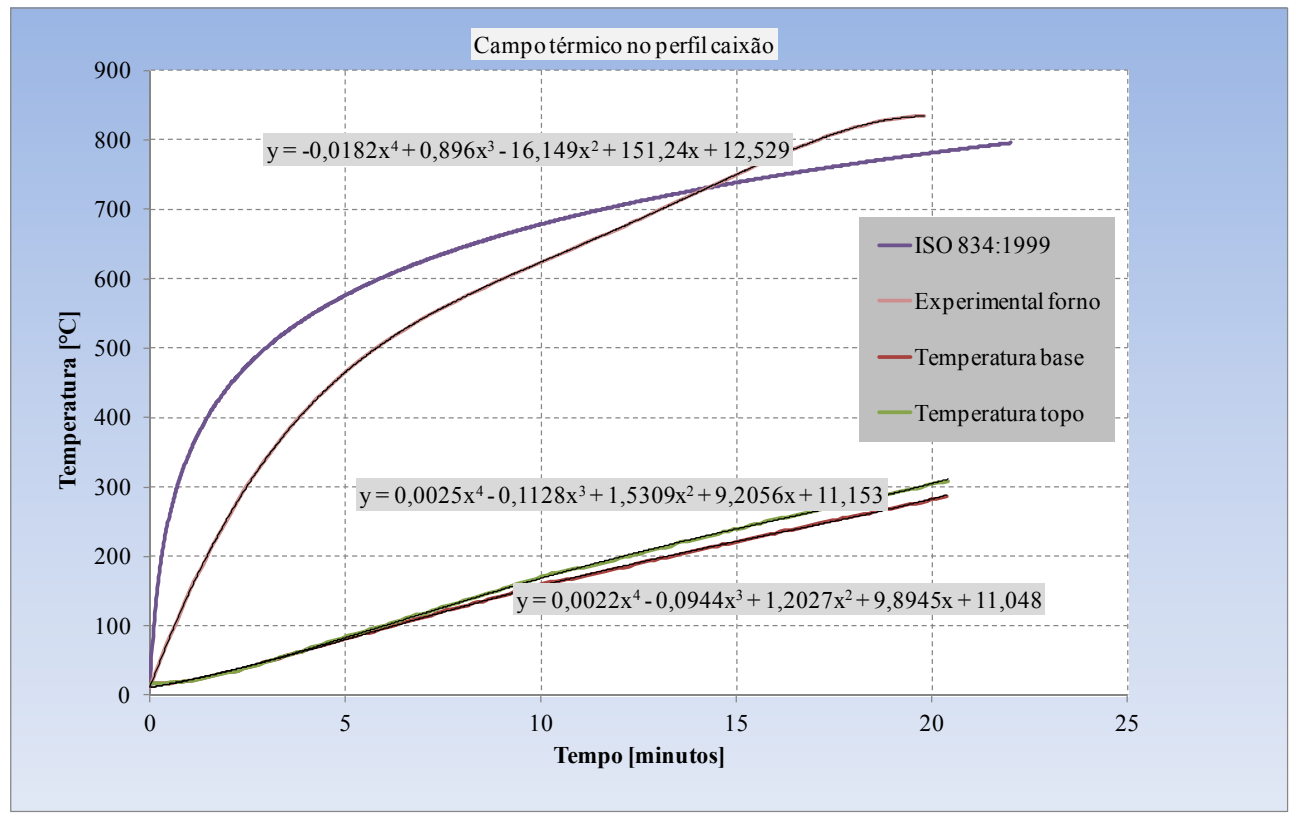

Figura 5.9: Ação térmica inserida numericamente no perfil caixão.

\subsubsection{Resultados da análise térmica}

A ação térmica descrita em 5.1.3 permitiu obter, como resultado de interesse os campos térmicos em função do tempo. Nas figuras 5.10 e 5.11 estão ilustrados tais resultados 
numéricos expressos em curvas "temperatura no perfil $x$ tempo" dos perfis I enrijecido e caixão, respectivamente. Nessas figuras também está indicada a curva padrão da norma ISO 834-1:1999 para fins de validação.

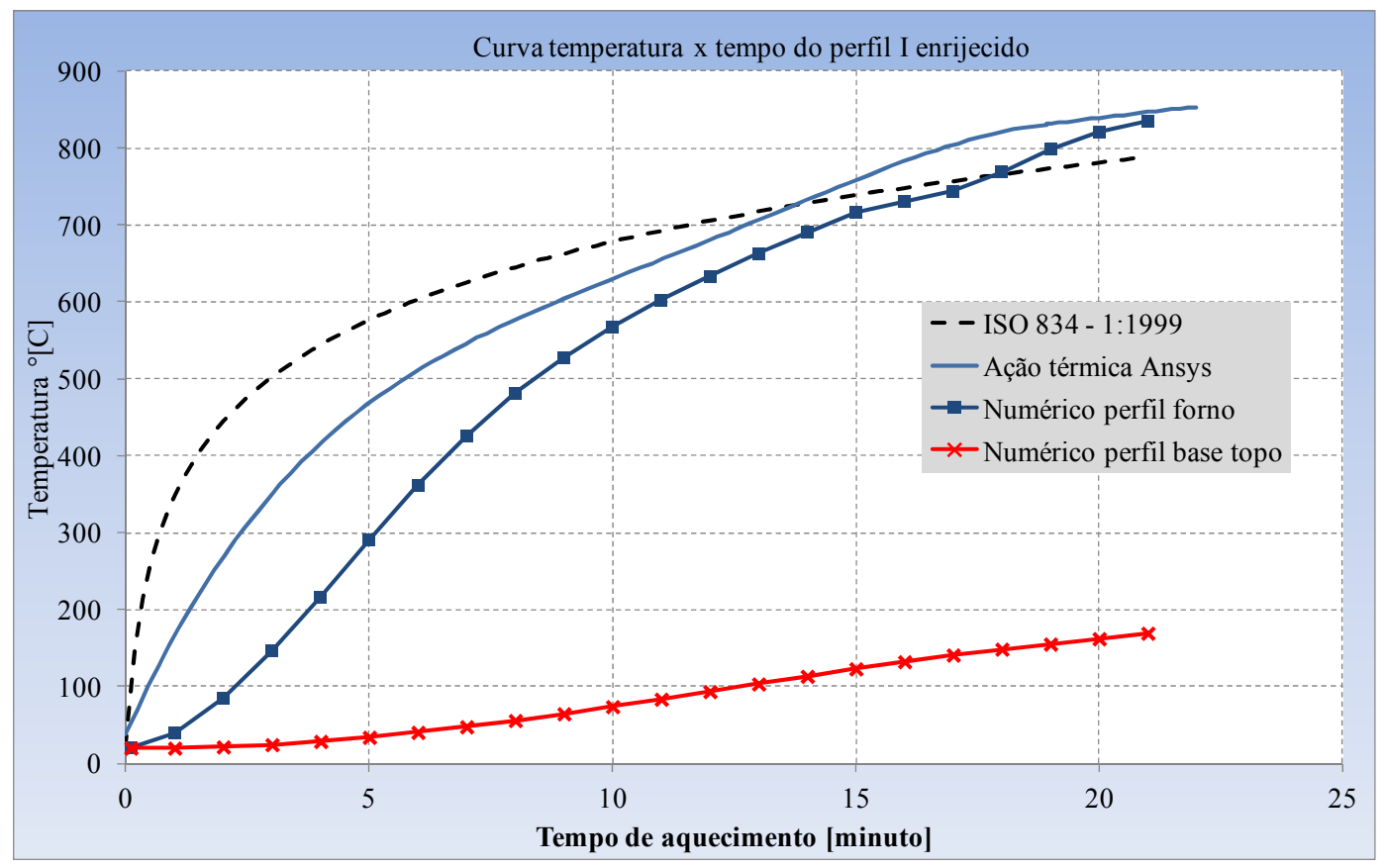

Figura 5.10: Temperatura resultante no modelo I.SI.04F em função do tempo de exposição à ação térmica.

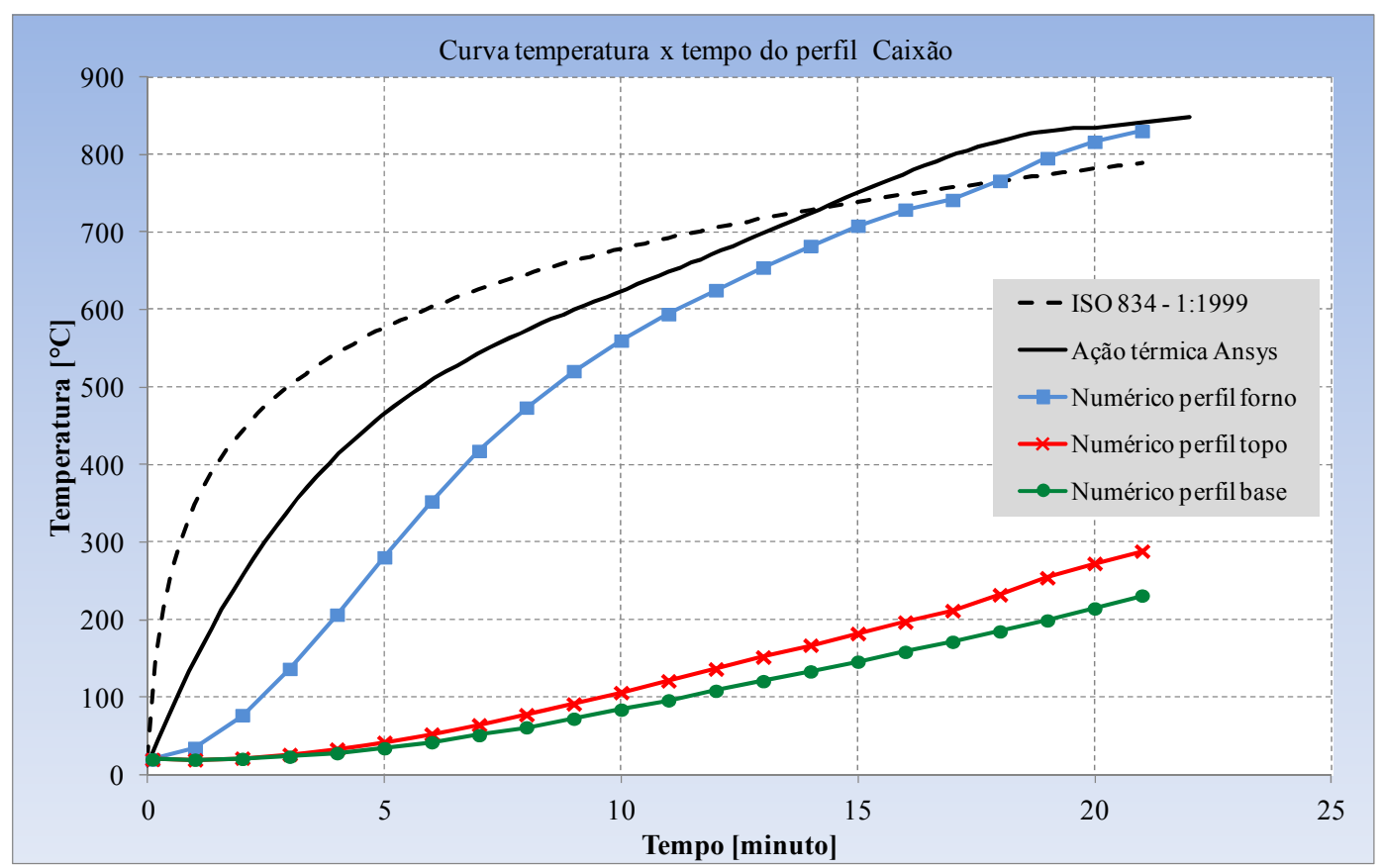

Figura 5.11: Temperatura resultante no modelo C.SI.04F em função do tempo de exposição à ação térmica. 


\subsection{Considerações referentes ao modelo estrutural}

A construção de elementos finitos para análise estrutural seguiu o mesmo procedimento utilizado na análise térmica, de forma a manter a mesma posição dos nós. A importância em seguir este procedimento está em possibilitar o acoplamento entre ambos os modelos, ou seja, o térmico anteriormente apresentado e o estrutural.

Para que os modelos numéricos fossem representativos dos modelos experimentais, as seguintes características foram consideradas:

- As condições de contorno nas extremidades do pilar são consideradas como rótulas cilíndricas, ou seja, apoios fixo na base e móvel no topo;

- O material possui comportamento não linear físico representado por uma "curva tensão $x$ deformação" multilinear;

- O modelo é geometricamente não linear, de forma a contemplar as imperfeições geométricas iniciais possíveis de existir;

- A aplicação da força axial considera uma excentricidade em relação ao centro geométrico da seção.

A estratégia numérica para a construção do perfil com a inclusão das características citadas é descrita nos subitens seguintes.

\subsubsection{Construção do modelo de elementos finitos}

O elemento finito utilizado na análise estrutural deve ser compatível com aquele utilizado na análise térmica. Para tanto, utilizou-se o elemento finito SHELL 181, ilustrado na figura 5.12. Esse elemento é composto por quatro nós e seis graus de liberdade por nó, ou seja, os três referentes à translação UX, UY e UZ e os três referentes à rotação ROTX, ROTY e ROTZ. 


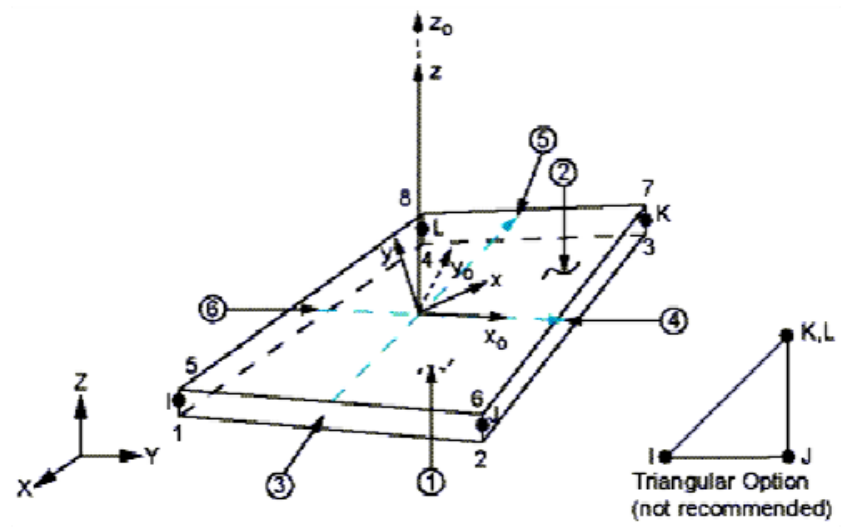

Figura 5.12: Elemento finito SHELL181, utilizado na construção do perfil de aço em análises estruturais.

No que tange as condições de vínculo, esses foram definidos como rótulas cilíndricas, de forma a permitir rotação apenas em uma direção, a qual é definida sobre o eixo de menor inércia. Portanto, na base, são inseridas as restrições ao deslocamento nas direções $\mathrm{X}, \mathrm{Y}$ e Z e, como os perfis não possuem restrição axial, no topo, o deslocamento na direção X é livre e os transversais são impedidos. As figuras 5.13 e 5.14 ilustram tais condições de contorno.

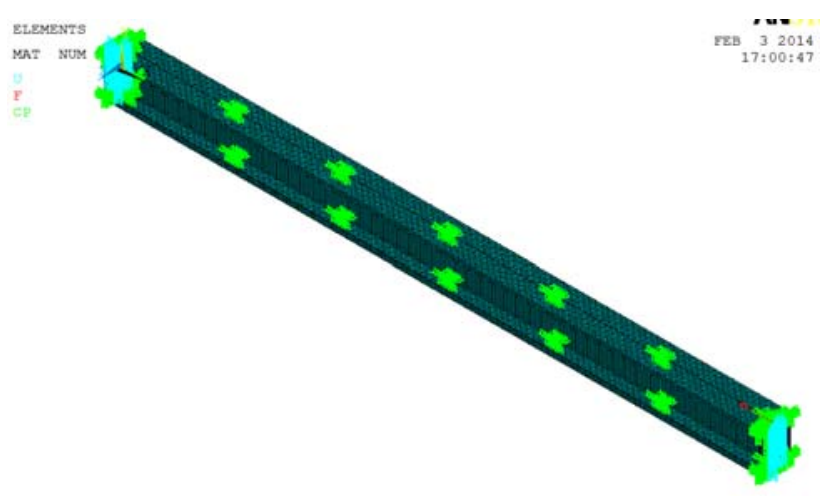

(a)

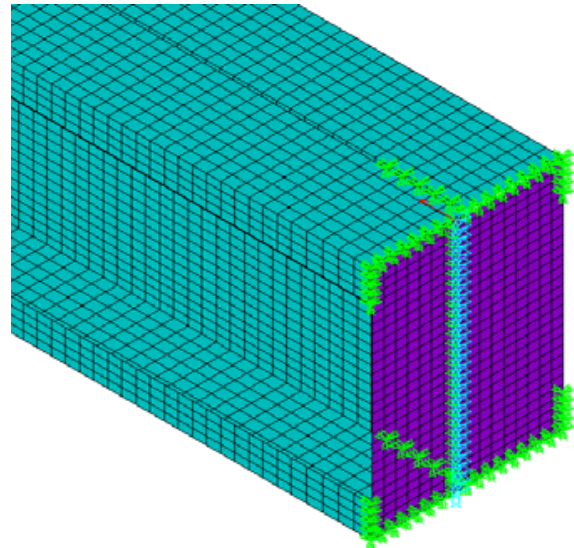

(b)

Figura 5.13: (a) União dos perfis $U_{\mathrm{e}}$ e (b) condições de contorno do perfil I enrijecido.
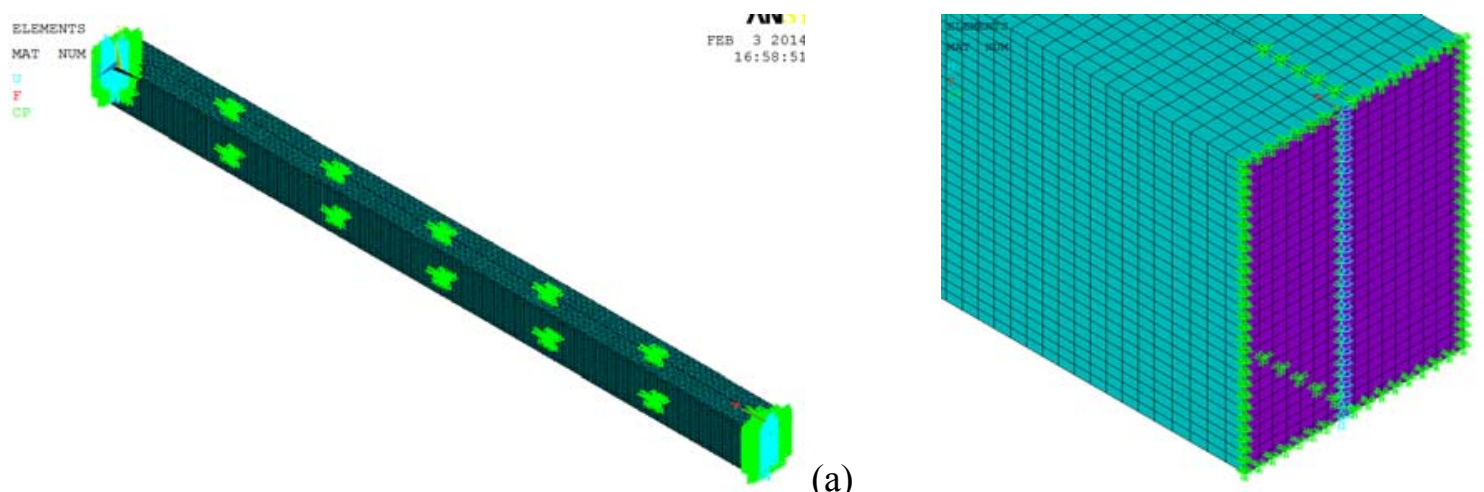

(a)

(b)

Figura 5.14: (a) União dos perfis $U_{e}$ e (b) condições de contorno do perfil caixão. 
Ainda nas figuras 5.13 e 5.14, a solda intermitente que garante a união dos perfis $U_{\mathrm{e}}$ de ambas as seções compostas é representada pelo acoplamento de nós em comprimentos iguais aos dos cordões de solda. Ao inserir o acoplamento, os nós acoplados têm os graus de liberdade restringidos entre si. Dessa forma, um nó tem os mesmos deslocamentos que o nó a ele acoplado. Os nós pertencentes à condição de contorno também foram acoplados, porém, apenas na direção axial. Este recurso evita que, ao aplicar a força de compressão centrada, ocorra regiões singulares de concentração de tensões.

\subsubsection{Propriedades do material}

O modelo numérico considera a não linearidade física do material, porém, a inserção da grande quantidade de pontos do diagrama real obtido do ensaio de caracterização é sabidamente inviável. Logo, o modelo constitutivo foi implementado de forma discretizada em um diagrama multilinear e para cada nível de temperatura. Os pontos coordenados "tensão $x$ deformação" de cada trecho definem a tensão de proporcionalidade, a resistência ao escoamento, o trecho de encruamento e o trecho descendente referente ao colapso que caracterizam o material.

Para as análises numéricas termoestruturais apresentadas adiante, essa curva multilinear, assim como o módulo de elasticidade, foram ponderados pelos fatores de redução do Eurocode 3 - part 1.2, atribuídos aos perfis de classe quatro, ou seja, aqueles sujeitos à flambagem local. A figura 5.15 ilustra a curva "tensão $x$ deformação" à temperatura ambiente e em vários níveis de temperatura entre $100{ }^{\circ} \mathrm{C}$ e $1200{ }^{\circ} \mathrm{C}$ em um mesmo gráfico.

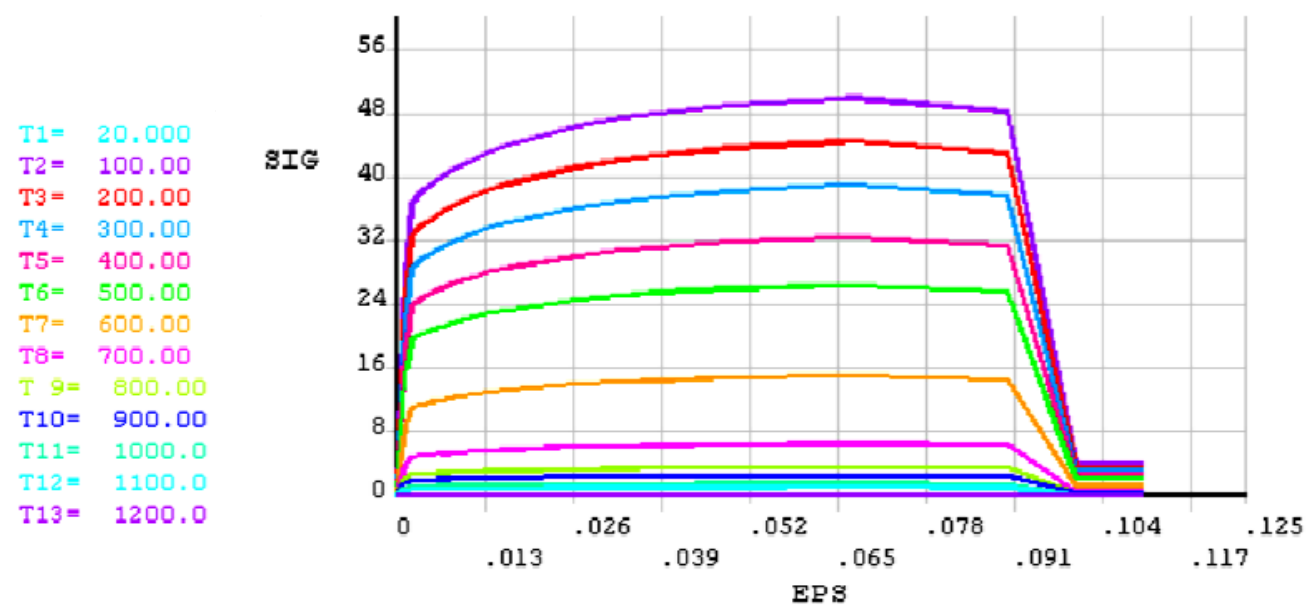

Figura 5.15: Relação constitutiva do aço implementada no pacote computacional ANSYS. 


\subsubsection{Não linearidade geométrica}

A análise estrutural considera também as imperfeições geométricas iniciais a que os perfis de aço em geral, e principalmente os formados a frio, estão sujeitos a apresentar. Uma estratégia para inserir tais imperfeições e já apresentada em trabalhos como Almeida (2007) e Maia (2010) entre outros, consiste em realizar uma Análise de Autovalor do pacote computacional ANSYS. Por meio dessa análise, realizada em regime elástico linear, é possível obter como resultados a força crítica (autovalor) e o correspondente modo de instabilidade (autovetor).

Em ambos os perfis abordados neste trabalho, a configuração deformada do primeiro modo de instabilidade resultante corresponde ao modo local. No perfil I enrijecido, é possível observar a instabilidade distorcional relativos a autovalores (força crítica) de maior magnitude. As figuras 5.16 (a) e (b) e 5.17 (a) a (b) ilustram a deformada do perfil I enrijecido e caixão, respectivamente.
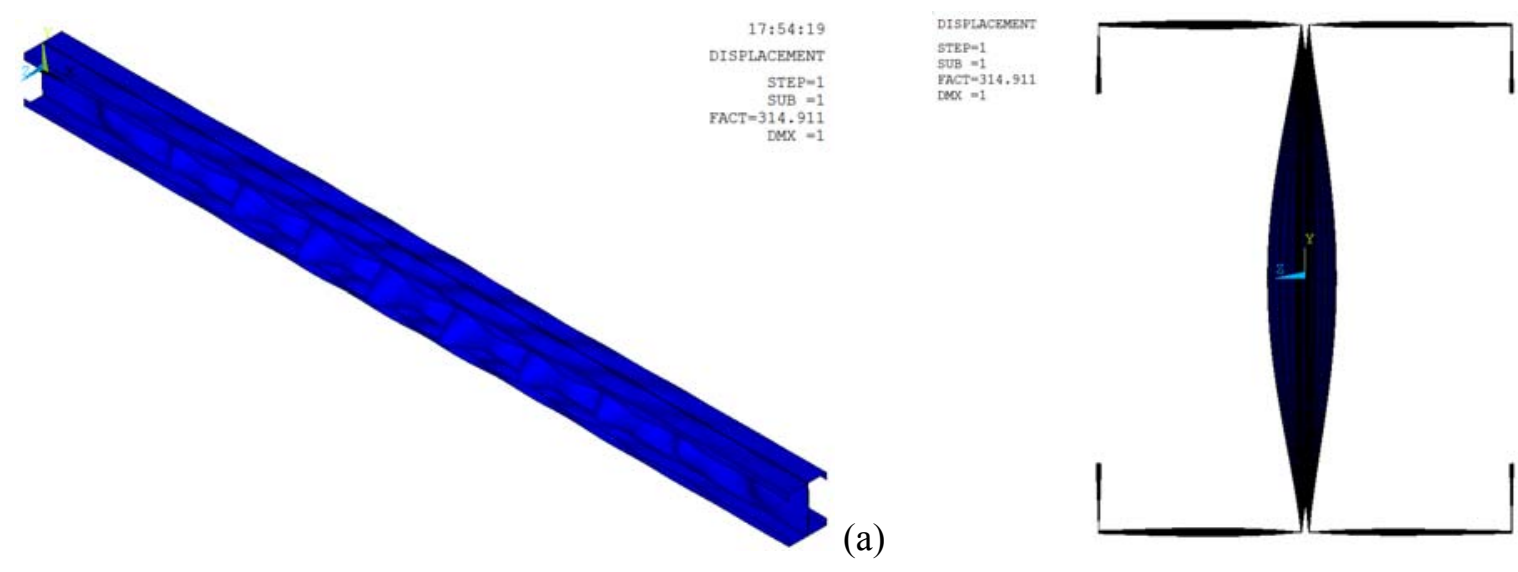

(b)

Figura 5.16: Configuração deformada relativa ao primeiro modo de instabilidade do perfil I enrijecido: (a) modos locais ao longo do comprimento e (b) na seção transversal.
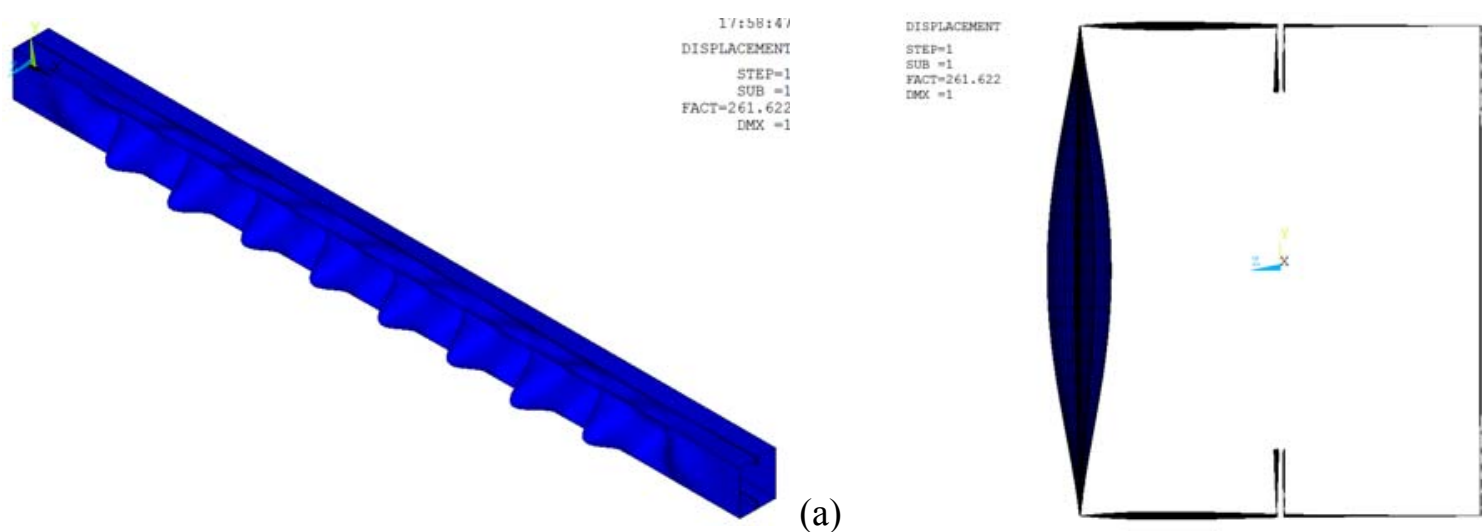

Figura 5.17: Configuração deformada relativa ao primeiro modo de instabilidade do perfil I enrijecido: (a) modos locais ao longo do comprimento e (b) na seção transversal. 
Devido à baixa esbeltez global dos perfis, a análise de estabilidade elástica resultou apenas em deformadas locais e distorcionais no perfil I enrijecido e locais no perfil caixão. Porém, a análise de estabilidade, ou análise de autovalor do Ansys, que forneceu as imperfeições geométricas iniciais não fornecem outros modos de imperfeição geométrica inicial possíveis de acontecer nos perfis de aço. Tais imperfeições são referentes às tolerâncias nas formas, as quais são estabelecidas pela ABNT NBR 6355: 2012, intitulada "Perfis estruturais de aço formados a frio - Padronização".

Nesse sentido, a solicitação de compressão foi aplicada considerando uma excentricidade de L/500 no sentido da flexão e uma torção no perfil igual a $1 \%$ metro, valores esses adotados conforme a referida norma técnica.

No tocante à amplitude das imperfeições geradas pela análise de autovalor, diversos estudos já foram publicados a esse respeito. Ainda com base nas investigações apresentadas em Maia (2012), tomou-se uma amplitude de imperfeições geométricas locais de $\delta=0,64 \cdot t$, em que $\boldsymbol{t}$ é a espessura do perfil.

\subsection{Análise acoplada térmica e estrutural}

Embora continue no contexto das análises estruturais, optou-se por descrever esta etapa em um novo item, por envolver duas ações distintas, uma mecânica e uma térmica.

Nesse modelo estrutural, a ação mecânica foi inserida em termos de força axial e mantida constante durante o aquecimento. A magnitude dessa ação corresponde a uma proporção da força de colapso determinada experimentalmente à temperatura ambiente. Dois valores de carregamento imposto foram adotados, os quais são $0,4 \cdot \mathrm{N}_{\exp }$ e $0,7 \cdot \mathrm{N}_{\text {exp }}$, em que $\mathrm{N}_{\text {exp }}$ é a força axial obtida na investigação experimental à temperatura ambiente. A opção por se aplicar tais valores de carregamento recai sobre a ideia de estabelecer uma correlação entre força aplicada constante e tempo de resistência a um campo térmico crescente.

Seguida da ação mecânica, é inserida a ação térmica por meio do acoplamento da análise térmica descrita em 5.1. Por ser variável em função do tempo, o campo térmico resultante daquela análise é aplicado em intervalos de um minuto. 
Ao processar a análise, o modelo associa a temperatura dos elementos num determinado instante às correspondentes propriedades mecânicas, relação constitutiva e módulo de elasticidade, para então determinar uma nova posição de equilíbrio entre carregamento imposto e deslocamentos resultantes. Alcançado o equilíbrio (ou na linguagem comum em análise numérica, a convergência do passo), o próximo passo é impor o campo térmico do minuto seguinte e recalcular a nova posição de equilíbrio. Numericamente, esses passos são repetidos até que, decorrido um determinado tempo, o perfil se encontra em um campo térmico tal que sua capacidade resistente de escoamento não é suficiente para suportar o carregamento de compressão imposta.

Essa análise termoestrutural pode ser considerada como uma espécie de acoplamento indireto, pois, uma vez que é necessário resolver primeiro a análise térmica para depois a estrutural, não há um processo iterativo entre ambos. Por fim, ressalta-se também que não há nenhuma forma de perda na precisão dos resultados numéricos obtidos pelo procedimento utilizado.

\subsubsection{Resultados da análise numérica termoestrutural}

O modelo numérico elaborado com o pacote computacional Ansys, por fim, resulta com um comportamento mais rígido se comparado ao modelo experimental, devido a algumas simplificações adotadas durante a sua elaboração. Embora sejam inseridas as imperfeições iniciais na geometria das barras, bem como as propriedades elásticas e plásticas do material, questões como as tensões residuais na região das dobras não foram possíveis de ser exploradas.

Os gráficos ilustrados nas figuras 5.18 e 5.19 mostram que o modelo reproduziu satisfatoriamente a variação do deslocamento axial em função do aquecimento. A curva que representa o deslocamento axial se inicia em um valor não nulo, no sentido da contração, em

razão da força axial aplicada. À medida em que se insere a ação térmica à taxas crescentes, a deformação térmica de dilatação aumenta proporcionalmente. Esta deformação permanece crescente até que, a uma determinada temperatura, o material apresente sua capacidade resistente reduzida de tal modo que não suporte a ação de compressão aplicada e mantida constante. Numericamente, isso significa a perda de convergência do passo de carga na análise. Ressalta-se que o critério de parada da análise térmica não tem nenhuma analogia 
com o critério de parada aplicado no trabalho experimental. No capítulo 6, item 6.2, os resultados obtidos pela análise numérica são devidamente comparados com aqueles obtidos na análise experimental para fins de validação do modelo numérico.

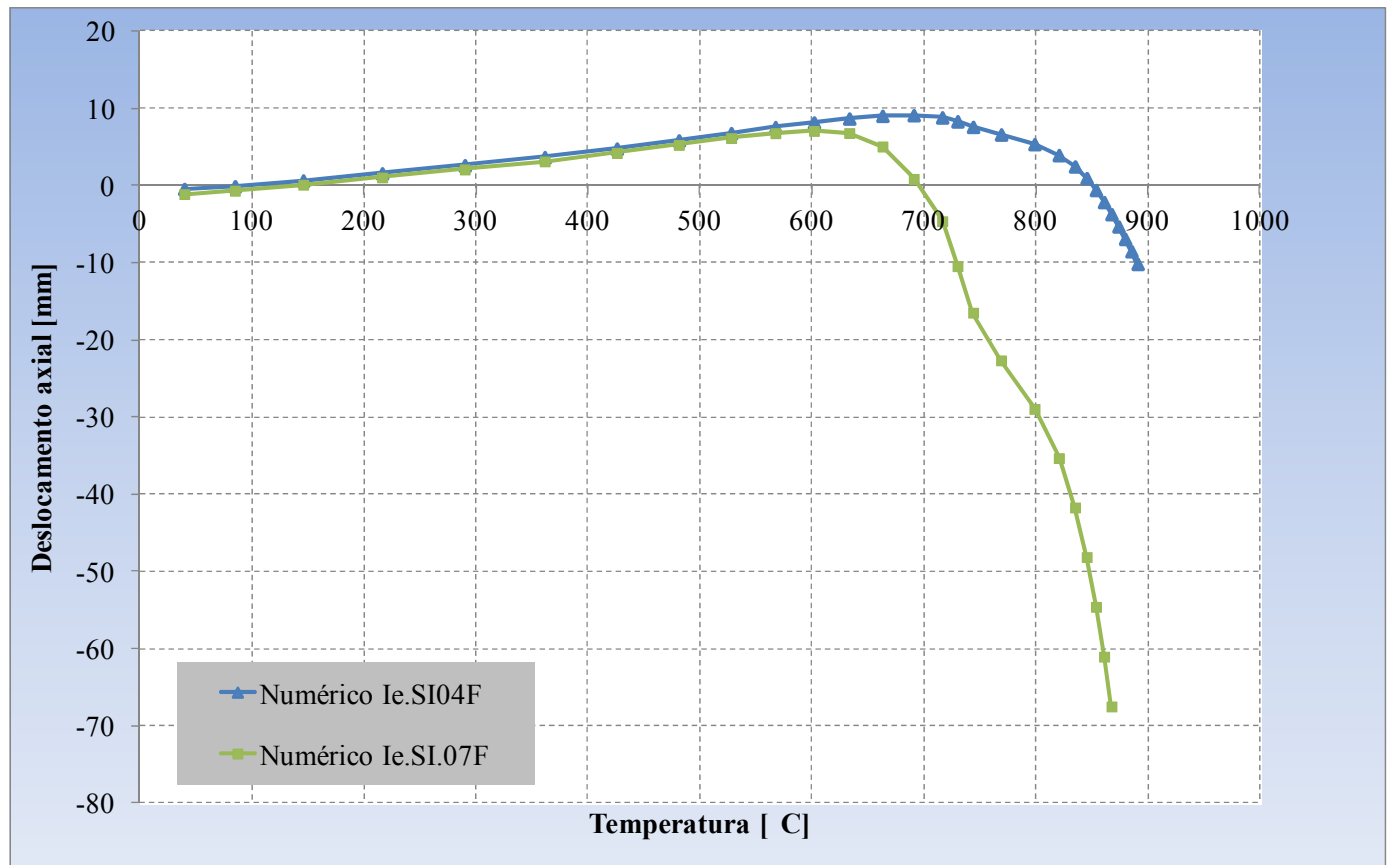

Figura 5.18: Deslocamento axial em função do aumento da temperatura do aço obtido nas análises do perfil I enrijecido.

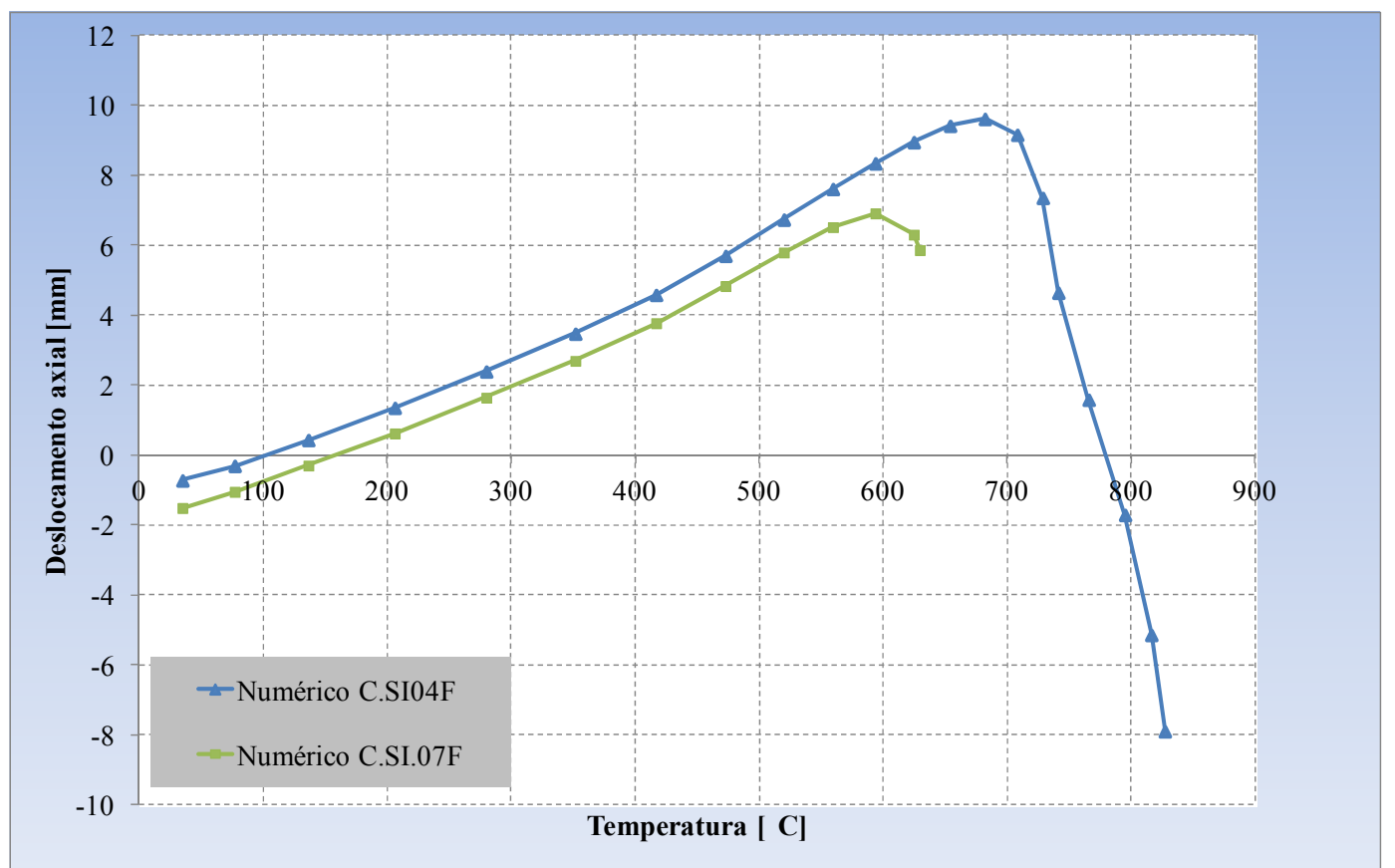

Figura 5.19: Deslocamento axial em função do aumento da temperatura do aço obtido nas análises do perfil caixão. 
Ao observar as figuras 5.20 e 5.21, percebe-se que ambos os perfis, submetidos a um mesmo carregamento, apresentaram trajetórias de deslocamentos e campo de temperatura semelhantes a até o instante de colapso.

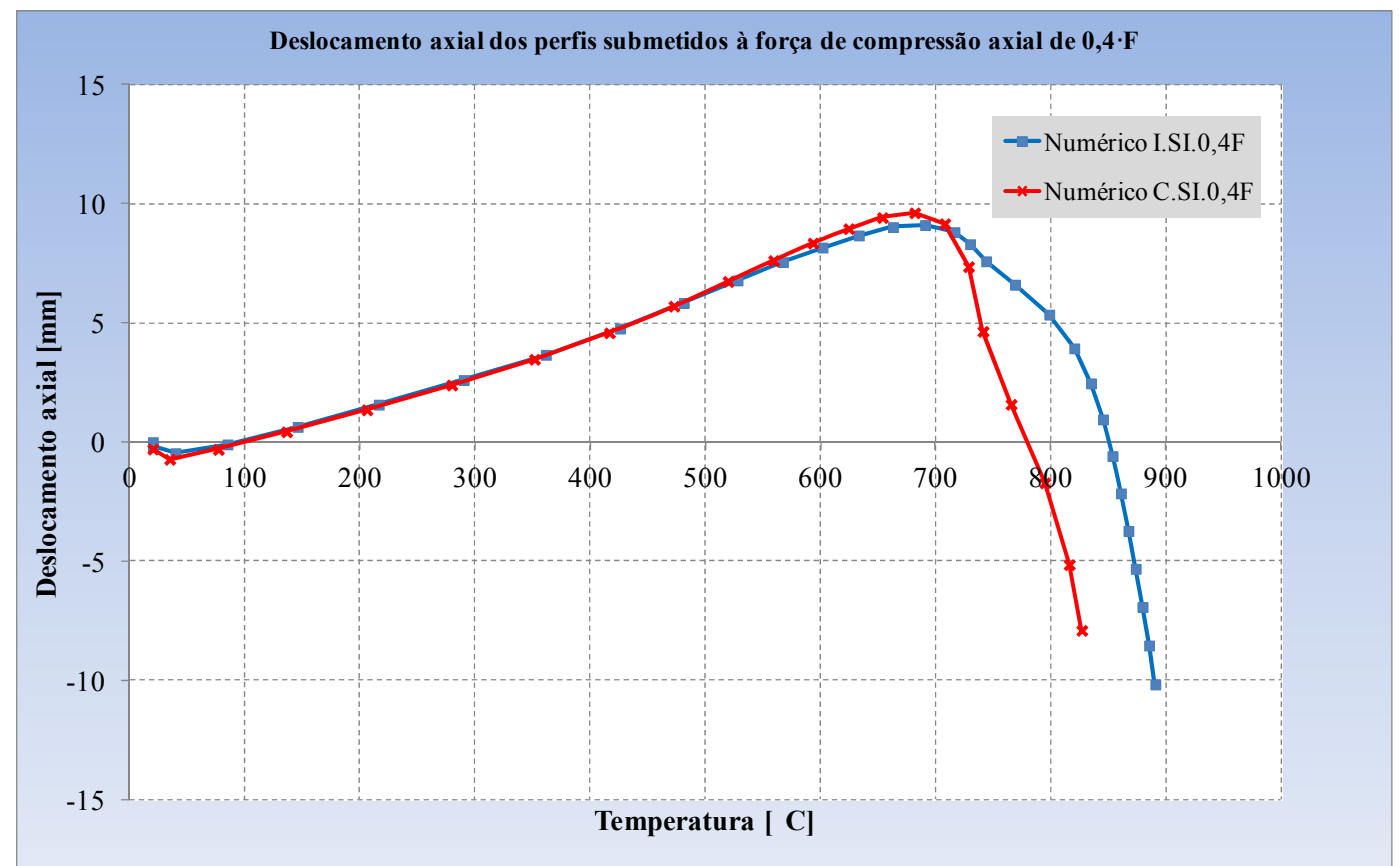

Figura 5.20: Deslocamentos axiais dos perfis I enrijecido e caixão submetidos a uma compressão de $0,4 \cdot \mathrm{N}_{\exp }$.

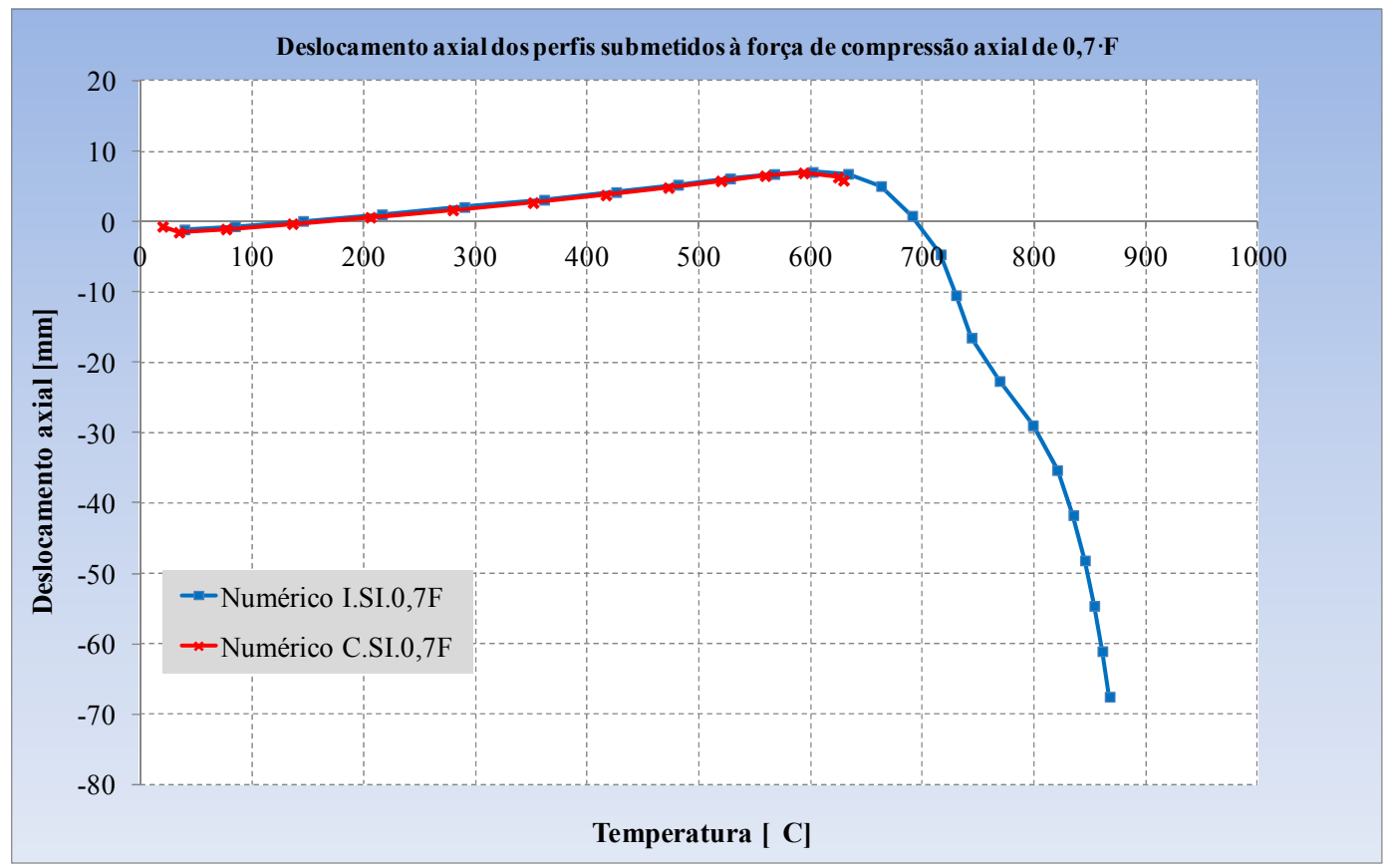

Figura 5.21: Deslocamentos axiais dos perfis I enrijecido e caixão submetidos a uma compressão de $0,7 \cdot \mathrm{N}_{\text {exp }}$. 
As figuras 5.22 e 5.23 ilustram as deformações térmicas resultantes no último passo da análise. À medida que se caminha para o centro do modelo são observadas as maiores deformações térmicas. Esse comportamento é consequência do campo térmico inserido no problema, em que a parte central refere-se a aquela submetida à ação térmica do forno.

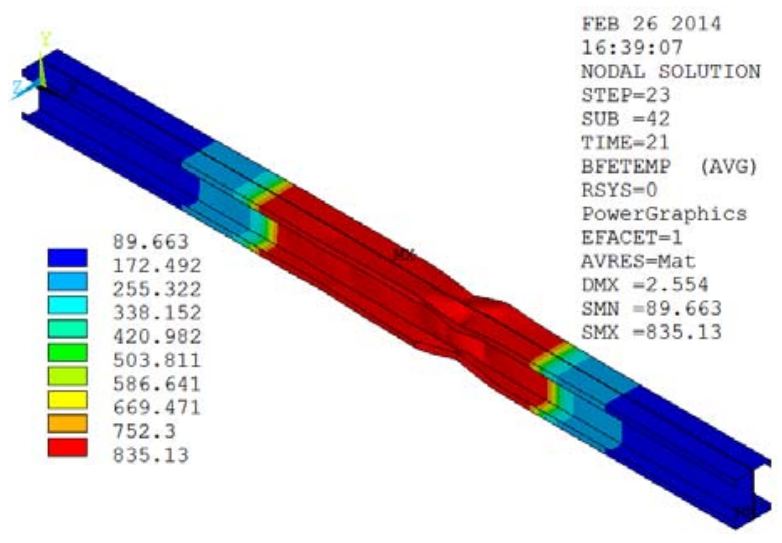

(a)

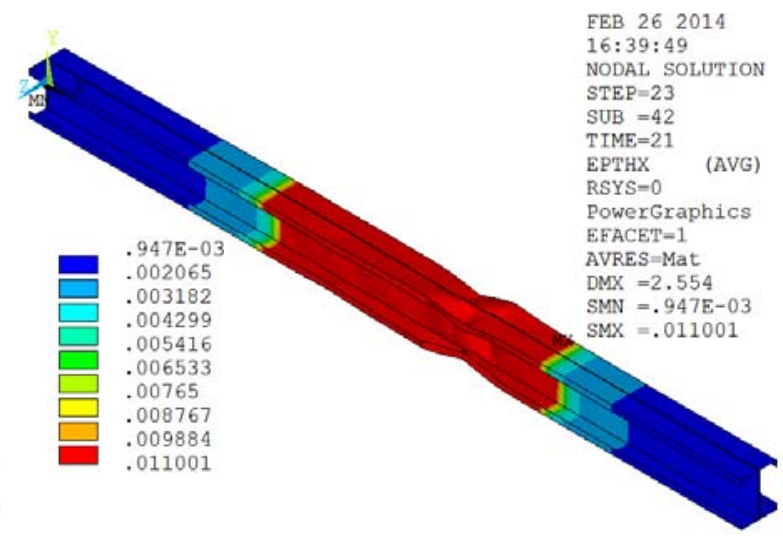

(b)

Figura 5.22: Campo térmico e as correspondentes deformações térmicas no perfil I enrijecido.

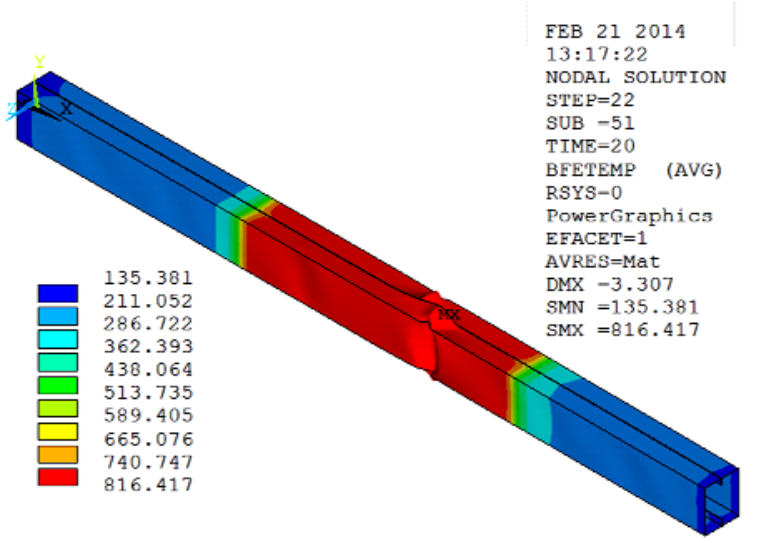

(a)

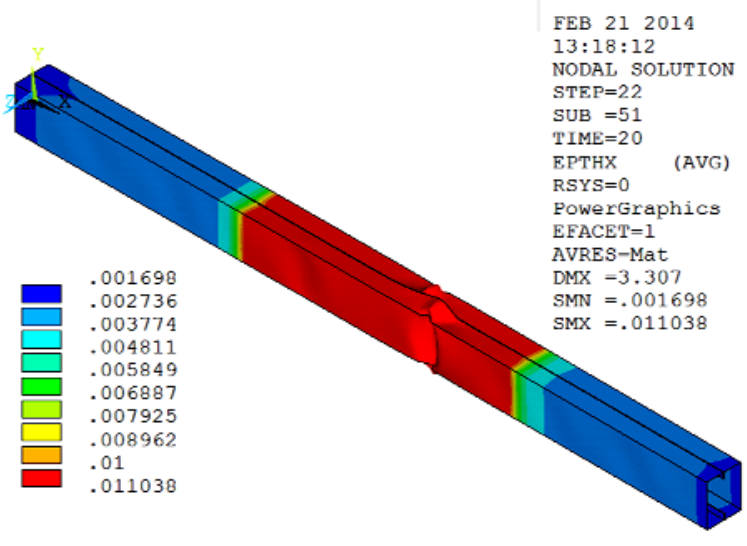

(b)

Figura 5.23: Campo térmico e as correspondentes deformações térmicas no perfil caixão.

No que tange ao campo das tensões, ao final da aplicação da ação mecânica de compressão, cujo valor é de, no máximo $70 \%$ da força resistente à temperatura ambiente, o modelo ainda apresenta comportamento elástico. As figuras 5.24 e 5.25 ilustram o estado das tensões principais provocado apenas pela compressão axial. 


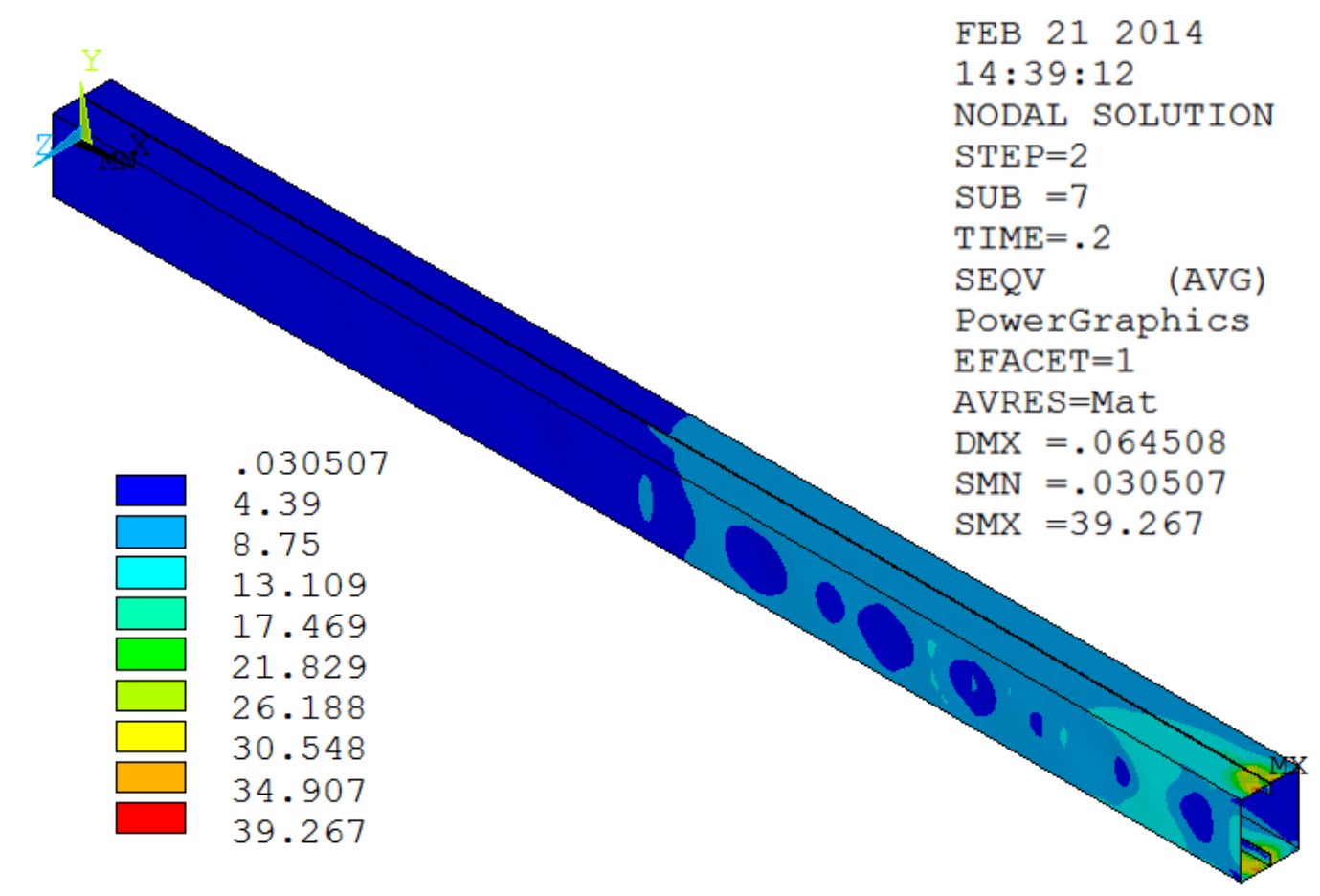

Figura 5.24: Tensões principais devidas à força axial de $70 \% * \mathrm{~N}_{\exp }$ no perfil caixão, modelo CSI07F.

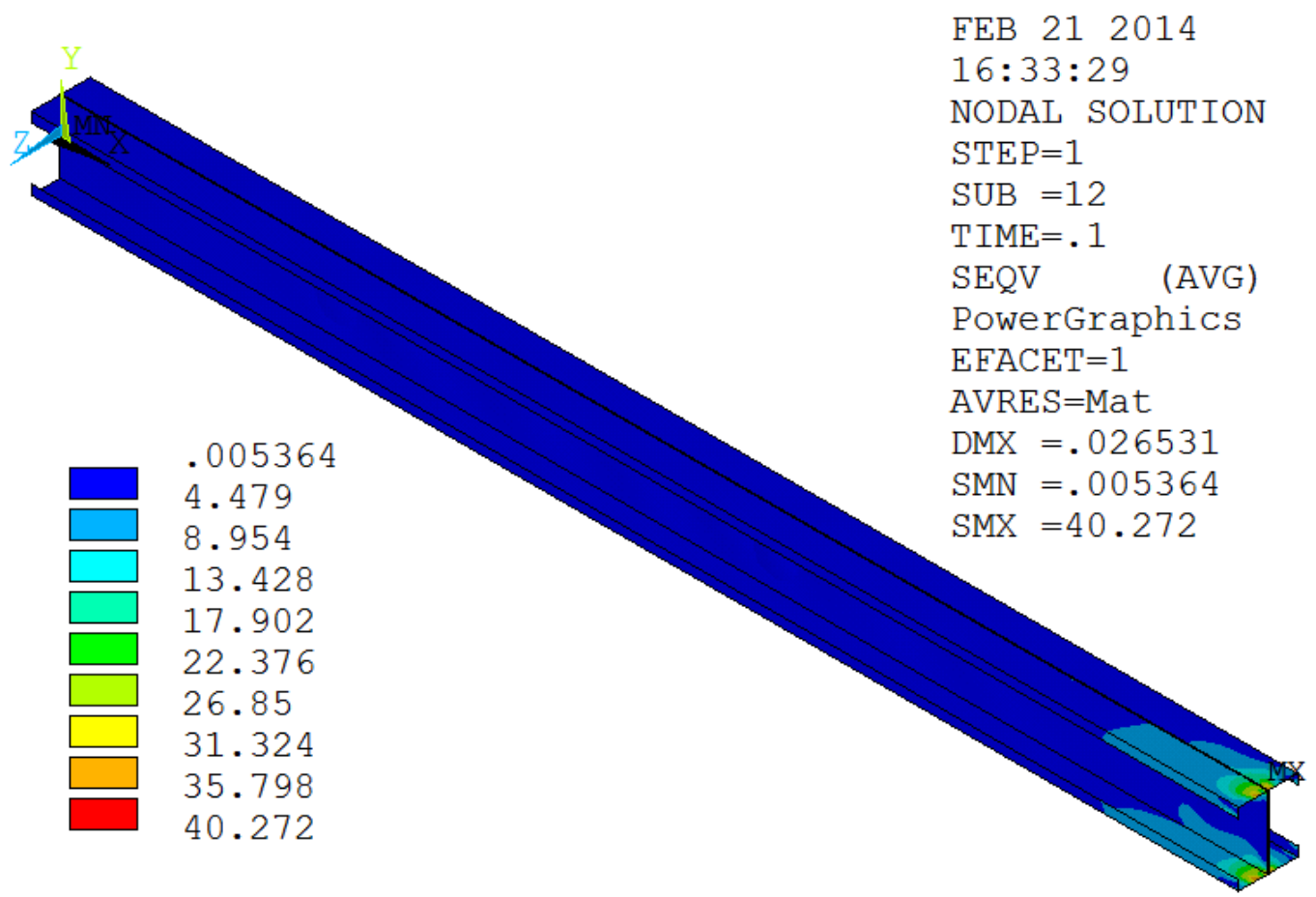

Figura 5.25: Tensões principais devidas à força axial de $70 \% * \mathrm{~N}_{\exp }$ no perfil I enrijecido, modelo ISI07F.

Ao inserir o campo térmico de forma incremental, o campo de tensões no perfil tem variação crescente até um limite de tempo em que as tensões solicitantes não ultrapassem a tensão resistente dos elementos mais aquecidos. Depois desse tempo e, portanto, quando os 
elementos centrais estão a níveis elevados de temperatura, as tensões nessa região são menores e reduzem conforme a ação continua, e a compressão passa a ser suportada pela parte do perfil de aço fora do forno (menos aquecido). As sequências de figuras 5.26 e 5.27 ilustram o campo das tensões principais correspondentes ao campo térmico a que os perfís estão submetidos.

\section{Temperatura no perfil}

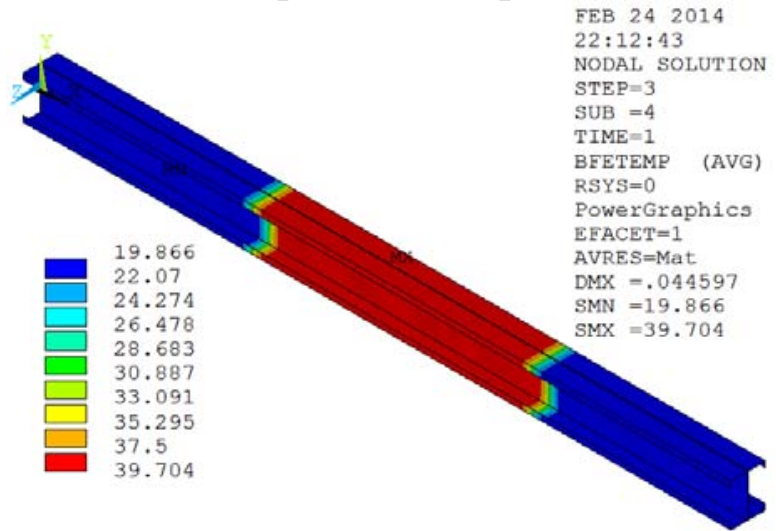

(a)

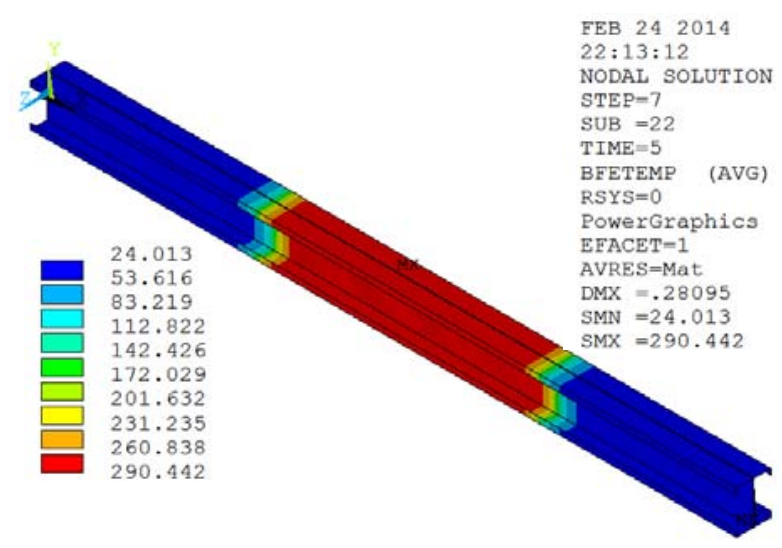

(c)

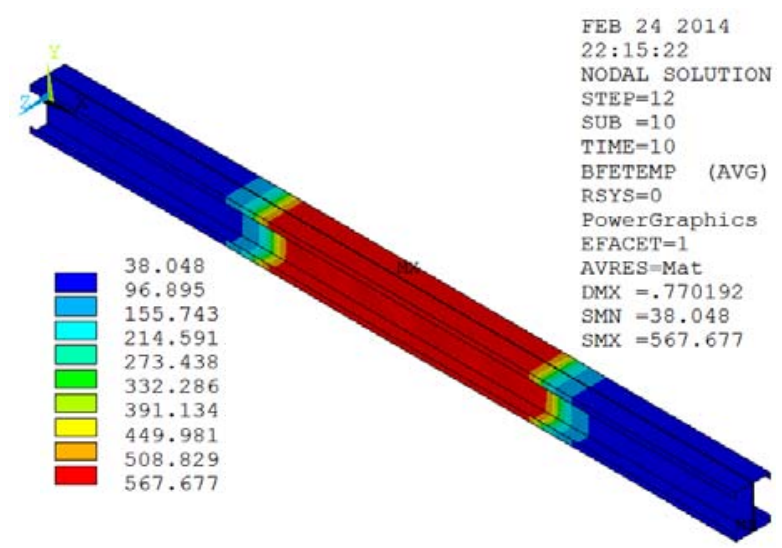

(e)

\section{Estado de tensões - Von Mises}

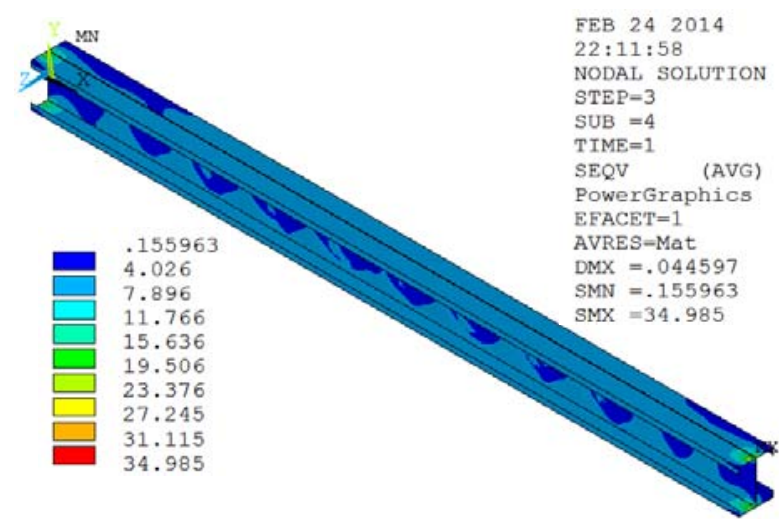

(b)

1 minuto

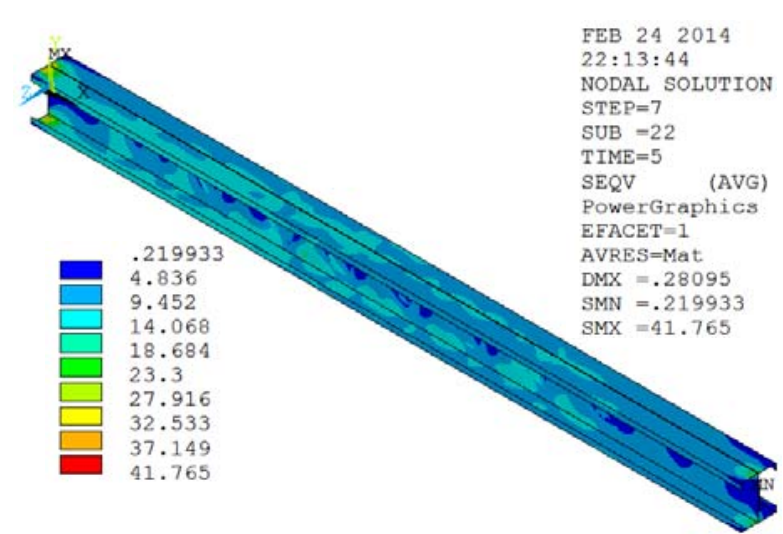

(d)

\section{5 minutos}

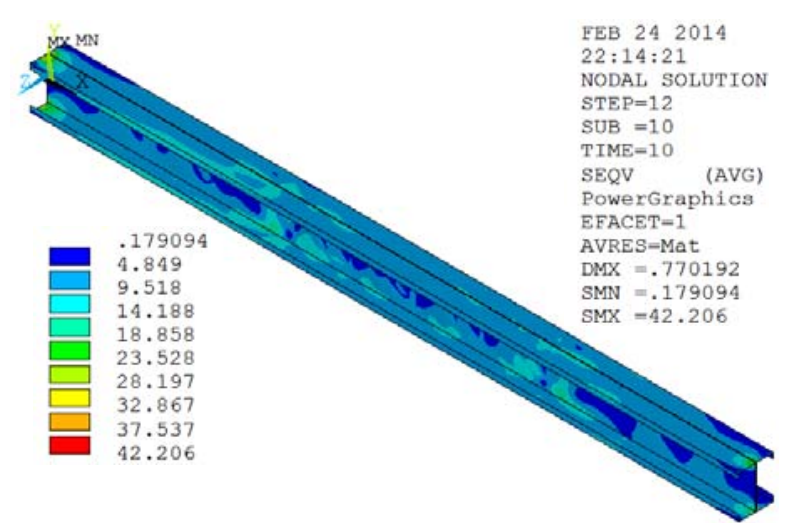

(f)

Figura 5.26 : Estado de tensões principais de Von Mises do perfil I enrijecido no seu correspondente campo térmico, obtidos em intervalos de tempo de 5 minutos. 


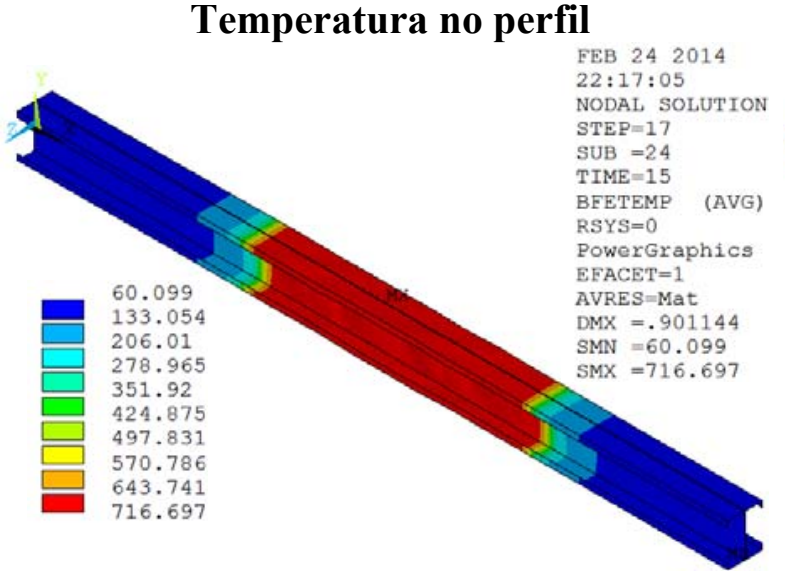

$(\mathrm{g})$

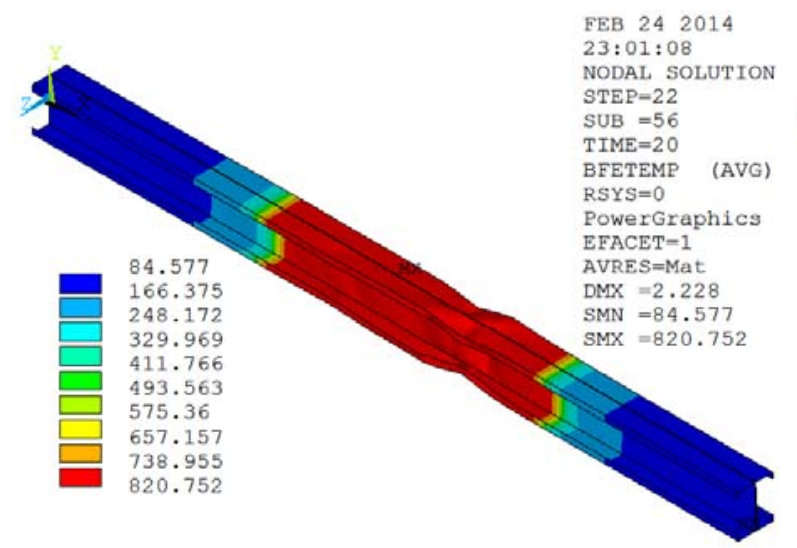

(i)

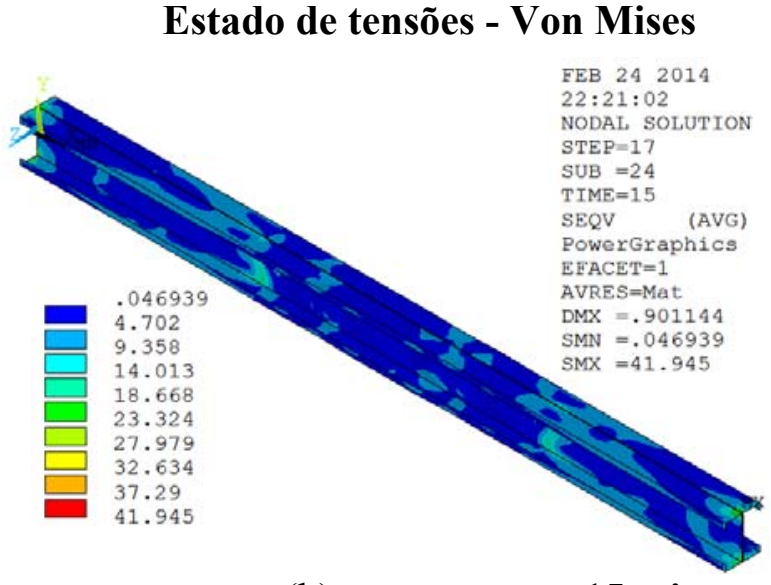

(h)

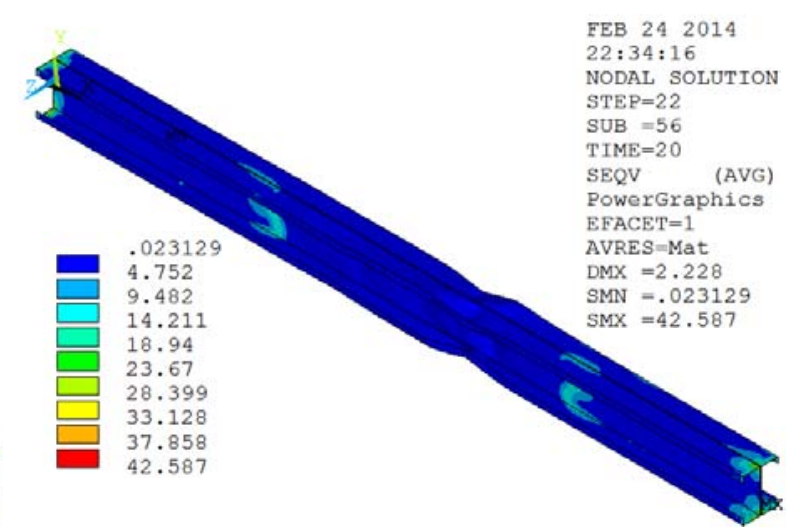

(j)

20 minutos

Figura 5.26 (Continuação): Estado de tensões principais de Von Mises do perfil I enrijecido no seu correspondente campo térmico, obtidos em intervalos de tempo de 5 minutos.

\section{Temperatura no perfil}

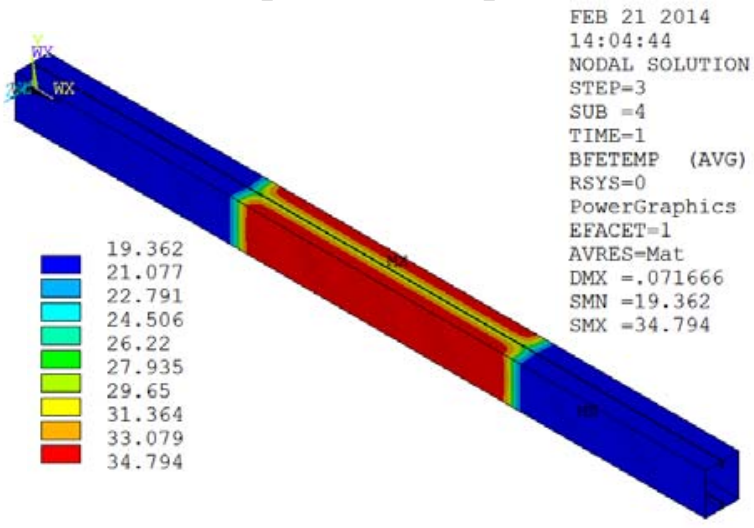

(a)

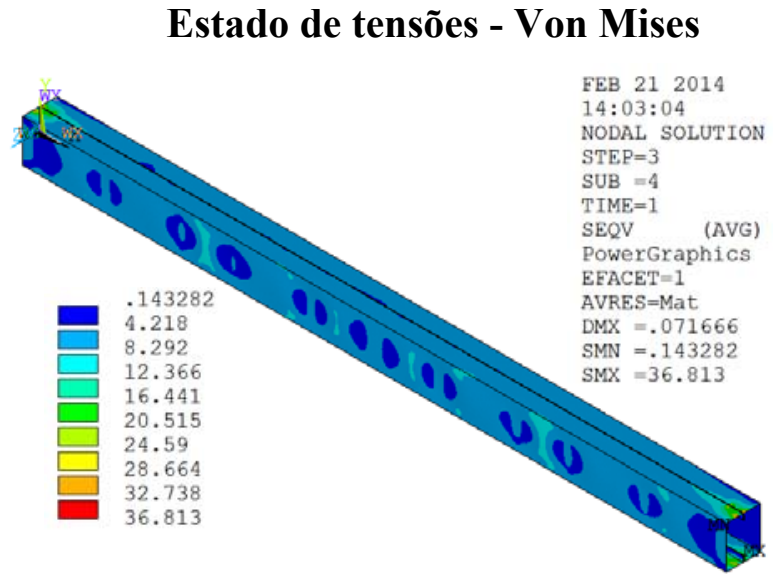

(b)

1 minuto

Figura 5.27: Estado de tensões principais de Von Mises do perfil caixão no seu correspondente campo térmico, obtidos em intervalos de tempo de 5 minutos. 


\section{Temperatura no perfil}

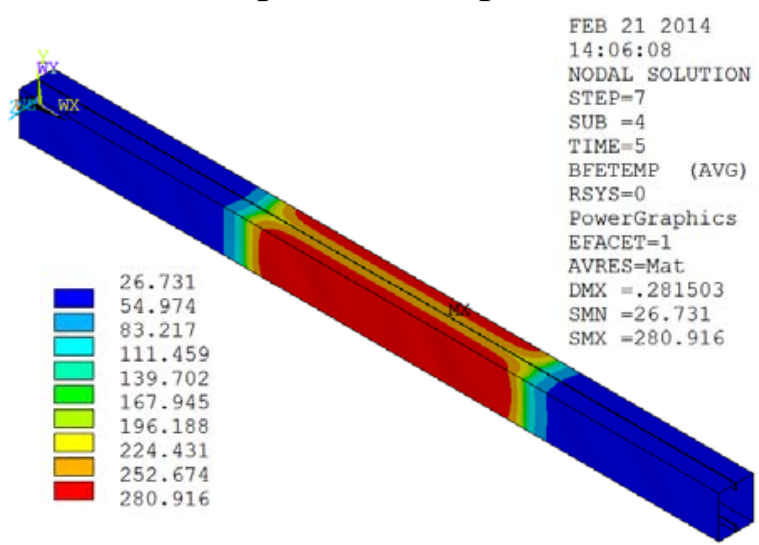

(c)

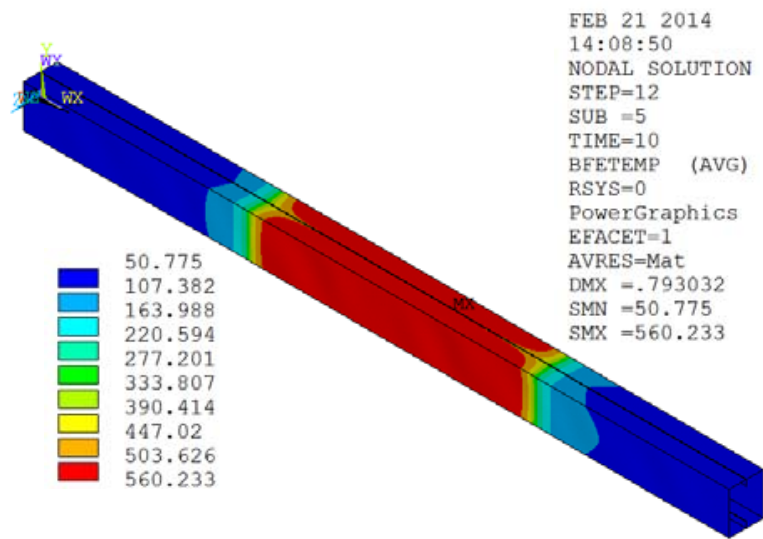

(e)

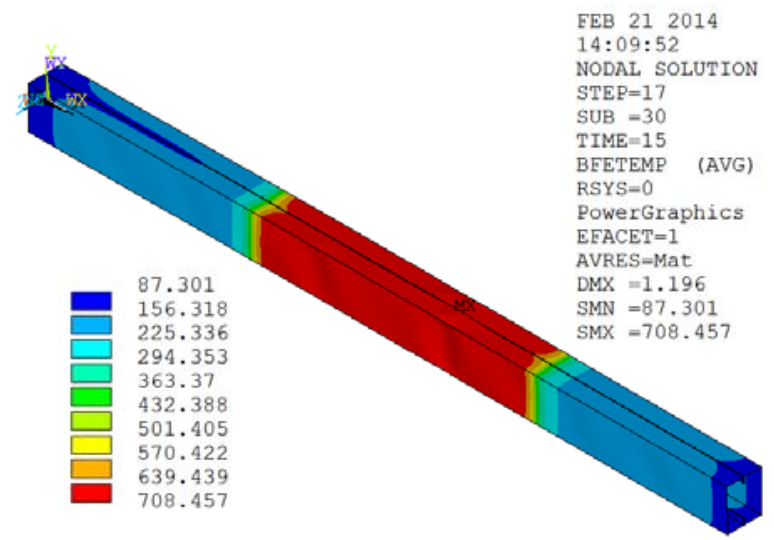

(g)
Estado de tensões - Von Mises

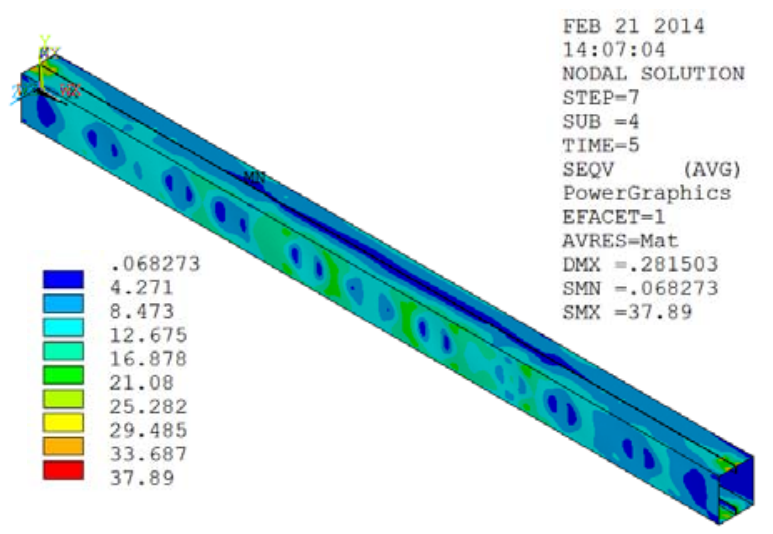

(d)

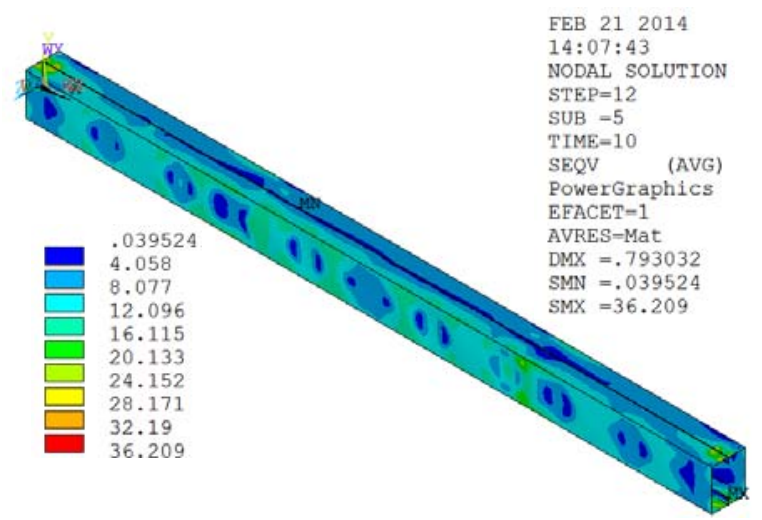

(f)

10 minutos

Figura 5.27 (Continuação): Estado de tensões principais de Von Mises do perfil caixão no seu correspondente campo térmico, obtidos em intervalos de tempo de 5 minutos. 


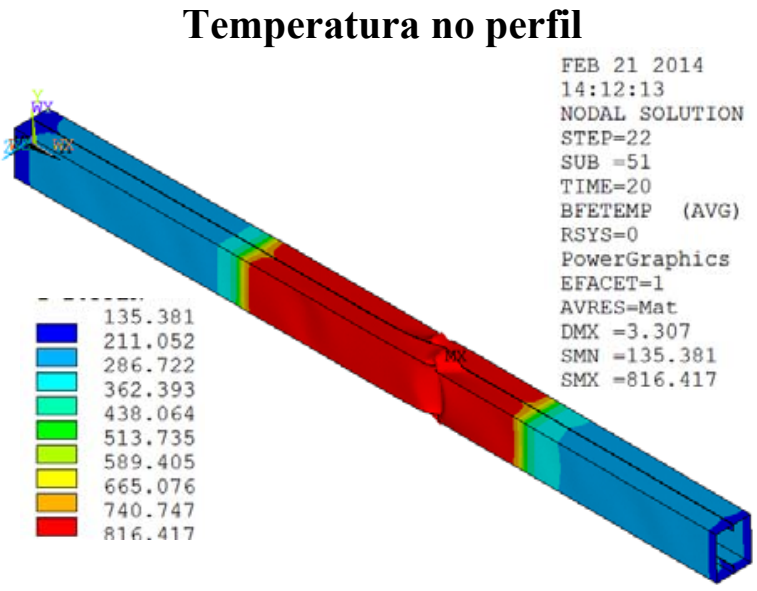

(i)

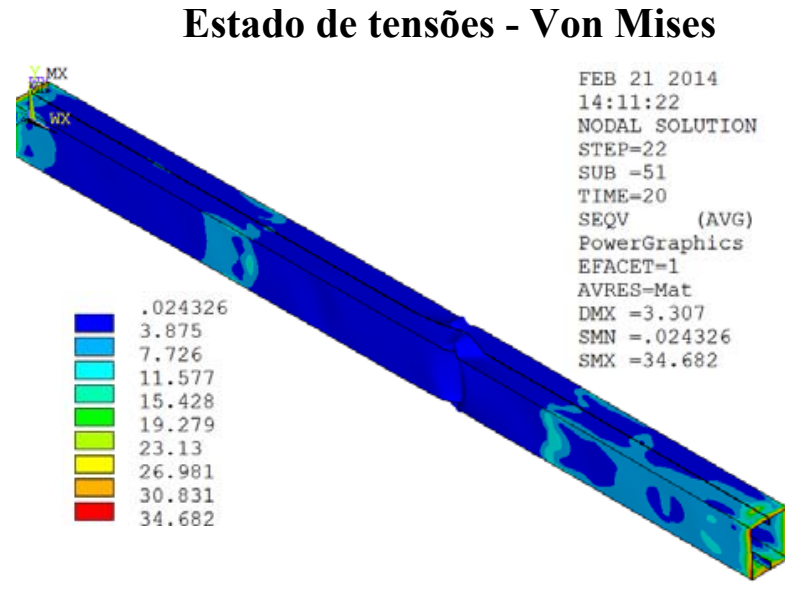

(j)

20 minutos

Figura 5.27 (Continuação): Estado de tensões principais de Von Mises do perfil caixão no seu correspondente campo térmico, obtidos em intervalos de tempo de 20 minutos.

Ainda numa reabordagem do campo de deformações que podem ser observados nas figuras 5.26 e 5.27 (a) a (j) é quanto à questão dos modos de falha. No modelo numérico, foram consideradas as imperfeições geométricas iniciais na forma do perfil de aço formado a frio. Ao acompanhar a variação das deformações ao longo da aplicação da ação térmica, avaliação essa que não foi possível de realizar na análise experimental, observou-se que a ocorrência do modo de instabilidade na seção transversal caixão se iniciou na alma, por ser o elemento mais esbelto. A seção transversal com maior amplitude do modo local apresentou a mesa também deformada. Ao final da análise, quando o modelo numérico atingiu a representação do comportamento pós crítico do perfil, o modo de deformação distorcional já é visível na região crítica. A figura 5.28 (a) ilustra a deformada do perfil caixão já no comportamento pós crítico.

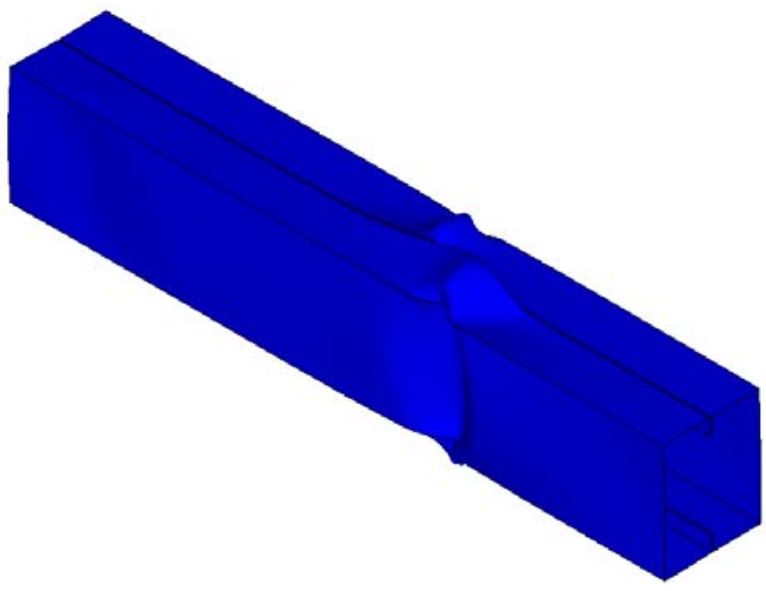

(a)

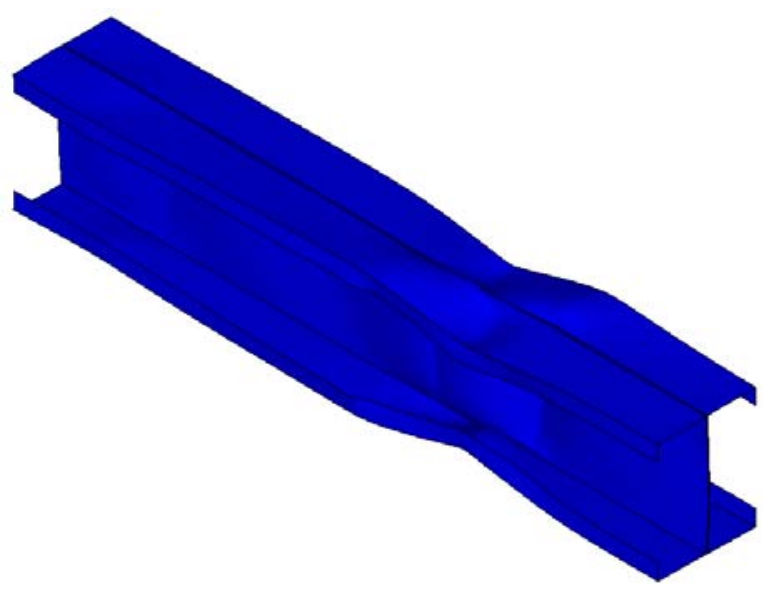

(b)

Figura 5.28: Deformações de colapso no perfil (a) caixão e (b) I enrijecido. 
No perfil I enrijecido, figura 5.28 (b), os comprimentos de semionda relativos à instabilidade local surgem na alma de cada perfil $U_{\mathrm{e}}$. Conforme o aumento da temperatura, há ocorrência de instabilidade local na mesa, nas seções transversais de maior amplitude de deformações. Conforme o material tem sua resistência ao escoamento reduzido pela ação térmica, a deformada global de flexão em torno do eixo de menor inércia tem sua amplitude aumentada. Por fim, na fase pós-crítica, o conjunto mesa - enrijecedor apresentou modo de falha distorcional.

Os gráficos relativos aos resultados obtidos numericamente têm uma trajetória mais uniforme em comparação aos resultados experimentais. Além disso, ressalta-se que no modelo numérico, dificilmente são inseridas todas as variáveis físicas de um problema real. Porém, mesmo com as simplificações consideradas, a análise numérica deve representar satisfatoriamente o problema físico. No capítulo seguinte, é apresentada uma análise comparativa dos resultados experimentais e numéricos, bem como uma aplicação dos procedimentos normativos para os perfis de interesse neste trabalho. 
Neste capítulo são apresentadas análises referentes aos resultados experimentais e numéricos obtidos. Junto a esses resultados, é apresentada e discutida a aplicação dos procedimentos normativos para os perfis de interesse neste trabalho. A descrição dos resultados está dividida em itens, os quais estão organizados da mesma forma das etapas de trabalho desenvolvidas neste projeto.

\subsection{Sobre a análise térmica}

Os efeitos térmicos são verificados em duas partes. A primeira trata da ação térmica transiente a que o forno foi programado para inserir ao volume de gases internos. A segunda parte está relacionada ao campo térmico resultante no perfil. Para obter esse resultado, foram utilizadas propriedades térmicas não extraídas de ensaios de caracterização do material, mas sim valores fornecidos por procedimentos normativos.

\subsubsection{Ação térmica do forno}

A taxa de aquecimento, bem como os procedimentos para controle da temperatura são estabelecidos pela norma internacional ISO 834-1:1999. A leitura da temperatura dos gases aquecidos no forno de ensaios foi realizada por um conjunto de termopares de controle localizados a uma distância entre cinco e $15 \mathrm{~cm}$ dos perfis. Os gráficos das figuras 6.1 e 6.2 mostram as curvas de incêndio obtidas pelo forno nos ensaios, as curvas de incêndio implementadas no modelo numérico, bem como a curva de incêndio-padrão, a título de comparação, para os perfis I enrijecido e caixão, respectivamente. 


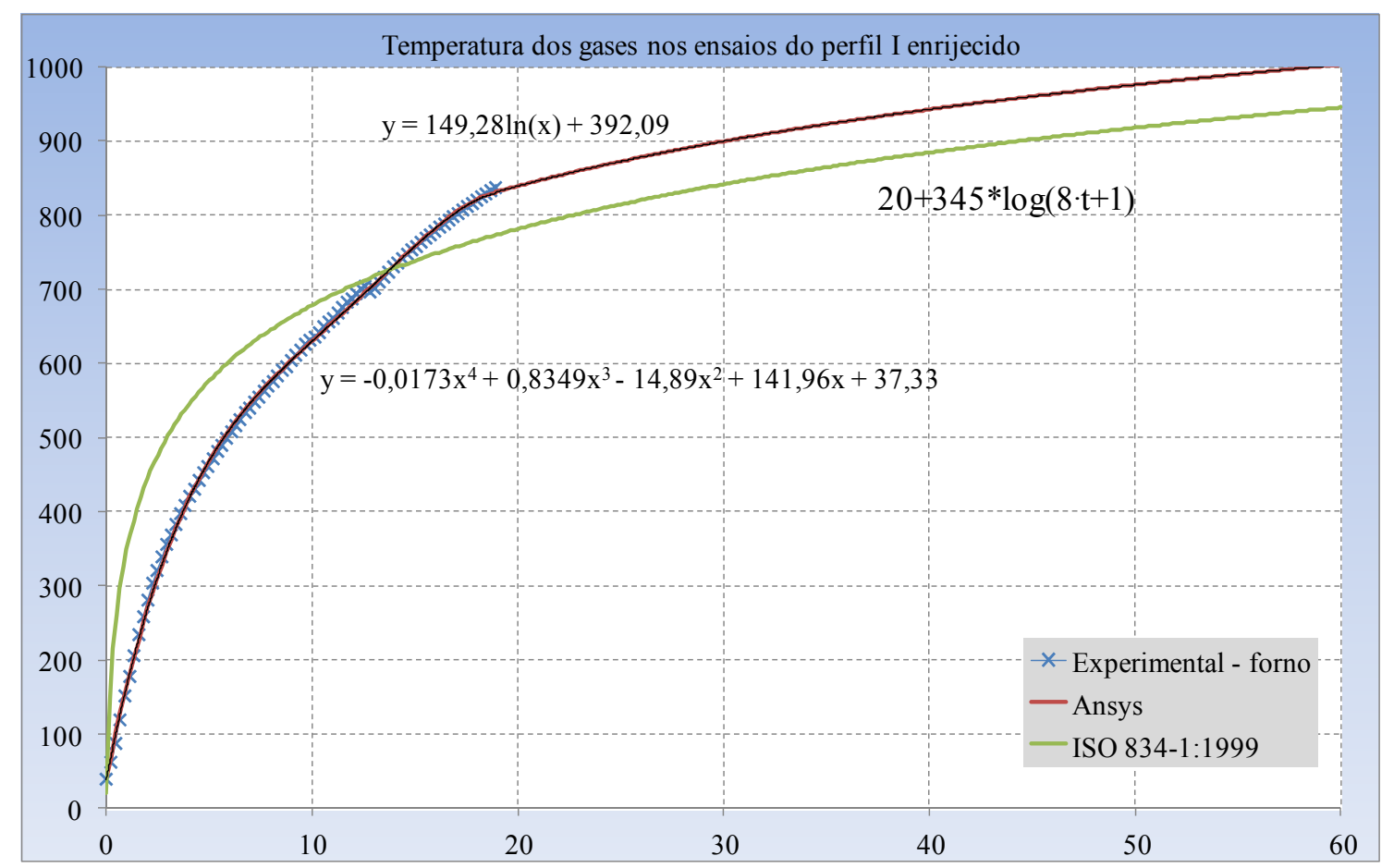

Figura 6.1: Temperatura dos gases no interior do forno nos ensaios do perfil I enrijecido.

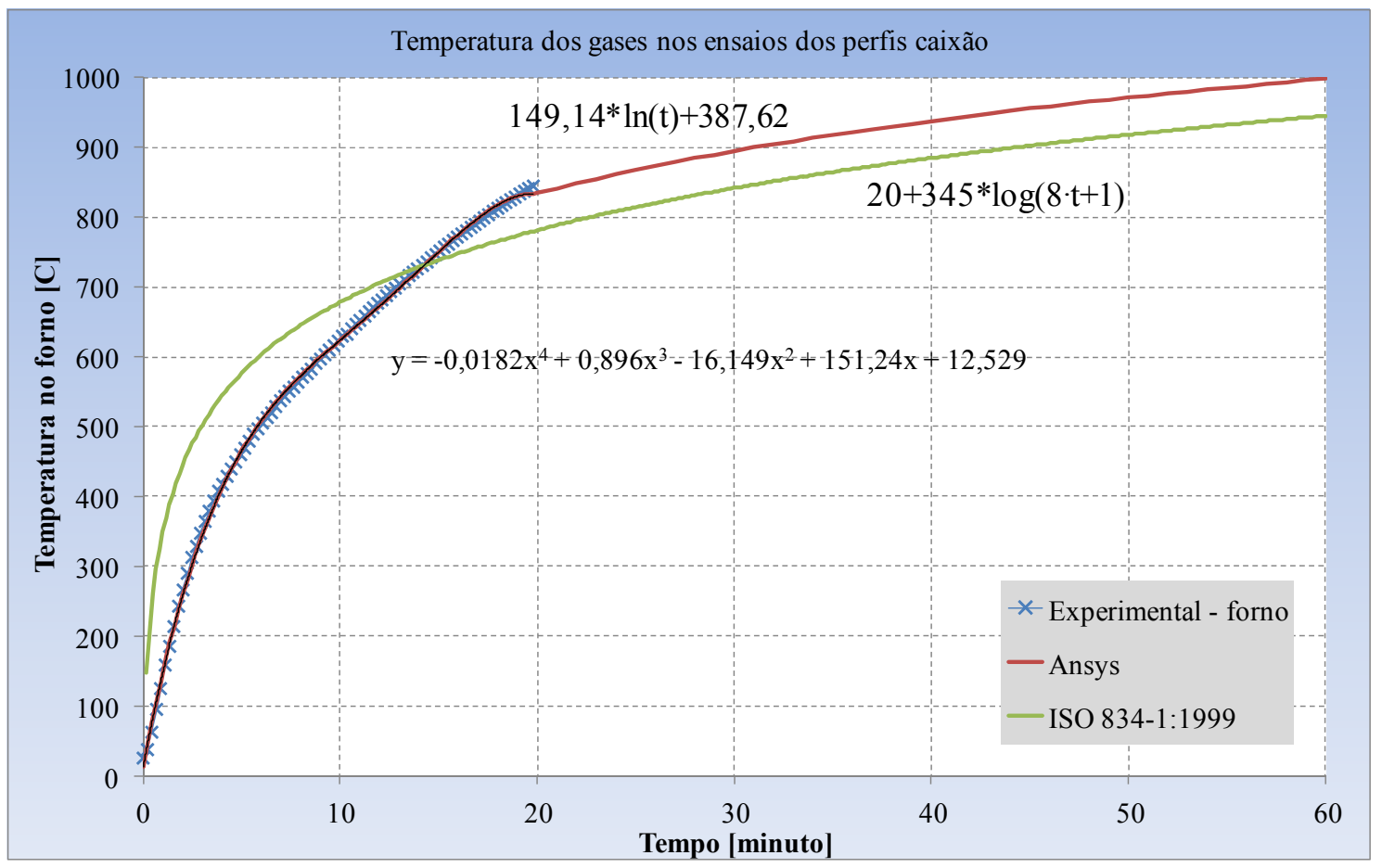

Figura 6.2: Temperatura dos gases no interior do forno nos ensaios do perfil caixão.

Ainda de acordo com esse procedimento, a temperatura de controle do forno não deve ultrapassar o critério de tolerância estabelecido na equação 6.1, definido em termos da área delimitada pelas curvas "tempo x temperatura dos gases". Esse critério é definido em termos da diferença percentual entre a área da curva obtida pelo forno e da curva de incêndio-padrão. 


$$
\begin{array}{lll}
d_{e} \leq 15 \% & \text { para } & 5<t \leq 10 \\
d_{e}=15-0,5(t-10) \% & \text { para } & 10<t \leq 30 \\
d_{e} \leq 5-0,083(t-30) \% & \text { para } & 30<t \leq 60 \\
d_{e} \leq 2,5 \% & \text { para } & t>10 \\
d_{e}=\frac{A-A_{s}}{A_{s}} \times 100 & &
\end{array}
$$

Em que:

$\mathbf{d}_{\mathbf{e}}$ é erro percentual;

A é a área sob a curva de incêndio obtida pelo forno;

$\mathbf{A}_{\mathbf{s}}$ é a área sob a curva de incêndio padrão;

t é o tempo, em minutos.

O tempo máximo de duração do ensaio não ultrapassou 20 minutos. A tabela 6.1 mostra os desvios percentuais identificados com relação à temperatura.

Tabela 6.1: Desvio percentual da curva de temperatura do forno em relação à curva de incêndio padrão da ISO 834-1:1999.

\begin{tabular}{lll}
\hline \multirow{2}{*}{$5<t \leq 10$ minutos } & I enrijecido & Caixão \\
\cline { 2 - 3 } & $11,91 \%$ & $12,46 \%$ \\
\hline $10<t \leq 20$ minutos & $1,93 \%$ & $1,01 \%$ \\
\hline
\end{tabular}

Pela tabela 6.1, é possível observar que o erro no valor da ação aplicada é mais acentuado nos primeiros 10 minutos. Isso se deve à elevada velocidade de aquecimento requerida no início do ensaio. Nos primeiros dois minutos, por exemplo, a taxa de aquecimento da curva ISO 834-1:1999 é de $146^{\circ} \mathrm{C} /$ minuto. Em ensaios em que são utilizados fornos elétricos, como foi o caso da presente pesquisa, há uma complexidade em atingir essa taxa, como pôde ser observado na tabela 6.1, devido à grande demanda energética do equipamento. Isso justifica uma tolerância mais branda nesse primeiro intervalo. 


\subsubsection{Campo térmico resultante no modelo}

A título de validação do modelo numérico, o campo térmico obtido na análise numérica foi comparado com o obtido na análise experimental e com o que foi obtido com base na norma brasileira ABNT NBR 14323:2013. A elevação da temperatura no aço num intervalo de tempo $\Delta t$, de acordo com o procedimento normativo é determinada por meio da equação 6.2, que leva em consideração as propriedades físicas e térmicas do aço, bem como as características geométricas da seção transversal. Vale lembrar que essa equação é valida para perfis estruturais submetidos à distribuição uniforme de temperatura na seção transversal sem revestimento contra fogo situado no interior de uma edificação.

$\Delta \theta_{a, t}=k_{s h} \cdot \frac{\left(u / A_{g}\right)}{c_{a} \cdot \rho_{a}} \cdot \varphi \cdot \Delta t$

Na equação 6.2, as variáveis são definidas como se seguem:

$\left(\mathrm{u} / \mathrm{A}_{\mathrm{g}}\right)$ é o fator de massividade de elementos prismáticos sem revestimento de proteção contra fogo, em $\mathrm{m}^{-1}$;

u é o perímetro exposto ao incêndio do elemento estrutural de aço, em m;

$\mathrm{A}_{\mathrm{g}}$ é a área bruta da seção transversal, em $\mathrm{m}^{2}$;

$\rho_{\mathrm{a}}$ é a massa especifica do aço, em $\mathrm{kg} / \mathrm{m}^{3}$;

$\mathrm{c}_{\mathrm{a}}$ é o calor especifico do aço, em $\mathrm{J} / \mathrm{kg} \cdot{ }^{\circ} \mathrm{C}$;

$\Delta \mathrm{t}$ é o intervalo de tempo, em s, não adotado maior que $5 \mathrm{~s}$;

$\mathrm{k}_{\mathrm{sh}}$ é o fator de correção para efeito de sombreamento. Em seções transversais fechadas $\mathrm{k}_{\mathrm{sh}} \mathrm{e}$ tomado igual a 1,0. Em seções do tipo I ou H, essa variável é determinada pela equação 6.3;

$k_{s h}=0,9 \cdot \frac{\left(u / A_{g}\right)_{b}}{\left(u / A_{g}\right)}$

Na equação 6.3, conforme descrito na ABNT NBR 14323:2013, a relação $\left(u / A_{g}\right)_{b}$ é definido como o fator de massividade de uma caixa hipotética que envolve o perfil. 
O coeficiente $\varphi$ representa o fluxo de calor por unidade de área, em W/m². O valor de $\varphi$, dado pela equação 6.4 é formado pela parcela referente ao fluxo de calor devido à convecção e pela parcela referente ao fluxo por radiação, dadas pelas equações 6.5 e 6.6, respectivamente.

$\varphi=\varphi_{c}+\varphi_{r}$

$\varphi_{c}=\alpha_{c} \cdot\left(\theta_{g}-\theta_{a}\right)$

$\varphi_{r}=5,57 \times 10^{-8} \cdot \varepsilon_{r e s} \cdot\left[\left(\theta_{g}+273\right)^{4}-\left(\theta_{a}+273\right)^{4}\right]$

Nas equações 6.4 a 6.6, tem-se as seguinte variáveis:

$\varphi_{c}$ é o componente do fluxo de calor devido à convecção, em $\mathrm{W} / \mathrm{m}^{2}$;

$\varphi_{\mathrm{r}}$ é o componente do fluxo de calor devido à radiação, em $\mathrm{W} / \mathrm{m}^{2}$;

$\alpha_{c}$ é o coeficiente de transferência de calor por convecção. No caso de elementos estruturais de aço expostos ao incêndio-padrão da ISO 834-1:1999, $\alpha_{c}$ pode ser tomado igual a $25 \mathrm{~W} / \mathrm{m}^{2}$;

$\theta_{\mathrm{g}}$ é a temperatura dos gases, em ${ }^{\circ} \mathrm{C}$;

$\theta_{\mathrm{a}}$ é a temperatura da superfície do aço, em ${ }^{\circ} \mathrm{C}$;

$\varepsilon_{\text {res }}$ é a emissividade resultante, tomado igual a 0,7 .

O gráfico ilustrado na figura 6.3 faz uma comparação entre a elevação da temperatura nos perfis I enrijecido e caixão, obtida pelo procedimento da ABNT NBR 14323:2013, por meio da análise numérica e da investigação experimental. Observou-se que, embora o perfil I enrijecido apresente maior superfície em comparação ao perfil caixão, a elevação da temperatura em ambos os perfis ocorreu em taxas semelhantes nos três critérios avaliados. 


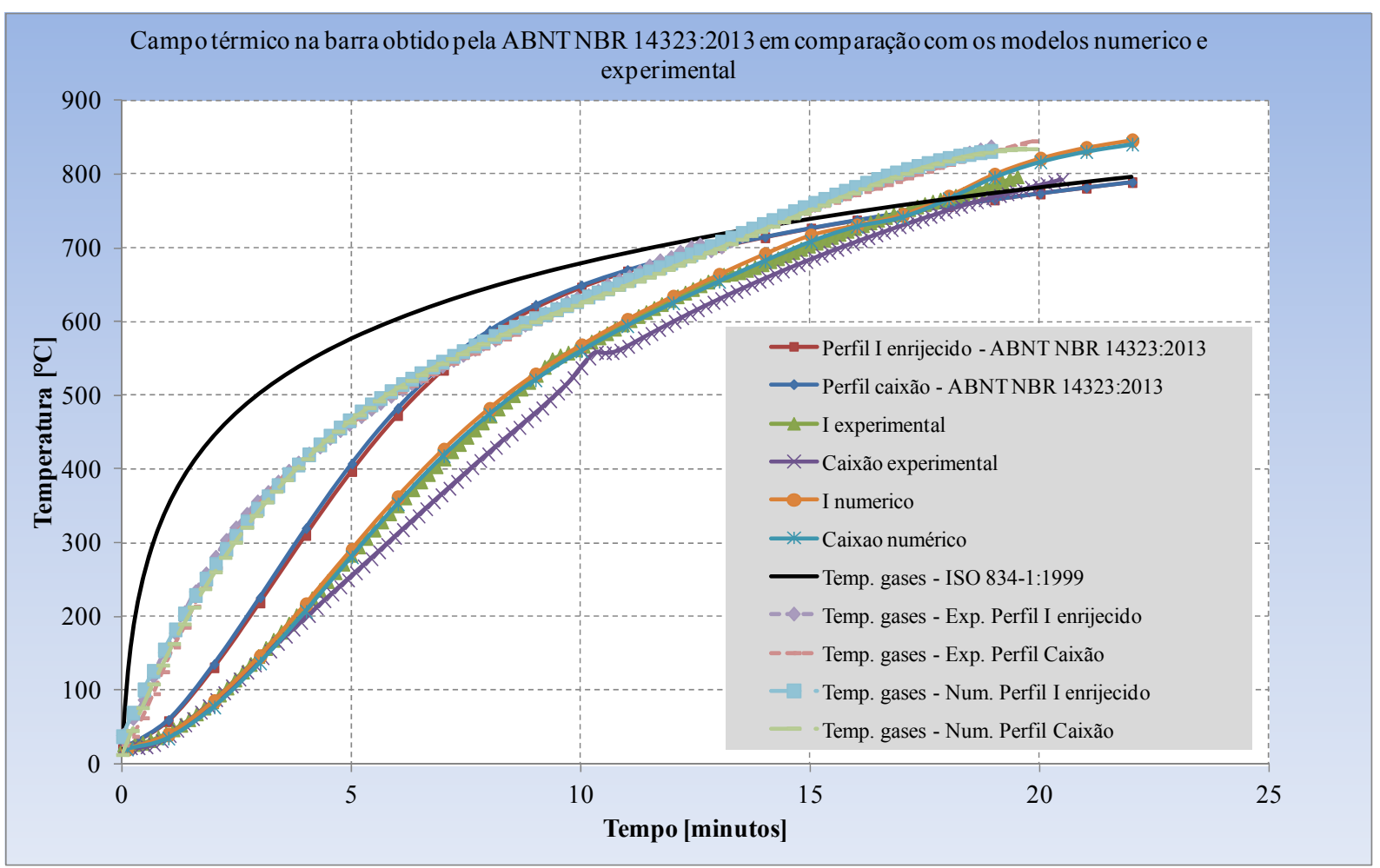

Figura 6.3: Comparação entre a elevação da temperatura nos perfis I enrijecido e caixão.

Foram tomadas três seções transversais dos perfis para análise do campo térmico. A primeira seção transversal analisada é a que está submetida à ação térmica de aquecimento do forno de ensaios. As outras duas estão, respectivamente acima e abaixo do forno. Esse procedimento foi adotado em virtude de a ação térmica não se distribuir uniformemente ao longo do comprimento dos perfis.

O gráfico da figura 6.4 mostra o aumento da temperatura no aço do perfil I enrijecido, obtido por meio da investigação experimental, numérica e do procedimento de cálculo da ABNT NBR 14323:2013 (aplicado ao trecho central). Nas investigações com abordagem a esse perfil, conforme explicado no capítulo quatro, os trechos fora do forno apresentaram variações de temperatura semelhantes, de forma que possam ser representados pela mesma curva.

Observa-se que, para esse perfil, tanto as seções externas como interna ao forno, o modelo numérico forneceu resultados satisfatórios em comparação com os valores obtidos no programa experimental, de forma a respeitar a condição de não uniformidade da distribuição da temperatura. 


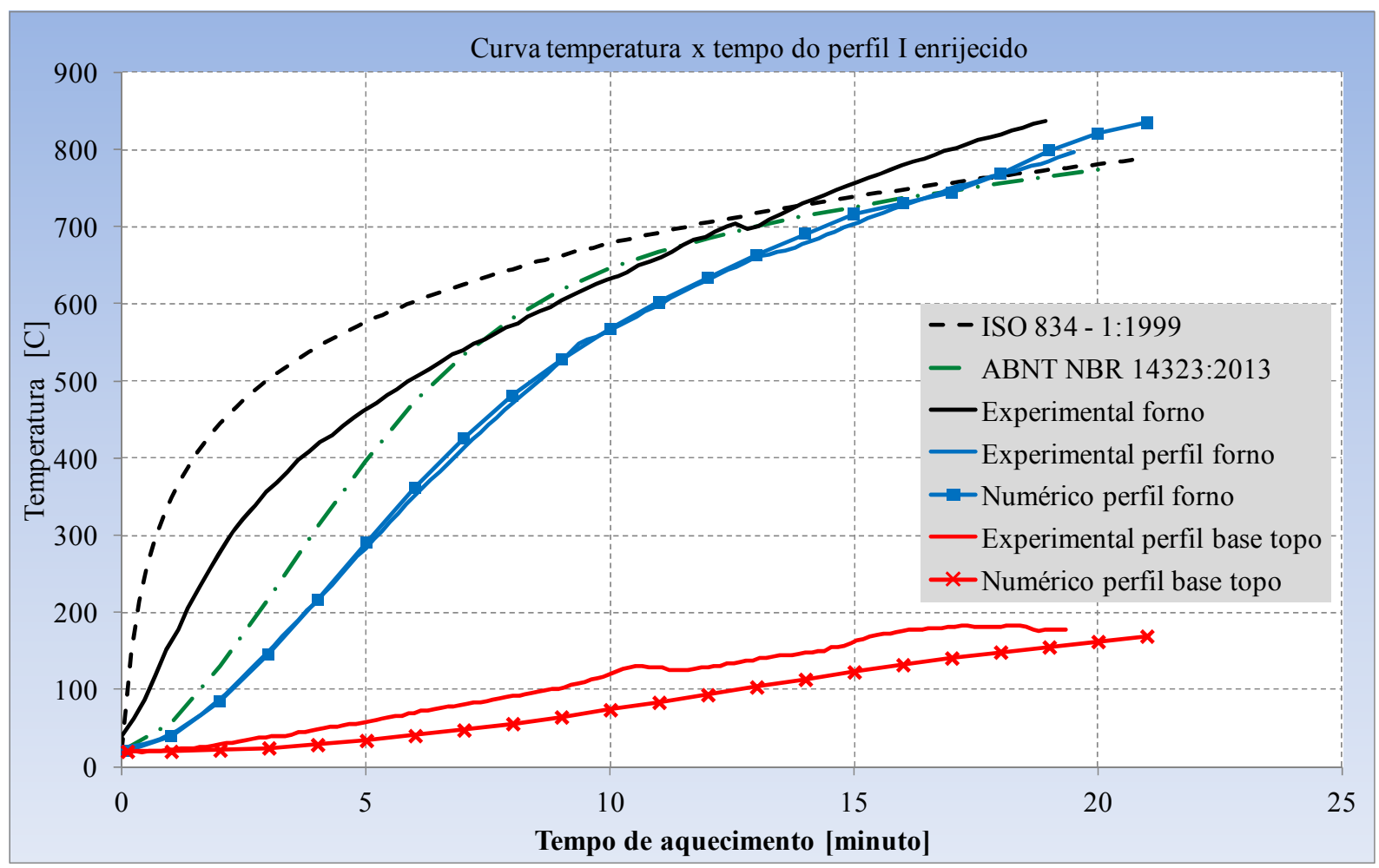

Figura 6.4: Campo térmico resultante no perfil I enrijecido.

O campo térmico obtido pelo procedimento da norma brasileira resulta em temperaturas mais elevadas em comparação aos obtidos tanto pela análise numérica como experimental. Isso se deve ao fato de o procedimento normativo aplicar a variação de temperatura dos gases de acordo com a curva de incêndio-padrão da norma ISO 834-1:1999 na sua equação para determinação do campo térmico, ao passo que os modelos numérico e experimental aplicam a variação da temperatura fornecida pelo forno de ensaios, cuja taxa de aquecimento é menor que a da curva de incêndio-padrão nos instantes iniciais.

O aquecimento do perfil caixão é ilustrado em gráfico na figura 6.5. Nesse perfil, os campos térmicos obtidos nas seções externas são visivelmente distintos e mostram que a taxa de aquecimento na seção acima do forno é maior que na seção abaixo. O modelo numérico resultou em valores inferiores aos obtidos na investigação experimental.

Essa divergência entre os resultados numérico e experimental na região fora do forno se deve, de fato, à complexidade na obtenção dos dados experimentais. Para obter as temperaturas nas regiões externas ao forno, o termopar é alocado na cavidade do perfil caixão por meio de um orifício próprio para a sua passagem. Porém, a sua fixação não garantiu a 
precisão na leitura, visto que houve a possibilidade de o termopar ter tido contato e, por consequência, lido a temperatura interna do perfil e não dos gases aquecidos.

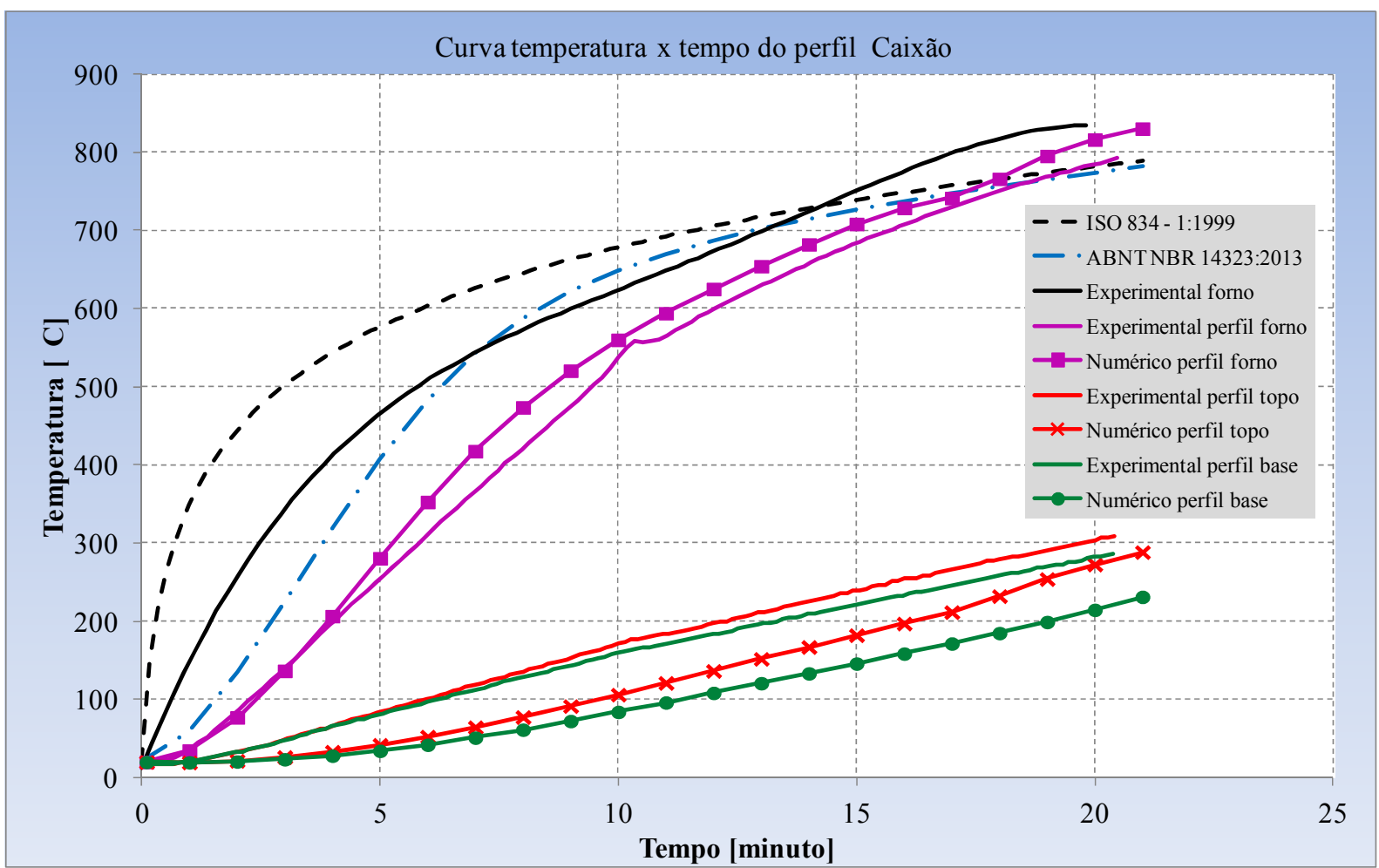

Figura 6.5: Campo térmico resultante no perfil caixão.

Para ambos os perfis estudados, os gráficos indicam uma concordância satisfatória entre o campo térmico apresentado pelo modelo numérico e o resultado experimental referente à região intermediaria. Porém, admite-se certa complexidade em representar o campo térmico nas regiões externas ao forno, uma vez que o modelo numérico resultou em campos de temperatura abaixo do que foi obtido nos modelos experimentais.

\subsection{Sobre a análise termoestrutural}

A validação do modelo numérico termoestrutural é apresentada com base na comparação com os resultados obtidos na investigação experimental, em termos de trajetória do deslocamento axial em função da temperatura. De forma geral, ao observar a evolução dos deslocamentos axiais, ressalta-se que não foi possível controlar a velocidade da queda do deslocamento após a compressão aplicada no perfil atingir seu valor máximo. Uma das razões é que o ensaio utilizou cilindro hidráulico para aplicação da compressão, portanto, não foi possível realizar o controle do deslocamento axial da barra, mas sim da aplicação da força. 
Além disso, o sistema de aquisição não foi programado para controlar a taxa de deslocamento axial de curso do cilindro. Dessa forma, o critério de parada dos ensaios, em vez daquele estabelecido pela ISO 834-1:1999, considerou o patamar de deslocamento em que a força aplicada ainda se mantém constante. Em outras palavras, o tempo e a correspondente temperatura de colapso é caracterizado pelo instante em que ocorre a queda repentina da força aplicada.

O gráfico da figura 6.6 mostra a variação do deslocamento axial do perfil I enrijecido submetido a $40 \%$ da compressão de colapso obtida na investigação experimental à temperatura ambiente - $\mathrm{N}_{\text {exp. }}$. O patamar de deslocamento obtido no modelo numérico apresentou concordância com o experimental. Em relação à temperatura de colapso, a diferença observada entre os modelos numérico e experimental não teve influencia no comportamento estrutural.

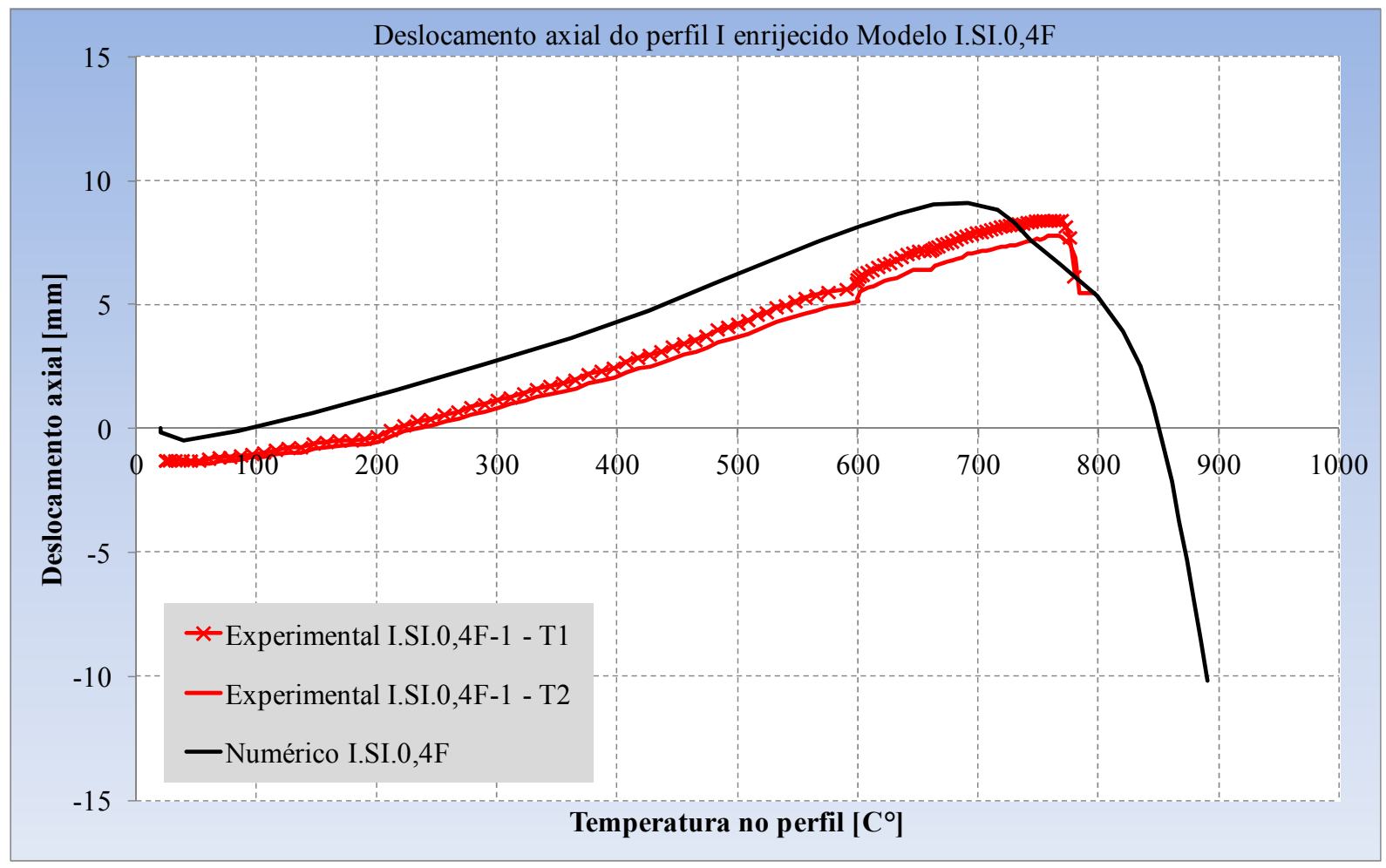

Figura 6.6: Deslocamento axial do modelo I.SI.0,4F em função do aumento de temperatura.

Em todos os modelos numéricos desenvolvidos, os deslocamentos iniciais de contração, na fase à temperatura ambiente, resultaram menores do que os obtidos nos ensaios. Os modelos submetidos às maiores força de compressão foram os que apresentaram as maiores diferenças em relação ao resultado experimental, como ilustra o gráfico da figura 6.7, 
o que mostra de fato, uma maior rigidez do modelo numérico em comparação com o experimental. De modo geral, o comportamento estrutural após a barra ter alcançado a temperatura de colapso no modelo numérico foi melhor representado em comparação com os resultados obtidos nos ensaios.

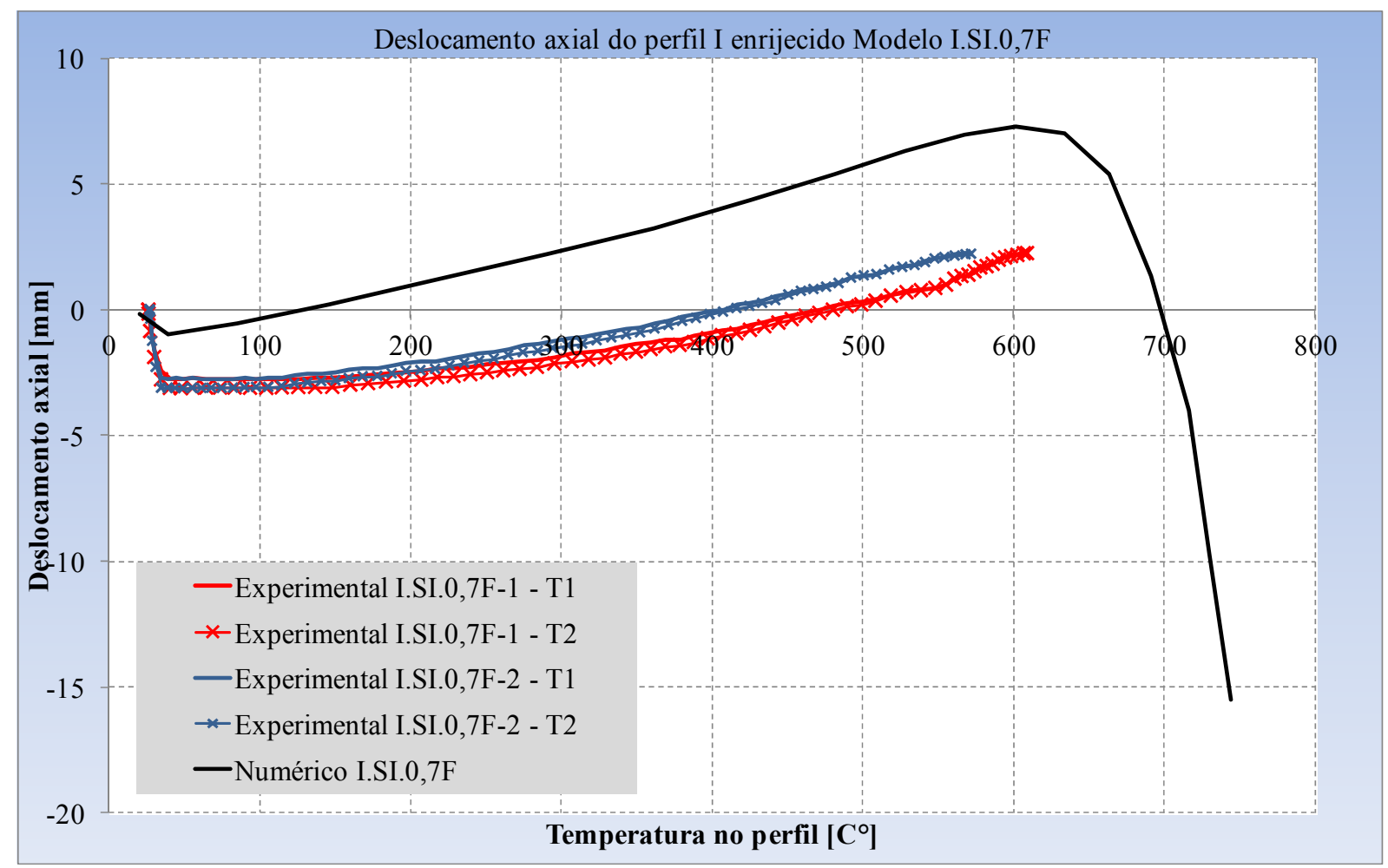

Figura 6.7: Deslocamento axial do modelo I.SI.0,7F em função do aumento de temperatura.

O gráfico da figura 6.8 ilustra a trajetória de deslocamento axial do perfil caixão submetido a $40 \%$ de $\mathrm{N}_{\text {exp. }}$ Embora o patamar de deslocamento axial de dilatação térmica seja maior em comparação aos resultados obtidos nos ensaios, a temperatura de colapso se manteve dentro dos valores obtidos experimentalmente. 


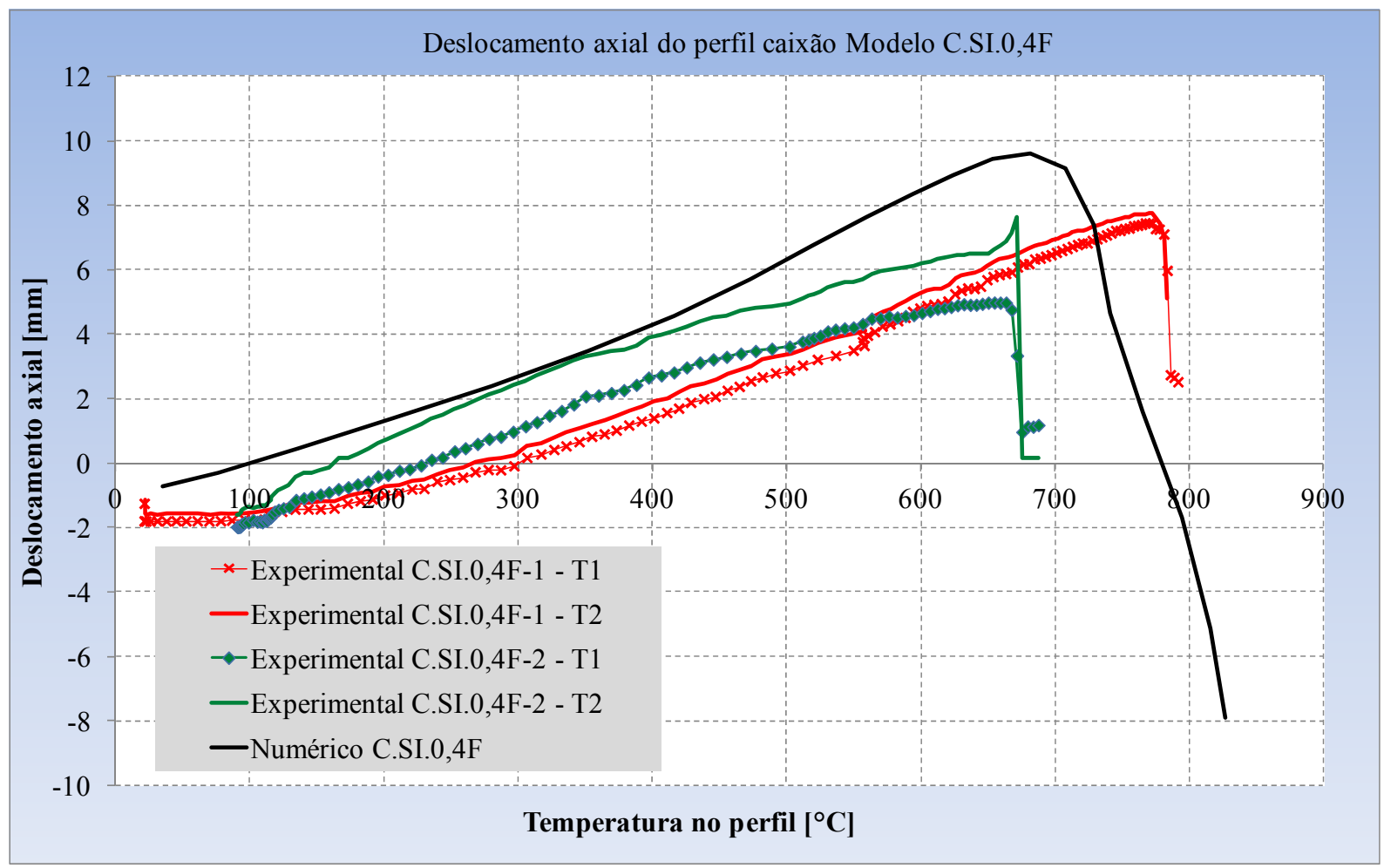

Figura 6.8: Deslocamento axial do modelo C.SI.0,4F em função do aumento de temperatura.

Como a aplicação da força ocorreu por meio de um cilindro hidráulico, não foi possível controlar o deslocamento do pistão, de forma que o deslocamento axial foi medido por dois transdutores diametralmente opostos. Por fim, observa-se que o modelo numérico forneceu resultados em termos de deslocamento axial e correspondente temperatura de colapso dentro do intervalo obtido na investigação experimental.

O modelo numérico da figura 6.9 está visivelmente mais rígido em comparação às barras ensaiadas, o que resultou num patamar de deslocamento e de temperaturas de colapso superiorres ao de ambas as repetições de ensaios. Os modelos experimentais aqui apresentados, que tratam dos perfis caixão submetidos a $70 \%$ de $\mathrm{N}_{\exp }$, resultaram em trajetórias de deslocamento distintas, em que a temperatura de colapso no primeiro modelo foi, aproximadamente $130{ }^{\circ} \mathrm{C}$ menor que no segundo modelo. 


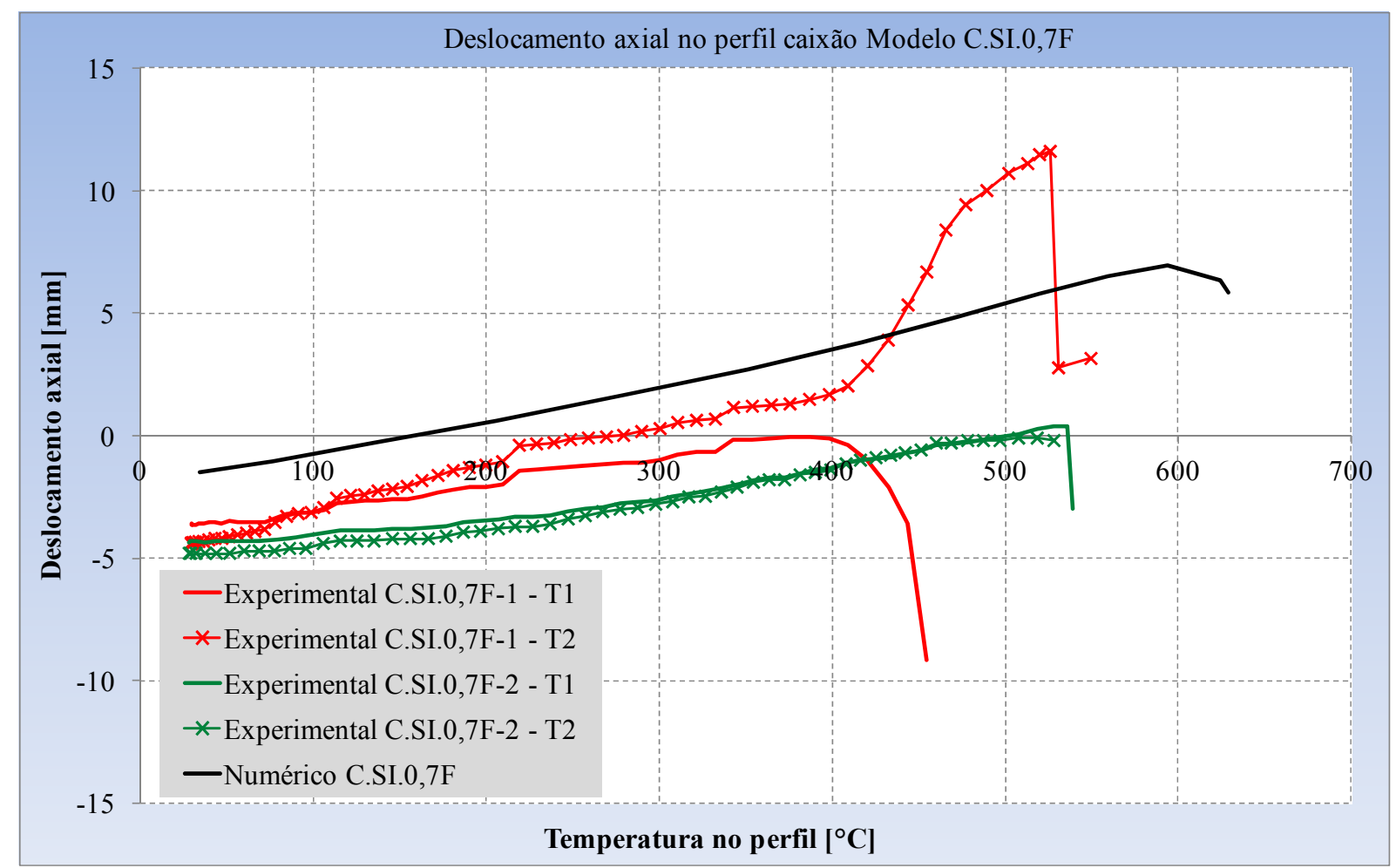

Figura 6.9: Deslocamento axial do modelo C.SI.0,7F em função do aumento de temperatura.

As tabelas 6.2 e 6.3 mostram resumidamente, os valores de temperaturas que as barras atingiram no instante de falha nas análises experimental e numérica. De acordo com os resultados (campo térmico experimental/numérico) é possível afirmar que houve uma concordância satisfatória do campo térmico numérico em relação ao experimental.

Tabela 6.2: Tempo e a respectiva temperatura de colapso: obtidos via programa experimental e via análise numérica para as barras de perfil I enrijecido.

\begin{tabular}{cccccc}
\hline Barra & $\begin{array}{c}\text { Temperatura } \\
\text { final (exp.) }\left[{ }^{\circ} \mathbf{C}\right]\end{array}$ & $\begin{array}{c}\text { Tempo final } \\
\left.(\mathbf{e x p}){ }^{\circ} \mathbf{C}\right]\end{array}$ & $\begin{array}{c}\text { Temperatura } \\
\text { final (num.) } \\
{\left[{ }^{\circ} \mathbf{C}\right]}\end{array}$ & $\begin{array}{c}\text { Tempo final } \\
\left(\text { num.) }\left[{ }^{\circ} \mathbf{C}\right]\right.\end{array}$ & $\begin{array}{c}\text { Temperatura de colapso: } \\
(\text { experimental/numérico) }\end{array}$ \\
\hline \hline I.SI04F-3 & 763 & $15^{\prime} 45^{\prime \prime}$ & 690 & $14^{\prime}$ & 1,11 \\
\hline I.SI04F-5 & 770 & $19^{\prime} 30^{\prime \prime}$ & 690 & $14^{\prime}$ & 1,12 \\
\hline I.SI07F-1 & 609 & $13^{\prime} 18^{\prime \prime}$ & 602 & $11^{\prime}$ & 1,01 \\
\hline I.SI07F-2 & 572 & $11^{\prime} 46^{\prime \prime}$ & 602 & $11^{\prime}$ & 0,95 \\
\hline
\end{tabular}


Tabela 6.3: Tempo e a respectiva temperatura de colapso: obtidos via programa experimental e via análise numérica para as barras de perfil caixão.

\begin{tabular}{cccccc}
\hline Barra & $\begin{array}{c}\text { Temperatura } \\
\text { final }(\mathbf{e x p})\left[^{\circ} \mathbf{C}\right]\end{array}$ & $\begin{array}{c}\text { Tempo final } \\
(\mathbf{e x p})\left[^{\circ} \mathbf{C}\right]\end{array}$ & $\begin{array}{c}\text { Temperatura } \\
\text { final (num.) } \\
{\left[{ }^{\circ} \mathbf{C}\right]}\end{array}$ & $\begin{array}{c}\text { Tempo final } \\
\left(\text { num.) }\left[{ }^{\circ} \mathbf{C}\right]\right.\end{array}$ & $\begin{array}{c}\text { Temperatura de colapso: } \\
(\text { experimental/numérico) }\end{array}$ \\
\hline \hline C.SI04F-2 & 654 & $17^{\prime} 06^{\prime \prime}$ & 681 & $14^{\prime}$ & 0,96 \\
\hline C.SI04F-3 & 767 & $19^{\prime} 37^{\prime \prime}$ & 681 & $14^{\prime}$ & 1,13 \\
\hline C.SI07F-1 & 375 & $8^{\prime}$ & 593 & $11^{\prime}$ & 0,63 \\
\hline C.SI07F-2 & 535 & $10^{\prime} 30^{\prime \prime}$ & 593 & $11^{\prime}$ & 0,90 \\
\hline
\end{tabular}

\subsection{Procedimentos normativos aplicados aos perfis formados a frio de seção transversal composta}

O objetivo deste item é apresentar a verificação da força de compressão resistente de cálculo em situação de incêndio por meio dos procedimentos da norma brasileira ABNT NBR 14323:2013, da norma europeia EN 1993 -1-2:2005, e da norma americana ANSI/AISC 36010, juntamente com a aplicação do Método da Resistência Direta que, atualmente, faz parte do corpo da norma AISI S100 - 2007.

\subsubsection{Investigação à temperatura ambiente}

Antes da realização dos ensaios à temperaturas elevadas, uma investigação experimental à temperatura ambiente foi realizada com intuito de determinar a força de colapso e, consequentemente a força a ser aplicada nas análises termoestruturais. A título de verificação complementar, o valor obtido nos ensaios foi comparado aos resultados numéricos e obtidos pelos procedimentos das normas ABNT NBR 14762:2010, Eurocode 3 - 1.3 e AISI S-100:2007. Em todas as comparações, os resultados experimentais ficaram aquém tanto dos resultados obtidos numericamente como daqueles obtidos por meio das normas estudadas.

A tabela 6.4 mostra a comparação dos resultados experimentais e numéricos com os valores nominais da força de compressão resistente calculada por meio da norma ABNT NBR 14762:2010. A última coluna mostra a concordância dos resultados numéricos com os resultados obtidos com base nos calculados conforme especificações da norma brasileira, que podem ser considerada satisfatória ao resultar num desvio percentual menor que quatro por 
cento para ambos os perfis. Em contrapartida, os resultados experimentais tiveram um desvio de até $29 \%$ inferior ao valor calculado pela norma brasileira.

Tabela 6.4: Verificação da compressão resistente por meio da ABNT NBR 14762:2010

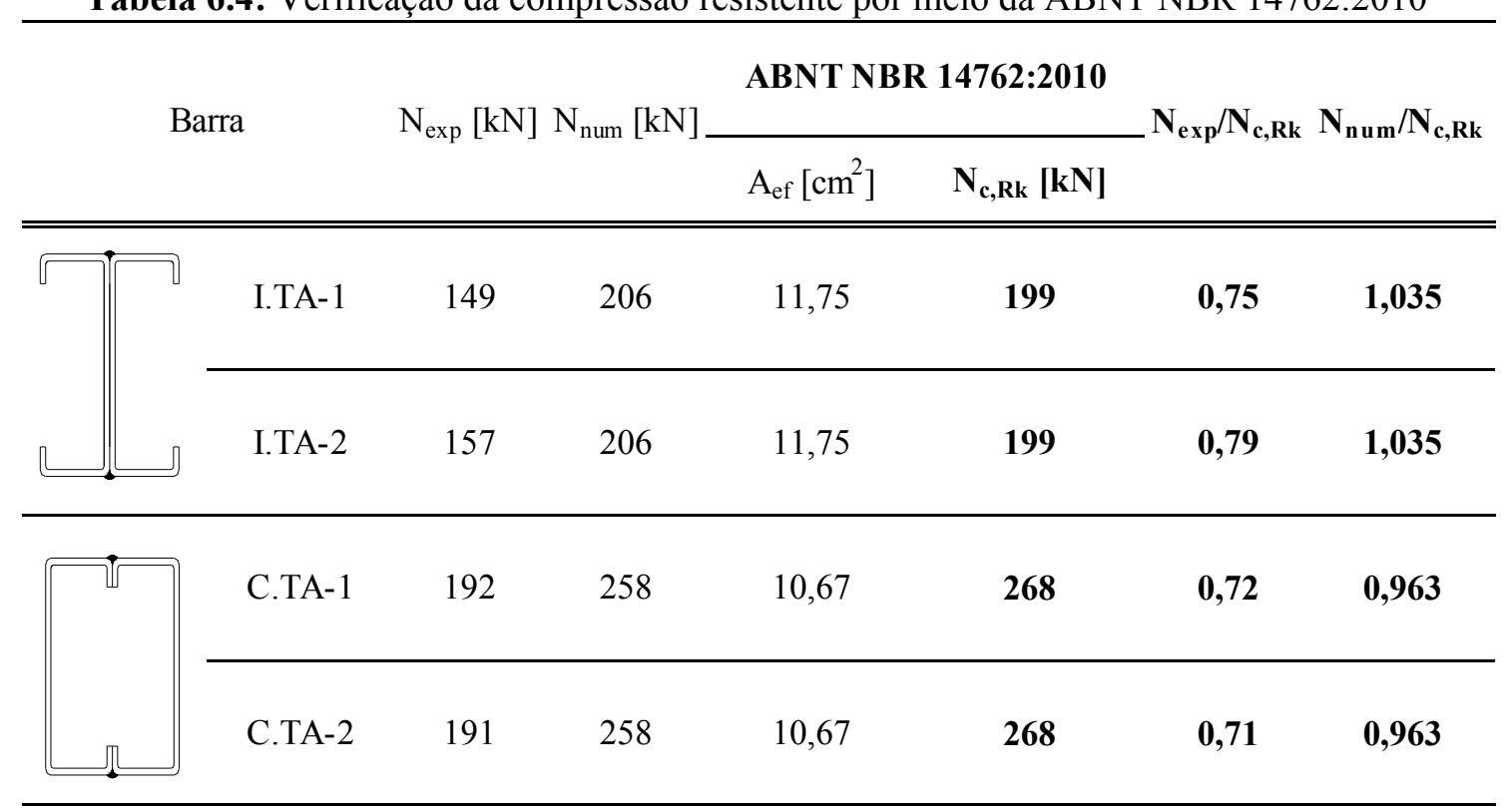

Os resultados de verificação da resistência nominal à compressão por meio da norma europeia EN 1993-1-3:2006 são mostrados na tabela 6.5. A força resistente à compressão nominal do perfil caixão calculada por ess a norma resultou maior que os métodos dos demais procedimentos normativos.

Tabela 6.5: Verificação da compressão resistente por meio da EN 1993-1-3:2006

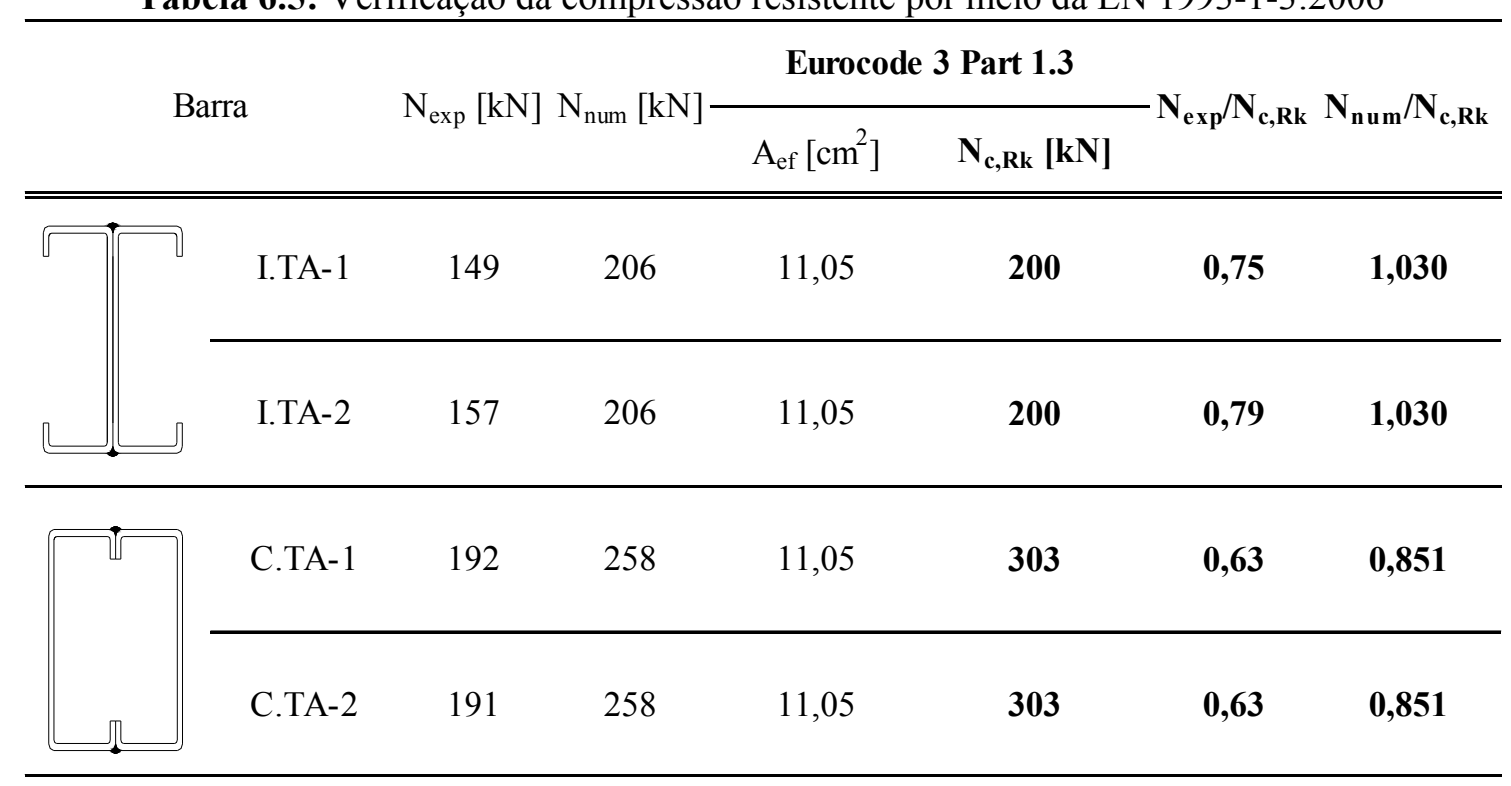


A tabela 6.6 mostra a comparação da força resistente obtida no programa experimental e na análise numérica com os valores calculados por meio da norma americana AISI S100:2007. Os procedimentos de cálculo desta norma são semelhantes aos da norma brasileira. O método de cálculo por essa norma forneceu valores de compressão nominal resistente maiores, porém, mais próximos da investigação numérica.

Tabela 6.6: Verificação da compressão resistente por meio da AISI S-100:2007

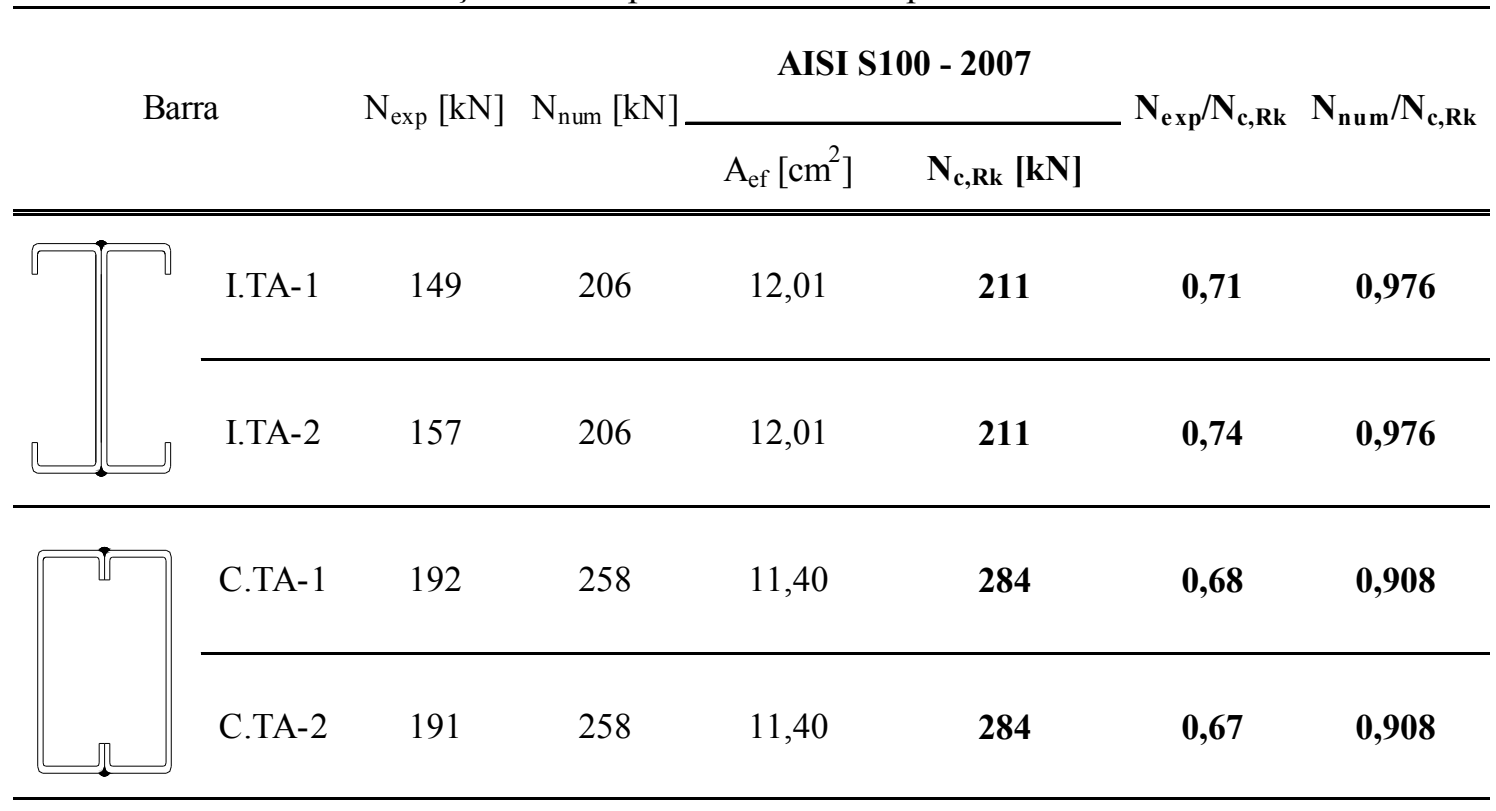

O AISI S-100:2007 também apresenta no primeiro apêndice o Método da Resistência Direta como um método alternativo de cálculo para determinação de esforços resistentes em perfis formados a frio. A razão pela qual esse método tem sido amplamente utilizado está associada ao fato de este dispensar o cálculo da área efetiva, o que torna a verificação mais simples e rápida. Como comentado no capítulo três, o equacionamento leva em conta a força de flambagem elástica local, distorcional e global.

Para a determinação da força de flambagem então, foi utilizado o código computacional CUFSM. Esse código, formulado com base no Método das Faixas Finitas e conforme descrito detalhadamente em Chodraui (2006), foi desenvolvido pelo professor Benjamim W. Schafer, da Johns Hopkins University e pelo professor Teoman Peköz, da Cornell University. Esse código foi desenvolvido para realizar a análise de estabilidade elástica de seções transversais submetidas a qualquer distribuição de tensões normais. Tal análise pode ser realizada para perfis sujeitos a esforços de flexão, compressão ou 
flexocompressão. A força de estabilidade elástica é definida para vários comprimentos da barra, a ser definido pelo usuário.

As figuras 6.11 e 6.12 mostram a interface gráfica do código CUFSM. No gráfico apresentado nessas figuras, a abscissa representa o comprimento de semionda do modo de instabilidade e a ordenada representa o fator de carregamento, ou seja, a relação $N_{e} /\left(A_{g} \cdot f_{y}\right)$. entre a força de flambagem elástica $\left(N_{e}\right)$ e a força de escoamento $\left(A_{g} \cdot f_{y}\right)$. O primeiro ponto de mínimo do gráfico corresponde ao modo local e o segundo, ao modo distorcional.

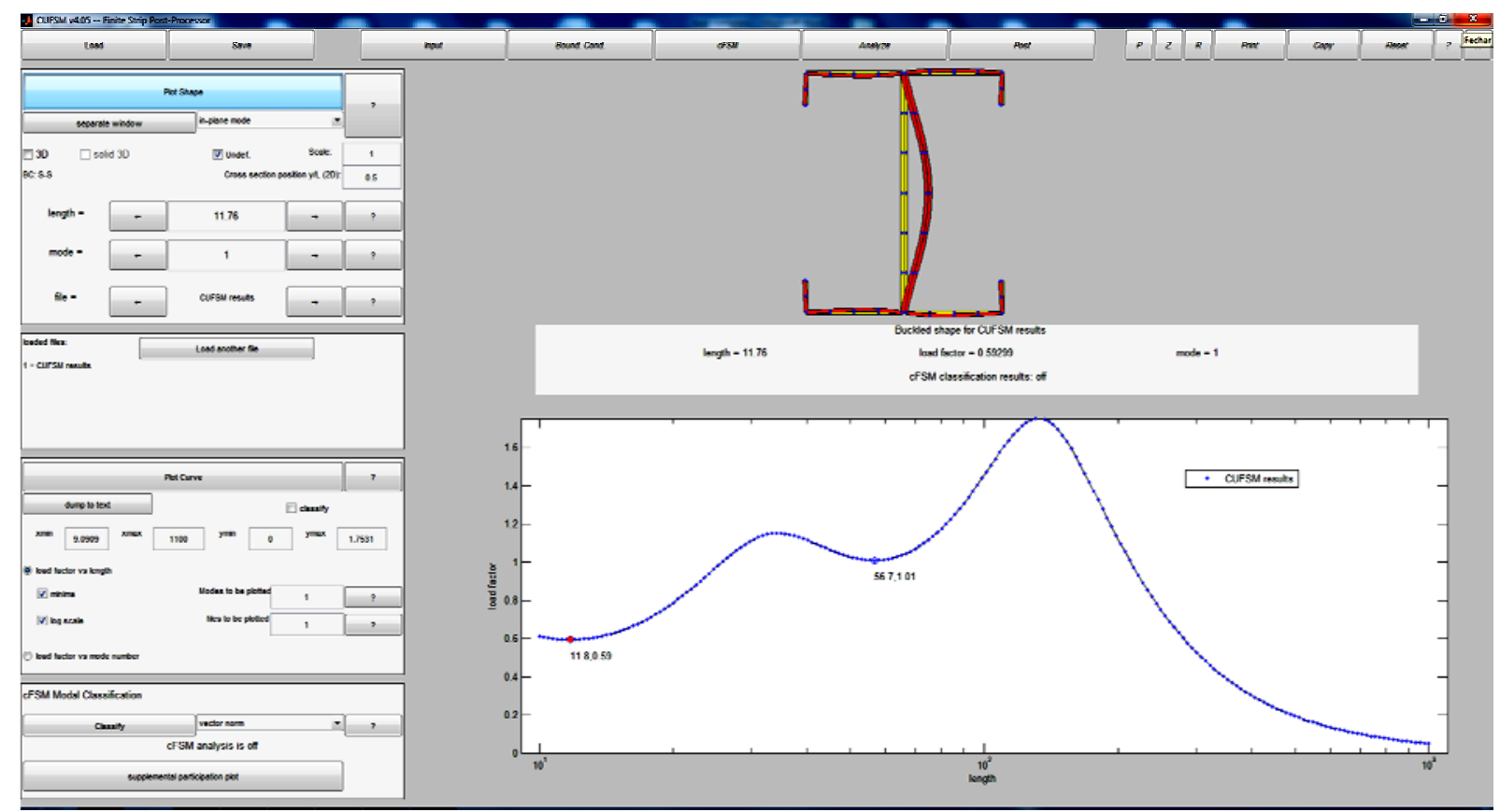

Figura 6.10: Determinação da força de flambagem elástica do perfil I enrijecido por meio do código CUFSM.

No perfil I enrijecido, por exemplo, representado na figura 6.11 o comprimento de meia onda relativo ao modo de falha local é $11,8 \mathrm{~cm}$ e a força de flambagem elástica vale 0,59· $\left(A_{g} \cdot f_{y}\right)$. No segundo ponto de mínimo, o que corresponde ao modo de falha distorcional, o comprimento de semionda vale $56,7 \mathrm{~cm}$ e o fator de carregamento correspondente vale 1,01 . A partir da força de flambagem elástica, é determinado o esforço resistente nominal por meio das equações apresentadas no terceiro capítulo, subitem 3.4.3.1. 


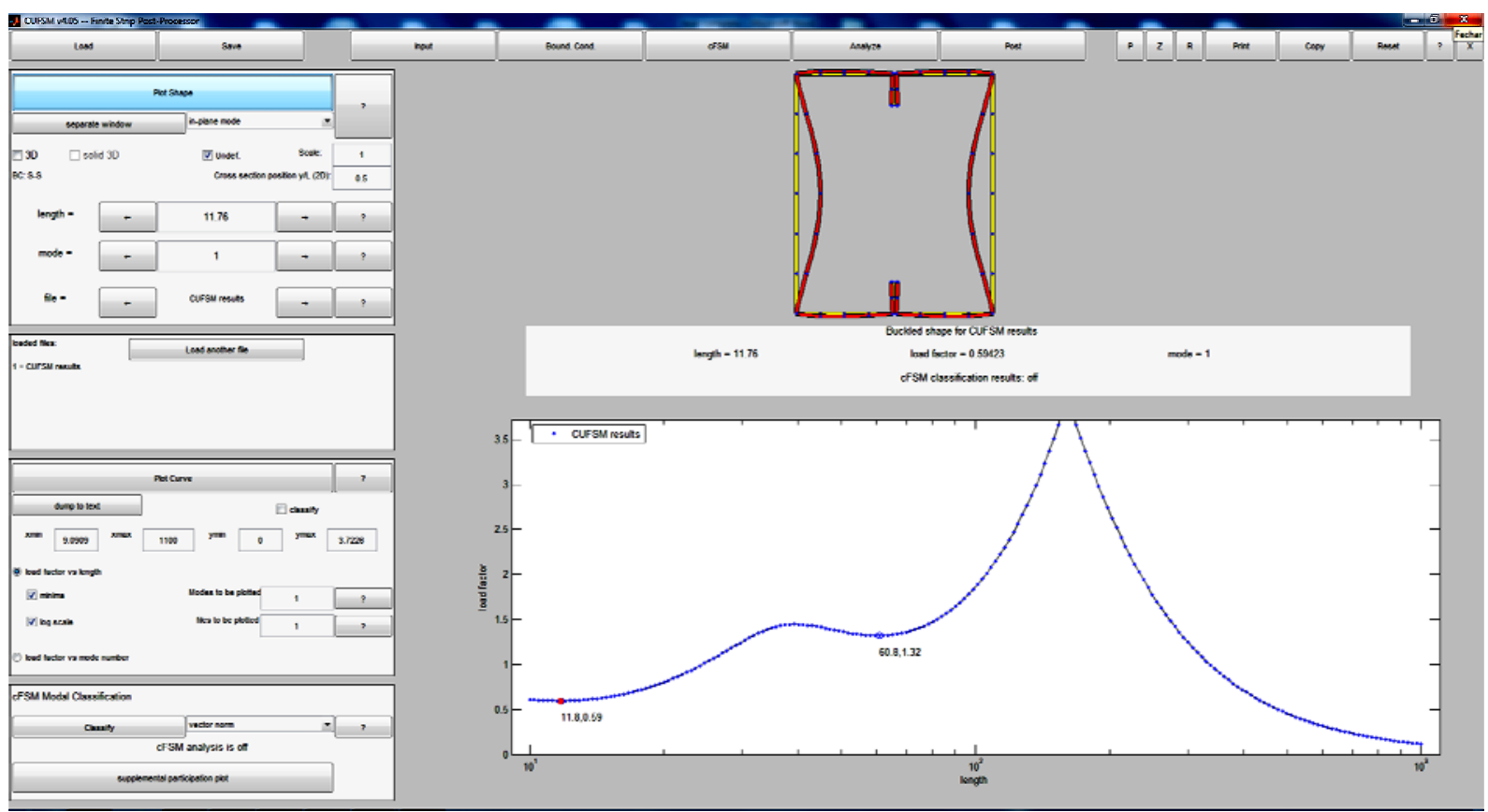

Figura 6.11: Determinação da força de flambagem elástica do perfil caixão por meio do código CUFSM.

As tabelas 6.6 e 6.7 apresentam valores nominais da compressão resistente. Os resultados obtidos por este método foram os que mais se aproximaram da análise numérica.

Tabela 6.6: Verificação da compressão resistente por meio do MRD

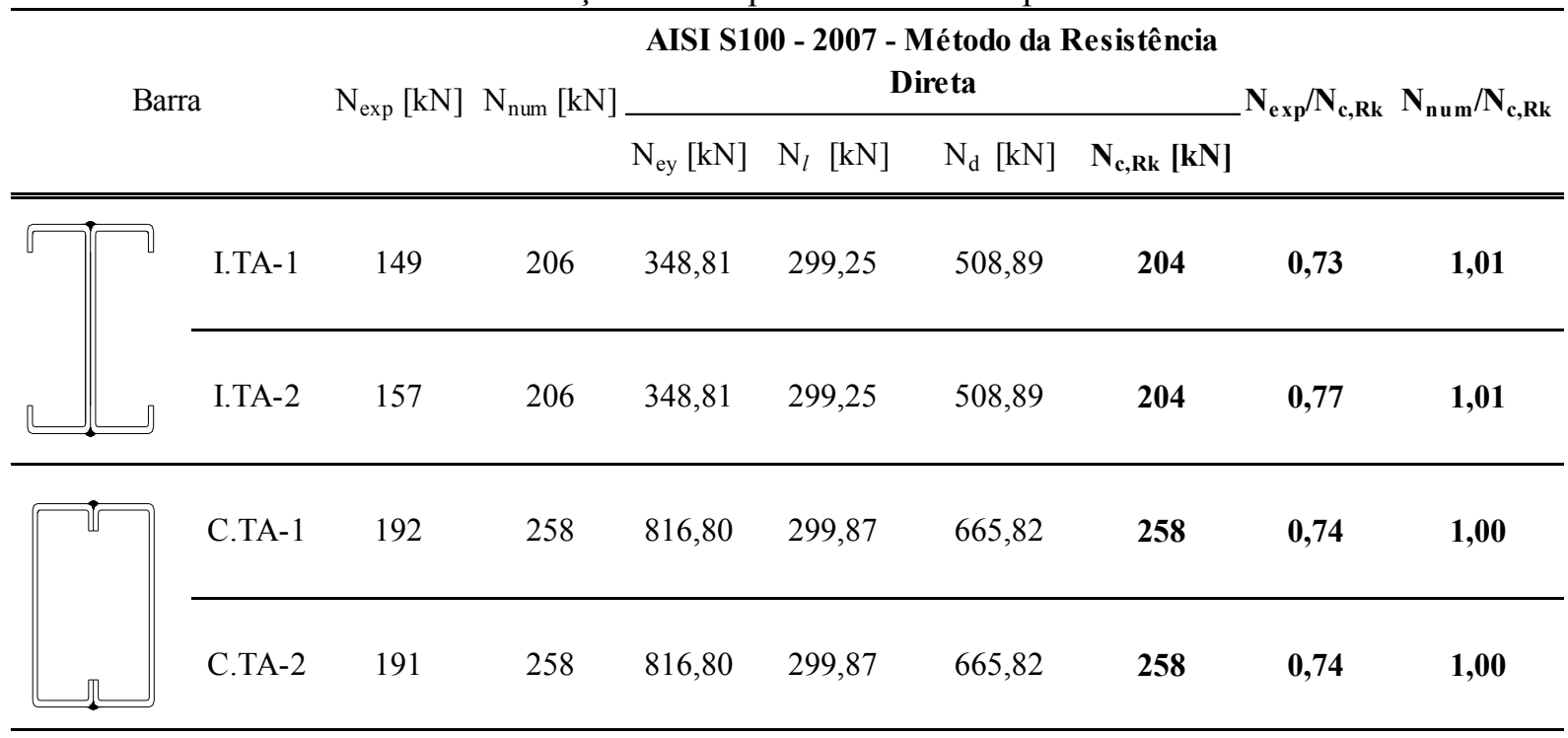

Embora tenha havido divergências entre os resultados experimentais e numéricos, os valores das forças de compressão obtidos nos ensaios resultaram próximos entre si. Dessa forma, para manter a correlação com a análise experimental, a ação de compressão implementada no modelo numérico em temperaturas elevadas foram os mesmos obtidos nos 
ensaios. O item seguinte apresenta uma análise comparativa entre a força de compressão aplicada nos modelos experimentais e numéricos em temperaturas elevadas e a força de compressão resistente obtida pelas normas abordadas no capítulo três deste trabalho.

\subsubsection{Investigação em temperaturas elevadas}

Neste item, julgou-se pertinente apresentar e comentar os resultados obtidos por métodos simplificados de verificação das normas ABNT NBR 14323:2013, Eurocode 3 part 1-2:2005 e ANSI/AISC 360 - 10. Em caráter complementar, este trabalho aplicou o Método da Resistência Direta proposto na especificação americana AISI S-100:2007 aos perfis compostos em temperaturas elevadas aqui estudados.

\subsubsection{Verificações segundo a norma ABNT NBR 14323:2013}

O método simplificado de verificação do esforço resistente de perfis de aço formados a frio sujeitos a instabilidade local, cujo equacionamento foi apresentado no terceiro capítulo, prevê que a elevação da temperatura no material tem influência sobre a sua resistência (considerada por meio do fator $\mathrm{k}_{\mathrm{y}, \theta}$ ) e, por consequência, sobre o fator de redução associado à instabilidade global $\chi_{\mathrm{fi}}$. Para a verificação aqui apresentada, o comprimento efetivo em temperaturas elevadas foi tomado como 1,0 L (em que L é o comprimento real do perfil) de forma a considerar o aquecimento uniforme ao longo do comprimento do perfil.

Embora o campo térmico da investigação experimental tenha sido não uniforme no comprimento total, essa condição foi considerada para viabilizar a aplicação do equacionamento proposto pelos processos normativos correntes. Análises experimentais e normativas análogas foram apresentadas em Leite Junior (2009) em estudo de pilares mistos esbeltos preenchidos com concreto. Em tal análise comparativa experimental/numérico, foi constatado que, quanto mais alta a temperatura de colapso, mais conservadora resulta a compressão resistente nominal calculada analiticamente. Em geral, existe uma grande complexidade (questão essa já abordada em outros trabalhos na área) em conseguir que a ação térmica se distribua uniformemente ao longo do comprimento em investigações experimentais.

Em contrapartida à consideração da instabilidade global, os cálculos para determinação da área efetiva pelo método das larguras efetivas para contar o efeito da instabilidade local são realizados com os parâmetros à temperatura ambiente conforme a norma ABNT NBR 
14762:2010. As tabelas 6.7 a 6.10 mostram os resultados comparativos obtidos para ambos os perfis estudados neste trabalho. Por esses resultados, bem como pelas relações $\mathrm{N}_{\text {exp }} / \mathrm{N}_{\mathrm{NBR}}$ e $\mathrm{N}_{\text {num }} / \mathrm{N}_{\mathrm{NBR}}$, pode se observar que os valores calculados são visivelmente conservadores em relação aos obtidos pelo programa experimental.

Tabela 6.7: Resultados do procedimento normativo da $A B N T$ NBR 14323:2013 comparados com os obtidos nas investigações experimentais do perfil I enrijecido.

\begin{tabular}{ccccccc}
\hline Barra & $\begin{array}{c}\text { Temperatura } \\
\text { final (exp.) }\left[{ }^{\circ} \mathbf{C}\right]\end{array}$ & $\begin{array}{c}\text { Tempo final } \\
\left.(\mathbf{e x p}){ }^{\circ} \mathbf{C}\right]\end{array}$ & $\begin{array}{c}\mathbf{N}_{\text {exp }}[\mathbf{k N}] \\
\text { Modo de falha } \\
(\mathbf{e x p})\end{array}$ & $\begin{array}{c}\text { ABNT NBR } \\
\mathbf{1 4 3 2 3 : 2 0 1 3} \\
\mathbf{N}_{\text {fi,Rk }}[\mathbf{k N}]\end{array}$ & $\mathbf{N}_{\text {exp }} / \mathbf{N}_{\text {fi,Rk }}$ \\
\hline \hline I.SI04F-3 & 763 & $15^{\prime} 45^{\prime \prime}$ & 63 & L- W $/ \mathrm{D}$ & $\mathbf{1 4 , 1}$ & $\mathbf{4 , 4 6}$ \\
\hline I.SI04F-5 & 770 & $19^{\prime} 30^{\prime \prime}$ & 63 & L- W /D & $\mathbf{1 3 , 5}$ & $\mathbf{4 , 6 7}$ \\
\hline I.SI07F-1 & 609 & $13^{\prime} 18^{\prime \prime}$ & 110 & L- W /D & $\mathbf{4 3 , 6}$ & $\mathbf{2 , 5 2}$ \\
\hline I.SI07F-2 & 572 & $11^{\prime} 46^{\prime \prime}$ & 110 & L- W /D & $\mathbf{5 5 , 9}$ & $\mathbf{1 , 9 7}$ \\
\hline \hline
\end{tabular}

L-w: Local na alma ; D: Distorcional

Tabela 6.8: Resultados do procedimento normativo da $A B N T$ NBR 14323:2013 comparados com os obtidos nas investigações numéricas do perfil I enrijecido.

\begin{tabular}{|c|c|c|c|c|c|c|}
\hline Barra & $\begin{array}{c}\text { Tempe ratura } \\
\text { final (num.) } \\
{\left[{ }^{\circ} \mathbf{C}\right]}\end{array}$ & $\begin{array}{l}\text { Tempo final } \\
\text { (num.) }\left[{ }^{\circ} \mathrm{C}\right]\end{array}$ & $\begin{array}{c}\mathbf{N}_{\text {num }, \mathrm{fi}} \\
{[\mathrm{kN}]}\end{array}$ & $\begin{array}{l}\text { Modo de falha } \\
\quad \text { (num.) }\end{array}$ & $\begin{array}{c}\text { ABNT NBR } \\
14323: 2013 \\
N_{\text {fi,Rk }}[k N]\end{array}$ & $\begin{array}{l}\mathbf{N}_{\text {num }} / \\
\mathbf{N}_{\text {fi,Rk }}\end{array}$ \\
\hline I.SI04F & 690 & $14^{\prime}$ & 63 & L- w /D & 24,9 & 2,53 \\
\hline I.SI07F & 602 & $11^{\prime}$ & 110 & L- w/D & 45,4 & 1,97 \\
\hline
\end{tabular}

L-w: Local na alma ; D: Distorcional 
Tabela 6.9: Resultados do procedimento normativo da $A B N T N B R$ 14323:2013 comparados com os obtidos nas investigações experimentais do perfil caixão.

\begin{tabular}{|c|c|c|c|c|c|c|}
\hline Barra & $\begin{array}{l}\text { Temperatura } \\
\text { final (exp.) }\left[{ }^{\circ} \mathrm{C}\right]\end{array}$ & $\begin{array}{l}\text { Tempo final } \\
\text { (exp.) }\left[{ }^{\circ} \mathrm{C}\right]\end{array}$ & $\begin{array}{l}\mathbf{N}_{\text {exp }} \\
{[\mathrm{kN}]}\end{array}$ & $\begin{array}{l}\text { Modo de falha } \\
\quad \text { (exp.) }\end{array}$ & $\begin{array}{c}\text { ABNT NBR } \\
14323: 2013 \\
N_{\text {fi,Rk }}[k N]\end{array}$ & $\mathbf{N}_{\mathbf{e x p}} / \mathbf{N}_{\mathbf{f i}, \mathbf{R k}}$ \\
\hline C.SI04F-2 & 654 & $17^{\prime} 06^{\prime \prime}$ & 75 & L- w $/ D$ & 51,0 & 1,47 \\
\hline C.SI04F-3 & 767 & $19^{\prime} 37^{\prime \prime}$ & 75 & L- w $/ D$ & 22,0 & 3,41 \\
\hline C.SI07F-1 & 375 & $8^{\prime}$ & 135 & L- w $/ D$ & 167,2 & 0,81 \\
\hline C.SI07F-2 & 535 & $10^{\prime} 30^{\prime \prime}$ & 135 & L- w $/ D$ & 110,1 & 1,23 \\
\hline
\end{tabular}

L-w: Local na alma ; D: Distorcional

Tabela 6.10: Resultados do procedimento normativo da ABNT NBR 14323:2013 comparados com os obtidos nas investigações numéricas do perfil caixão.

\begin{tabular}{|c|c|c|c|c|c|c|}
\hline Barra & $\begin{array}{c}\text { Temperatura } \\
\text { final (num.) } \\
{\left[{ }^{\circ} \mathrm{C}\right]}\end{array}$ & $\begin{array}{l}\text { Tempo final } \\
\text { (num.) }\left[{ }^{\circ} \mathrm{C}\right]\end{array}$ & $\begin{array}{c}\mathbf{N}_{\text {num,fi }} \\
{[\mathrm{kN}]}\end{array}$ & $\begin{array}{c}\text { Modo de falha } \\
\quad \text { (num.) }\end{array}$ & $\begin{array}{c}\text { ABNT NBR } \\
\text { 14323:2013 } \\
\text { N }_{\text {fi,Rk }}[k N]\end{array}$ & $\begin{array}{l}\mathbf{N}_{\text {num }} / \\
\mathbf{N}_{\text {fi, Rk }}\end{array}$ \\
\hline C.SI04F & 681 & $14^{\prime}$ & 75 & L- w /D & 39,8 & 1,89 \\
\hline C.SI07F & 593 & $11^{\prime}$ & 135 & L- w $/ D$ & 77,4 & 1,74 \\
\hline
\end{tabular}

L-w: Local na alma ; D: Distorcional

Os fatores de redução aplicados à resistência ao escoamento e ao módulo de elasticidade do aço e, especificamente ao escoamento dos perfis formados a frio, implicitamente sugerem que o perfil atinge o colapso a temperaturas maiores que $500{ }^{\circ} \mathrm{C}$, uma vez que, acima dessa temperatura, a resistência do material é inferior a $50 \%$ da resistência à temperatura ambiente. Dessa forma, é cabível afirmar que a segurança dos perfis formados a frio é garantida apenas com aplicação de revestimento contra fogo, já que esse nível de temperatura é alcançado antes dos primeiros 10 minutos da curva de incêndio-padrão.

Alguns trabalhos sugerem tratar a questão dos fatores de redução da resistência ao escoamento, seja sob o enfoque numérico ou experimental, em vez de fazer a aplicação direta das recomendações normativas. Em Rodrigues (2000), a caracterização do material em temperatura elevada já havia sido tomada como recomendação. 
Em Kankanamge e Mahendran (2011) são apresentadas curvas "tensão x deformação" de perfis $U_{e}$, para diversos níveis de temperatura, obtidas a partir de ensaio de caracterização para obtenção dos fatores de redução da resistência ao escoamento. Neste programa experimental, foi identificado que um dos fatores que podem ter influência em tais fatores de redução é a própria resistência ao escoamento do aço.

Em Rodrigues, Caldas e Costa (2013) foram apresentados vastos estudos de caráter numérico e analítico, a explorar diversos tipos de perfis $U_{e}$ previstos na ABNT NBR 6355:2003 para diferentes temperaturas, o qual comprova que o fator de redução $\mathrm{k}_{\sigma, \theta}$ também é influenciado pela esbeltez global e largura dos elementos da seção transversal. Em perfis cujo índice de esbeltez reduzido associado à instabilidade global do perfil $\lambda_{0}$ assume valores entre 0,5 e 1,0 o fator k é maior que os valores tabelados no Eurocode 3, part 1.2 e na ABNT NBR 14323:2013. Para valore de $\lambda_{0}$ acima de 1,0, o valor de $k_{\sigma, \theta}$ resulta menor que aqueles recomendados pelas normas. Foi proposto, então, que o fator $\mathrm{k}_{\sigma, \theta}$ fosse ponderado pelo índice de esbeltez $\lambda_{c}^{b}$, que leva em conta, além da esbeltez global do perfil, a relação $b_{\mathrm{w}} / b_{\mathrm{f}}$ entre a altura da alma e a largura da mesa, respectivamente.

\subsubsection{Verificações segundo a norma Eurocode 3 - part 1.2}

Analogamente à ABNT NBR 14323:2013, a norma europeia considera a influência da temperatura na redução da resistência ao escoamento e do módulo de elasticidade também na determinação do fator de redução associado à instabilidade global $\chi_{\mathrm{fi}}$. Porém, a mesma norma recomenda que o cálculo da área efetiva para a consideração da instabilidade local seja realizado conforme a EN 1993-1-3:2006 e a EN 1993-1-5:2006 com as propriedades mecânicas à temperatura ambiente.

Porém, a determinação da área efetiva está relacionada diretamente com o adimensional $E / f_{y}$. De acordo com o que foi apresentado em Heva (2009), como o fator de redução do módulo de elasticidade é maior que da resistência ao escoamento, a razão $E / f_{y}$ aumenta com a elevação da temperatura. Logo, a área efetiva em temperatura elevada é maior que a área efetiva à temperatura ambiente. Dessa forma, a não consideração da variação da área efetiva em função da temperatura pode fornecer resultados superestimados do esforço resistente de compressão. 
As tabelas 6.11 a 6.14 mostram os resultados obtidos e o desvio em relação aos valores obtidos experimentalmente e numericamente. Observa-se que o método de cálculo da norma europeia forneceu valores de compressão resistente nominal ligeiramente maiores que os obtidos pela ABNT NBR 14323:2013. Porém, a redução da força resistente para temperaturas acima de $600{ }^{\circ} \mathrm{C}$ ainda resultou superestimado em relação aos resultados experimentais.

Tabela 6.11: Resultados do procedimento normativo da Eurocode 3, part 1.2 comparados com os obtidos nas investigações experimentais do perfil I enrijecido.

\begin{tabular}{ccccccc}
\hline Barra & $\begin{array}{c}\text { Temperatura } \\
\text { final (exp.) }\left[{ }^{\circ} \mathbf{C}\right]\end{array}$ & $\begin{array}{c}\text { Tempo final } \\
\left.(\mathbf{e x p}){ }^{\circ} \mathbf{C}\right]\end{array}$ & $\begin{array}{c}\mathbf{N}_{\text {exp }}[\mathbf{k N}] \\
\text { Modo de falha } \\
(\mathbf{e x p})\end{array}$ & $\begin{array}{c}\mathbf{E C ~ 3 - 1 . 2} \\
\mathbf{N}_{\text {fi,Rk }}[\mathbf{k N}]\end{array}$ & $\mathbf{N}_{\text {exp }} / \mathbf{N}_{\text {fi,Rk }}$ \\
\hline \hline I.SI04F-3 & 763 & $15^{\prime} 45^{\prime \prime}$ & 63 & L- W $/ \mathrm{D}$ & $\mathbf{1 7 , 9}$ & $\mathbf{3 , 5 2}$ \\
\hline I.SI04F-5 & 770 & $19^{\prime} 30^{\prime \prime}$ & 63 & L- W $/ \mathrm{D}$ & $\mathbf{1 7 , 3}$ & $\mathbf{3 , 6 5}$ \\
\hline I.SI07F-1 & 609 & $13^{\prime} 18^{\prime \prime}$ & 110 & L- W /D & $\mathbf{5 2 , 3}$ & $\mathbf{2 , 1 0}$ \\
\hline I.SI07F-2 & 572 & $11^{\prime} 46^{\prime \prime}$ & 110 & L- W /D & $\mathbf{6 8 , 5}$ & $\mathbf{1 , 6 1}$ \\
\hline \hline
\end{tabular}

L-w: Local na alma ; D: Distorcional

Tabela 6.12: Resultados do procedimento normativo da Eurocode 3, part 1.2 comparados com os obtidos nas investigações numéricas do perfil I enrijecido.

\begin{tabular}{|c|c|c|c|c|c|c|}
\hline Barra & $\begin{array}{c}\text { Temperatura } \\
\text { final (num.) } \\
{\left[{ }^{\circ} \mathrm{C}\right]}\end{array}$ & $\begin{array}{l}\text { Tempo final } \\
\text { (num.) }\left[{ }^{\circ} \mathrm{C}\right]\end{array}$ & $\begin{array}{c}\mathbf{N}_{\text {num,fi }} \\
{[\mathrm{kN}]}\end{array}$ & $\begin{array}{l}\text { Modo de falha } \\
\quad \text { (num.) }\end{array}$ & $\begin{array}{c}\text { EC } 3-1.2 \\
N_{\text {fi, Rk }}[k N]\end{array}$ & $\begin{array}{l}\mathbf{N}_{\text {num }} / \\
\mathbf{N}_{\text {fi,Rk }}\end{array}$ \\
\hline I.SI04F & 690 & $14^{\prime}$ & 63 & L- w /D & 29,5 & 2,14 \\
\hline I.SI07F & 602 & $11^{\prime}$ & 110 & L- w /D & 54,6 & 2,02 \\
\hline
\end{tabular}

L-w: Local na alma ; D: Distorcional 
Tabela 6.13: Resultados do procedimento normativo da Eurocode 3, part 1.2 comparados com os obtidos nas investigações experimentais do perfil caixão.

\begin{tabular}{ccccccc}
\hline Barra & $\begin{array}{c}\text { Temperatura } \\
\text { final (exp.) }\left[{ }^{\circ} \mathbf{C}\right]\end{array}$ & $\begin{array}{c}\text { Tempo final } \\
\left.(\mathbf{e x p}){ }^{\circ} \mathbf{C}\right]\end{array}$ & $\begin{array}{c}\mathbf{N}_{\text {exp }} \\
{[\mathbf{k N}]}\end{array}$ & $\begin{array}{c}\text { Modo de falha } \\
(\mathbf{e x p})\end{array}$ & $\begin{array}{c}\mathbf{E C ~ 3 ~ - ~ 1 . 2 ~} \\
\mathbf{N}_{\text {fi,Rk }}[\mathbf{k N}]\end{array}$ & $\mathbf{N}_{\text {exp }} / \mathbf{N}_{\text {fi,Rk }}$ \\
\hline \hline C.SI04F-2 & 654 & $17^{\prime} 06^{\prime \prime}$ & 75 & L- W /D & $\mathbf{5 7 , 9}$ & $\mathbf{1 , 3 0}$ \\
\hline C.SI04F-3 & 767 & $19^{\prime} 37^{\prime \prime}$ & 75 & L- W /D & $\mathbf{2 5 , 8}$ & $\mathbf{2 , 9 1}$ \\
\hline C.SI07F-1 & 375 & $8^{\prime}$ & 135 & L- W /D & $\mathbf{1 8 9 , 8}$ & $\mathbf{0 , 7 1}$ \\
\hline C.SI07F-2 & 535 & $10^{\prime} 30^{\prime \prime}$ & 135 & L- W/D & $\mathbf{1 2 7 , 7}$ & $\mathbf{1 , 0 6}$ \\
\hline \hline
\end{tabular}

L-w: Local na alma ; D: Distorcional

Tabela 6.14: Resultados do procedimento normativo da Eurocode 3, part 1.2 comparados com os obtidos nas investigações numéricas do perfil caixão.

\begin{tabular}{|c|c|c|c|c|c|c|}
\hline Barra & $\begin{array}{c}\text { Temperatura } \\
\text { final (num.) } \\
{\left[{ }^{\circ} \mathrm{C}\right]}\end{array}$ & $\begin{array}{l}\text { Tempo final } \\
\text { (num.) }\left[{ }^{\circ} \mathrm{C}\right]\end{array}$ & $\begin{array}{c}\mathbf{N}_{\text {num,fi }} \\
{[\mathrm{kN}]}\end{array}$ & $\begin{array}{l}\text { Modo de falha } \\
\quad \text { (num.) }\end{array}$ & $\begin{array}{c}\text { EC } 3-1.2 \\
\mathrm{~N}_{\mathrm{fi}, \mathrm{Rk}}[\mathrm{kN}]\end{array}$ & $\begin{array}{l}\mathbf{N}_{\text {num }} / \\
\mathbf{N}_{\text {fi,Rk }}\end{array}$ \\
\hline C.SI04F & 681 & $14^{\prime}$ & 75 & L- w/D & 45,0 & 1,67 \\
\hline C.SI07F & 593 & $11^{\prime}$ & 135 & L- w/D & 88,4 & 1,53 \\
\hline
\end{tabular}

L-w: Local na alma ; D: Distorcional

\subsubsection{Verificações segundo a norma ANSI/AISC 360-10}

O instituto americano que normatiza as construções em perfis de aço formados a frio não fornece procedimentos de cálculo específicos para verificação dos esforços resistentes em situação de incêndio, uma vez que a perda da capacidade estrutural ocorre num intervalo de tempo muito curto. Em compensação, o Instituto Americano da Construção em Aço fornece o Design Guide 19 - Fire Resistance of Structural Steel Framing, que prescreve os procedimentos para o dimensionamento da proteção ativa contra fogo.

De uma maneira relativamente simples e direta, a norma americana recomenda que os cálculos para determinação dos esforços resistentes siga o equacionamento da verificação à temperatura ambiente, porém, com as propriedades mecânicas ponderadas pelos respectivos coeficientes de redução. Dessa forma, tanto os fatores de redução associados à instabilidade global como o cálculo das larguras efetivas para consideração da instabilidade local têm influência da elevação da temperatura. 
As tabelas 6.15 e 6.18 mostram os resultados obtidos por essa norma e os compara com os resultados obtidos no programa experimental e na análise numérica. Embora sejam calculadas com as propriedades mecânicas reduzidas, tanto a área efetiva como o índice de esbeltez reduzido apresentaram uma variação muito pequena.

Tabela 6.15: Resultados do procedimento normativo da ANSI/AISC 360 - 10 comparados com os obtidos nas investigações experimentais do perfil I enrijecido.

\begin{tabular}{|c|c|c|c|c|c|c|}
\hline Barra & $\begin{array}{c}\text { Temperatura } \\
\text { final }(\exp .)\left[{ }^{\circ} \mathrm{C}\right]\end{array}$ & $\begin{array}{l}\text { Tempo final } \\
(\exp .)\left[{ }^{\circ} \mathrm{C}\right]\end{array}$ & $\begin{array}{l}\mathbf{N}_{\text {exp }} \\
{[\mathrm{kN}]}\end{array}$ & $\begin{array}{l}\text { Modo de falha } \\
\quad(\text { exp.) }\end{array}$ & $\begin{array}{c}\text { ANSI/AISC } \\
\mathbf{3 6 0 - 1 0} \\
\mathbf{N}_{\mathrm{fi}, \mathrm{Rk}}[\mathrm{kN}]\end{array}$ & $\mathbf{N}_{\text {exp }} / \mathbf{N}_{\mathbf{f i}, \mathbf{R k}}$ \\
\hline I.SI04F-3 & 763 & $15^{\prime} 45^{\prime \prime}$ & 63 & L- w /D & 13,9 & 4,53 \\
\hline I.SI04F-5 & 770 & $19^{\prime} 30^{\prime \prime}$ & 63 & L- w /D & 13,6 & 4,63 \\
\hline I.SI07F-1 & 609 & $13^{\prime} 18^{\prime \prime}$ & 110 & L- w/D & 42,3 & 2,60 \\
\hline I.SI07F-2 & 572 & $11^{\prime} 46^{\prime \prime}$ & 110 & L- w /D & 54,2 & 2,03 \\
\hline
\end{tabular}

L-w: Local na alma ; D: Distorcional

Tabela 6.16: Resultados do procedimento normativo da ANSI/AISC 360 - 10 comparados com os obtidos nas investigações numéricas do perfil I enrijecido.

\begin{tabular}{ccccccc}
\hline Barra & $\begin{array}{c}\text { Temperatura } \\
\text { final (num.) } \\
{\left[{ }^{\circ} \mathbf{C}\right]}\end{array}$ & $\left.\begin{array}{c}\text { Tempo final } \\
(\text { num.) }\end{array}{ }^{\circ} \mathbf{C}\right]$ & $\begin{array}{c}\mathbf{N}_{\text {num,fi }} \\
{[\mathbf{k N}]}\end{array}$ & $\begin{array}{c}\text { Modo de falha } \\
\text { (num.) }\end{array}$ & $\begin{array}{c}\text { ANSI/AISC } \\
\mathbf{3 6 0 - 1 0} \\
\mathbf{N}_{\text {fi,Rk }}[\mathbf{k N}]\end{array}$ & $\begin{array}{c}\mathbf{N}_{\text {num }} / \\
\mathbf{N}_{\text {fi, Rk }}\end{array}$ \\
\hline \hline I.SI04F & 690 & $14^{\prime}$ & 63 & L- w /D & $\mathbf{2 3 , 7}$ & $\mathbf{2 , 6 6}$ \\
\hline I.SI07F & 602 & $11^{\prime}$ & 110 & L- w /D & $\mathbf{4 4 , 5}$ & $\mathbf{2 , 4 7}$ \\
\hline \hline
\end{tabular}

L-w: Local na alma ; D: Distorcional

Tabela 6.17: Resultados do procedimento normativo da ANSI/AISC 360 - 10 comparados com os obtidos nas investigações experimentais do perfil caixão.

\begin{tabular}{ccccccc}
\hline Barra & $\begin{array}{c}\text { Temperatura } \\
\text { final (exp.) }\left[{ }^{\circ} \mathrm{C}\right]\end{array}$ & $\begin{array}{c}\text { Tempo final } \\
\text { (exp.) }\left[{ }^{\circ} \mathbf{C}\right]\end{array}$ & $\begin{array}{c}\mathbf{N}_{\text {exp }} \\
{[\mathbf{k N}]}\end{array}$ & $\begin{array}{c}\text { Modo de falha } \\
\text { (exp.) }\end{array}$ & $\begin{array}{c}\text { ANSI/AISC } \\
\mathbf{N}_{\text {fi, Rk }}[\mathbf{k N}]\end{array}$ & $\mathbf{N}_{\text {exp }} / \mathbf{N}_{\text {fi, Rk }}$ \\
\hline \hline C.SI04F-2 & 654 & $17^{\prime} 06^{\prime \prime}$ & 75 & L- w /D & $\mathbf{3 6 , 2 3}$ & $\mathbf{2 , 0 7}$ \\
\hline C.SI04F-3 & 767 & $19^{\prime} 37^{\prime \prime}$ & 75 & L- w /D & $\mathbf{1 7 , 2 5}$ & $\mathbf{4 , 3 5}$ \\
\hline C.SI07F-1 & 375 & $8^{\prime}$ & 135 & L- w /D & $\mathbf{1 2 8 , 7 6}$ & $\mathbf{1 , 0 5}$ \\
\hline C.SI07F-2 & 535 & $10^{\prime} 30^{\prime \prime}$ & 135 & L- w /D & $\mathbf{8 3 , 5 6}$ & $\mathbf{1 , 6 2}$ \\
\hline \hline
\end{tabular}

L-w: Local na alma ; D: Distorcional 
Tabela 6.18: Resultados do procedimento normativo da ANSI/AISC 360 - 10 comparados com os obtidos nas investigações numéricas do perfil caixão.

\begin{tabular}{|c|c|c|c|c|c|c|}
\hline Barra & $\begin{array}{c}\text { Temperatura } \\
\text { final (num.) } \\
{\left[{ }^{\circ} \mathrm{C}\right]}\end{array}$ & $\begin{array}{l}\text { Tempo final } \\
\text { (num.) }\left[{ }^{\circ} \mathrm{C}\right]\end{array}$ & $\begin{array}{c}\mathbf{N}_{\text {num }, \mathrm{fi}} \\
{[\mathrm{kN}]}\end{array}$ & $\begin{array}{l}\text { Modo de falha } \\
\text { (num.) }\end{array}$ & $\begin{array}{c}\text { ANSI/AISC } \\
360-10 \\
\mathbf{N}_{\mathrm{fi}, \mathrm{Rk}}[\mathrm{kN}]\end{array}$ & $\begin{array}{l}\mathbf{N}_{\text {num }} / \\
\mathbf{N}_{\text {fi,Rk }} /\end{array}$ \\
\hline C.SI04F & 681 & $14^{\prime}$ & 75 & L- w /D & 31,5 & 2,38 \\
\hline C.SI07F & 593 & $11^{\prime}$ & 135 & $\mathrm{~L}-\mathrm{w} / \mathrm{D}$ & 60,1 & 2,25 \\
\hline
\end{tabular}

L-w: Local na alma ; D: Distorcional

A formulação do AISC é voltada ao dimensionamento de perfis laminados e soldados, portanto não se aplica aos perfis leves. Observou-se que os valores da força de compressão característica resultaram mais conservadores em comparação aos obtidos pelas normas já comentadas ABNT NBR 14323:2010 e EN 1993-1-2:2005.

\subsubsection{Verificações por meio do Método da Resistência Direta - MRD}

Por fim, apresenta-se a aplicação do Método da Resistência Direta aos perfís compostos do presente trabalho em temperaturas elevadas. $\mathrm{O}$ equacionamento foi apresentado no capítulo três e, para considerar o efeito do aquecimento, as propriedades mecânicas foram ponderadas com os respectivos fatores de redução para cada nível de temperatura. Dessa forma, está implícita que a temperatura foi considerada uniformemente distribuída ao longo do seu comprimento para o cálculo dos esforços em temperaturas elevadas.

A determinação da força crítica de flambagem elástica foi realizada com auxílio do código computacional CUFSM, analogamente ao apresentado no subitem 6.3.1. Os gráficos das figuras 6.12 e 6.13 mostram a força de flambagem elástica, implícita na ordenada "fator de carregamento", e o correspondente comprimento de semionda para cada nível de temperatura elevada. 


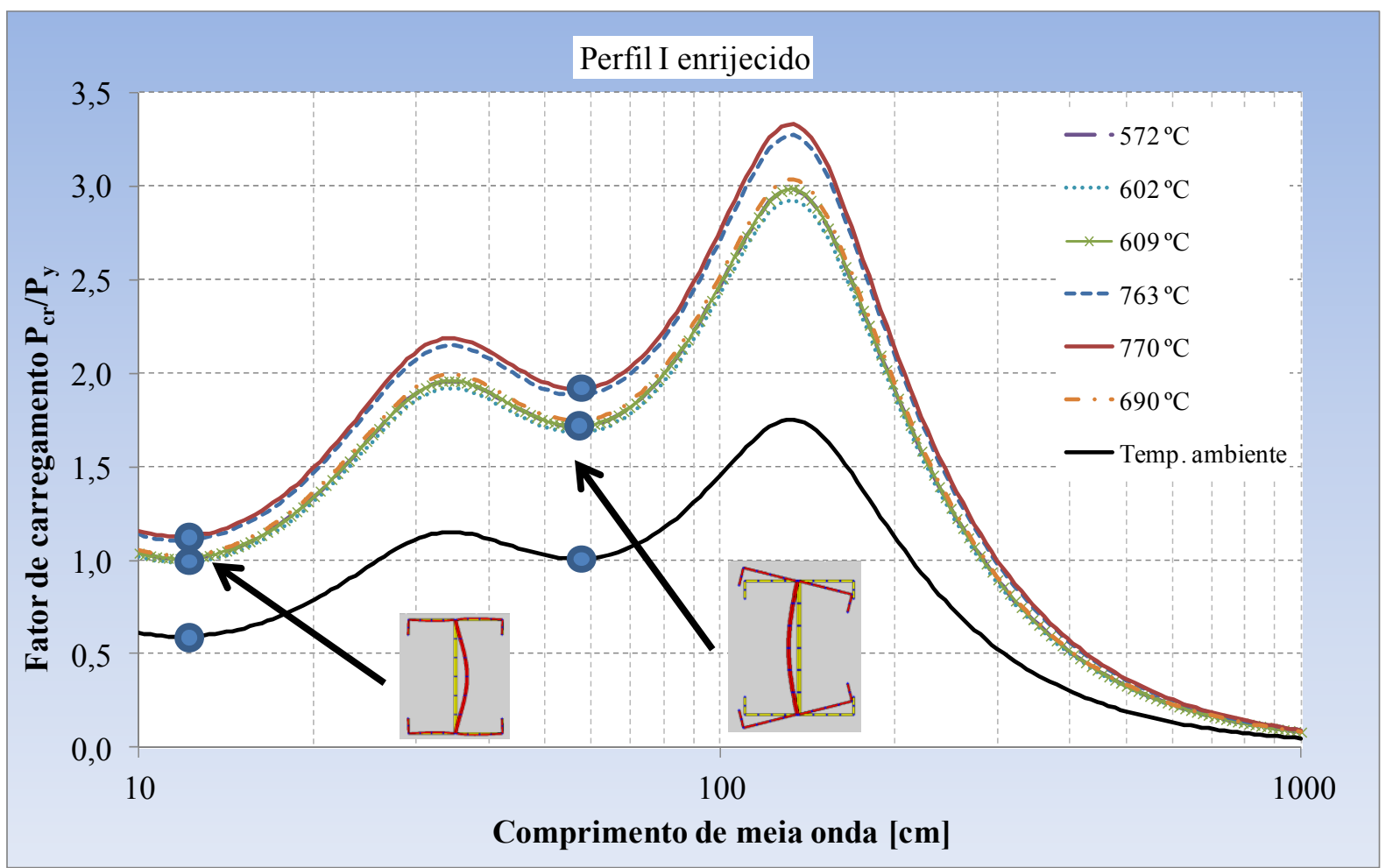

Figura 6.12: Resultados obtidos via CUFSM para determinação da força critica de flambagem elástica para o perfil I enrijecido em temperaturas elevadas

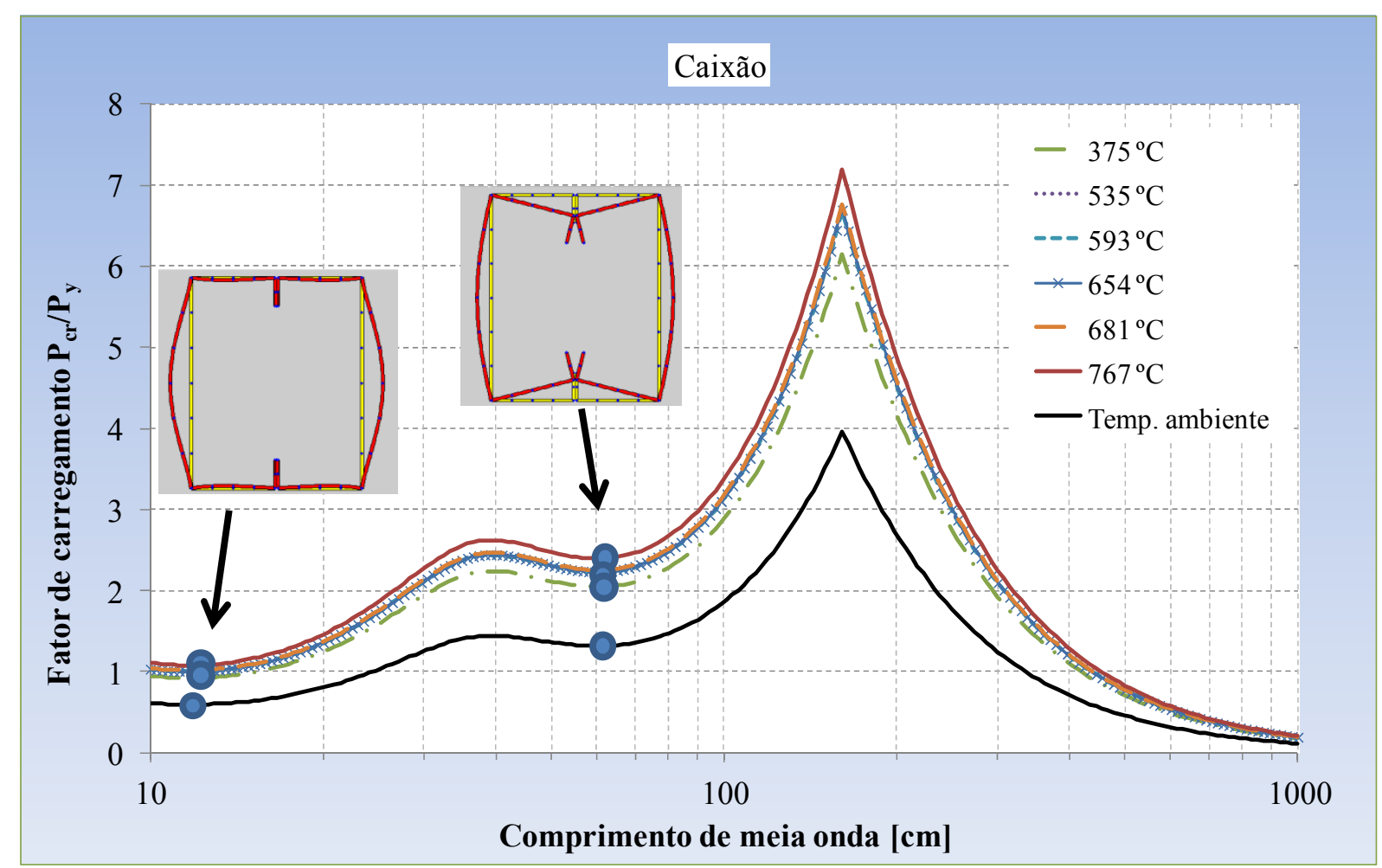

Figura 6.13: Resultados obtidos via CUFSM para determinação da força critica de flambagem elástica para o caixão em temperaturas elevadas 
Nas tabelas 6.19 e 6.20, são mostrados os fatores de carregamento relativos aos pontos de mínimo indicados nos gráficos 6.13 e 6.14 .

Tabela 6.19: Fatores de carregamento do perfil I enrijecido obtidos pelo código CUFSM para determinação da força de flambagem elástica.

\begin{tabular}{|c|c|c|c|c|c|c|}
\hline \multicolumn{3}{|c|}{ Barra } & $\begin{array}{c}\text { Temperatura } \\
{\left[{ }^{\circ} \mathrm{C}\right] \text { no colanso }}\end{array}$ & LF-L & LF-D & LF-G \\
\hline \multirow{2}{*}{$\sqrt{i}$} & & I.SI04F-3 & 763 & 1,1066 & 1,8818 & 1,4010 \\
\hline & & I.SI04F-5 & 770 & 1,1267 & 1,9160 & 1,4265 \\
\hline \multirow{2}{*}{ 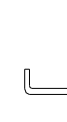 } & & I.SI07F-1 & 609 & 1,0099 & 1,7174 & 1,2786 \\
\hline & $\sqrt{21}$ & I.SI07F-2 & 572 & 1,0085 & 1,7152 & 1,2770 \\
\hline
\end{tabular}

LF-L: Fator de carregamento associado à instabilidade local

LF-D: Fator de carregamento associado à instabilidade distorcional

LF-G: Fator de carregamento associado à instabilidade global

Tabela 6.20: Fatores de carregamento do perfil caixão obtidos pelo código CUFSM para determinação da força de flambagem elástica.

\begin{tabular}{|c|c|c|c|c|c|}
\hline \multicolumn{2}{|c|}{ Amostra } & $\begin{array}{c}\text { Temperatura } \\
{\left[{ }^{\circ} \mathrm{C}\right] \text { no colapso }}\end{array}$ & LF-L & LF-D & LF-G \\
\hline$\sqrt{5}$ & C.SI04F-2 & 654 & 1,0053 & 2,2320 & 3,0023 \\
\hline \multirow{3}{*}{ Iـ } & C.SI04F-3 & 767 & 1,0786 & 2,3950 & 3,2217 \\
\hline & C.SI07F-1 & 375 & 0,9283 & 2,0637 & 2,7793 \\
\hline & C.SI07F-2 & 535 & 1,0043 & 2,2299 & 2,9996 \\
\hline
\end{tabular}

LF-L: Fator de carregamento associado à instabilidade local

LF-D: Fator de carregamento associado à instabilidade distorcional

LF-G: Fator de carregamento associado à instabilidade global

Em relação ao perfil aberto I enrijecido, é possível observar nas curvas "fator de carregamento x comprimento de meia onda", à temperatura ambiente e em temperaturas elevadas, que o modo de falha mais provável de ocorrer é o local. Por esses valores, foi possível prever que o campo térmico não uniforme forneceria como resultado modos locais de falha.

O perfil caixão também apresentou colapso por instabilidade local em todos os níveis de temperatura. Esse modo de instabilidade foi o mesmo identificado no perfis de seção transversal caixão estudados na investigação experimental do presente trabalho. Dessa forma, 
é possível afirmar que o campo térmico não uniforme ao longo do comprimento não teve influência no modo de falha que o perfil caixão tende a apresentar. As tabelas 6.21 a 6.24 mostram os resultados obtidos pela aplicação do MRD aos perfis afetados pelo aumento de temperatura.

Tabela 6.21: Resultados obtidos pelo Método da Resistência Direta comparados com os obtidos nas investigações experimentais do perfil I enrijecido.

\begin{tabular}{|c|c|c|c|c|c|c|}
\hline Amostra & $\begin{array}{c}\text { Temperatura } \\
\text { final (exp.) }\left[{ }^{[} \mathbf{C}\right]\end{array}$ & $\begin{array}{l}\text { Tempo final } \\
\text { (exp.) }\left[{ }^{\circ} \mathrm{C}\right]\end{array}$ & $\begin{array}{l}\mathbf{N}_{\text {exp }} \\
{[\mathrm{kN}]}\end{array}$ & $\begin{array}{l}\text { Modo de falha } \\
\quad \text { (exp.) }\end{array}$ & $\begin{array}{l}\text { AISI S - } 100 \\
\quad \text { MRD } \\
\mathbf{N}_{\mathrm{fi}, \mathrm{Rk}}[\mathrm{kN}]\end{array}$ & $\mathbf{N}_{\mathrm{exp}} / \mathbf{N}_{\mathrm{fi}, \mathbf{R k}}$ \\
\hline I.SI04F-3 & 763 & $15^{\prime} 45^{\prime \prime}$ & 63 & L- w/D & 21,63 & 2,91 \\
\hline I.SI04F-5 & 770 & $19^{\prime} 30^{\prime \prime}$ & 63 & L- w/D & 21,38 & 2,95 \\
\hline I.SI07F-1 & 609 & $13^{\prime} 18^{\prime \prime}$ & 110 & L- w/D & 66,85 & 1,65 \\
\hline I.SI07F-2 & 572 & $11^{\prime} 46^{\prime \prime}$ & 110 & L- w/D & 85,68 & 1,28 \\
\hline
\end{tabular}

L-w: Local na alma ; D: Distorcional

Tabela 6.22: Resultados obtidos pelo Método da Resistência Direta comparados com os obtidos nas investigações numéricas do perfil I enrijecido.

\begin{tabular}{|c|c|c|c|c|c|c|}
\hline Barra & $\begin{array}{c}\text { Temperatura } \\
\text { final (num.) } \\
{\left[{ }^{\circ} \mathrm{C}\right]}\end{array}$ & $\begin{array}{l}\text { Tempo final } \\
\text { (num.) }\left[{ }^{\circ} \mathrm{C}\right]\end{array}$ & $\begin{array}{c}\mathbf{N}_{\text {num,fi }} \\
{[\mathrm{kN}]}\end{array}$ & $\begin{array}{l}\text { Modo de falha } \\
\quad \text { (num.) }\end{array}$ & $\begin{array}{c}\text { AISI S - } 100 \\
\text { MRD } \quad N_{\text {fi,Rk }}[\mathbf{k N}]\end{array}$ & $\begin{array}{l}\mathbf{N}_{\text {num }} / \\
\mathbf{N}_{\text {fi,Rk }}\end{array}$ \\
\hline I.SI04F & 690 & $14^{\prime}$ & 63 & L- w/D & 37,19 & 1,69 \\
\hline I.SI07F & 602 & $11^{\prime}$ & 110 & L- w $/ D$ & 69,88 & 1,57 \\
\hline
\end{tabular}

L-w: Local na alma ; D: Distorcional

Tabela 6.23: Resultados obtidos pelo Método da Resistência Direta comparados com os obtidos nas investigações experimentais do perfil caixão.

\begin{tabular}{ccccccc}
\hline Barra & $\begin{array}{c}\text { Temperatura } \\
\text { final (exp.) }\left[{ }^{\circ} \mathbf{C}\right]\end{array}$ & $\begin{array}{c}\text { Tempo final } \\
(\mathbf{e x p})\left[^{\circ} \mathbf{C}\right]\end{array}$ & $\begin{array}{c}\mathbf{N}_{\text {exp }} \\
{[\mathbf{k N}]}\end{array}$ & $\begin{array}{c}\text { Modo de falha } \\
\text { (exp.) }\end{array}$ & $\begin{array}{c}\text { AISI S - 100 } \\
\text { MRD } \\
\mathbf{N}_{\text {fi,Rk }}[\mathbf{k N}]\end{array}$ & $\mathbf{N}_{\text {exp }} / \mathbf{N}_{\text {fi,Rk }}$ \\
\hline \hline C.SI04F-2 & 654 & $17^{\prime} 06^{\prime \prime}$ & 75 & L- w /D & $\mathbf{5 9}$ & $\mathbf{1 , 2 7}$ \\
\hline C.SI04F-3 & 767 & $19^{\prime} 37^{\prime \prime}$ & 75 & L- w /D & $\mathbf{2 7 , 5 6}$ & $\mathbf{2 , 7 2}$ \\
\hline C.SI07F-1 & 375 & $8^{\prime}$ & 135 & L- W /D & $\mathbf{2 1 4 , 9}$ & $\mathbf{0 , 6 3}$ \\
\hline C.SI07F-2 & 535 & $10^{\prime} 30^{\prime \prime}$ & 135 & L- w /D & $\mathbf{1 3 6 , 1 2}$ & $\mathbf{0 , 9 9}$ \\
\hline \hline
\end{tabular}

L-w: Local na alma ; D: Distorcional 
Tabela 6.24: Resultados obtidos pelo Método da Resistência Direta comparados com os obtidos nas investigações numéricas do perfil caixão.

\begin{tabular}{|c|c|c|c|c|c|c|}
\hline Barra & $\begin{array}{c}\text { Tempe ratura } \\
\text { final (num.) } \\
{\left[{ }^{\circ} \mathrm{C}\right]}\end{array}$ & $\begin{array}{l}\text { Tempo final } \\
\text { (num.) }\left[{ }^{\circ} \mathrm{C}\right]\end{array}$ & $\begin{array}{c}\mathbf{N}_{\text {num,fi }} \\
{[\mathbf{k N}]}\end{array}$ & $\begin{array}{l}\text { Modo de falha } \\
\quad \text { (num.) }\end{array}$ & $\begin{array}{c}\text { AISI S - 100 } \\
\text { MRD } \mathbf{N}_{\mathrm{fi}, \mathrm{Rk}} \\
{[\mathrm{kN}]}\end{array}$ & $\begin{array}{l}\mathbf{N}_{\text {num }} / \\
\mathbf{N}_{\text {fi, Rk }}\end{array}$ \\
\hline C.SI04F & 681 & $14^{\prime}$ & 75 & L- w /D & 51,15 & 1,47 \\
\hline C.SI07F & 593 & $11^{\prime}$ & 135 & $\mathrm{~L}-\mathrm{w} / \mathrm{D}$ & 98,01 & 1,38 \\
\hline
\end{tabular}

L-w: Local na alma ; D: Distorcional

Em todos os casos, as investigações normativas foram conservadoras. Uma das razões se deve evidentemente ao campo de temperaturas não uniforme em que o segmento central se encontra com temperaturas mais elevadas que os trechos de extremidade. Consequentemente, com esse campo térmico, o perfil apresenta sua capacidade resistente mais reduzida no segmento central em comparação com os trechos adjacentes, com temperatura menos elevada.

Alguns autores sugerem a aplicação do Eurocode 3 part 1.3 para verificação de perfis formados a frio em temperaturas elevadas, considerando os devidos fatores de redução das propriedades mecânicas. Essa ideia parte da premissa de que a aplicação do Eurocode 3 part 1.2 fornece resultados mais conservadores que o Eurocode 3 part 1.3.

As recomendações do ANSI/AISC 360 - 10 para verificação em temperaturas elevadas não são aplicáveis aos perfis formados a frio. Os coeficientes de redução da resistência ao escoamento da norma americana foram determinados para os perfis laminados e soldados.

Investigações experimentais apresentadas por outros autores em perfis de aço formados a frio de seções transversais simples já mostraram que as previsões das normas para verificações em temperaturas elevadas são conservadoras. Nas verificações em perfis compostos do presente trabalho, tais procedimentos também resultaram conservadores.

Os resultados obtidos na investigação experimental apresentaram uma variabilidade considerável, principalmente para o perfil caixão. As barras com essa seção transversal submetidas a 70\% da compressão resistente à temperatura ambiente resultaram contra a segurança. Nas demais verificações, a compressão resistente determinada pelos procedimentos analíticos resultou conservadora em relação aos valores obtidos na análise experimental. 
Em todas as barras de seção transversal I enrijecido que apresentaram colapso à temperatura superior a $600{ }^{\circ} \mathrm{C}$, os resultados foram conservadores em relação a aqueles obtidos no programa experimental.

No que tange à comparação entre os valores de compressão resistente obtidos pelos pela análise numérica e os obtidos pelos procedimentos normativos abordados neste trabalho, observou-se que os valores obtidos pelas normas estudadas são mais próximos aos valores de compressão aplicados na análise numérica. Os valores calculados analiticamente para o perfil I enrijecido resultaram inferiores aos aplicados nos modelos numéricos, porém, esse fato não implica em considerar que estes resultados são conservadores em comparação às respostas numéricas. Para o perfil caixão, pode-se considerar que houve uma correlação satisfatória entre os resultados numéricos e aqueles obtidos por procedimentos normativos. 


\section{CONCLUSÕES}

O presente trabalho apresentou um estudo sobre o comportamento de perfis de aço formados a frio sob compressão centrada, submetidos à temperaturas elevadas. Neste estudo foram abordados dois tipos de perfis comumente utilizados na construção civil brasileira, no caso, seções transversais aberta tipo I enrijecido e fechada do tipo caixão.

No que tange à análise experimental do presente trabalho, ressalta-se a complexidade na etapa de calibração do forno de ensaios, visto que isso só foi possível após a manutenção corretiva do equipamento. Como consequência, esse cuidado resultou positivamente em uma curva de aquecimento do forno de ensaios de acordo com a tolerância estabelecida pela norma ISO 834-1:1999, embora isso tenha sido implementado apenas para um único módulo dos dois disponíveis.

Devido à própria condição de ensaio (ressalta-se que a ação térmica foi aplicada apenas pelo módulo central do forno de ensaios), o campo térmico resultou em uma distribuição não uniforme de temperatura ao longo do comprimento das barras analisadas. Como consequência, as propriedades mecânicas da superfície mais próxima da fonte de calor teve maior redução em comparação às demais.

A investigação experimental forneceu resultados de grande variabilidade. A temperatura crítica de colapso para barras submetidas às forças de compressão de maior magnitude, que neste trabalho correspondeu a $0,70 \cdot N_{\text {exp }}$, apresentou variação considerável entre as repetições, principalmente para o perfil caixão. Para a condição de aquecimento estabelecida no presente trabalho, o modo de falha identificado nas barras ensaiadas em temperaturas elevadas foi semelhante ao obtido nos ensaios dos perfis à temperatura ambiente.

As barras com seção transversal I enrijecido apresentaram deformações locais na alma ao atingir a resistência máxima. O comportamento da barra após o máximo esforço de compressão resistente foi caracterizado pelo modo distorcional na região central de maior 
temperatura. $\mathrm{O}$ modo global de flexão, identificado após a barra atingir a resistência máxima à temperatura ambiente, não ocorreu em temperatura elevadas em decorrência do campo térmico resultante, que penalizou as propriedades mecânicas no trecho central do perfil.

As barras de seção transversal caixãa apresentaram colapso devido à falha local na alma. No comportamento pós-crítico durante o ensaio à temperatura ambiente, foi identificada a falha local na mesa. Em temperatura elevada foi observada uma instabilidade distorcional e local de pequena amplitude entre os cordões de solda centrais.

Como conclusões extraídas da investigação experimental realizada, ressalta-se a importância de, em análises futuras que abordem pilares de edificações, implementar a ação térmica com distribuição uniforme ao longo do comprimento, pois com uma taxa crescente de temperatura nessa condição, a depender dos índices de esbeltez local e global, o perfil pode apresentar colapso por instabilidade local a até um determinado valor de campo térmico e instabilidade global para temperaturas superiores.

No que tange à estratégia numérica elaborada, o modelo numérico termoestrutural contemplou a não linearidade do material por meio de uma curva multilinear para representar a relação tensão $x$ deformação para diversos níveis de temperatura variando entre $20{ }^{\circ} \mathrm{C}$ e $1200{ }^{\circ} \mathrm{C}$. O modelo também teve as imperfeições geométricas iniciais implementadas por meio da análise de instabilidade e de acordo com a tolerância nas formas estabelecidas pela ABNT NBR 6355:2012. Como resultado, o modelo numérico representou de forma satisfatória o campo térmico e o comportamento estrutural do perfil.

O tempo de resistência ao fogo obtido numericamente apresenta concordância satisfatória com os resultados experimentais. O maior desvio identificado entre os resultados observados foi de $23 \%$ para uma das repetições do perfil caixão do modelo C.SI.0,7F, porém, a segunda repetição apresentou desvio de apenas 5\%. Para o perfil I enrijecido, o maior desvio registrado foi também de $23 \%$ para uma das repetições do modelo I.SI.0,4F e $11 \%$ para a segunda repetição.

Em relação ao campo térmico, o desvio máximo obtido para o perfil caixão foi de $36 \%$ em comparação a uma das repetições do modelo C.SI.0,4F e $9 \%$ em comparação à segunda repetição. Para o perfil I enrijecido, os maiores desvios foram $16 \%$ para a primeira repetição do modelo I.SI.0,5F-PP e 10\% para a segunda repetição do modelo I.SI.0,4F. 
O modelo numérico reproduziu o campo de deformações e deslocamentos conforme observado na investigação experimental. Além disso, permitiu visualizar o desenvolvimento incremental das deformações, o que foi de grande contribuição para este trabalho, uma vez que este acompanhamento não foi possível durante a realização da investigação experimental.

As deformações locais se iniciaram na alma e foram visíveis nos instantes intermediários de aquecimento. Com o incremento de temperatura e, consequentemente, a redução das propriedades mecânicas do aço, no perfil I enrijecido, foram observados os modos distorcional e local na mesa. Não foi identificado o modo global de flexão no comportamento pós-crítico como identificado na investigação experimental à temperatura ambiente No perfil caixão, também foram identificados os modos distorcional e local na mesa no comportamento pós-crítico, mas com comprimentos de meia onda menores que no perfil I enrijecido.

No tocante ao campo de deslocamentos, o modelo numérico mostrou um comportamento mais rígido em comparação ao que foi identificado nos ensaios. Os deslocamentos iniciais, relativos à ação estática foram menores do que os obtidos experimentalmente. Porém, o modelo reproduziu a variação dos deslocamentos devido à deformação térmica até o instante de colapso de forma satisfatória. O comportamento póscrítico resultou em uma curva descendente suave em comparação ao modelo experimental.

Por fim, observa-se que a análise numérica ainda é fortemente dependente de parâmetros normativos, de onde se tem por base as propriedades térmicas e os fatores de redução da resistência e do módulo de elasticidade. Mesmo assim, pelos resultados obtidos, a estratégia numérica permite o desenvolvimento de análises paramétricas futuras.

No tocante ao procedimento normativo para verificação dos perfis de aço formados a frio abordados no presente trabalho, entendeu-se que o campo amostral da análise experimental realizada não é suficiente para propor reformulações dos métodos de cálculo recomendados pelas normas atuais. Porém, alguns fatores foram identificados para aprimorar os procedimentos normativos atualmente aplicados.

Há a necessidade de revisar o fator de redução da resistência ao escoamento. Os resultados obtidos mostraram que as forças resistentes calculadas foram demasiadamente 
conservadoras em relação aos resultados obtidos tanto pela investigação experimental como pela análise numérica.

Algumas referências sugerem adaptar os procedimentos do Eurocode 3, part $1.3 \mathrm{em}$ vez daqueles apresentados no terceiro capítulo para a verificação dos perfis de aço formados a frio por meio da introdução dos fatores de redução $\mathrm{k}_{\mathrm{E}, \theta}$ e $\mathrm{k}_{\mathrm{p} 02, \theta}$. Na essência, esta alternativa põe em evidência o fato de que não há um consenso bem definido sobre o comportamento mecânico e também para o cálculo simplificado de dimensionamento desses elementos estruturais submetidos a temperaturas elevadas.

A proposta de realizar a verificação de perfis formados a frio à temperaturas elevadas utilizando as equações formuladas para verificações à temperatura ambiente com as devidas alterações nas propriedades mecânicas se deve ao fato de o método proposto pelo Eurocode 3, part 1.2 resultar em valores conservadores de esforços resistentes. Essa estimativa se comprovou também no presente trabalho.

Além da norma europeia, outra alternativa já proposta em alguns trabalhos é a verificação dos perfis formados a frio por meio das especificações da norma americana AISI S100-2007, considerando as devidas reduções nas propriedades mecânicas. A justificativa para tal sugestão também reside no fato de o Apêndice A da norma ANSI/AISC 360-10 não ser aplicável para a verificação de perfis leves em temperaturas elevadas.

Nesse sentido, o Método da Resistência Direta, inicialmente desenvolvido como um procedimento alternativo para verificação de perfis formados a frio à temperatura ambiente, atualmente incorporado na só na norma americana AISI S100-2007 (Apêndice 1), mas também na norma brasileira ABNT NBR 14762:2010 (Apêndice C) e na norma australiana AS/NZS 4600:2005 (Seção 7) forneceu resultados satisfatórios e, portanto, foi considerado conveniente para ser aplicado nas verificações em temperaturas elevadas com as devidas alterações nas propriedades mecânicas.

Como citado no segundo capítulo, este estudo já havia sido apresentado por outros pesquisadores que abordaram perfis de seção transversal simples e com modos de instabilidade bem definidos. No presente trabalho, foi observado que este método se adéqua também aos perfis com outras seções geométricas, como as seções compostas apresentadas. Além disso, o estudo sobre os pilares de aço aqui apresentados indicaram que a condição de 
aquecimento uniforme pode alterar o modo de instabilidade que o perfil tende a apresentar no instante de colapso, em função dos seus índices de esbeltez local e global.

Por fim, como já é sabido pela comunidade técnica e científica, o tema da Segurança e mesmo das Estruturas em Situação de Incêndio tem uma amplitude extensa e desafiadora que envolve várias áreas de conhecimento. $\mathrm{O}$ estudo das estruturas em perfis de aço formados a frio, pode ser considerado, de forma proporcional, como um subitem dentro dessa grande área e, a partir do trabalho apresentado, algumas sugestões podem ser levantadas como propostas futuras, a citar:

$\checkmark$ Análise das ligações em situação de incêndio;

$\checkmark$ Estudo paramétrico de elementos estruturas de perfis formados a frio em temperaturas elevadas;

$\checkmark$ Análise da interação termo-fluido-estrutura com consideração da elevação da temperatura;

$\checkmark$ Análise experimental do comportamento de elementos estruturais em perfis de aço formados a frio incorporadas a diversos tipos de proteção passiva contra incêndio;

$\checkmark$ Caracterização mecânica dos perfis de aço formados a frio utilizados na construção civil brasileira em situação de incêndio. 


\section{REFERÊNCIAS BIBLIOGRÁFICAS}

ALMEIDA, S. J. C de. Análise numérica de perfis de aço formados a frio comprimidos considerando as imperfeições geométricas iniciais. 2007. 108f. Dissertação (Mestrado em Ciências, Programa de Engenharia Civil - Estruturas) - Escola de Engenharia de São Carlos, Universidade de São Paulo, São Carlos, 2007.

ALMEIDA, S. J. C. de;. Análise do comportamento a temperaturas elevadas de elementos de aço formados a frio comprimidos considerando restrição ao alongamento térmico. 2012. 159 f. tese (Doutorado - Programa de Pós-Graduação e Área de Concentração em Engenharia de Estruturas) - Escola de Engenharia de São Carlos da Universidade de São Paulo e Faculdade de Ciências e Tecnologia da Universidade de Coimbra, 2012.

ALMEIDA, S. J. C.; RODRIGUES, J. P. C.; MUNAIAR NETO, J. Estudo experimental do comportamento à temperaturas elevadas de elementos de aço formados a frio submetidos à compressão com restrição ao alongamento térmico. In: CONGRESSO IBERO-LATINO AMERICANO SOBRE SEGURANÇA CONTRA INCÊNDIO, 2013, Coimbra. Procedings. Coimbra, 2013.

AMERICAN INSTITUTE OF STEEL CONSTRUCTION. ANSI/AISC 360-05: Specifications for structural steel buildings. Chicago, 2005.

AMERICAN INSTITUTE OF STEEL CONSTRUCTION. ANSI/AISC 360 - 10: Specifications for structural steel buildings, Chicago, 2010.

AMERICAN IRON AND STEEL INSTITUTE. AISI S100: North American Specification for the design of Cold Formed Steel Structural Members. Washington. 1999.

AMERICAN IRON AND STEEL INSTITUTE. AISI S100-07: North American Specification for the design of Cold Formed Steel Structural Members. Washington. 2007.

AMERICAN SOCIETY TESTING AND MATERIALS. ASTM A370-12: Standard test methods for mechanical testing of steel products. West Conshohocken, 2012.

AMERICAN SOCIETY TESTING AND MATERIALS. ASTM E119: Standard test methods for fire tests of building construction and materials. West Conshohocken, 2000. 
ANSYS INC. Release Notes, Canonsburg, 2009.

ASSOCIAÇÃO BRASILEIRA DE NORMAS TÉCNICAS. ABNT NBR 143: Dimensionamento de estruturas de aço constituídas por perfis formados a frio. Rio de Janeiro, 1967.

ASSOCIAÇÃO BRASILEIRA DE NORMAS TÉCNICAS. ABNT NBR 6355: Perfis estruturais de aço formados a frio. Rio de Janeiro, 1980.

ASSOCIAÇÃO BRASILEIRA DE NORMAS TÉCNICAS. ABNT NBR 6355: Perfis estruturais de aço formados a frio. Rio de Janeiro, 2003.

ASSOCIAÇÃO BRASILEIRA DE NORMAS TÉCNICAS. ABNT NBR 6355: Perfis estruturais de aço formados a frio. Rio de Janeiro, 2012.

ASSOCIAÇÃO BRASILEIRA DE NORMAS TÉCNICAS. ABNT NBR 7190: Projeto de estruturas de madeira. Rio de Janeiro, 1997.

ASSOCIAÇÃO BRASILEIRA DE NORMAS TÉCNICAS. ABNT NBR 14323: Dimensionamento de estruturas de aço de edifícios em situação de incêndio - Procedimento. Rio de Janeiro, 1999.

ASSOCIAÇÃO BRASILEIRA DE NORMAS TÉCNICAS. ABNT NBR 14323: Dimensionamento de estruturas de aço de edifícios em situação de incêndio - Procedimento. Rio de Janeiro, 2013.

ASSOCIAÇÃO BRASILEIRA DE NORMAS TÉCNICAS. ABNT NBR 14432 - Exigências de resistência ao fogo de elementos construtivos de edificações - Procedimento. Rio de Janeiro, 2000.

ASSOCIAÇÃO BRASILEIRA DE NORMAS TÉCNICAS. ABNT NBR 14762: Dimensionamento de estruturas de aço constituídas por perfis formados a frio. Rio de Janeiro, 2001.

ASSOCIAÇÃO BRASILEIRA DE NORMAS TÉCNICAS. ABNT NBR 14762: Dimensionamento de estruturas de aço constituídas por perfis formados a frio. Rio de Janeiro, 2010.

ASSOCIAÇÃO BRASILEIRA DE NORMAS TÉCNICAS. ABNT NBR 15200: Projeto de estruturas de concreto em situação de incêndio. Rio de Janeiro, 2004. 
ASSOCIAÇÃO BRASILEIRA DE NORMAS TÉCNICAS. ABNT NBR 15200: Projeto de estruturas de concreto em situação de incêndio. Rio de Janeiro, 2012.

ASSOCIAÇÃO BRASILEIRA DE NORMAS TÉCNICAS. ABNT NBR 8800: Projeto e execução de estruturas de aço de edifícios. Rio de Janeiro, 2008.

AUSTRALIAN/NEW ZEALAND STANDARD (2005): AS/NZS 4600:2005: Cold formed steel structures.

CHODRAUI, G. M. B. Análise teórica e experimental de perfis de aço formado a frio submetidos à compressão. 2006. 154 f. Tese (Doutorado em Ciências, Programa de Engenharia Civil - Estruturas) - Escola de Engenharia de São Carlos, Universidade de São Paulo, São Carlos, 2006.

CLARET, A.M. Resistência ao fogo de vigas mistas aço-concreto modeladas pelo método dos elementos finitos. In: JORNADAS SUDAMERICANAS DE INGENIERIA ESTRUCTURAL, 2000, Punta del Este. Procedings. Punta del Leste, 2000.

CRAVEIRO, H. D.; RODRIGUES, J. P. C.; LAIM, L. Análise experimental do comportamento ao fogo de elementos comprimidos em aço enformado a frio. In: CONGRESSO IBERO-LATINO AMERICANO SOBRE SEGURANÇA CONTRA INCÊNDIO, 2013, Coimbra. Procedings. Coimbra, 2013.

Design guide 19 - fire resistance of structural steel framing.

DORR, J. B. Modelos numéricos de pilares de aço em situação de incêndio considerando a influencia da restrição axial. 2010. 105 f. Dissertação (Mestrado em Ciências, Programa de Engenharia Civil - Estruturas) - Escola de Engenharia de São Carlos, Universidade de São Paulo, São Carlos, 2010.

DUBINA, D.; UNGUREANU, V.; LANDOLFO, R. Design of cold-formed steel structures: Eurocode 3: Design of steel structures. Part 1-3 - design of cold formed steel structures. First edition. Portugal. ECCS - European Convention for Constructional Stell Work. Wiley Black Well. 2012. ISBN: 978-92-9147-107-2, 978-3-433-02979-4.

EUROPEAN COMMITTEE FOR STANDARDIZATION. EN 1991-1-2: 2002: Eurocode 1 - Actions on structures. Part 1-2: General actions - Actions on structures exposed to fire. Brussels, 2002.

EUROPEAN COMMITTEE FOR STANDARDIZATION. EN 1993-1-1: 2005: Eurocode 3 - Design of steel structures. Part 1-1: General rules and rules for buildings. Brussels, 2005. 
EUROPEAN COMMITTEE FOR STANDARDIZATION. EN 1993-1-2: 2005: Eurocode 3

- Design of steel structures. Part 1-2: General rules - Structural fire design. Brussels, 2005.

EUROPEAN COMMITTEE FOR STANDARDIZATION. EN 1993-1-3:2006: Eurocode 3 Design of Steel Structures. Part 1-3: General rules - Supplementary rules for cold-formed members and sheeting. Brussels, 2006.

EUROPEAN COMMITTEE FOR STANDARDIZATION. EN 1993-1-5:2006: Eurocode 3 Design of Steel Structures. Part 1-5: Plated structural elements. Brussels, 2006.

FENG, M.; WANG, Y. C.; DAVIES, J. M. Structural Behaviour of cold-formed thin-walled short steel channel columns at elevated temperatures. Part 1: experiments. Thin Walled Structures, v.41, n. 6, p. $543-570,2002$.

FENG, M.; WANG, Y. C.; DAVIES, J. M. Structural Behaviour of cold-formed thin-walled short steel channel columns at elevated temperatures. Part 2: Design calculations and numerical analysis. Thin Walled Structures, v.41, n. 6, p. 571 - 594, 2002.

FENG, M.; WANG, Y. C.; DAVIES, J. M. Axial strength of cold-formed thin-walled steel channels under non-uniform temperatures in fire. Fire Safety Journal, v. 38, n. 8, p. 679 707, 2003.

GOMIDE, K. A. Colunas esbeltas de pequeno diâmetro mistas de aço preenchidas com concreto em situação de incêndio. 2008. 121 f. Tese (Doutorado em Engenharia Civil, Área de Concentração em Engenharia de Estruturas) - Faculdade de Engenharia Civil, Arquitetura e Urbanismo, Universidade Estadual de Campinas, Campinas, 2008.

HANCOCK, G. J.; MURRAY, T. M.; ELLIFRITT, D. S. Cold-formed steel structures to the AISI specification. New York: Marcel Dekker, 2001. 398 p. ISBN: 0824792947.

HEVA, Y. B. Behaviour and design of cold-formed steel compression member at elevated temperatures. 2009. 225 f. Ph. D. Thesis (Science and Engineering Faculty Research Area in Complex Urban System Design) - Queensland University of Technology, Brisbane, Australia, 2009.

INTERNATIONAL STANDARD. ISO 834-1:1999: Fire-resistance tests — Elements of building construction - Part 1: General requirements. Genève, Switzerland, 1999.

KAITILA, O. Imperfection sensitivity analysis of lipped channel columns at high temperatures. Journal of Constructional Steel Research, v. 58, n. 3,p.333 - 351, 2002. 
KANKANAMGE, N. D.; MAHENDRAN, M. Mechanical properties of cold-formed steels at elevated temperatures. Thin-Walled Structures, v. 49, n.1, p. 26 - 44, 2011.

KIMURA, E. F. A. Análise termoestrutural de pilares de aço em situação de incêndio. 2009. 113 f. Dissertação (Mestrado em Ciências, Programa de Engenharia Civil - Estruturas) Escola de Engenharia de São Carlos, Universidade de São Paulo, São Carlos, 2009.

KIRCHHOF, L. D. Uma contribuição ao estudo de vigas mistas aço-concreto simplesmente apoiadas em temperatura ambiente e em situação de incêndio. 2004. 72 f. Dissertação (Mestrado em Ciências, Programa de Engenharia Civil - Estruturas) - Escola de Engenharia de São Carlos, Universidade de São Paulo, São Carlos, 2004.

KLIPPSTEIN, K. H. Strength of cold formed steel studs exposed to fire. In:FOURTH SPECIALTY CONFERENCE ON COLD FORMED STEEL STRUCTURE, 1978, Saint Louis. Proceedings Saint Louis: Academic Press, 1978. p.513.

KOTINDA, T. I. (2006). Modelagem numérica de vigas mistas aço-concreto simplesmente apoiadas: ênfase ao estudo da interface laje-viga. 2006. 62f. Dissertação (Mestrado - Programa de Pós-Graduação e Área de Concentração em Engenharia de Estruturas) - Escola de Engenharia de São Carlos, Universidade de São Paulo, São Carlos, 2006.

LAIM, L.; RODRIGUES, J. P. C. Experimental and numerical analysis on the structural behaviour of cold-formed steel beams. Thin Walled Structures, v.72, p. 1 - 13, 2013.

LANDESMANN, A.; CAMOTIN, D. Simulação de colunas de aço de paredes finas com modo de falha distorcional sob incêndio. Mecânica Computacional, v. XXIX, p.6957 - 6970, 2010 .

LEAL, D. F. Sobre perfis de aço formados a frio compostos por dupla cantoneira com seção "T" submetidos à compressão. 2011. 166f. Dissertação (Mestrado em Ciências, Programa de Engenharia Civil - Estruturas) - Escola de Engenharia de São Carlos, Universidade de São Paulo, São Carlos, 2011.

LEITE JUNIOR, G. S. Colunas mistas esbeltas de aço preenchidas com concreto de alta resistência em temperatura ambiente e em situação de incêndio. 2009. 147 f. Tese (Doutorado em Engenharia Civil, Área de Concentração em Engenharia de Estruturas) Faculdade de Engenharia Civil, Arquitetura e Urbanismo, Universidade Estadual de Campinas, Campinas, 2009. 
LI Z. Finite strip modeling of thin-walled members. 2011. 130 f. Master Thesis (Department of Civil Engineering - Thin-Walled Structures Research Group) - Johns Hopkins University, Baltimore, Maryland, United States of America, 2011.

MAIA, W. F.; MUNAIAR NETO, J.; MALITE, M. Theoretical analysis of cold-formed steel battened double angle members under compression. In: TWENTIETH INTERNATIONAL SPECIALTY CONFERENCE ON COLD-FORMED STEEL STRUCTURES, 2010, Saint Louis. Proceedings... Saint Louis: Academic Press, 2010. p. 121-135.

MAIA, W. F. Análise teórica e experimental de barras em dupla cantoneira de aço formada a frio submetidas à compressão. 2012. 131 f. tese (Doutorado - Programa de PósGraduação e Área de Concentração em Engenharia de Estruturas) - Escola de Engenharia de São Carlos, Universidade de São Paulo. 2012.

MENDES, C. L. Estudo sobre perfis formados a frio em situação de incêndio. 2004. $80 \mathrm{f}$. Dissertação (Mestrado em Ciências, Programa de Engenharia Civil - Estruturas) - Escola de Engenharia de São Carlos, Universidade de São Paulo, São Carlos, 2004.

PIERIN, I.; SILVA, V. P. Análise linear de estabilidade de perfis formados a frio em situação de incêndio. In: Construmetal - Congresso Latino-americano da Construcao Metalica, 2006, São Paulo. Proceedings.p. 1 - 10.

RANAWAKA, T.; MAHENDRAN, M. Distortional buckling tests of cold-formed steel compression members at elevated temperatures. Journal of Constructional Steel Research, v. 65 , n. 2 , p. $249-259,2009$ - a.

RANAWAKA, T.; MAHENDRAN, M. Experimental study os mechanical properties of light gauge cold-formed steel at elevated temperatures. Fire Safety Journal, v. 49, n.2, p. 219 229, 2009 - b.

REGOBELLO, R. Análise numérica de seções transversais e de elementos estruturais de aço e mistos de aço e concreto em situação de incêndio. 2007. 130 f. Dissertação (Mestrado em Ciências, Programa de Engenharia Civil - Estruturas) - Escola de Engenharia de São Carlos, Universidade de São Paulo, São Carlos, 2007.

RIGOBELlO, R. Desenvolvimento e aplicação de código computacional para análise de estruturas de aço aporticadas em situação de incêndio. 2011. 148 f. Tese (Doutorado em Ciências, Programa de Engenharia Civil - Estruturas) - Escola de Engenharia de São Carlos, Universidade de São Paulo, São Carlos, 2011. 
REVISTA ARQUITETURA \& AÇO, número 15, setembro de 2008, - Publicação do Centro Brasileiro da Construção em Aço.

REVISTA CONSTRUÇÃO METÁLICA, Edição 84, 2007, ISSN 14146517 - Publicação Especializada ABCEM - Associação Brasileira da Construção Metálica

REVISTA CONSTRUÇÃO METÁLICA, Edição 94, 2009, ISSN 14146517 - Publicação Especializada ABCEM - Associação Brasileira da Construção Metálica.

RODRIGUES, J. P. C. Fire resistance of steel columns with restrained thermal elongation. 2000. 172 f. Dissertação (Doutoramento em Engenharia Civil) - Universidade Técnica de Lisboa, Instituto Superior Técnico, Lisboa, 2000.

RODRIGUES, F. C.; CALDAS, R. B.; COSTA, A. A. R. Fator de redução da resistência ao escoamento de perfis U enrijecidos. In: CONGRESSO IBERO-LATINO AMERICANO SOBRE SEGURANÇA CONTRA INCÊNDIO, 2013, Coimbra. Procedings. Coimbra, 2013.

SANT'ANNA, M. S. Pilares mistos esbeltos em aço preenchidos com concreto, de seção quadrada, em situação de incêndio. 2009. 101 f. Dissertação (Mestrado em Engenharia Civil, Área de Concentração em Engenharia de Estruturas) - Faculdade de Engenharia Civil, Arquitetura e Urbanismo, Universidade Estadual de Campinas, Campinas, 2009.

SANTOS, R. T. Modelos numéricos de pilares mistos curtos de seções circulares de aço preenchidos com concreto em situação de incêndio. 2009. 89 f. Dissertação (Mestrado em Ciências, Programa de Engenharia Civil - Estruturas) - Escola de Engenharia de São Carlos, Universidade de São Paulo, São Carlos, 2009.

SHAHBAZIAN, A.; WANG, Y. C. Calculating the global buckling resistance of thin-walled steel members with uniform and non-uniform elevated temperature under axial compression. Thin-Walled Structures, v. 49, n. 11, p. 1415 - 1428, 2011 - a.

SHAHBAZIAN, A.; WANG, Y. C. Application of direct strength method to local buckling resistance of thin-walled steel structures with non-uniform temperature under axial compression. Thin-Walled Structures, v. 53,p. 188 - 199, 2012.

SHAHBAZIAN, A.; WANG, Y. C. Direct strength method for calculating distortional buckling capacity of cold-formed thin-walled steel columns with uniform and non-uniform elevated temperature. Thin-Walled Structures, v. 49, n. 11, p. 1415 - 1428, 2011 - a. 
SILVA, V. P. e; RODRIGUES, F. C.; FAKURY, R. H.; PANNONI, F. D. Incendio real em um apartamento de interesse social - estudo de caso. Revista Escola de Minas, v. 60, n. 2, p. $315-324,2007$.

STONE, T. A.; LABOUBE, R. A. Behavior of cold-formed steel built-up-I-sections. Thin Walled Structures, v.43, n. 12, p. $1805-1817,2005$.

WANG, Y. C. Steel and Composite Structures - Behavior and Design for Fire Safety. London: Taylor \& Francis, 2002. 332 p. ISBN: 0415244366.

YU, W. W. Cold-formed steel design. Third edition. New York: John Wiley \& Sons, 2000. 756 p. ISBN: 0-471-34809-0.

YU, W. W.; LABOUBE, R. A. Cold-formed steel design. Fourth edition. Hoboken, New Jesey: John Wiley \& Sons, 2010. 528 p. ISBN: 978-0470462454; 0470462450. 